\title{
THE MAY 2010 ERUPTION OF PACAYA VOLCANO, GUATEMALA: AN EXPERIMENTAL STUDY OF SUBLIQUIDUS MAGMA RHEOLOGY
}

A Thesis presented to the Faculty of the Graduate School

University of Missouri-Columbia

In Partial Fulfillment
of the Requirements for the Degree
Masters of Science
by
ANTHONY J. BOLLASINA
Dr. Alan G. Whittington, Thesis Supervisor
MAY 2014


The undersigned, appointed by the Dean of the Graduate School, have examined the thesis entitled:

THE MAY 2010 ERUPTION OF PACAYA VOLCANO, GUATEMALA: AN EXPERIMENTAL STUDY OF SUBLIQUIDUS MAGMA RHEOLOGY

presented by Anthony Bollasina, a candidate for the degree of Master of Science, and hereby certify that, in their opinion, it is worthy of acceptance.

\begin{tabular}{l}
\hline Alan G. Whittington \\
\hline Kevin Shelton \\
\hline
\end{tabular}

Stephen Lombardo 


\section{ACKNOWLEDGEMENTS}

This work could not have been completed without the generous help of a number of people who I am very thankful for. Firstly, I must thank my advisor, Dr. Alan Whittington, for taking me on an epic adventure over not just the duration of graduate school, but during my undergraduate years as well. Through his patience and guidance, I have grown into the professional that I am today. I must also thank Dr. Kevin Shelton, and Dr. Stephen Lombardo, for providing their time and participating on my thesis committee. I next need to thank my fellow lab mates and field researchers, Alexander Sehlke and Geneviéve Robert. Thank you both for your tireless help in the lab, and for helping to keep me sane over the years. I would also like to thank the National Science Foundation for funding this project, and providing me with the opportunity to explore science in the field and laboratory. Thank the University of Missouri Geology department and alumni for providing generous scholarships over the years, which I am thankful to have received. I would also like to thank all of the faculty and professors I have worked with over the years, for which I am very grateful for all the time we have shared together and for all I have learned from you. Thanks to INSIVUMEH and resident researchers and scientists of Guatemala, namely, Don Eddy, Gustavo Chigna, and our trusted guide José. Last but, certainly not least, I need to thank my friends and family. Thanks to Elizabeth Gammel, who has endured my ramblings, singing, and dancing, while being the best study buddy I could ask for. Thanks to my mother, father, step-parents, and grandmother for providing me with the support and guidance I needed so dearly. Thanks to my sister for being the smarter sibling and causing me to always try harder. Finally, thanks to my best friend, girlfriend, and roommate, for loving me unconditionally through the roller coaster of graduate school, I couldn't have done this without you. 


\section{TABLE OF CONTENTS}

ACKNOWLEDGEMENTS......................................................ii

LIST OF FIGURES.......................................................v-viii

LIST OF TABLES..................................................................ix

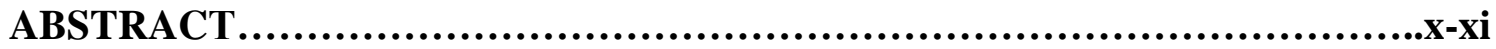

\section{CHAPTER 1- INTRODUCTION AND GEOLOGIC SETTING}

1.1 Motivation......................................................................1

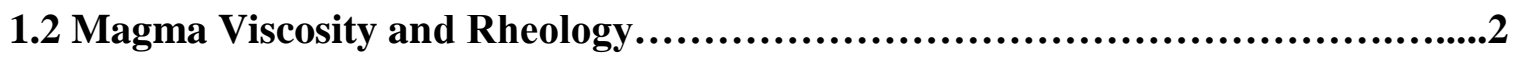

1.3 Geologic Setting of Pacaya.......................................................5

1.4 May 2010 Eruption of Pacaya Volcano..........................................7

1.5 Overview.............................................................................11

CHAPTER 2- PETROGRAPHY AND CHEMISTRY OF ERUPTION PRODUCTS

FROM MAY 2010

2.1 Sample Acquisition...............................................................13

2.2 Methods of Sample Petrography and Characterization............................17

2.3 Sample Petrography and Characterization....................................22

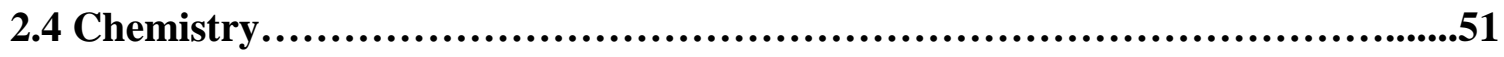

2.5 Petrographic Conclusions.....................................................63 


\section{CHAPTER 3- EXPERIMENTAL WORK}

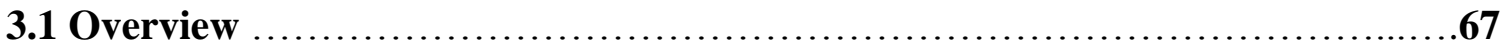

3. 2 Introduction to Viscometry Techniques ..............................67

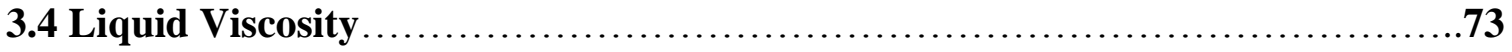

3.5 Magma Viscosity at Subliquidus Conditions .............................79

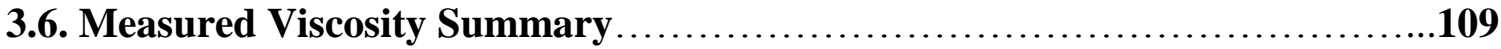

3.7. Modeling Magma Viscosity .......................................112

\section{CHAPTER 4- CONCLUSIONS}

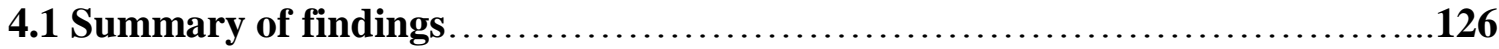

4.2 Petrologic Model.....................................................130

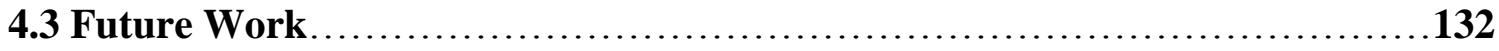

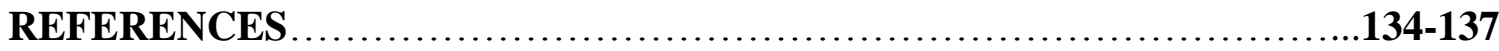

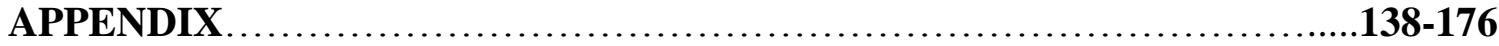




\section{LIST OF FIGURES}

Figure

Description

Page

1.1

Map of Guatemala......

. .2

Flow curves plotted on stress vs. strain rate diagram.........................4

Mapped flows that formed between 1961-2010 (Rose et al. 2013)...........6

Before and After (A and B) looking south towards Pacaya ................7, 8

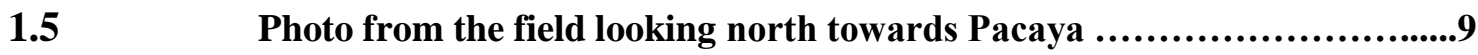

Map of Pacaya showing location of recent vents, (Wolf 2010)...............10

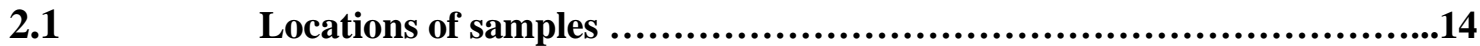

$2.2 \quad$ Large Bomb..............................................................

2.3 Schematic of core used in vesicle calculations...............................20

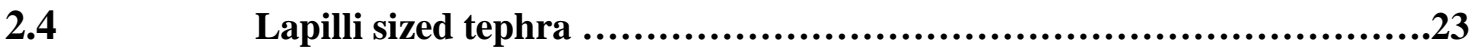

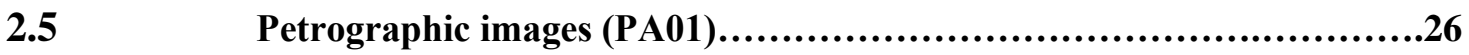

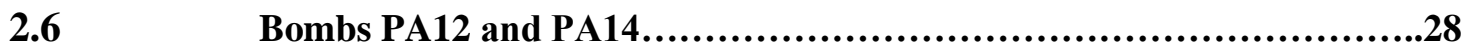

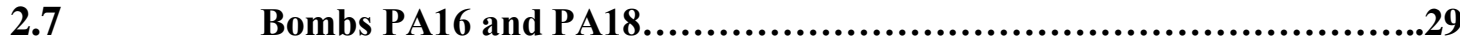

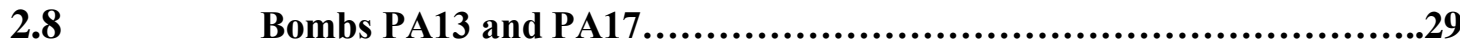

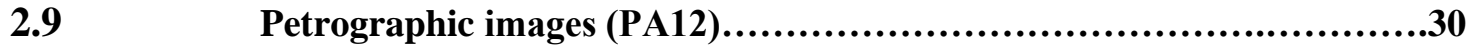

$2.10 \quad$ Petrographic images (PA16)................................................31

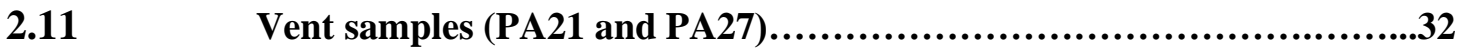

Petrographic images (PA21).............................................33

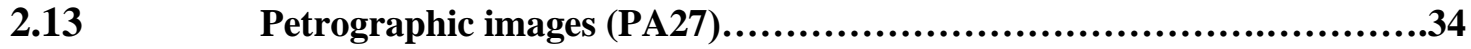

NW mid-flow samples (PA23 and PA24)...............................35

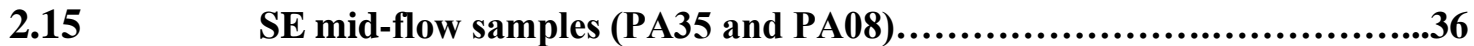

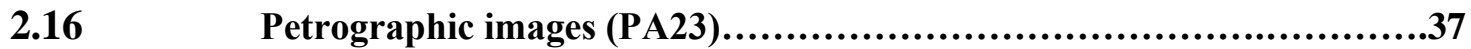


Petrographic images (PA35) ................................... 38

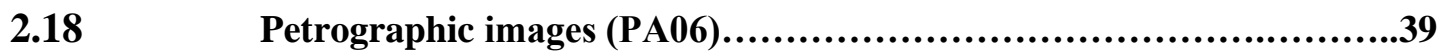

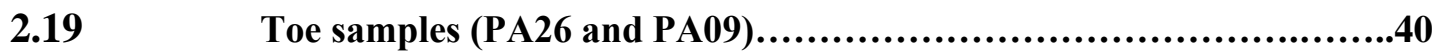

2.20 Petrographic images (PA26)..........................................41

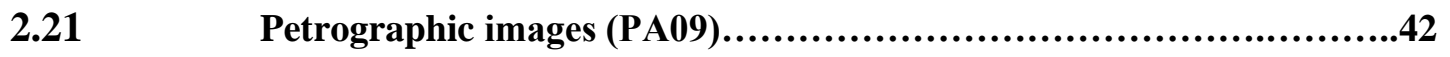

Density of natural samples, using all methods........................ 44

Calculated total bubble $\%\left(\varphi_{\mathrm{T}}\right)$ for natural samples.....................46

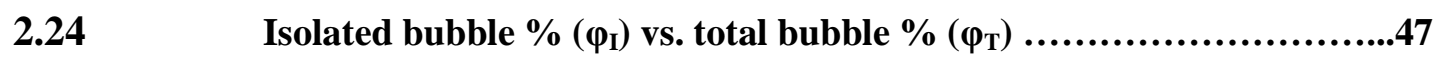

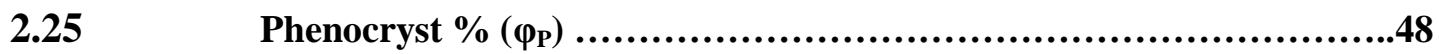

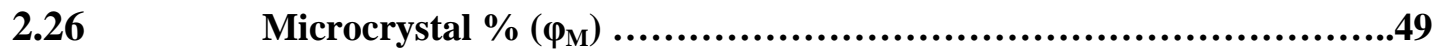

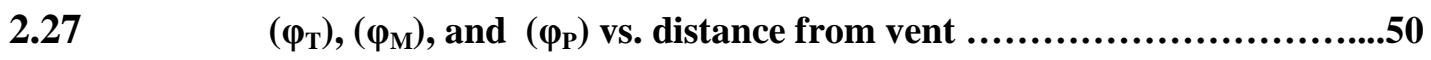

2.28 Bulk rock Harker diagrams...................................... 53

Total alkalis vs. distance from vent................................... 54

Fe Redox of natural samples......................................57

TAS diagram with glass and whole rock analyses......................58

Ca\# of plagioclase crystals..........................................59

Mg \# of olivine crystals............................................60

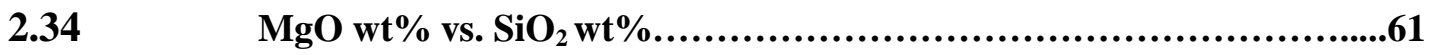

$2.35 \mathrm{CaO}$ wt $\%$ vs. $\mathrm{SiO}_{2}$ wt $\%$........................................62

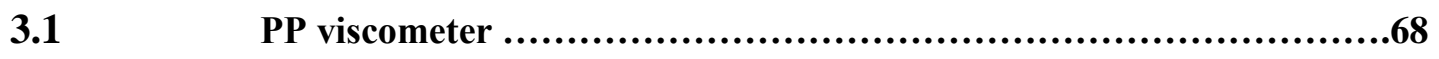

Close up of PP viscometer .......................................69

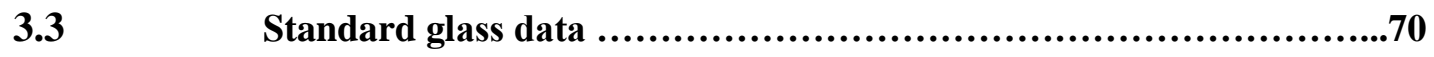

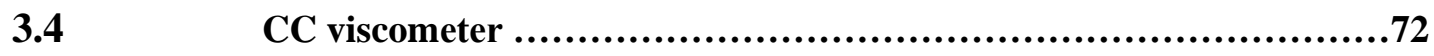

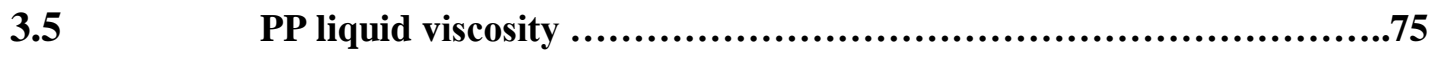


3.7 All liquid viscosity and GRD 08 . .79

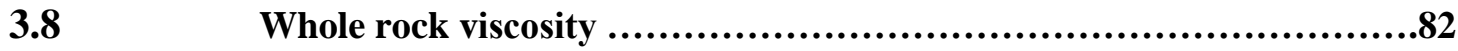

Isothermal subliquidus viscosity .....................................84

3.10 Post-CC BSE images...............................................87

3.11 Crystal fraction vs. temperature for post-CC experiments..........88

Crystal fraction vs. temperatures using MELTs....................88

Melt accumulation on spindles.....................................90

Stress vs. strain rate.................................................91

3.15 Log viscosity and stress vs. $\log$ strain rate before correction.......93

3.16 Log viscosity and stress vs. $\log$ strain rate after correction .........94

PP viscosity of partially crystalline remelts............................97

Post-PP BSE images.......................................................98

3.19 BSE images showing micro-crystallization .......................99

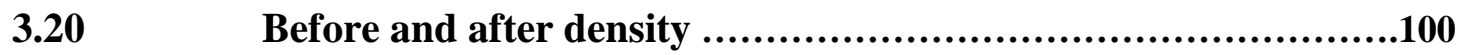

Crystal fraction comp between post-CC and post-PP.............101

TAS with glass comps of partially crystalline remelts ..............104

3.23 $\mathrm{CaO}$ wt $\%$ vs. $\mathrm{SiO}_{2}$ for partially crystalline samples..................105

Ca\# for plagioclase crystals .....................................106

FeO redox of partially crystalline samples $\ldots . \ldots \ldots \ldots \ldots \ldots \ldots \ldots \ldots . . . \ldots 107$

Low temperature crystallization experiments....................109

All subliquidus viscosity vs. 10,000/T $\ldots \ldots \ldots \ldots \ldots \ldots \ldots \ldots \ldots \ldots \ldots \ldots . \ldots \ldots 11$

3.28 Texture comparison between high and low temperature exp.....112

3.29 Calculated viscosity using MDR and MLM $n$...................118 
3.30 $n$ calculated with MLM and measured vs. crystal fraction........119

3.31 Calculated viscosity using MDR and measured $n$..................120

Calculated viscosity using HB and measured $n$..................121

Calculated viscosity using NN power law and measured $n \ldots \ldots . . .122$

4.1 Model for May 2010 eruption of Pacaya Volcano ..................131

A-4 All post CC BSE images used for calculation of xtal \% $\ldots . . . .145-150$

A-5 All post PP BSE images used for calculation of xtal \% ........151-156 


\section{LIST OF TABLES}

Table Description $\quad$ Page

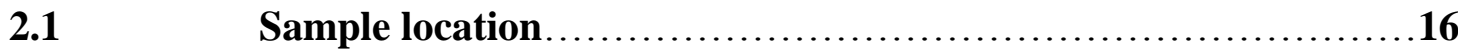

2.2 Sample density, bubble \%, and crystal $\% \ldots \ldots \ldots \ldots \ldots \ldots \ldots \ldots \ldots$

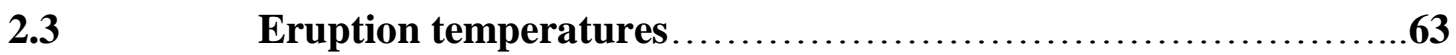

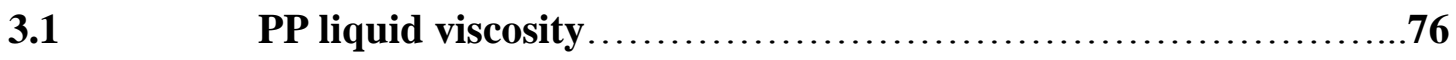

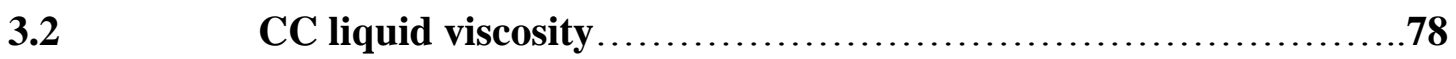

Slope of $\log$ stress vs, $\log$ strain rate $\ldots \ldots \ldots \ldots \ldots \ldots \ldots \ldots \ldots \ldots$

3.4 Crystal \% post-PP and post-CC and Density before and after..102

Low temperature viscosity data and crystal $\% \ldots \ldots \ldots \ldots \ldots \ldots$

3.6 Properties used in modeling ...............................117

Rmsd for magma viscosity calculations ........................124

A-1 Bulk rock analyses for natural samples....................138

A-2 Fe Redox for natural samples.............................

A-3 Microprobe analyses for natural samples...............140-144

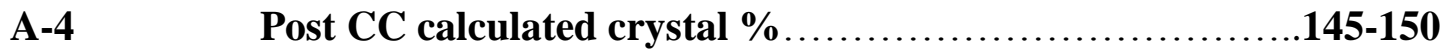

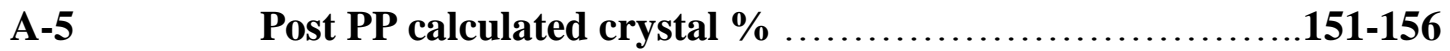

A-6 Microprobe analyses of partially crystalline remelts........157-162

A-7 Measured and Calculated viscosities (MDR and calc $n$ ).....163-166

A-8 Measured and Calculated viscosities (MDR and meas $n$ )...167-170

A-9 Measured and Calculated viscosities (HB and meas $n$ ).....171-175

A-10 Measured and Calculated viscosities (NN and meas $n$ )........176 


\title{
THE MAY 2010 ERUPTION OF PACAYA VOLCANO, GUATEMALA: AN EXPERIMENTAL STUDY OF SUBLIQUIDUS MAGMA RHEOLOGY
}

\author{
Anthony Bollasina \\ Dr. Alan Whittington, Thesis Advisor \\ ABSTRACT
}

\begin{abstract}
Pacaya volcano, Guatemala, erupted in May 2010 with two lava flows from lateral vents preceding a violent Strombolian eruption from the central vent. Compositions and textures of lava flow and tephra samples suggest a layered magma chamber and a range of cooling rates.
\end{abstract}

The effects of crystallization on magma rheology were investigated through a series of high temperature experiments. Six isothermal experiments at temperatures between 1255 and $1207^{\circ} \mathrm{C}$ produced crystal fractions between $\sim 17$ and $\sim 42 \%$ over 3-30 hrs, with textures similar to those observed in lava flows. Four isothermal experiments at $\sim 950^{\circ} \mathrm{C}$ produced a range in crystal fractions between $\sim 42$ and $80 \%$ over $0-2$ hours. The crystal textures resemble those in lapilli tephra samples, but are smaller $(\leq 1 \mu \mathrm{m})$.

Magma rheology was measured over a range of temperature, and strain rates for each of the partially crystalline samples. The results were used to test the accuracy of current models that predict magma viscosity. Rheological measurements are best fit as a shear thinning non-Newtonian flow with a power-law equation at up to $30 \%$ crystals, with higher contents up to $42 \%$ crystals requiring determination of a yield strength and 
the use of a Herschel-Bulkley flow equation. Even at $42 \%$ crystals, the yield strength was only $140 \mathrm{~Pa}$. Currently available models for predicting liquid and magma viscosity do not accurately predict the measurements, and are especially poor at low temperatures and high crystal contents.

Field and laboratory observations were combined to formulate a model for the May 2010 eruption, in which early-erupted more silicic magma tapped from the upper magma chamber either remains trapped under a rheological plug in the main conduit, or escapes to erupt at lateral vents. Following rupture of the plug in the violent strombolian eruption of May $27 \mathrm{th}^{\text {th }}$, lateral vents continued to tap deeper levels of the magma chamber producing more mafic flows. 


\section{CHAPTER 1- INTRODUCTION AND GEOLOGIC SETTING}

\subsection{Motivation}

Guatemala is home to three currently active volcanoes that exist along a volcanic arc that parallels the trench marking the subduction of the Cocos plate (Figure 1.1). These volcanoes exhibit a wide range of eruption styles ranging from effusive lava flows, to explosive strombolian and vulcanian eruptions. This range in eruption style is due to high water content (up to $6 \mathrm{wt} \%$ ) in magmas feeding arc volcanoes (Sisson and Layne 1993). Variations in dwell time in the magma chamber and ascent rate in the volcanic conduit result in different degrees of water saturation within the magma at the eruptive stage. During an eruption, magma can ascend slowly enough that degassing is near complete by the surface, allowing for lava flows or gentler Strombolian activity. In other settings, or even during the same eruption, ascent rate can exceed degassing rate, resulting in more explosive eruptions. Common arc volcano eruptions are characterized by a primary phase of volatile rich magma leaving the magma chamber first, causing a more explosive strombolian or vulcanian eruption, which is followed by the degassed and volatile deficient magma leaving the chamber later during an effusive eruption (Pinkerton et al. 2002). The May 2010 eruption of Pacaya volcano is somewhat atypical compared to this common eruptive sequence. The May 2010 eruption consisted of continuous effusive activity for 2-3 weeks at two lava flows on opposing flanks of the volcano, with a period of more explosive eruptions from the central vent occurring on May $27^{\text {th }}$, approximately 7-10 days after effusive eruptions began. This study uses petrographic and chemical data of erupted rocks to present a conceptual model for the eruption. This study also presents 
quantitative data for the effect of crystallization on magma rheology. The results are used to test the accuracy of current models that predict magma viscosity.

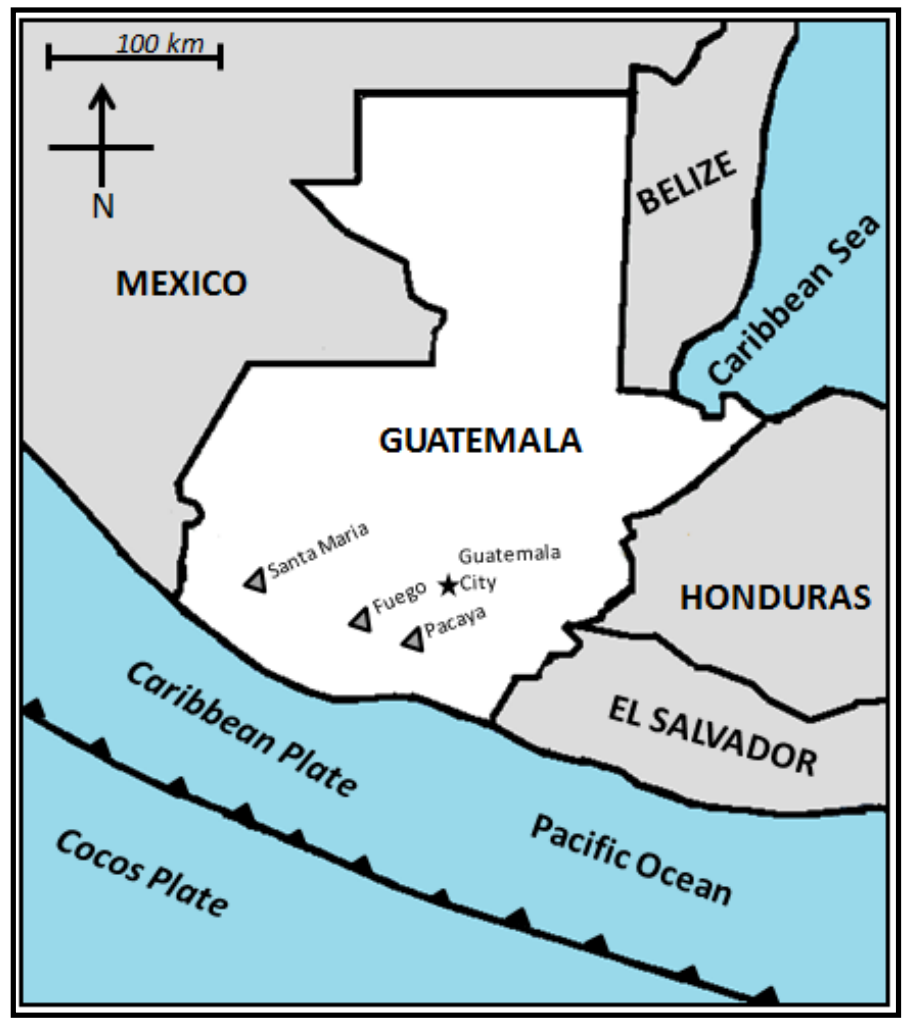

Figure 1.1. Map of Guatemala with location of currently active volcanoes and Guatemala City noted. Map modified from Google Earth.

\subsection{Magma Viscosity and Rheology}

Viscosity plays a critical role in the production, transport, and eruption of magma in volcanic systems (Dingwell 2006, and Giordano et al. 2008). Viscosity increases with decreasing temperature $(T)$, decreasing volatile content $(X)$ and/or increasing crystal fraction $\left(\varphi_{C}\right)$. These observations have prompted many studies aimed at quantifying the viscosity of magma in different settings. Hui and Zhang (2007) and Giordano et al. (2008) present parameterized models for melt viscosity as a function of $\mathrm{T}$ and $X$, while Costa et al. (2009) and Mueller et al. (2010) present a model for the effect of crystals on 
magma viscosity. Viscosity of naturally crystallized magmas has been studied by, Avard and Whittington (2012), Cimarelli et al. (2007), Gurioli et al. (2013), Ishibashi (2009), Lavallée et al. (2007), Sato (2005), Vona et al. (2011). A review of the rheology of two phase magmas is presented by Mader et al. (2013).

When discussing crystalline magmas we must first outline some basic principles of magma crystallization. The liquidus is the temperature above which a material is entirely liquid. Crystalline solids begin precipitating in the liquid (melt) when the temperature drops beneath the liquidus. The nucleated and crystallized phases either remain in chemical equilibrium with the liquid, or the system undergoes fractional crystallization as the phases are either removed from the liquid by density contrast or through chemical zoning. The fraction of crystals increases until the solidus temperature is reached, at which point the rock should be entirely crystalline. If temperature decreases rapidly enough through the liquidus and solidus temperatures that crystallization does not occur, i.e. the liquid is super-cooled, the liquid becomes solid like as the glass transition temperature $\left(\mathrm{T}_{\mathrm{g}}\right)$ is crossed. This is why tephra samples can contain glassy portions as they are quenched rapidly, cooling below $\mathrm{T}_{\mathrm{g}}$ faster than the rate of crystal nucleation and growth. Lava samples generally undergo slow crystallization while in the magma chamber, allowing for large crystals to grow, and are then erupted within a flow (and retain heat) allowing for relatively slower cooling and a second stage of crystallization in the residual liquid, yielding a porphyritic crystal distribution. The change in temperature beneath the liquidus is referred to as undercooling. Large undercooling represents temperatures further beneath the liquidus, where nucleation is greater than diffusion. 
Small undercooling represents temperatures closer to the liquidus, where diffusion is greater than nucleation. Our rheological study will investigate crystallization at both large and small degrees of undercooling.

The word rheology comes from the Greek word rheos, which means stream, and logy which essentially translates to the study of. The literal meaning translates to the study of flowing materials, mainly liquid and/or solids that deform plastically. When studying the rheology of fluids we have to consider the ratio between the applied shear stress $\tau$, and the resulting shear strain-rate $\gamma$ (Mader et al. 2013).

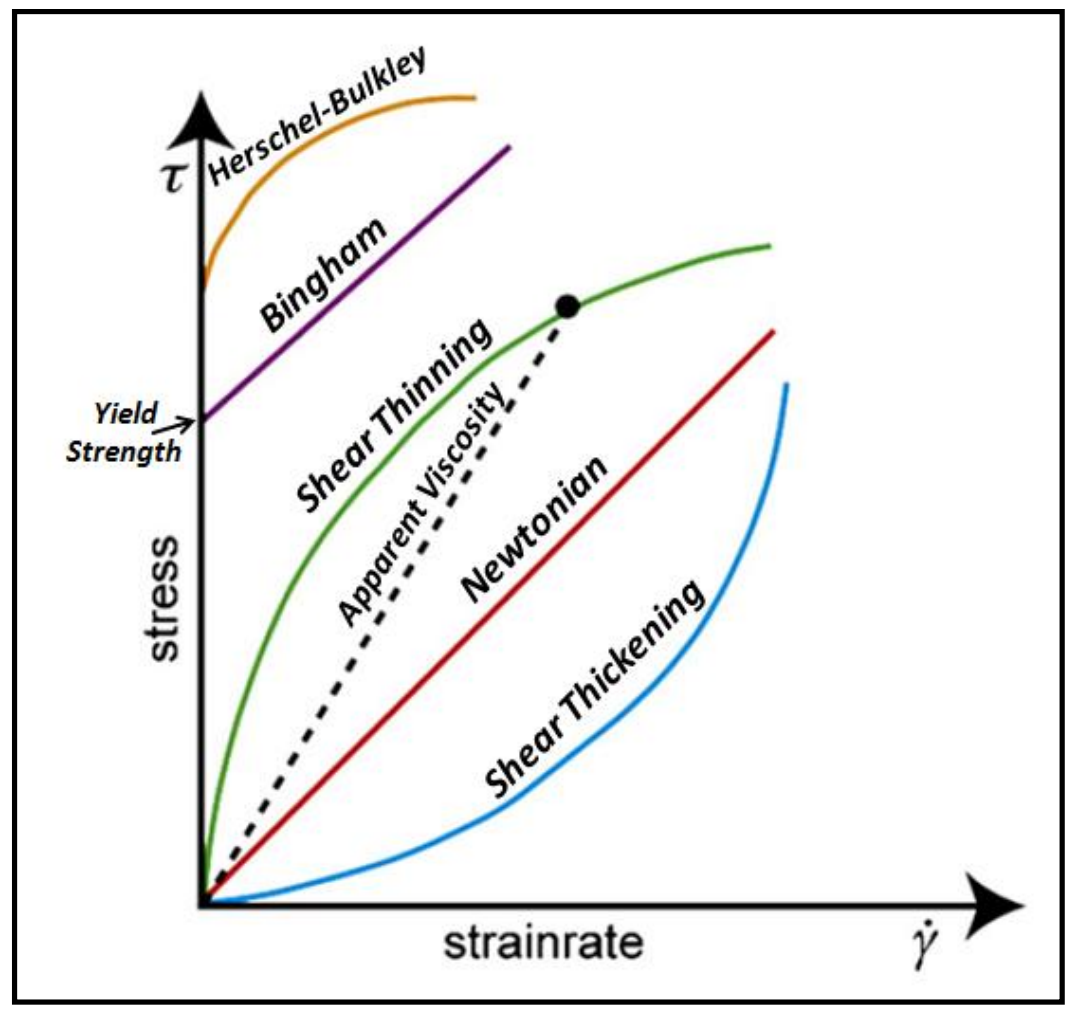

Figure 1.2. Flow curves for materials with different relationships between stress and strain rate. Modified from Mader et al. 2013. 
This simple ratio determines the apparent viscosity of a given material. Figure 1.2 is modified from Mader et al. 2013 and shows stress vs. strain rate with common lines, or flow curves, for materials with different relationships between stress and strain rate. The simplest relationship is Newtonian, where the fluid exhibits a viscosity ( $\eta$ ) that is independent of strain-rate. In cases where the viscosity is dependent on strain rate, the fluid is termed non-Newtonian and yields only an apparent viscosity ( $\eta_{\text {app }}$ ). At subliquidus temperatures, only apparent viscosities can be measured, because crystals suspended in the melt result in strain rates that are dependent on shear stresses (Ishibashi 2009). It should be noted that measured viscosity values throughout Chapter 3 are apparent viscosities $\left(\eta_{\mathrm{app}}\right)$, but will often be referred to as viscosity for brevity.

\subsection{Geologic Setting of Pacaya Volcano}

Volcanism in Guatemala is the result of the Cocos plate being subducted underneath the Caribbean plate (Bolge et al. 2009). At least 40 active volcanic centers in the Central American volcanic chain are the result of this subduction. More than 350 other volcanoes and volcanic vents are found throughout Guatemala, but only Pacaya, Fuego, and Santa Maria are currently active (Bohenberger 1969, Rose et al. 2013). The location of Pacaya with respect to these volcanoes and Guatemala City can be seen in Figure 1.1.

Pacaya is a volcanic complex consisting of at least six cones including Cerro Grande, Cerro Chiquito, Cerro Chino, Pacaya Viejo, Pacaya, and Cerro Mackenney (Rose et al. 2013). The complex overlaps the southern end of the (119-191 ka) Amatitllan 
Caldera (Wunderman and Rose 1984). The Pacaya volcanic complex has experienced 4 distinct phases of eruptive history since the initial building of the complex that started approximately 0.5 million years ago (Eggers 1972). The prehistoric Pacaya volcanic complex consisted of an andesitic composite volcano and a rhyodacite dome, with historic Pacaya erupting more mafic material (Bardintzeff et al. 1992).

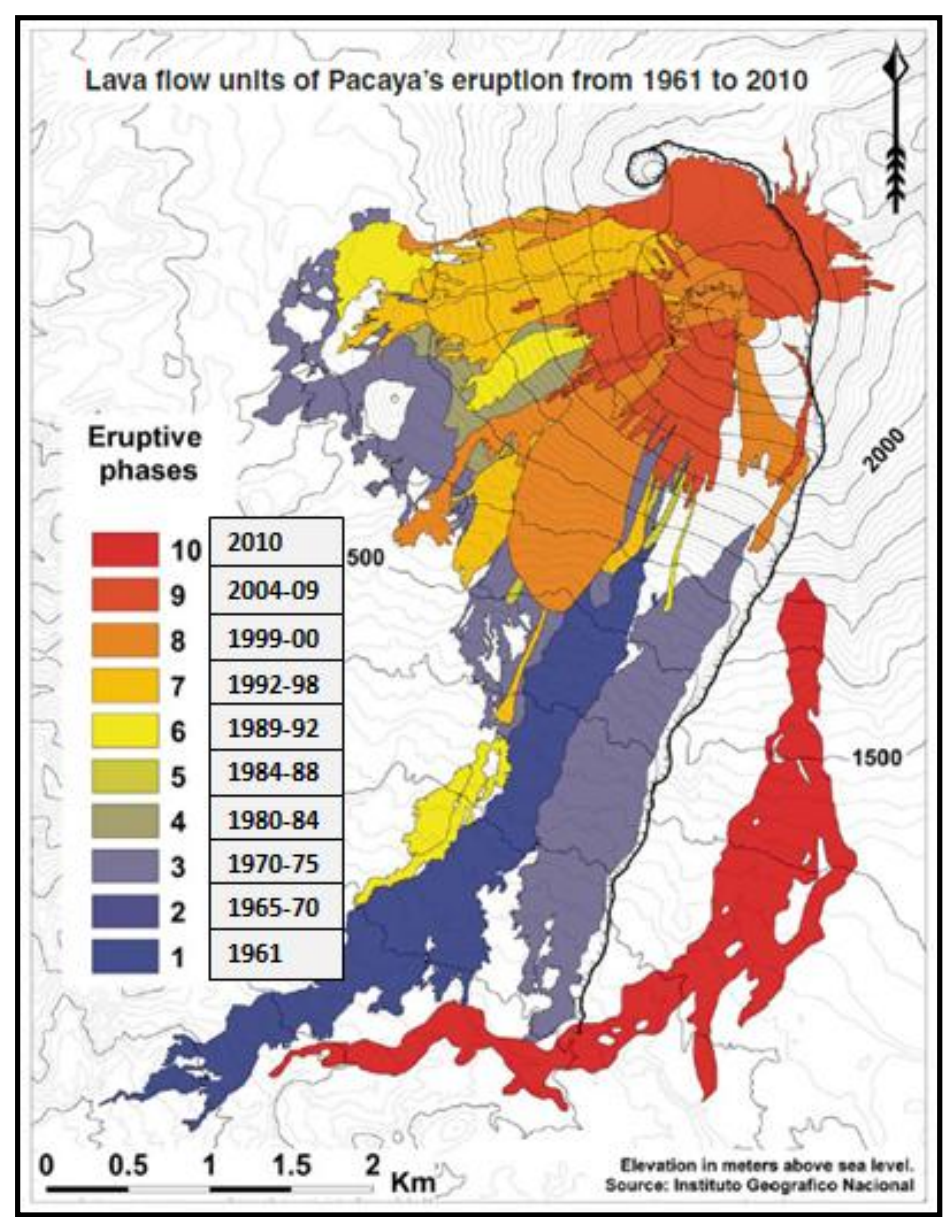

Figure 1.3. Mapped flows that formed between 1961-2010 (Modified from Rose et al. 2013). Years of activity labeled next to color legend.

The historic activity of Pacaya began in 1961 after approximately 200 years of quiescence. Rose et al. (2013) provides a comprehensive review of the 1961-2010 
eruptive history at Pacaya Volcano. In this period, basaltic eruptions predominantly occurred through the west flank of an older cone (Pacaya Viejo). Starting around 1965, the Mackenney Cone began growing in the Pacaya Viejo collapse scar, and started to resemble the modern day volcanic complex. Throughout the last 50 years of activity, eruptions and flows originated near the vent and/or along the flanks of the Mackenney Cone (Figure 1.3). A marked change in this eruptive behavior occurred in 2010.

\subsection{May 2010 Eruption of Pacaya Volcano}

On May $27^{\text {th }} 2010$ Pacaya volcano erupted explosively, producing tephra ranging in size from ash up to nearly meter-sized bombs. The eruption produced a $21 \mathrm{~km}$ high ash column and elongate ash blanket with volume estimates at $1.3 \times 10^{7} \mathrm{~m}^{3}$ (Rose et al. 2013). Two lava flows formed approximately $7-10$ before the main eruption and remained active during and after the main eruption. These flows erupted from vents aligned to either side of the former summit, which was destroyed during the eruption leaving a large fissure and elongate crater (Figures 1.4 and 1.5). This marks a change in the eruptive behavior of the volcano as lava flows active in 2009 originated from vents closer to the summit (Figure 1.3). The flow located on the northwestern side (NW flow) is $1.8 \mathrm{~km}$ long and was emitted from a vent at the base of the large fissure on the northwest side that formed during the eruption. Figures 1.4(A) and 1.4(B) show before

and after images from approximately the same perspective. The southeastern lava flow (SE flow) extends approximately $5.5 \mathrm{~km}$ from its main vent, which is located outside the Pacaya Viejo collapse scar on the southeastern flank of the volcano (Figure 1.5). 


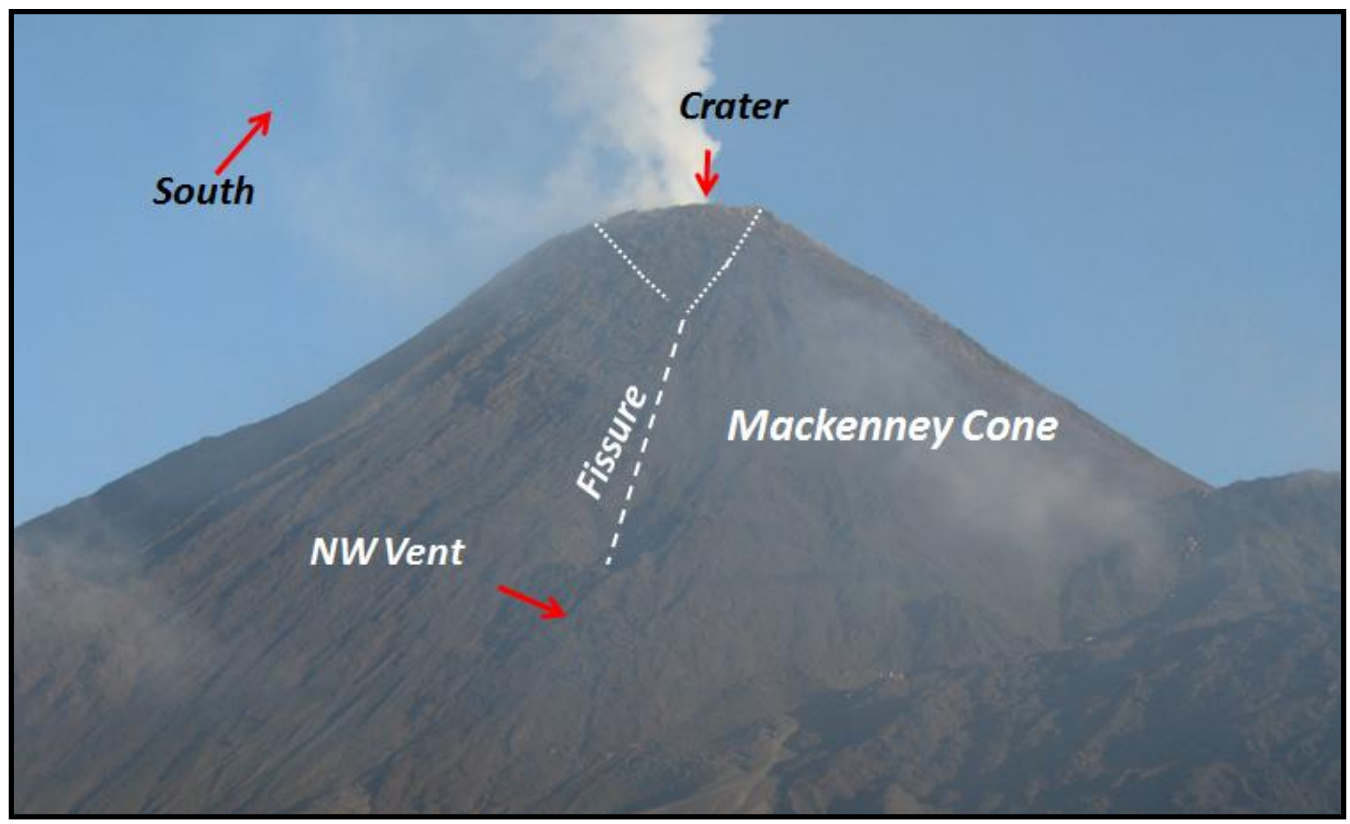

Figure 1.4 (A) Looking south towards the Mackenney Cone. Picture taken in January 2010, before the May 2010 eruption. Approximate locations of fissure and NW shown for comparison with Figure 1.4 (B)

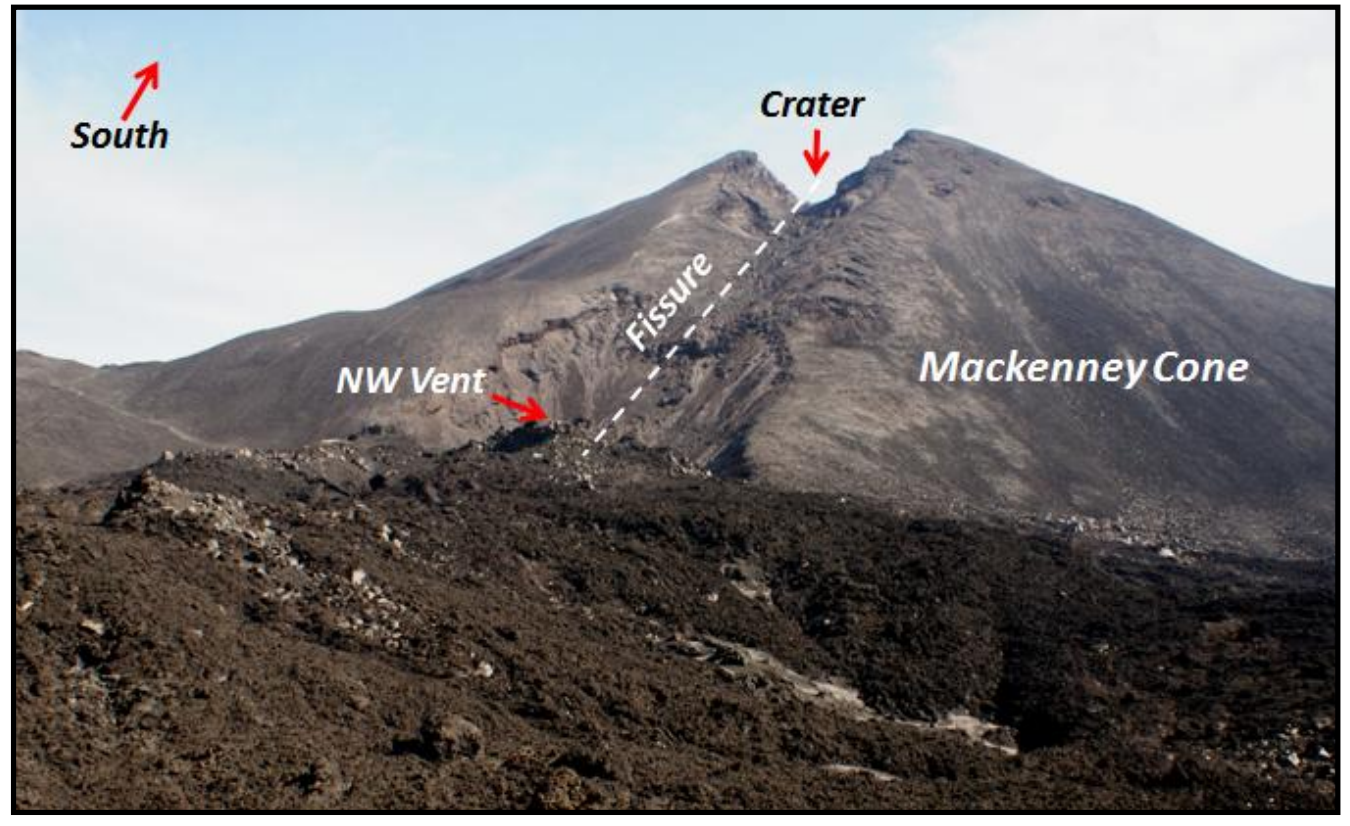

Figure 1.4 (B) Looking south towards the Mackenney Cone. The fissure that is aligned with the location of the NW and SE flow vents is labeled. 


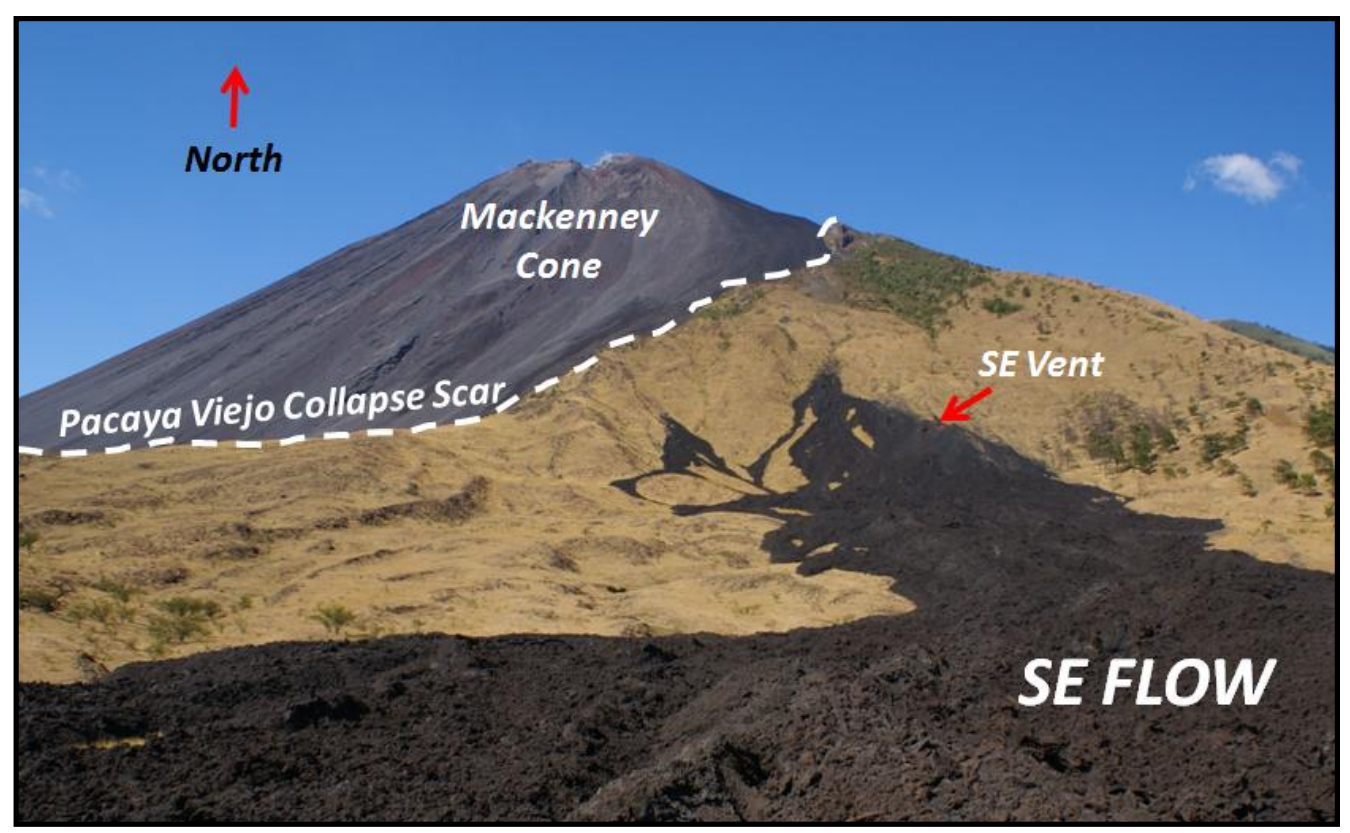

Figure 1.5 Looking north towards the Mackenney Cone. SE vent and flow relative to Pacaya Viejo collapse scar.

Figure 1.6 shows the locations of the 2010 vents relative to older vents, including the summit of Cerro Chino, and a more recent vent active in January 2014. Other members of the research team (Alan Whittington, Alexander Sehlke, and Arianna Soldati) visited Pacaya in January 2014 and acquired samples from the 2014 flow and determined the approximate location of the vent, which is also noted in Figure 1.6. Later eruptions, including 2014 eruptions will not be discussed in detail, as samples from the 2010 eruption are the focus of this project. The 2014 vent is important in this regard because it illustrates the relationship between the recent vents and the Cerro Chino summit. A dotted white line crosses each of these features, as well as two older vents denoted by OL-1 and OL-2, in Figure 1.6. Bolge et al. (2009) speculates that the approximate $\mathrm{N}-\mathrm{S}$ vent distribution, which is common within other volcanoes along the front, is associated with an underlying extensional graben associated with the regional 
tectonics. Lyon-Caen et al. (2006) determined an approximate 8mm/yr east-west extension, over approximately 4 years of GPS measurements (1999-2003), which likely results in the formation of these $\sim \mathrm{N}-\mathrm{S}$ trending grabens. While this extension explains the distribution of vents at the volcano, it does not explain the source of lava at each vent. We aim to determine if multiple magma chambers exist in the subsurface allowing for multiple vents and contemporaneous eruption of both effusive flows and explosive tephra.

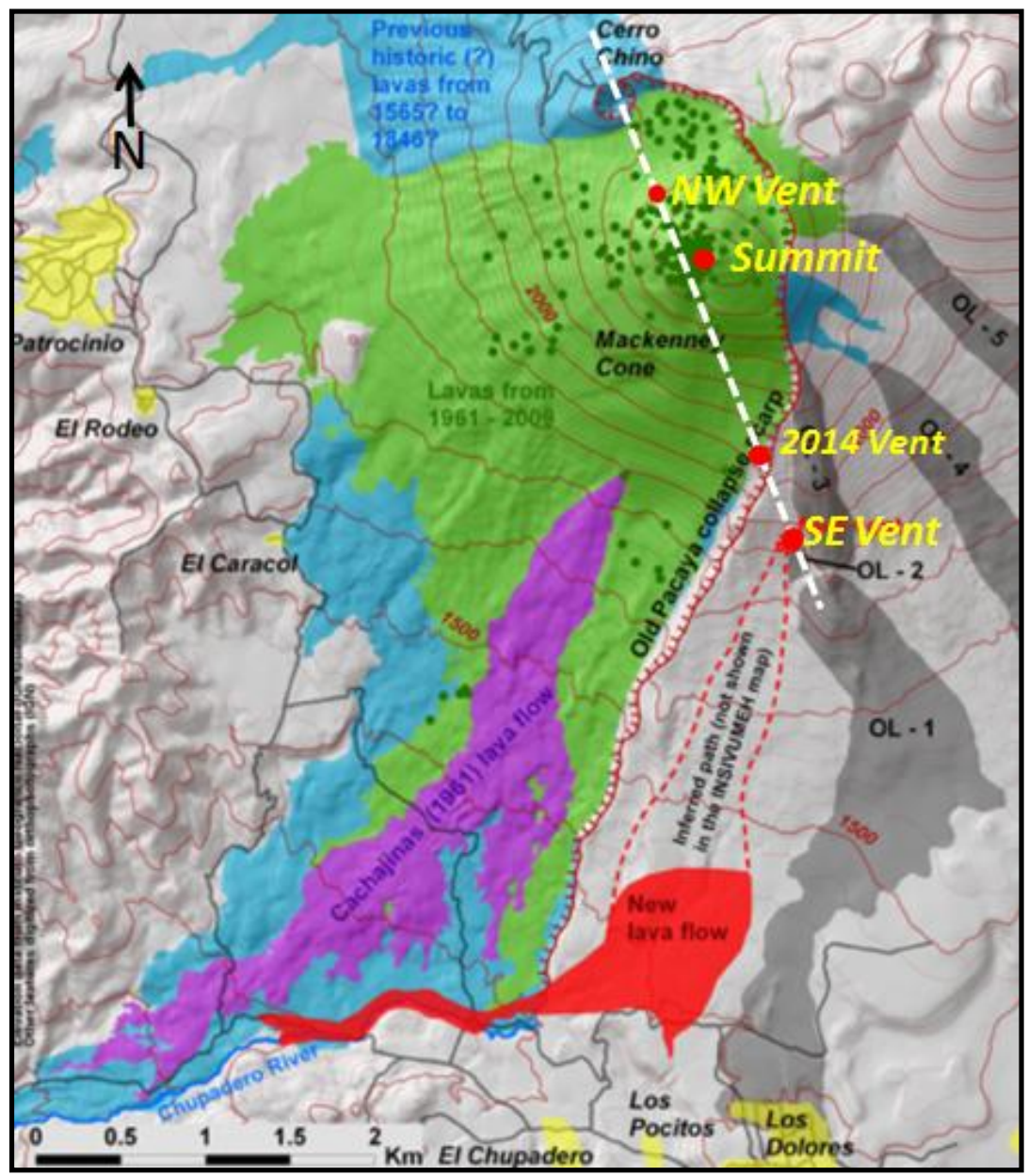

Figure 1.6 Map of Pacaya showing location of recent vents with relation to Cerro Chino summit. Feature is likely a $\sim \mathrm{N}-\mathrm{S}$ trending graben associated with regional extension. Modified from Wolf 2010. 


\subsection{Overview}

Pacaya is known for producing two different types of effusive activity; explosive Strombolian and/or vulcanian eruptions, and gentle strombolian eruptions accompanied by lava flows. This variation in eruption style can occur during separate eruptions or contemporaneously. This feature not only makes Pacaya a popular tourist attraction because of the lava flows and photogenic Strombolian eruptions, but also makes it a significant natural hazard. Pacaya is located approximately $30 \mathrm{~km}$ south of Guatemala City, which is the capital city of Guatemala with a population of more than 2 million (Figure 1.1). Ash from larger eruptions reaches the city, and can greatly disrupt ground and air travel. More at risk are the surrounding villages and farm lands that are affected by lava flows, ash, and ballistic projectiles during eruptions. Given its close proximity to highly populated regions and its eruptive history, it is imperative to study the controlling factors for explosive volcanism at Pacaya.

The eruptive behavior of Pacaya has prompted numerous geologic studies (Bardintzeff and Deniel 1991, Bardintzeff et al. 1992, Eggers 1972, Kitamura and Matías 1995, and Rose et al. 2013) including this thesis. This study first aims to provide a detailed physical and chemical analysis of the erupted products from the May 2010 eruption at Pacaya Volcano. The results will be used to construct a model that explains the timing of explosive and effusive eruptions and the origin of lavas associated with each eruption. Secondly, a set of subliquidus experiments will be used to induce partial crystallization within remelted samples at various degrees of undercooling. These results will be used to explain the various groundmass textures present in natural samples. 
Viscosity will also be measured on the partially crystalline remelts, and results will be used to test current models that predicate magma rheology.

The methods of sample acquisition, petrographic and chemical analysis, and results of such analysis will be provided in Chapter 2. Chapter 3 will provide the methods and results of rheology experiments in the lab and theoretical modeling aimed at quantifying the effects of crystallization on magma viscosity. Chapter 4 will summarize our findings and tie together the petrographic and rheological observations in a model for the May 2010 eruption. 


\section{CHAPTER 2- PETROGRAPHY AND CHEMISTRY OF ERUPTION PRODUCTS FROM MAY 2010}

\subsection{Sample Acquisition}

In January of 2012 our research team spent four days acquiring rock samples from the May 2010 eruption of Pacaya volcano. We used our own field observations as well as those of the resident observers who witnessed the eruption to determine the best method of sample acquisition. It was our goal to acquire samples that comprised each type of erupted material during the 2010 eruption, namely ash to lapilli sized tephra, ballistic bombs, and lava flows.

Upon acquisition, samples were given distinct names, wrapped in separate sample bags, and the location was determined using handheld GPS. Sample names were given in the general format: AW12-PA\#\#. Considering that the first four characters of the sample name (AW12) will not change, samples will commonly be referred to in the PA\#\# format for brevity. Samples are listed in Table 2.1 along with distance from source and UTM coordinates.

The eruption produced tephra ranging from ash size up to nearly meter-sized bombs. Lapilli sized tephra was acquired by Gustavo Chigna of INSIVUMEH (Instituto Nacional de Sismología, Vulcanología, Meteorología e Hidrología). Gustavo supplied us with generous amounts of tephra sample (PA01), sampled from the street in Guatemala City, and helped us plan our objectives for further sample acquisition at the volcano. Once at the volcano we were able to collect seven ballistic bombs from the north side of the volcano (Figure 2.1). Three bomb samples and a set of pumice samples were 
collected on Cerro Chino. The other four bombs were collected on the N/NW flank of the volcano. Although there was a wide range of bomb sizes produced by the eruption, sample sizes were limited by the ability to transport the samples over rough terrain. Figure 2.2 shows a photo of one of the largest bombs surrounded by smaller bomb fragments and lapilli sized tephra.

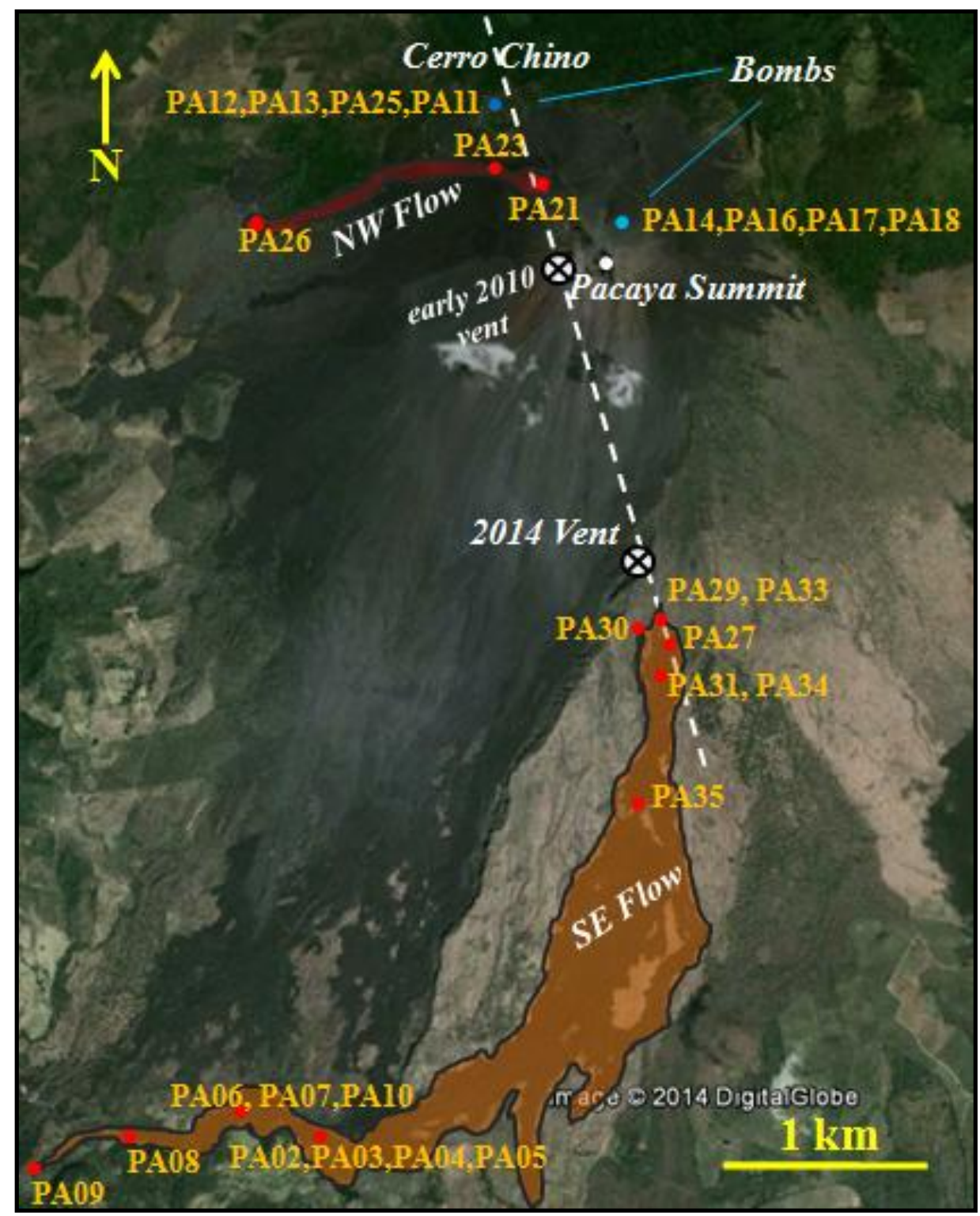

Figure 2.1. Locations of samples overlain on a Google earth image of Pacaya volcano. 


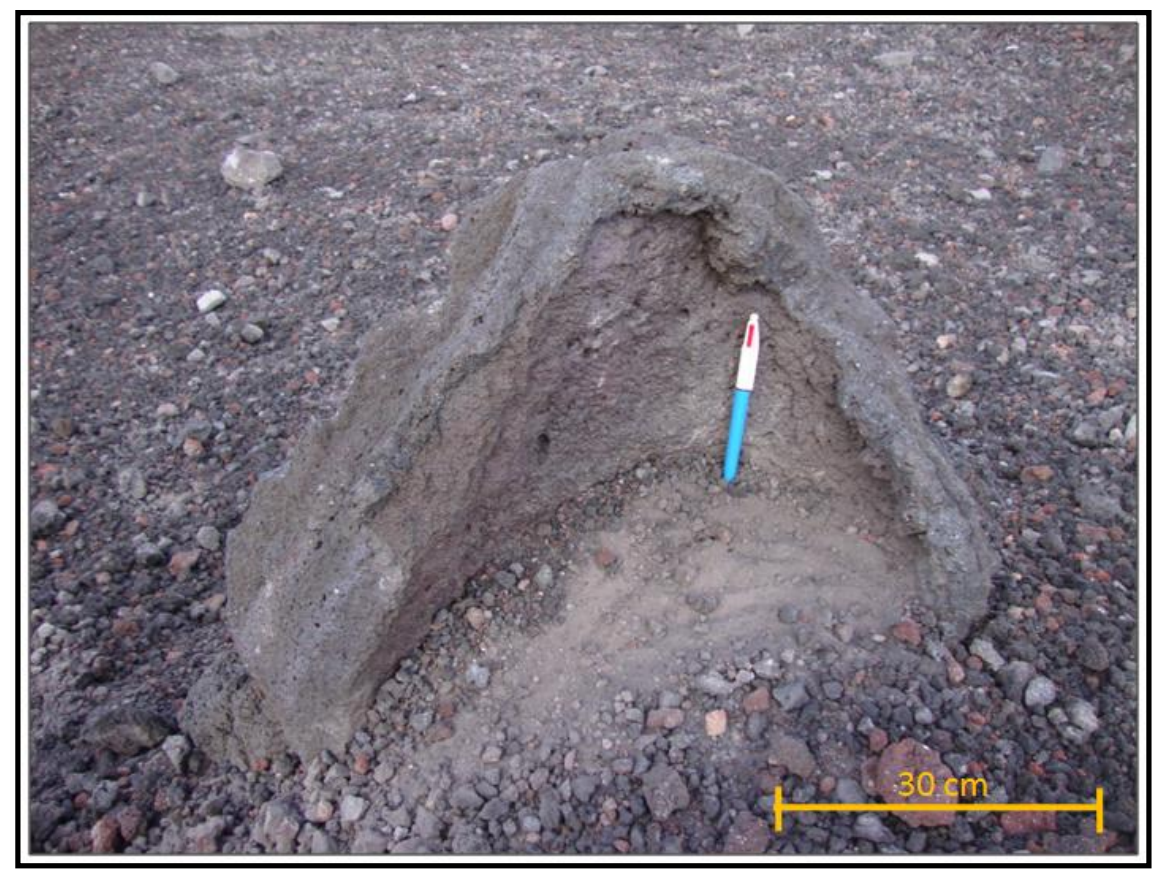

Figure 2.2. Large bomb surrounded by tephra, found where four other bombs (PA16, PA17, and PA18) were sampled on the north flank of the volcano.

As stated in Chapter 1, there are two main lava flows associated with the eruption.

For each flow we acquired samples from both the vent and toe, and various samples from the middle of each flow (Figure 2.1). Seventeen samples were acquired from the SE flow and four were acquired from the NW flow. We also collected several rhyolitic xenoliths that were incorporated into the flow during eruption. These xenoliths were studied by Emma Rosenow in a senior thesis research project aimed at determining temporal history of magma mixing with the xenoliths (Rosenow et al. 2013). She found that results are consistent with xenoliths being plucked from basement rock during magma ascent. Based on petrographic analysis of interaction zones between xenoliths and basalt, it was inferred that the xenoliths were either carried directly to the surface at a slow rate, or were captured in a shallow magma chamber possibly days to months before the eruption. 
Table 2.1. Sample names, distance from source, and location.

\begin{tabular}{|c|c|c|c|c|c|}
\hline Sample Name & Sample Description & $\begin{array}{c}\text { Distance -Source } \\
\mathbf{k m}\end{array}$ & Source & $\begin{array}{r}\mathbf{U} \\
\text { Easting }\end{array}$ & $\begin{array}{l}\text { ГM } \\
\text { Northing }\end{array}$ \\
\hline AW12-PA01 & Lapilli size Tephra & $\sim 15$ & Summit & 765833 & 1614121 \\
\hline AW12-PA02 & SE Mid-Low Flow & 3.75 & SE Vent & 757355 & 1586855 \\
\hline AW12-PA03 & SE Mid-Low Flow & 3.75 & SE Vent & 757288 & 1586855 \\
\hline AW12-PA04 & SE Mid-Low Flow & 3.75 & SE Vent & 757308 & 1586858 \\
\hline AW12-PA05 & SE Flow Xenolith & 3.75 & SE Vent & 757308 & 1586860 \\
\hline AW12-PA06 & SE Mid-Low Flow & 4.25 & SE Vent & 756829 & 1586912 \\
\hline AW12-PA07 & SE Mid-Low Flow & 4.25 & SE Vent & 756860 & 1586921 \\
\hline AW12-PA08 & SE Lower Flow & 4.9 & SE Vent & 756263 & 1586631 \\
\hline AW12-PA09 & SE Toe of Flow & 5.5 & SE Vent & 755754 & 1586631 \\
\hline AW12-PA10 & SE Flow Xenolith & 4.25 & SE Vent & 756700 & 1586930 \\
\hline AW12-PA11 & Pumice & 1 & Summit & 757940 & 1592220 \\
\hline AW12-PA12 & Bomb & 1 & Summit & 757940 & 1592220 \\
\hline AW12-PA13 & Vesicular Bomb & 1 & Summit & 757940 & 1592220 \\
\hline AW12-PA14 & Bomb & 0.3 & Summit & 758879 & 1591527 \\
\hline AW12-PA16 & Bomb & 0.5 & Summit & 758857 & 1591676 \\
\hline AW12-PA17 & Bomb & 0.5 & Summit & 758857 & 1591676 \\
\hline AW12-PA18 & Bomb & 0.5 & Summit & 758857 & 1591676 \\
\hline AW12-PA21 & NW Flow Vent & 0 & NW Vent & 758324 & 1591853 \\
\hline AW12-PA23 & NW Mid Flow & 0.3 & NW Vent & 758098 & 1591991 \\
\hline AW12-PA24 & NW Mid Flow & 0.3 & NW Vent & 758098 & 1591991 \\
\hline AW12-PA25 & Bomb & 1 & Summit & 757940 & 1592220 \\
\hline AW12-PA26 & NW Toe of Flow & 1.8 & NW Vent & 756618 & 1591839 \\
\hline AW12-PA27 & SE Flow Vent & 0 & SE Vent & 759084 & 1589575 \\
\hline AW12-PA28 & SE Upper Flow & 0 & SE Vent & 759031 & 1589621 \\
\hline AW12-PA29 & Highest Vent & $\sim 0$ & SE Vent & 759012 & 1589645 \\
\hline AW12-PA30 & 2nd Highest Vent & $\sim 0$ & SE Vent & 758900 & 1589645 \\
\hline AW12-PA31 & SE Upper Flow & 0.3 & SE Vent & 759011 & 1589319 \\
\hline AW12-PA33 & SE Flow Xenolith & $\sim 0$ & SE Vent & 759080 & 1589580 \\
\hline AW12-PA34 & SE Flow Xenolith & $\sim 0$ & SE Vent & 758973 & 1588738 \\
\hline AW12-PA35 & SE Mid-Upper Flow & 0.85 & SE Vent & 758934 & 1588711 \\
\hline
\end{tabular}




\subsection{Methods of Sample Petrography and Characterization}

\subsubsection{Petrographic Methods}

Following macroscopic analysis we then examined our samples using optical and electron microscopy. Each sample was cut into approximately 27 by $42 \mathrm{~mm}$ billets using an MK brand diamond blade tile saw. We chose pieces of the rock that appeared to be macroscopically homogenous relative to the whole rock. Billets were labeled and sent off to Texas Petrographic Services Inc. to be made into thin sections using conventional techniques. Each thin section was systematically photographed in both plane polarized light (PPL) and cross polarized light (XPL) at different magnifications using an Olympus BX41 laboratory microscope. Optical microscopy was used to identify phases and texturally characterize our samples before using electron microscopy.

Of the samples imaged optically, specific samples, representing the vent, middle, and toe of each flow, along with lapilli and two pieces of bomb sized tephra, were prepared for further microscopic analysis using electron microscopy. These samples were cut using a diamond saw and polished down to approximately $1 \mathrm{~mm}$ thickness using first 240 grit, then 600 grit carbide paper When the appropriate thickness was reached, felt polishing wheels and 5, 1, and 0.3 um alumina powders were used to attain an optimal polished surface. The polished samples were then mounted onto 1" round glass slides using Crystalbond to then be imaged using electron microscopes at the University of Missouri-Columbia (UMC) and Washington University, St. Louis (WUSTL).

The electron microscope used at UMC was a FEI Quanta 600 FEG Extended Vacuum Scanning Electron Microscope (Quanta). The Quanta was used in high vacuum 
mode with an accelerating voltage set to $20 \mathrm{kV}$. Secondary electron imaging (SEI) was used to locate samples, create sample montages, and aid in focusing. Back Scattered Electron (BSE) imaging was used to acquire gray scale images based on atomic number. BSEs are emitted during elastic interaction between electron-beam electrons and the atomic nuclei of the sample (Ginibre et al. 2007). The gray scale images produced through BSE imaging then directly relate to the atomic number of the sample, with brighter areas representing larger mean atomic numbers.

A JEOL JXA-8200 Electron Microprobe was used at WUSTL predominantly for microanalysis of the phases present in samples, but also for acquiring BSE images based on the same principles as described above. The chemical analyses from the JEOL microprobe will be provided in the subsequent chemistry sections. The following section will use images from all microscopic methods to provide a petrographic description of the samples acquired at Pacaya volcano.

\subsubsection{Determining Crystallinity}

The crystallinity of our samples was quantified on the basis of phenocryst $\%\left(\phi_{\mathrm{P}}\right)$, microcrystal \% $\left(\phi_{\mathrm{m}}\right)$, and glass $\%\left(\phi_{\mathrm{gl}}\right)$. The BSE images from both JEOL and Quanta were used to determine these values along with a pixel counting method using Adobe Photoshop. At lowest magnification (x40 JEOL), we used a freehand method of selecting the phenocrysts (approximately $>300 \mu \mathrm{m}$ ) and used the histogram function to count total pixels and obtain $\phi_{\mathrm{P}}$. The void spaces (bubbles) within images were excluded from the total pixel count to ensure that the crystal and glass percentages were that of only the dense rock. High magnification images were used to determine the proportion of 
microcrystals. Spaces between phenocrysts were highlighted and total pixels (minus void spaces) were counted using the histogram function. Then using the color select tool, microcrystal crystals ( $\sim 50-300$ um) were chosen and all microcrystals of the same shade were automatically selected. For samples with one microcrystal phase, this step was sufficient. For samples with multiple phases the process was repeated.

\subsubsection{Determining Density and Vesicularity}

The density and vesicularity of the natural samples was determined using three methods: geometric measurement, the Archimedean method, and helium pycnometry. By combining the results of each type, we were then able to determine the volume of open, isolated, and total vesicles in each sample. The methods for each type of measurement will briefly be outlined, with results provided in the following sections.

Four to six cylindrical cores of each sample were drilled using a drill press and a Starlite diamond coated drill bit. The length and diameter of drilled cores was approximately $1 \mathrm{~cm} \times 1 \mathrm{~cm}$. Our samples are generally both macro and microscopically heterogeneous based on the forthcoming analyses. For this reason multiple cores were drilled from each sample to obtain multiple measurements that can be averaged to represent the whole rock. Samples were polished evenly on top and bottom to ensure symmetry. For one vesicular sample (PA27) that could not be drilled, 4 cubes were cut using a low speed diamond saw. To obtain the geometric (bulk rock) density, the average length and diameter of each core (or length of each side of the cube) were determined, before being weighed in air 6 times. Samples were measured 6 times for precision and to account for any instrument drift. The geometric volume $\left(\mathrm{V}_{\mathrm{G}}\right)$ was then calculated using 
$\pi r^{2} h$, where $r$ is the average radius of the core and $h$ is the average length of the core. $\mathrm{V}_{\mathrm{G}}$ is depicted by the outline of the core, including any void spaces, represented by the dotted red line in Figure 2.3.

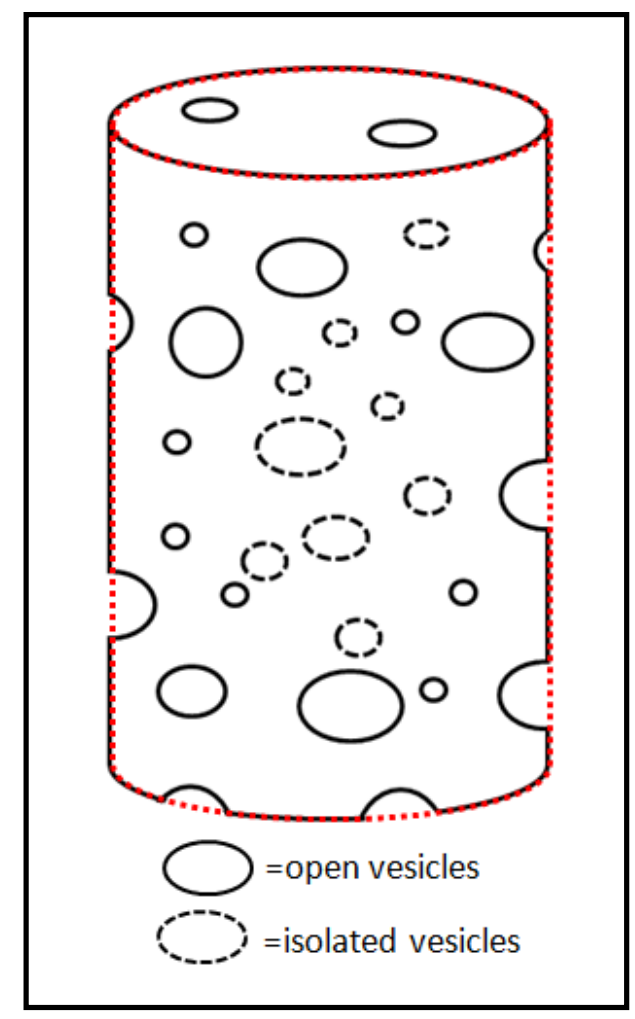

Figure 2.3. Schematic of core used in vesicle calculations.

The density for the drilled cores was next measured using Archimedes' principle. A Mettler Toledo xS205 Dual Range scale and density kit was used for the measurements. Archimedes' principle states that when a mass is submerged in a fluid, the buoyant force exerted on the mass is equal to the weight of the fluid displaced. The following equation defines how we use this principle to determine sample density.

$$
\rho=\frac{A}{A-B}\left(\rho_{o}-\rho_{L}\right)+\rho_{L}
$$


$\rho$ is the density of the sample, with $A$ being the weight of the sample in air, and $B$ being the weight of the sample in the immersion liquid (ethanol in our measurements). $\rho_{o}$ is the density of the immersion liquid, and $\rho_{L}$ is the density air $\left(0.0012 \mathrm{~g} / \mathrm{cm}^{3}\right)$. Before samples could be weighed in ethanol, they were allowed to soak overnight to ensure that any open pore spaces were saturated with the immersion fluid. Samples were then weighed 6 times each immersed in ethanol. The volume of the cored sample minus open vesicles $\left(\mathrm{V}_{\mathrm{E}}\right)$ can then be determined by dividing the mass of the sample in air by the density of the sample in ethanol. This is represented by the core minus bubbles marked with solid lines in Figure 2.3.

A Quantachrome MVP-D160-E Multipycnometer was used to measure 'skeletal' density (the rock minus any void spaces) of the rock for select samples at WUSTL. The pycnometer uses Archimedes' principle of fluid displacement to determine the volume of samples, where in this case the fluid is a gas. A known weight of powdered sample is placed into a sample chamber before allowing a known volume of gas to be pressurized into the chamber. The sample is powdered to eliminate any isolated void spaces and to ensure that volume determined is only that of the rock, yielding the skeletal density illustrated in Figure 2.3 as the core minus all void spaces. Helium is used as the gas because it has a small atomic dimension and can penetrate the powder better than larger elements. After the known volume of pressurized helium is allowed to enter the sample chamber, the differential pressure between the two chambers can be related to the volume of the sample chamber that the sample occupies. Principles of Boyle's law and the relationship $P V=n R T$ are used to determine this value. This volume $\left(\mathrm{V}_{\mathrm{P}}\right)$, when related to 
the sample as a core, is exhibited in Figure 2.3 as the core minus all void spaces. The skeletal density can then be calculated by dividing the starting mass of the powder by the determined volume.

Having measured the volume values of the sample in air $\left(\mathrm{V}_{\mathrm{G}}\right)$, in ethanol $\left(\mathrm{V}_{\mathrm{E}}\right)$, and crushed powder $\left(\mathrm{V}_{\mathrm{P}}\right)$, we can calculate the amount of connected/open, isolated, and total vesicles in each sample using the equations shown below.

$$
\begin{aligned}
& \left(V_{G}\right)-\left(V_{E}\right)=\text { Volume of connected/open vesicles }\left(V_{C}\right) \\
& \left(V_{G}\right)-\left(V_{P}\right)=\text { Volume of total vesicles }\left(V_{T}\right) \\
& \left(V_{T}\right)-\left(V_{C}\right)=\text { Volume of isolated vesicles }\left(V_{I}\right) \\
& \left(V_{C}, V_{T}, V_{I}\right) / V_{G} * 100=\text { Vesicle } \%\left(\varphi_{C}, \varphi_{T}, \varphi_{I}\right)
\end{aligned}
$$

All density and vesicularity values are provided in Table 2.2.

\subsection{Sample Petrography and Characterization}

The obtained optical and BSE images, along with the determined crystallinity and vesicularity will now be provided for each sample type. We have grouped the samples into three groups: lapilli tephra, bombs, and flows. 


\subsubsection{Lapilli Tephra}

Tephra samples denoted as PA01 consist of ash particles or lapilli sized fragments (Figure 2.4). Fragments larger than $6.4 \mathrm{~cm}$ are considered to be bombs (Fisher 1961). The larger lapilli fragments are generally spheroidal, with some pieces exhibiting a slightly elongated texture. Homogenously distributed vesicles are present in the $>1 \mathrm{~cm}$ sized fragments, with preferred vesicle orientation present in the elongated samples. The ash and lapilli fragments are mostly gray scale color, with some fragments exhibiting a red hue indicating oxidation.

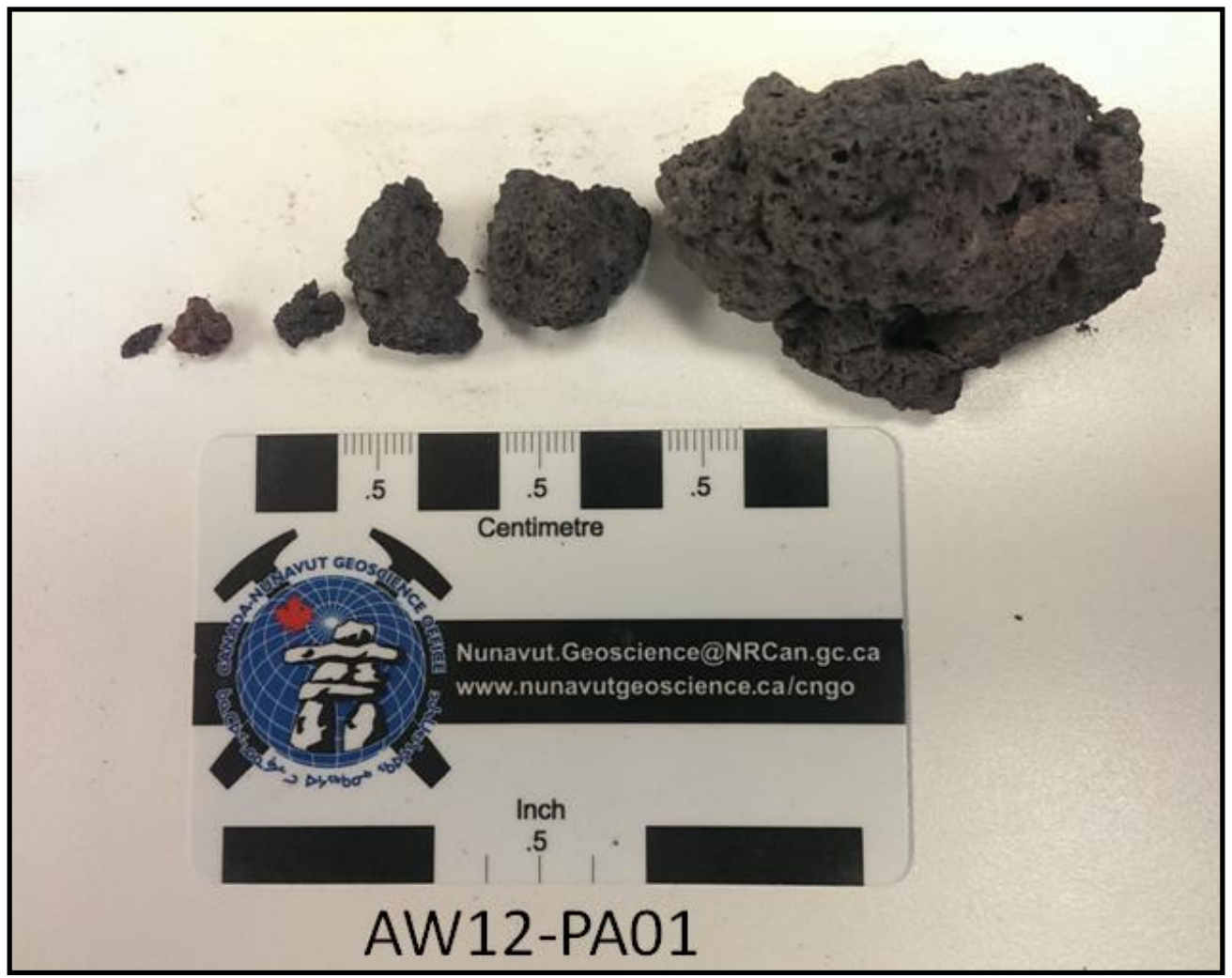

Figure 2.4. Lapilli sized tephra collected by Guatavo Chigna of INSIVUMEH.

These samples are highly vesiculated, with void spaces depicted in light blue within thin section images, and in black within BSE images (Figure 2.5). We were unable 
to drill cores from any of the PA01 samples and thus were unable to determine the vesicularity of the samples. Most of the flow and bomb samples can be considered relatively macroscopically homogenous with regards to vesicularity. In contrast, the tephra samples range from ash to lapilli size, and therefore cannot be used to calculate accurate vesicularity values. A density of $2.0 \mathrm{~g} / \mathrm{cm}^{3}$ was measured for a medium sized lapilli sample $(\sim 2-3 \mathrm{~cm})$ using Archimedes' method, while the powdered sample yielded a density of $2.9 \mathrm{~g} / \mathrm{cm}^{3}$ using helium pycnometry. The total porosity must therefore be on the order of $32 \%$, likely greater if we consider all fragments, including ash, to represent the whole sample.

Using two 40x (JEOL) BSE images we calculated approximately $48 \%$ phenocrysts $\left(\phi_{\mathrm{P}}\right)$ of mostly plagioclase and minor olivine. Higher magnification images of the groundmass, one at $\sim 1600 \mathrm{x}$ and another $\sim 3000 \mathrm{x}$ (Quanta), reveal between 15-52\% glass $\left(\phi_{\mathrm{G}}\right)$ and/or $0-38 \%$ microcrystals $\left(\phi_{\mathrm{m}}\right)$ within the whole sample, depending on the sample imaged (Figure 2.5 and Table 2.2). The lapilli tephra samples are unique in that there are distinct zones where $\mu \mathrm{m}$ scale acicular microcrystals dominate, and neighboring areas where microphenocrysts $(20-40 \mu \mathrm{m}$ in length) exist in glass. This results in the ranges in $\phi_{\mathrm{G}}$ and $\phi_{\mathrm{m}}($ Figure $2.5 \mathrm{D}, \mathrm{F}$, and $\mathrm{H})$. Both the acicular and skeletal textures are indicative of rapid growth (Lofgren 1974). Slides C, D, and E in Figure 2.5 show the general proportions of phenocrysts and microcrystals in PA01 samples. Some plagioclase phenocrysts reach nearly $0.5 \mathrm{~mm}$ in length and are generally larger than the less numerous olivine phenocrysts. Less common microphenocrysts of clinopyroxene and titanomagneitite also exist. 

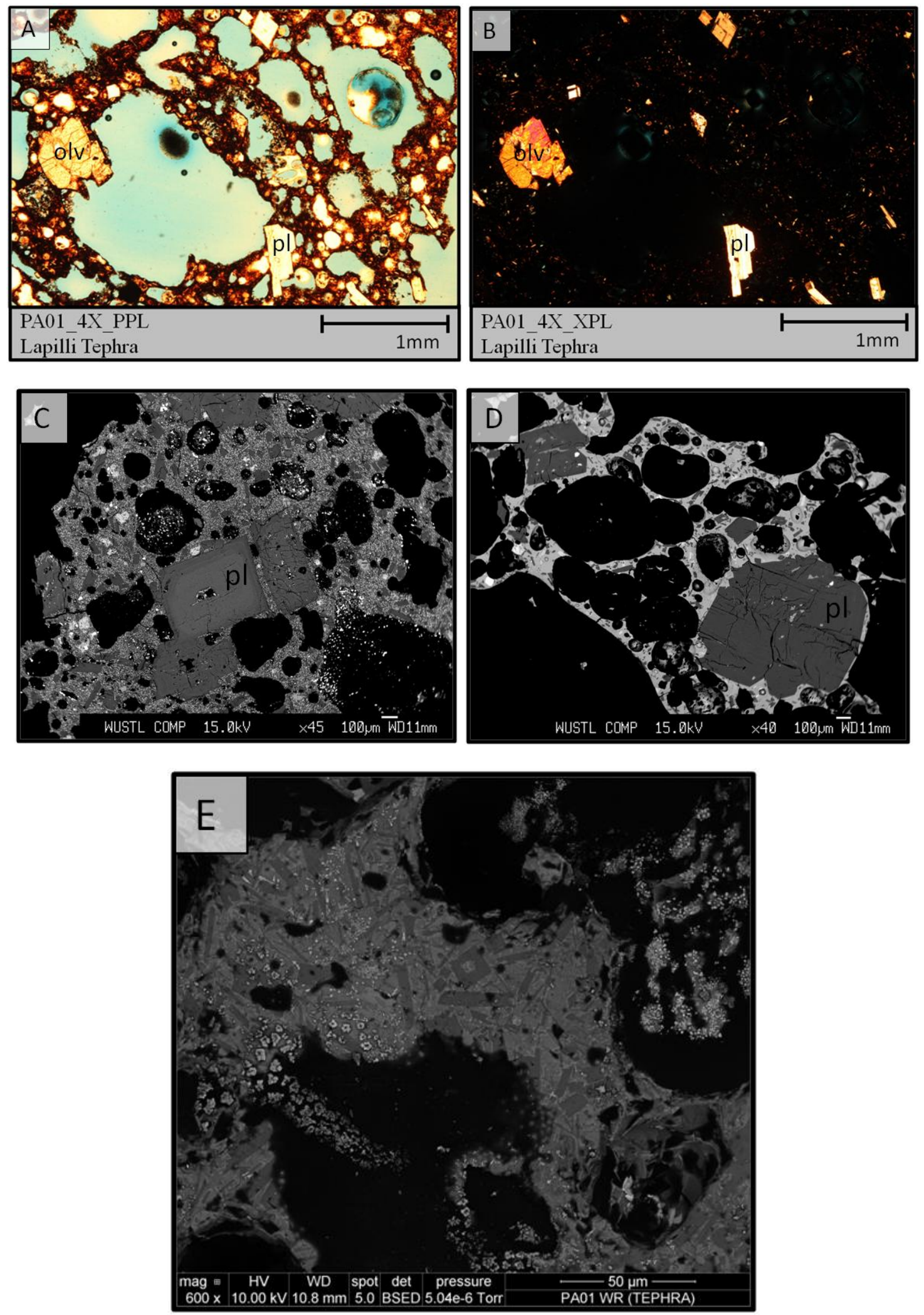

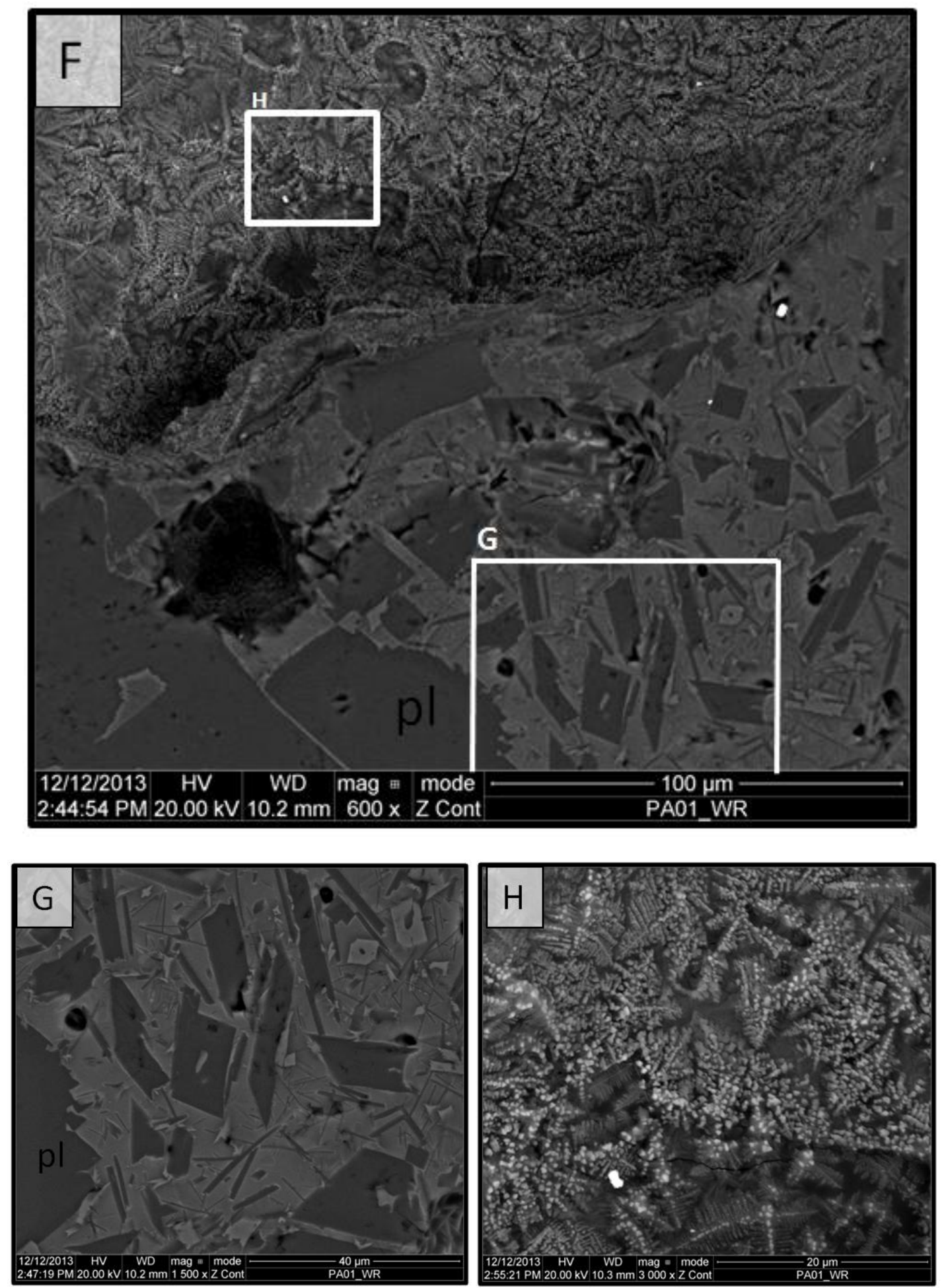

Figure 2.5. Lapilli Tephra (PA01) optical images (A and B) and BSE images (C and D are from JEOL WUSTL, and E, F, G, and $\mathrm{H}$ are from Quanta UMC). Phenocrysts of plagioclase (pl) and olivine (olv), within variable glassy and/or microcrystalline groundmass. 
Slide $\mathrm{C}$ in Figure 2.5 shows a $\sim 0.5 \mathrm{~mm}$ zoned plagioclase phenocrysts with a calcic core, surrounded by alternating more sodic and more calcic rims. This oscillatory zoning reflects magmatic processes, in which calcic cores precipitate at higher temperatures, and more sodic rims precipitate at relatively lower temperatures. The types of zoning present in samples can be used to infer temperature and crystallization history in the magma chamber. A summary and interpretation of this history will be provided following the petrographic description of samples.

\subsubsection{Bombs}

The collected bomb samples range in size from $\sim 7 \mathrm{~cm}$ (PA13) to $\sim 35 \mathrm{~cm}$ (PA16). The shapes of the bomb samples vary, ranging from very elongate to essentially spheroidal. PA12 consists of three very elongate bomb samples with aspect ratios approaching 5:1 (Figure 2.6). Each of the three PA12 samples are considered to be fusiform bombs, which is evidenced by the shape of the bomb suggesting that they were molten during flight and formed the elongate shape as they rotated and cooled in air. PA14 is also an elongate fusiform bomb that shows a similar aspect ratio compared to PA12, however the bomb is distinctively shaped like a "U" possibly due to impact occurring when the bomb was still partially molten (Figure 2.6). Aside from the "U" shape of PA14, samples PA12 and PA14 are essentially macroscopically identical.

PA16, PA17, and PA18 are all larger (PA16 is the largest) and more spheroidal in shape. PA16 and PA18 are denser compared to PA17, (possibly representative of blocks rather than bombs) however chilled margins are evident in both samples (Figure 2.7). PA17 is texturally different compared to PA16 and PA18, as it is largely fractured, 
exhibiting a bread crust texture, either the result of impact or continued compression during crystallization (Figure 2.8).

PA13 (which was collected on Cerro Chino) consist of three separate samples which look nearly identical to the lapilli sized samples, except on a larger scale (Figure 2.8). Based on macroscopic observation PA13 was likely formed with the lapilli sized tephra, and only represents a larger piece. PA13 is an obvious outlier compared to the other bombs with a geometric density of $0.9 \mathrm{~g} / \mathrm{cm}^{3}$, which is far less than the other bombs that have geometric densities between 2.4 to $2.8 \mathrm{~g} / \mathrm{cm}^{3}$. The range in densities is due to the range in vesicularity between the samples. The vesicular bomb (PA13) contains $70 \%$ total bubbles $\left(\phi_{\mathrm{T}}\right)$, while the dense bombs contain between only $6-8 \% \phi_{\mathrm{T}}$.

The density and vesicularity along with determined crystallinity for the bombs, and all other samples, are plotted in Table 2.2 and in Figures 2.22- 2.24 later in this chapter.

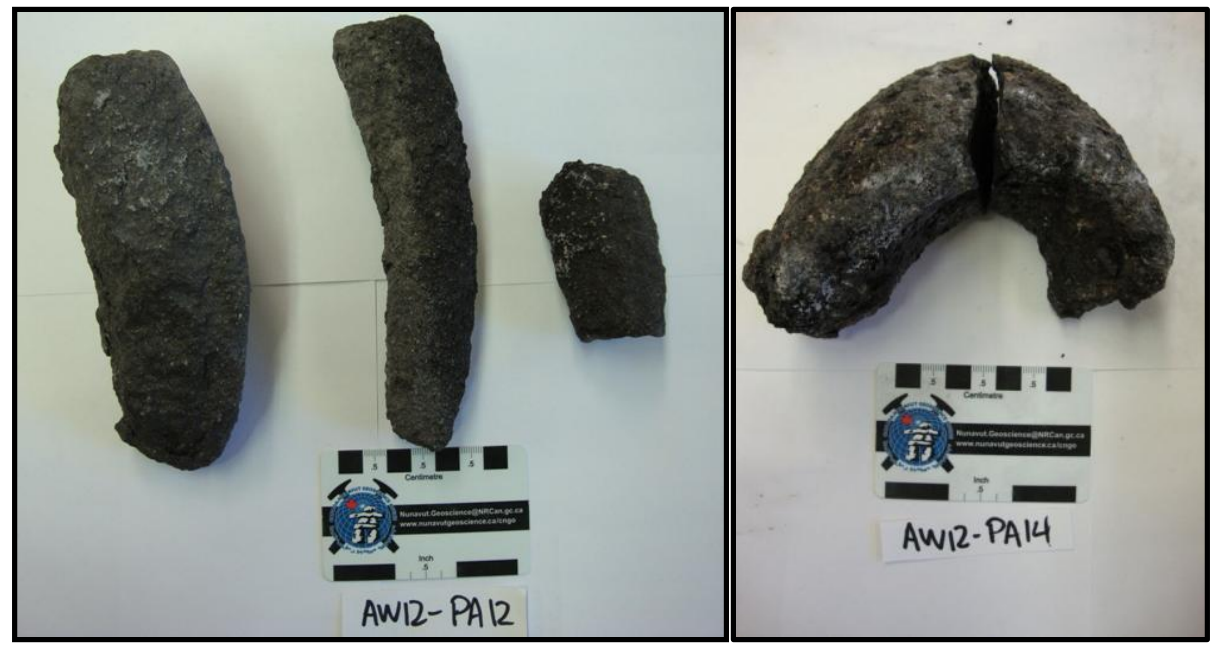

Figure 2.6. Elongate fusiform bombs. PA12 (left) was collected on Cerro Chino, and PA14 (right) was collected by local guide on north flank of the volcano. 


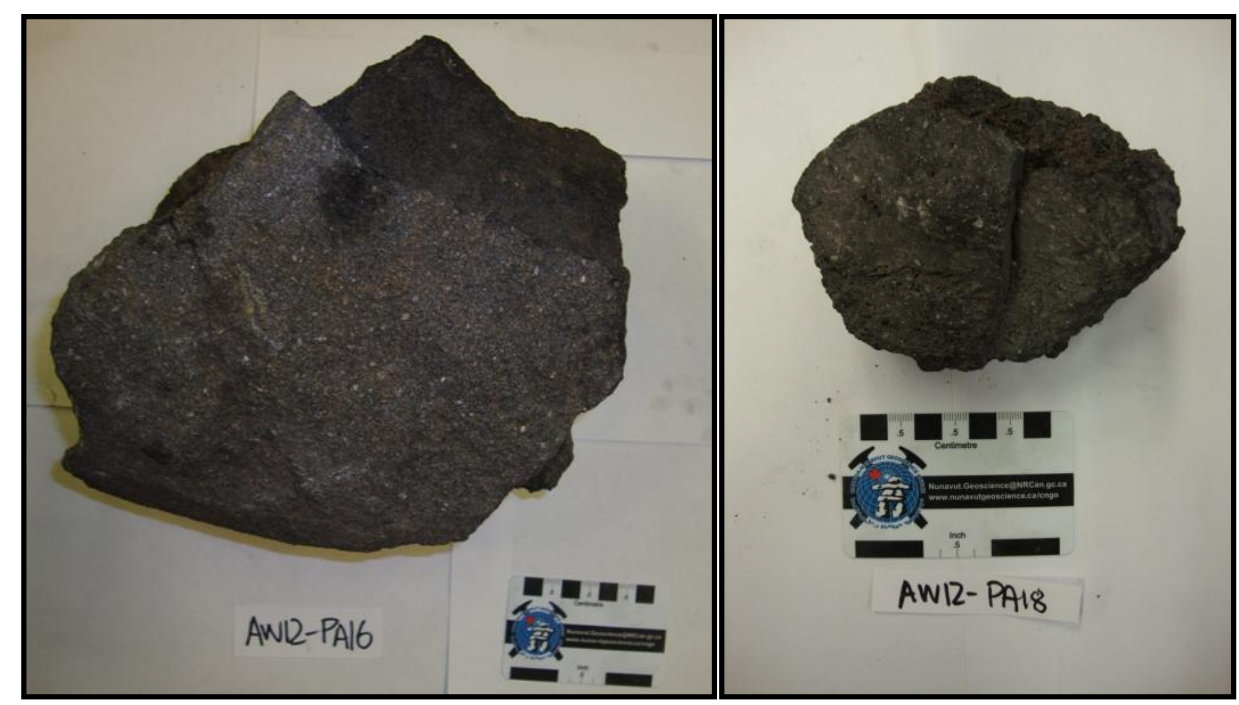

Figure 2.7. Spheroidal bombs collected on north flank of the volcano. PA16 (left) and PA18 (right).
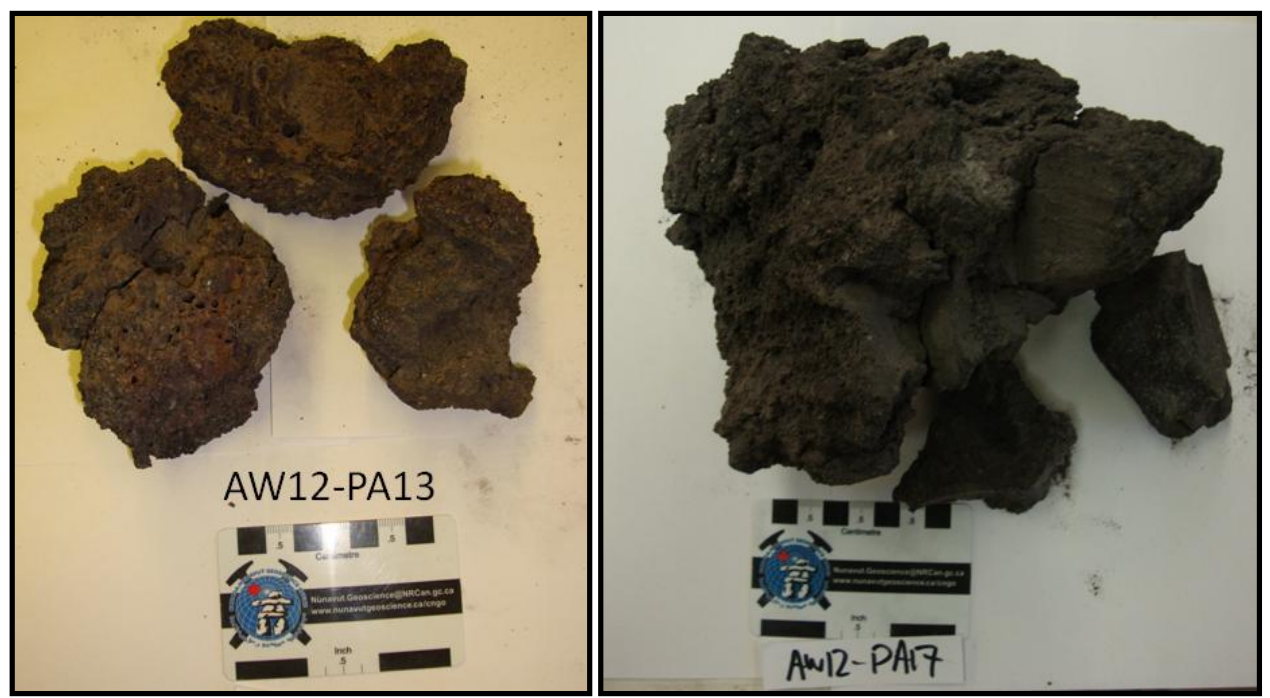

Figure 2.8. Vesicular bomb sized tephra samples PA13 (left) and fractured breadcrust bomb PA17 (right).

Samples PA12 and PA16 were imaged with optical and electron microscopes for petrographic analysis. The samples can best be described as $\sim 70 \% \phi_{\mathrm{P}}$ plagioclase and olivine as phenocrysts, and microphenocrysts, with less common clinopyroxene and titano-magnetite as microphenocrysts. Plagioclase crystals are generally not larger than $1 \mathrm{~mm}$ in length, while the olivines are smaller generally not exceeding $0.2 \mathrm{~mm}$. The 
groundmass consists of up to $12 \%$ microcrystals $\left(\phi_{\mathrm{m}}\right)$ and $16-32 \%$ glass within the whole rock minus any void spaces. (Figures 2.9 and 2.10). The range in $\phi_{\mathrm{m}}$ and $\phi_{\mathrm{gl}}$ is a result of high magnification (>600x Quanta) images only being acquired for one sample (PA16). Clear boundaries between micro crystals and glass were only evident at these high magnifications.
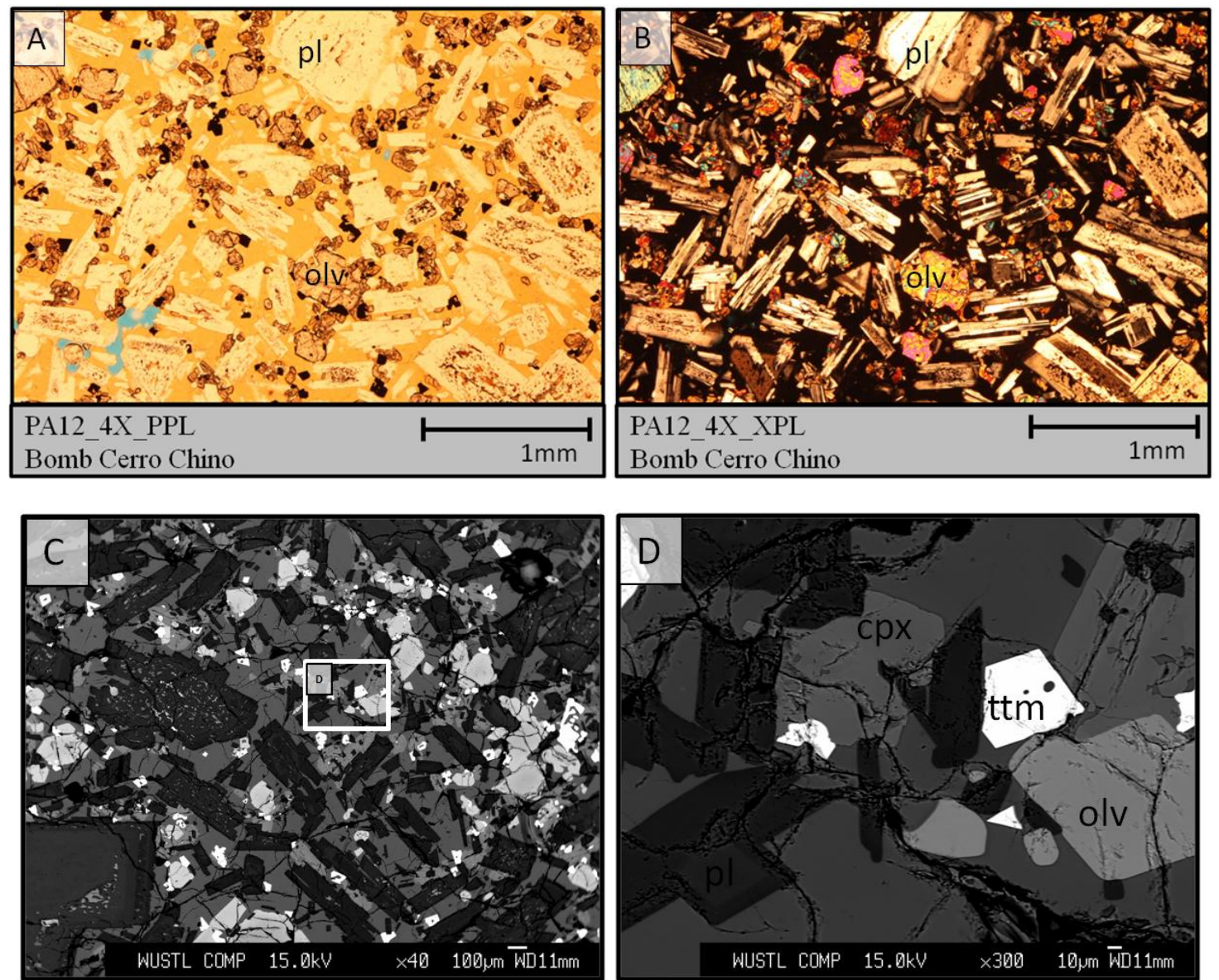

Figure 2.9. Bomb from Cerro Chino (PA12) optical images (A and B) and BSE images (C and D from JEOL WUSTL). Plagioclase (pl), olivine (olv) phenocrysts and microphenocrysts, with clinopyroxene (cpx) and titano-magnetite (ttm) and microphenocrysts. 

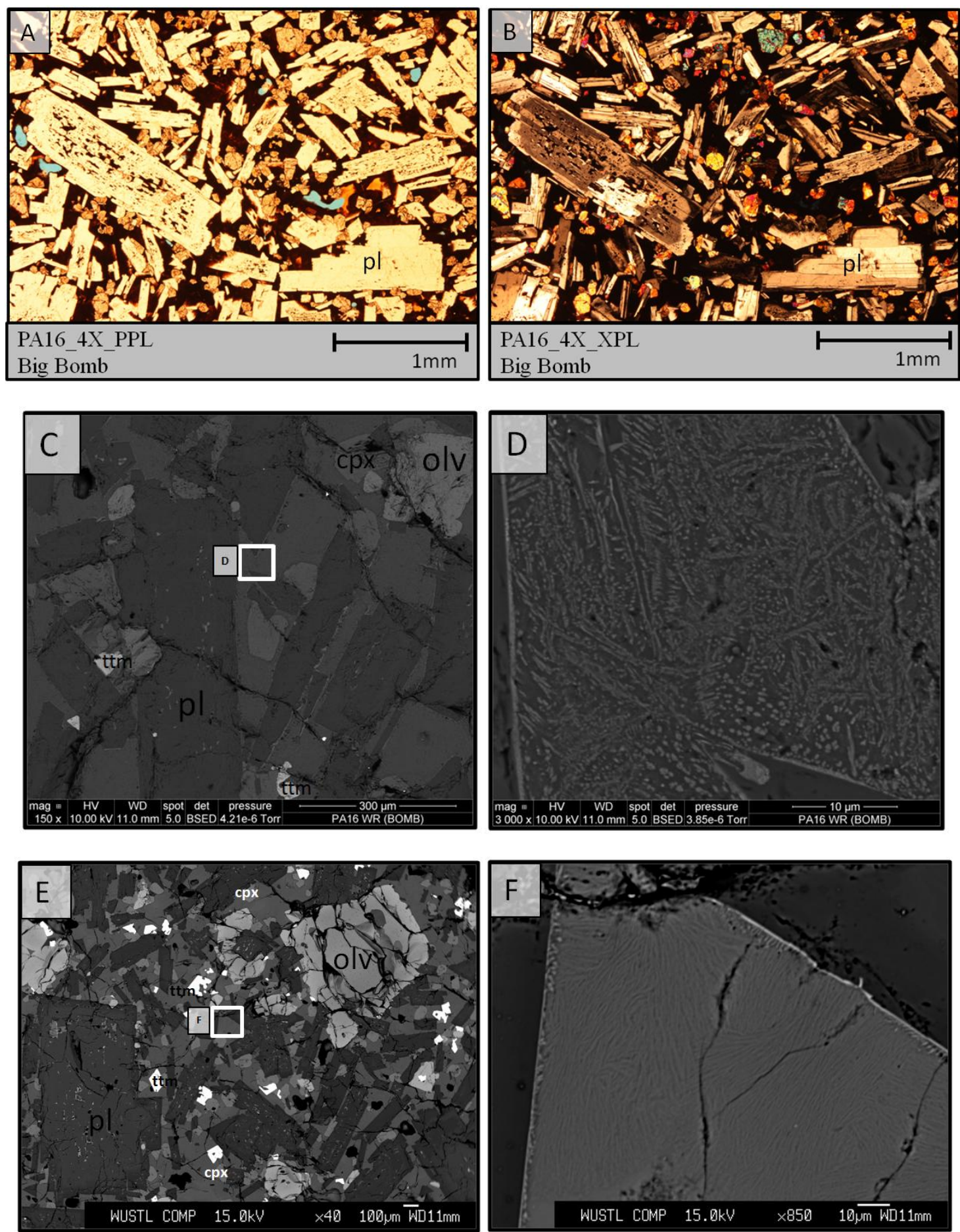

Figure 2.10. Big bomb from $N$ flank (PA16) optical images (A and B) and BSE images (C and $D$ and from Quanta UMC, and $E$ and $F$ are from JEOL WUSTL). Similar proportion of phenocrysts and microphenocrysts as PA12, with microcrystals evident at high magnification 
Slides C and D in Figure 2.9 and slide E in Figure 2.10 show great examples of plagioclase zoning within PA12 and PA16. The calcic cores are generally much larger in comparison to the oscillatory zones sodic and calcic rims. This zoning is a result of the same process described with regards to the lapilli tephra. A discussion regarding all samples and how zoning reflects magmatic processes will be provided after the analyses of the flow samples.

\subsubsection{Vents}

PA21 and PA27 represent vent samples of the NW and SE flows respectively. Aside from the lapilli tephra (PA01) and the vesicular bomb (PA13), the vent samples are the most vesicular with $\sim 50 \% \phi_{\mathrm{T}}$ and $\sim 67 \% \phi_{\mathrm{T}}$ calculated for PA21 and PA27 respectively. The bubbles in PA21 are elongate as this sample was acquired as part of a lava tube roof suggesting that the bubble orientation may reflect the direction of lava flow within the tube. The bubbles within PA27 are more homogenously distributed showing no preferred vesicle orientation.

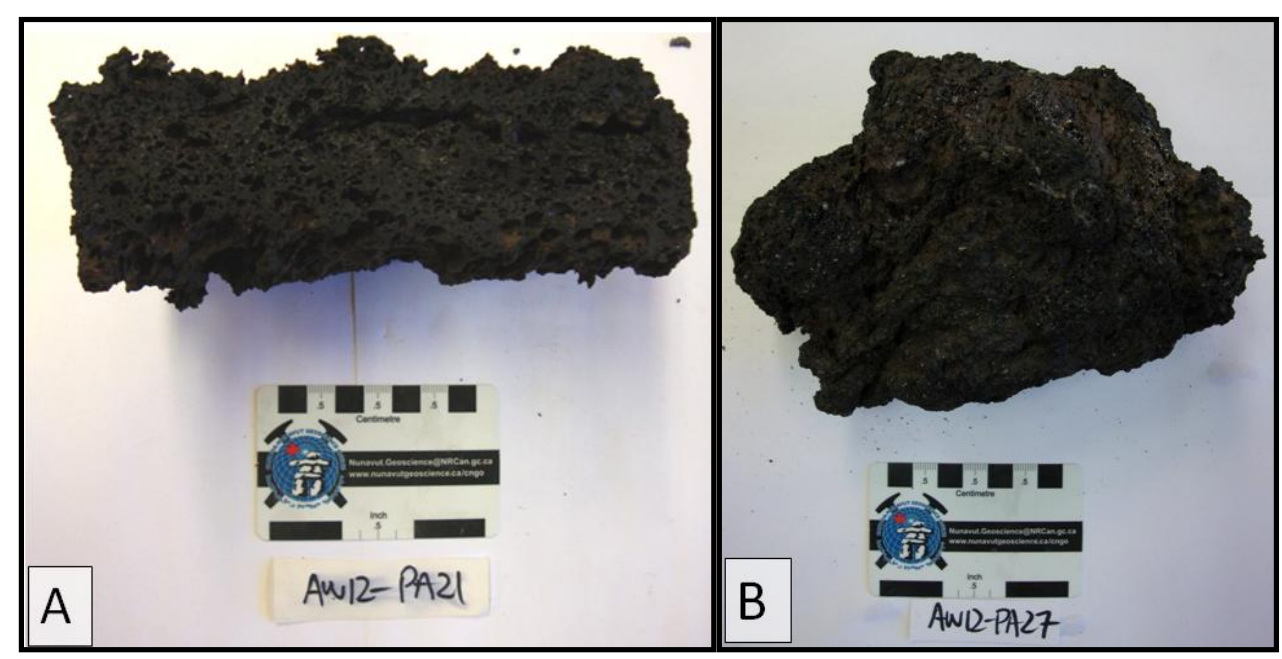

Figure 2.11. Vent samples from the northwest (A) and southeast (B) flows. 
The vent samples are microscopically very similar to the lapilli tephra samples. A single 40x (JEOL) BSE image for both PA21 and PA27 was used to calculate between $63-67 \% \phi_{\mathrm{P}}$. Phenocrysts and microphenocrysts of plagioclase and olivine with less common occurrences of clinopyroxene and titano-magnetite microphenocrysts are represented. When the vent samples are viewed at low magnification (40x JEOL and 150x Quanta), the area between phenocrysts seems to be entirely glass, however, when viewed in high magnification (>400x JEOL and >600x Quanta) the samples exhibit 18$22 \% \phi_{\mathrm{m}}$ and approximately $15 \% \phi_{\mathrm{gl}}$ on the basis of the whole rock excluding any bubbles (Figures 2.12slide D and 2.12 slides D and F).
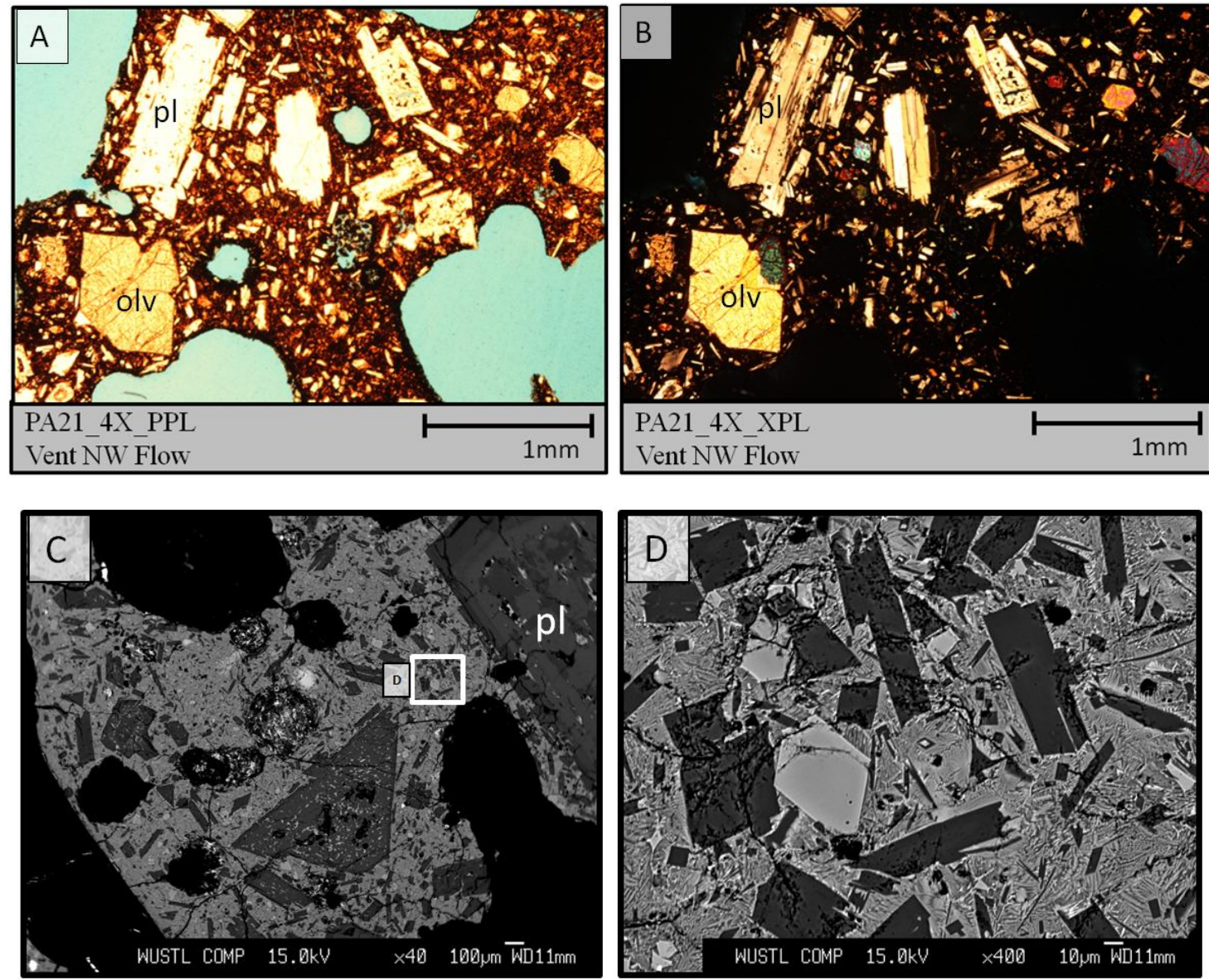

Figure 2.12. Vent from NW flow (PA21) optical images (A and B) and BSE images (C and D from JEOL WUSTL). Plagioclase (pl) and olivine (olv) phenocrysts in glassy groundmass. 

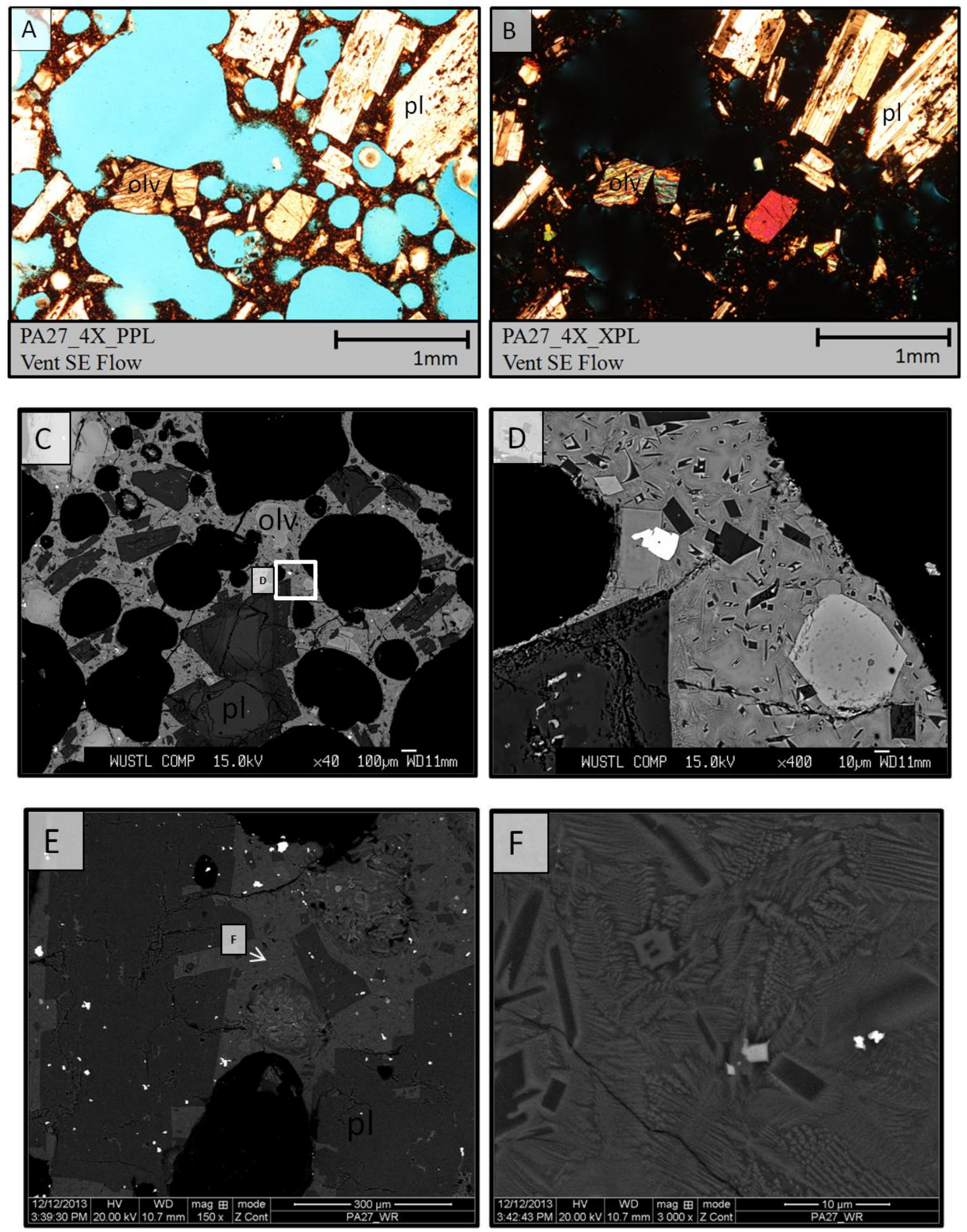

Figure 2.13. Vent from SE flow (PA27) optical images (A and B) and BSE images (C and D from JEOL WUSTL and E and F are from Quanta UMC). Plagioclase (pl) and olivine (olv) phenocrysts in glassy groundmass. Some microcrystals present at highest magnification. 


\subsubsection{Mid Flows}

Macro and microscopic analysis of the mid-flow samples are quite similar with outliers only occurring in the NW flow with regards to phenocryst proportion and vesicularity. Within the SE flow, geometric sample density ranges from $2.1-2.5 \mathrm{~g} / \mathrm{cm}^{3}$, and connected vesicularity ranges between $16-31 \% \phi_{\mathrm{T}}$. The NW flow is more variable with geometric density ranging between $2.0-2.6 \mathrm{~g} / \mathrm{cm}^{3}$, and vesicularity between $10-34 \%$ $\phi_{\mathrm{T}}$. The macroscopic differences between the flow samples are evident in Figures 2.14 and 2.14. Figure 2.15 shows PA23 from the NW flow which contains an oxidized red portion and is also more vesicular than the denser sample PA24. Figure 2.15 shows samples PA35 and PA08 from the SE flow which are generally more comparable with regards to density and vesicularity, although PA08 has distinctly larger phenocrysts $(\sim 1 \mathrm{~cm})$.

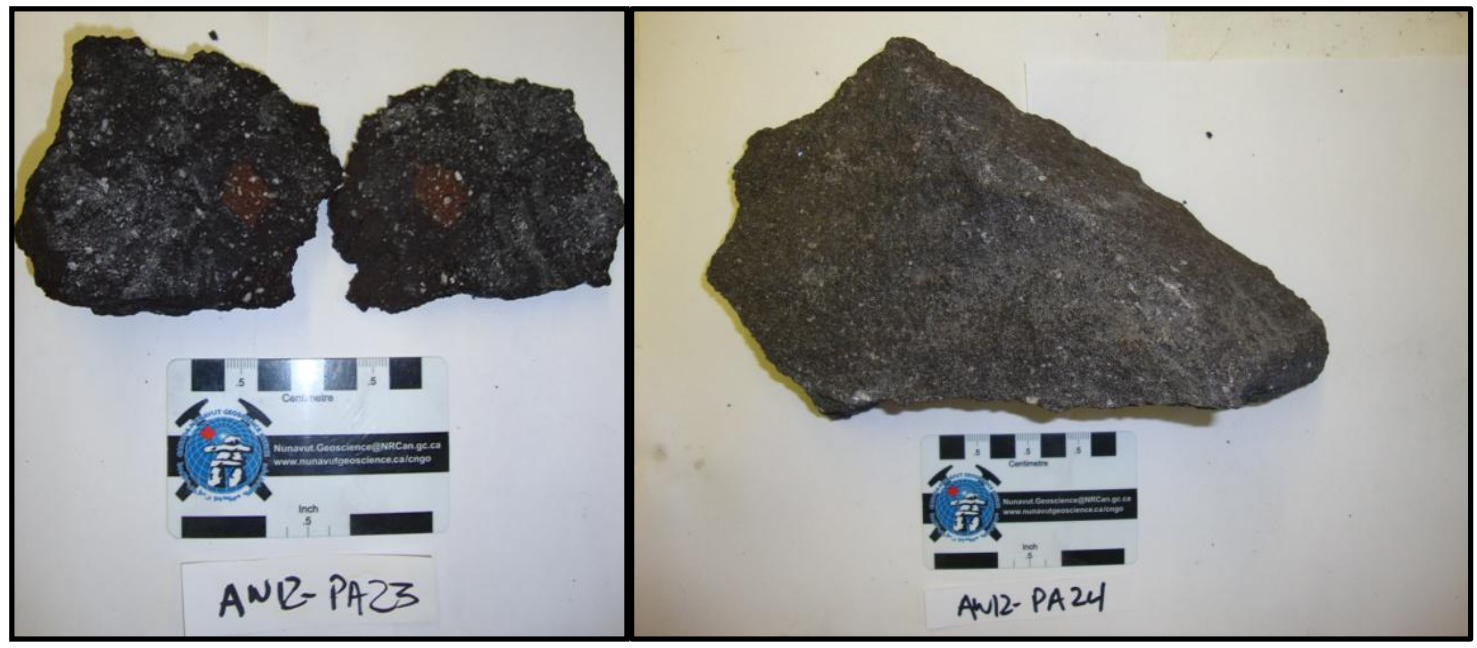

Figure 2.14. Mid NW flow samples PA23 (left) and PA24 (right). 

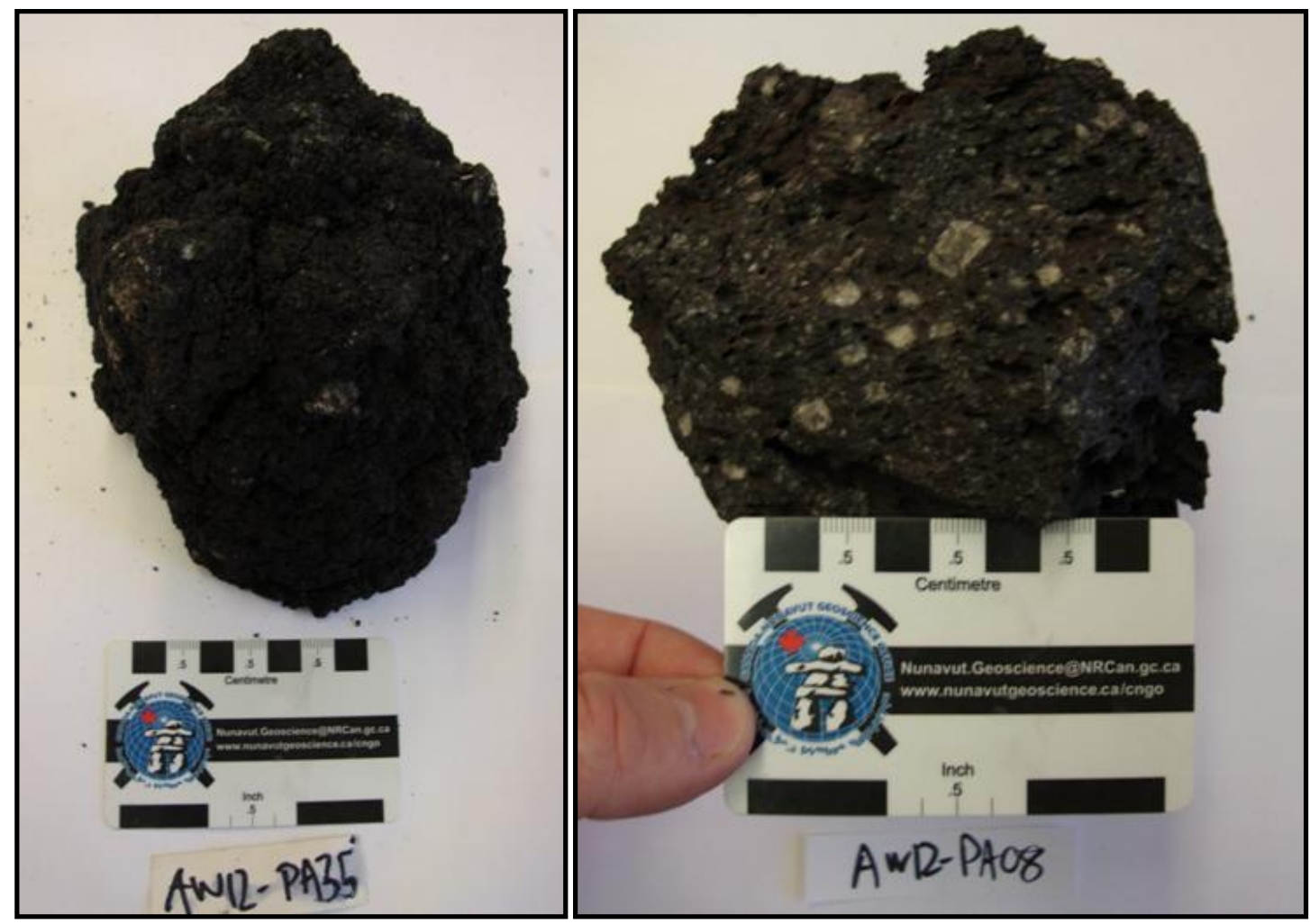

Figure 2.15. Mid SE flow samples PA35 (left) and PA08 (right).

Microscopic analysis further confirmed the differences between mid flow samples from the NW and SE flows. Figure 2.16 shows optical and BSE images for sample PA23. Slides A, B, and D represent the oxidized portion of the sample that contains larger phenocrysts that are not representative of the sample as a whole. Slide C more accurately represents the whole rock and contains only $\sim 16 \% \phi_{\mathrm{P}}$ represented as plagioclase and olivine phenocrysts and microphenocrysts with minor clinopyroxene and titano-magnetite present as microphenocrysts. Based on the scale of observation it was difficult to differentiate between glass and groundmass. We did not acquire high magnification images using the Quanta (UMC) and can therefore only approximate $0-84 \% \phi_{\mathrm{M}}$ or $\phi_{\mathrm{gl}}$ (or a combination of both) on the basis of the whole rock not including any void spaces. 

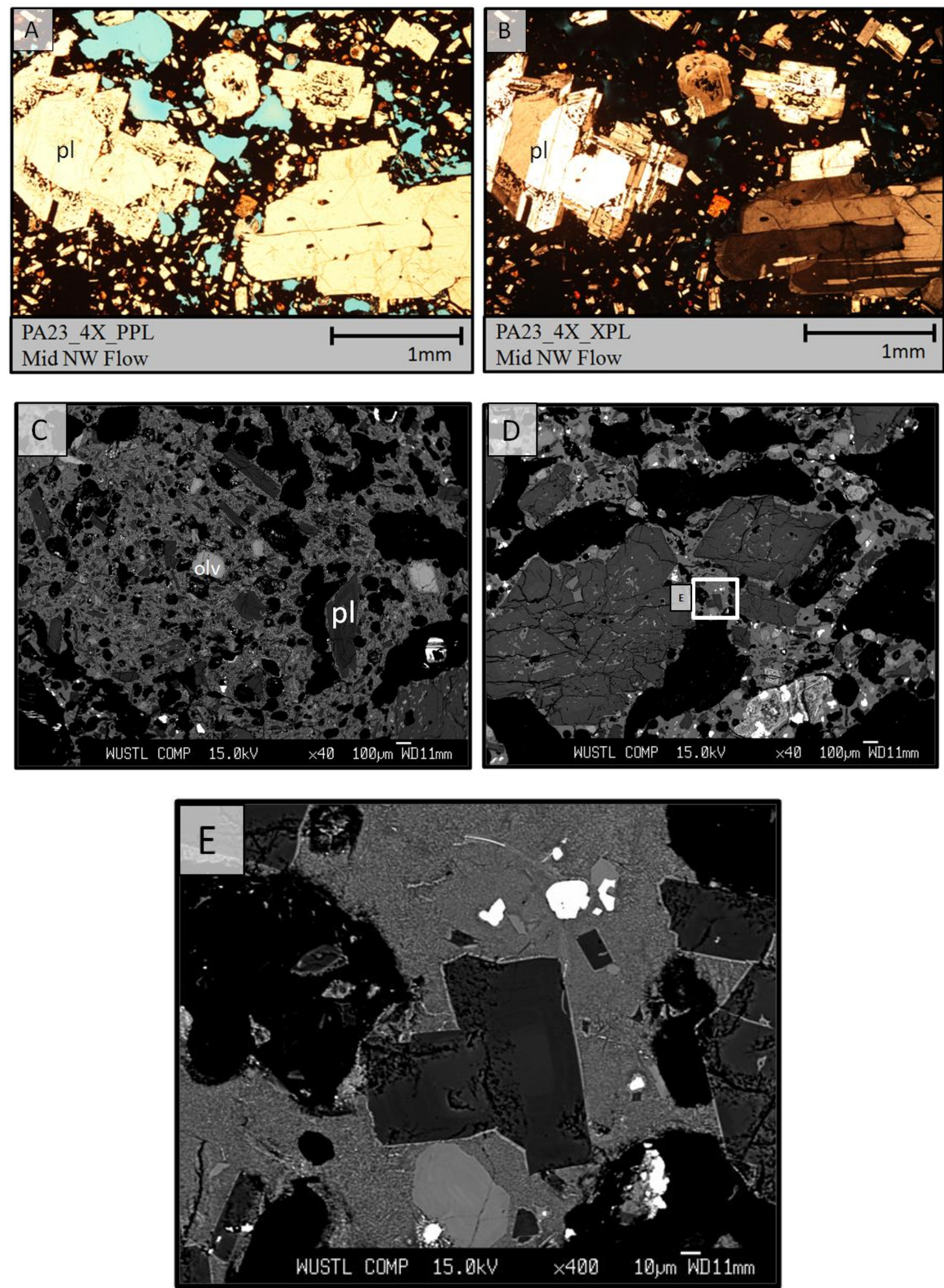

Figure 2.16. Mid NW flow SE flow (PA23) optical images (A and B) and BSE images (C, D, and $\mathrm{E}$ from JEOL WUSTL). Plagioclase (pl) and olivine (olv) phenocrysts variably glassy and microcrystalline groundmass. 
The BSE images of the SE flow samples show similar distributions of phenocrysts between $43-55 \% \quad \phi_{\mathrm{P}}$ represented as plagioclase and olivine phenocrysts and microphenocrysts with less common olvine and titano-magnetite microphenocrysts (Figures 2.17 and 2.18). At high magnification (>400x JEOL) an entirely crystalline groundmass between $45-57 \phi_{\mathrm{M}}$ with no $\phi_{\mathrm{gl}}$ is apparent within both samples on the basis of the whole rock minus any void spaces. Slide D in Figure 2.87 shows an example of plagioclase zoning. We will refer back to this image when discussing implications for magma chamber processes from zoned plagioclases in the summary of this chapter.
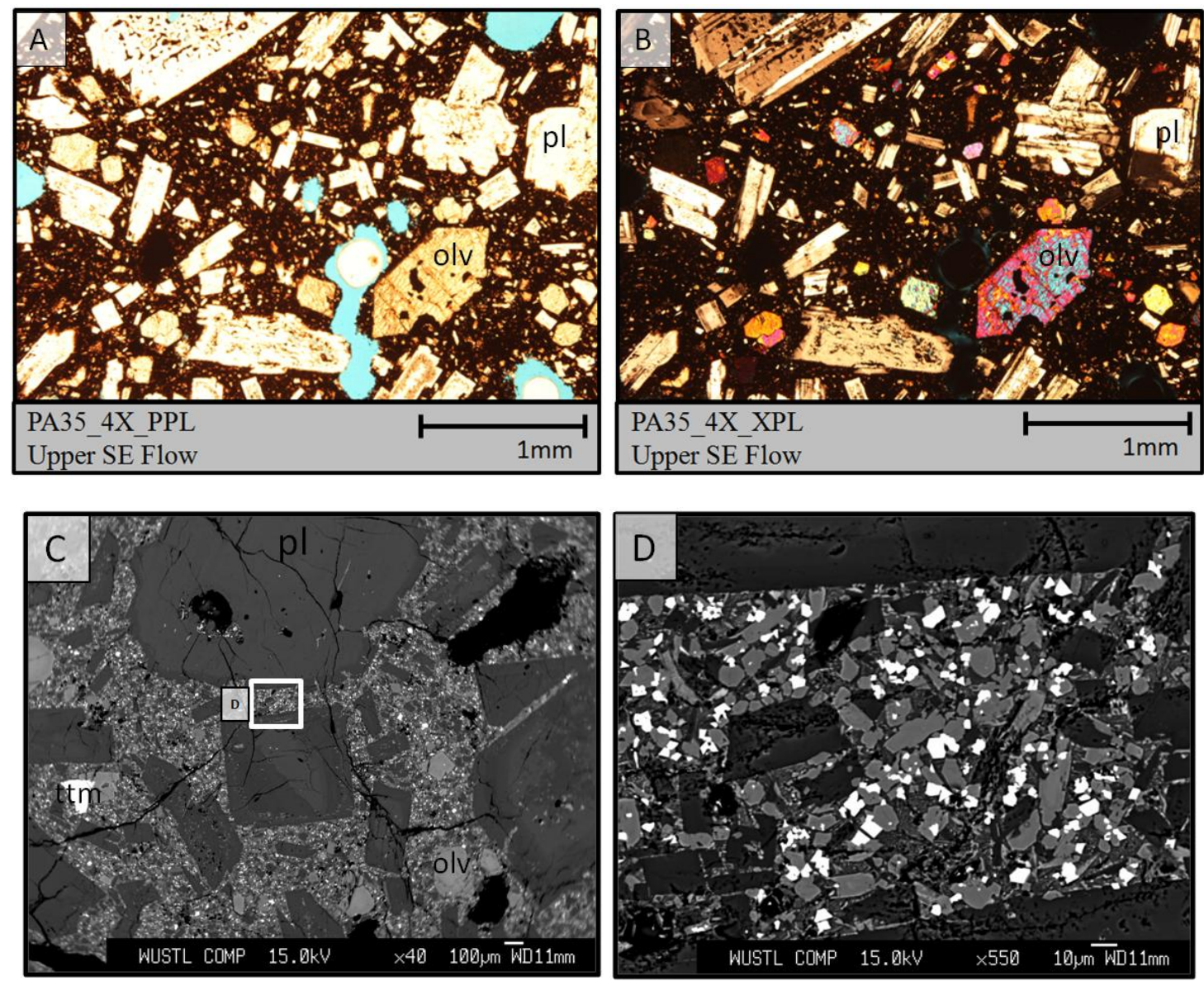

Figure 2.17. Upper-Mid SE flow (PA35) optical images (A and B) and BSE images (C and D from JEOL WUSTL). Plagioclase (pl) and olivine (olv) phenocrysts, with entirely crystalline groundmass. 

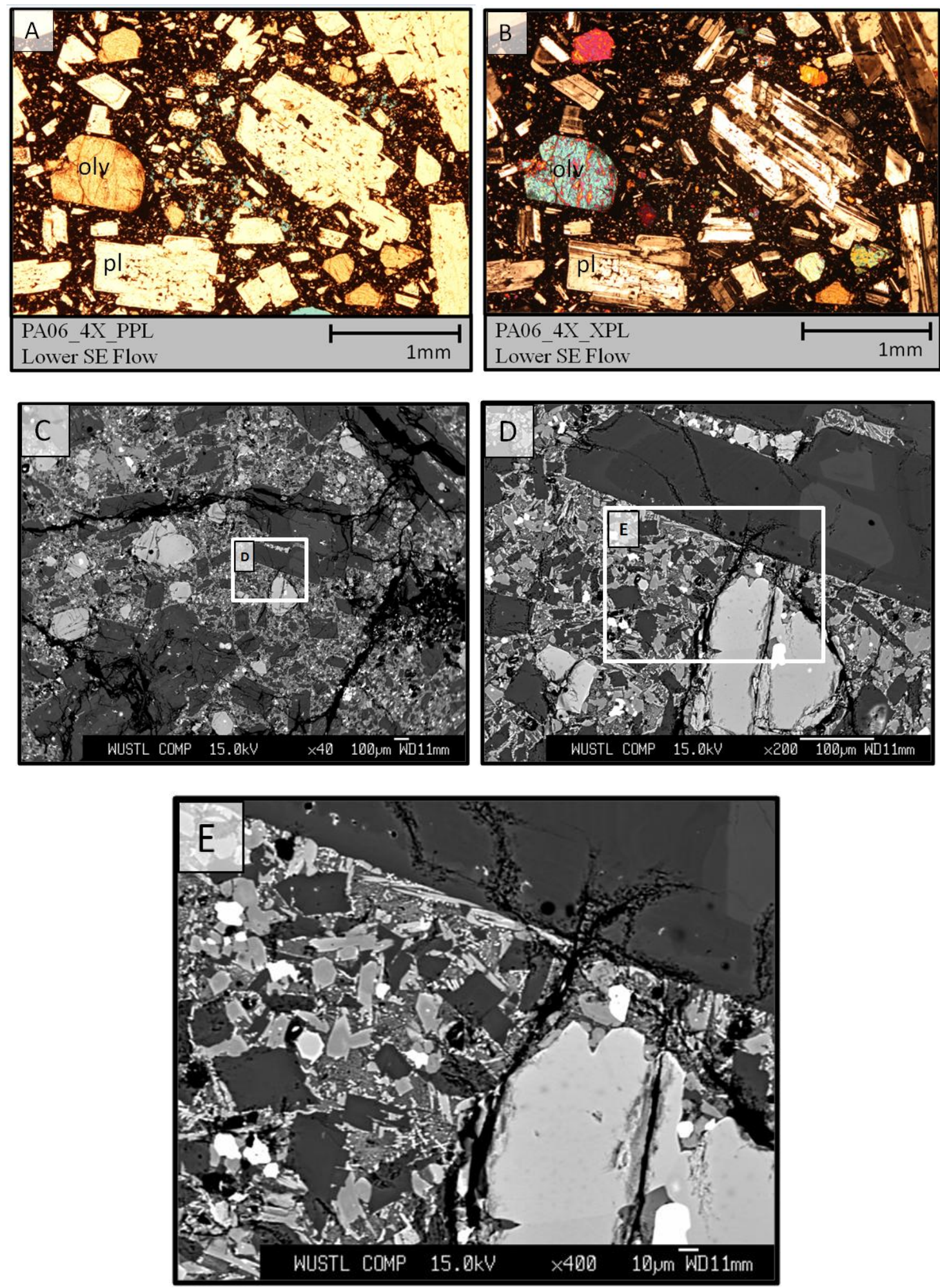

Figure 2.18. Lower-Mid SE flow (PA06) optical images (A and B) and BSE images (C, D, and $\mathrm{E}$ from JEOL WUSTL). Plagioclase (pl) and olivine (olv) phenocrysts, with entirely crystalline groundmass. 


\subsubsection{Toes}

The toe samples from each flow are not macroscopically discernible from the mid flow samples (Figure 2.19). Approximately 18 and 26\% $\phi_{\mathrm{T}}$ were calculated for the NW and SE toes respectively, which actually plot among the values for mid flow samples as shown in Figures 2.23-24 in the summary section. This observation will also be discussed in further detail in the summary section.
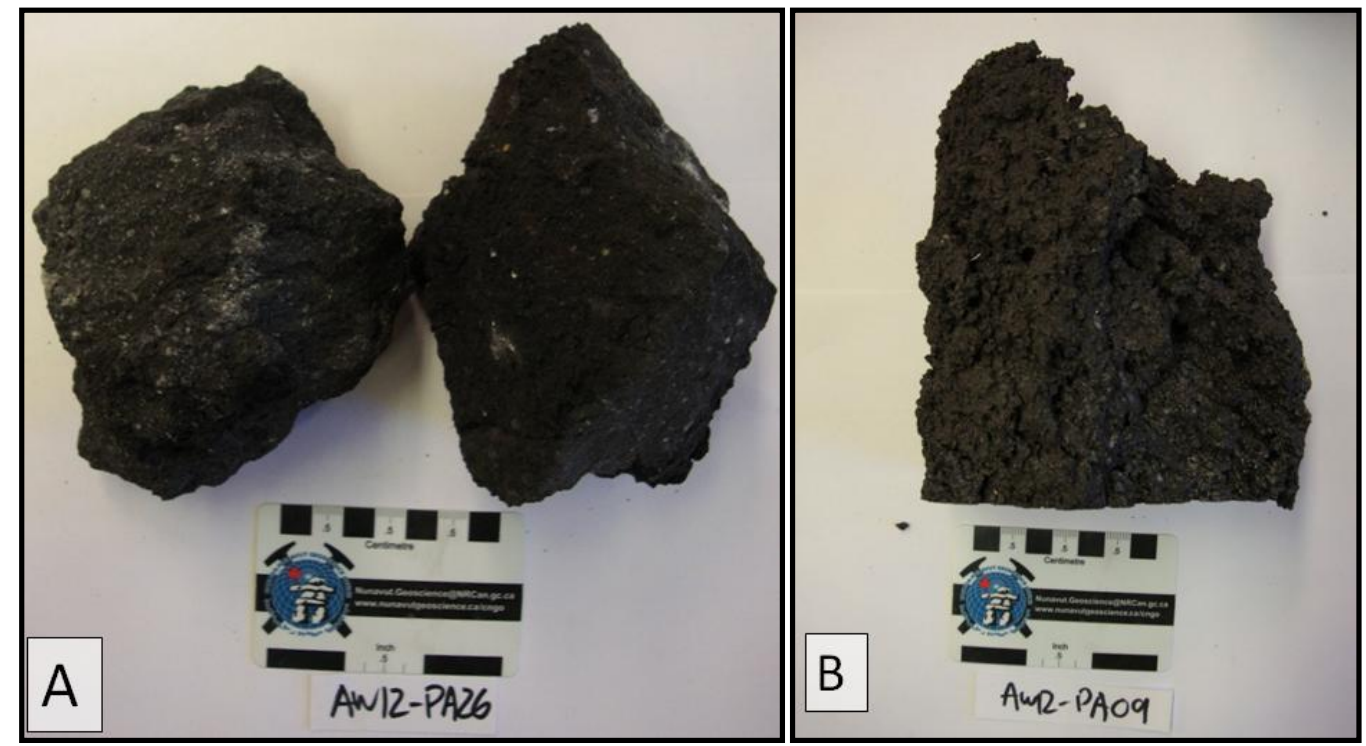

Figure 2.19. Toe samples. NW flow PA26 (left) and SE flow PA09 (right).

A single 40x (JEOL) BSE image for both PA26 and PA09 was used to calculate $28 \% \phi_{\mathrm{P}}$ for PA26 and $55 \% \phi_{\mathrm{P}}$ for PA09. Phenocrysts and microphenocrysts of plagioclase and olivine with less common occurrences of clinopyroxene and titanomagnetite microphenocrysts are represented. Unlike the vent samples, and the tephra samples (both lapilli and bomb) there is no glass between phenocrysts. $72 \% \phi_{\mathrm{m}}$ and $45 \%$ $\phi_{\mathrm{m}}$ was calculated for PA26 and PA09 respectively on the basis of the whole rock not including any void spaces. Figures 2.20 and 2.21 show the images used in the 
calculations. Figure 2.21 slide D shows another great example of oscillatory plagioclase zoning.
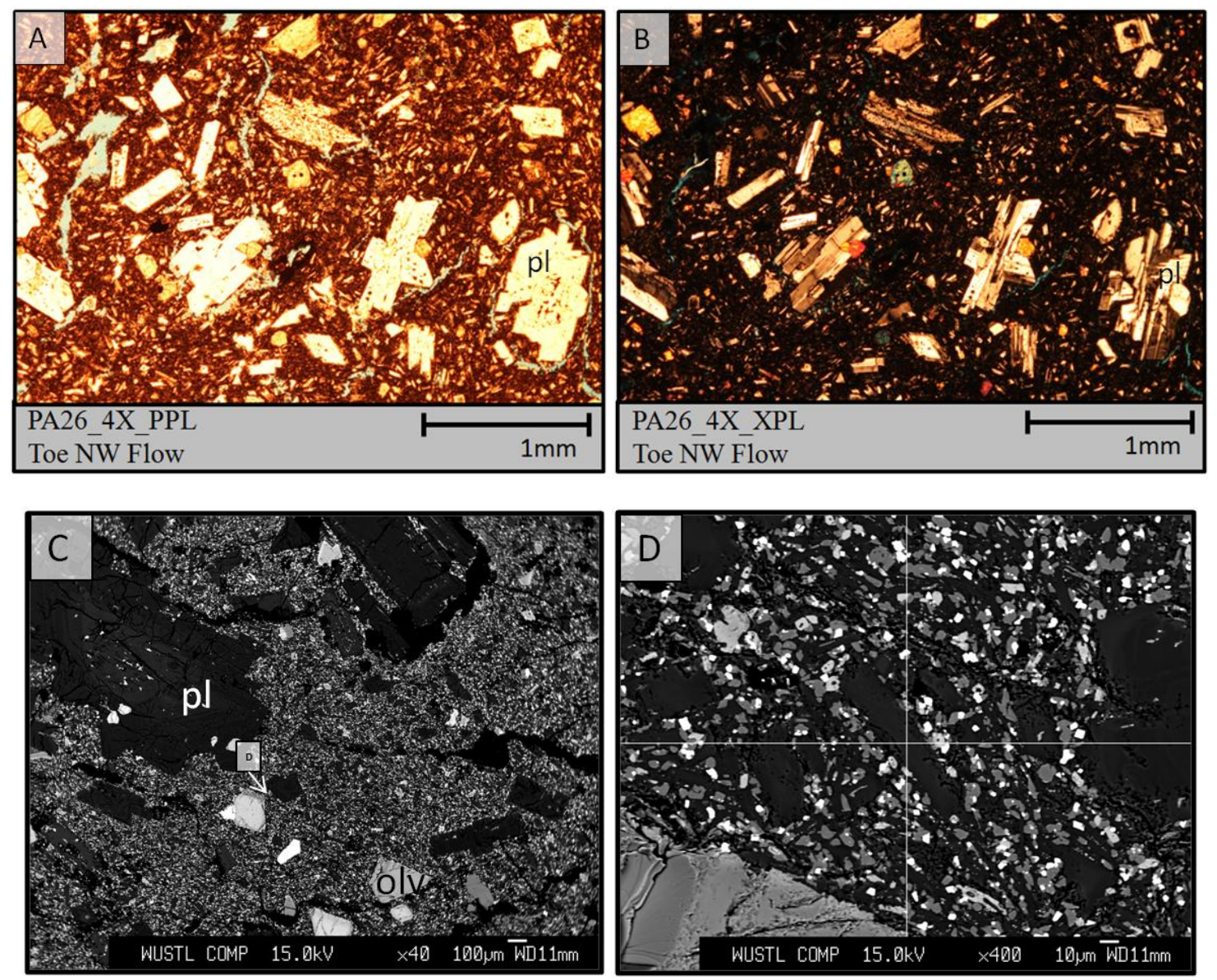

Figure 2.20. Toe from NW flow (PA26) optical images (A and B) and BSE images (C and D from JEOL WUSTL). Plagioclase (pl) and olivine (olv) phenocrysts, with entirely crystalline groundmass. 

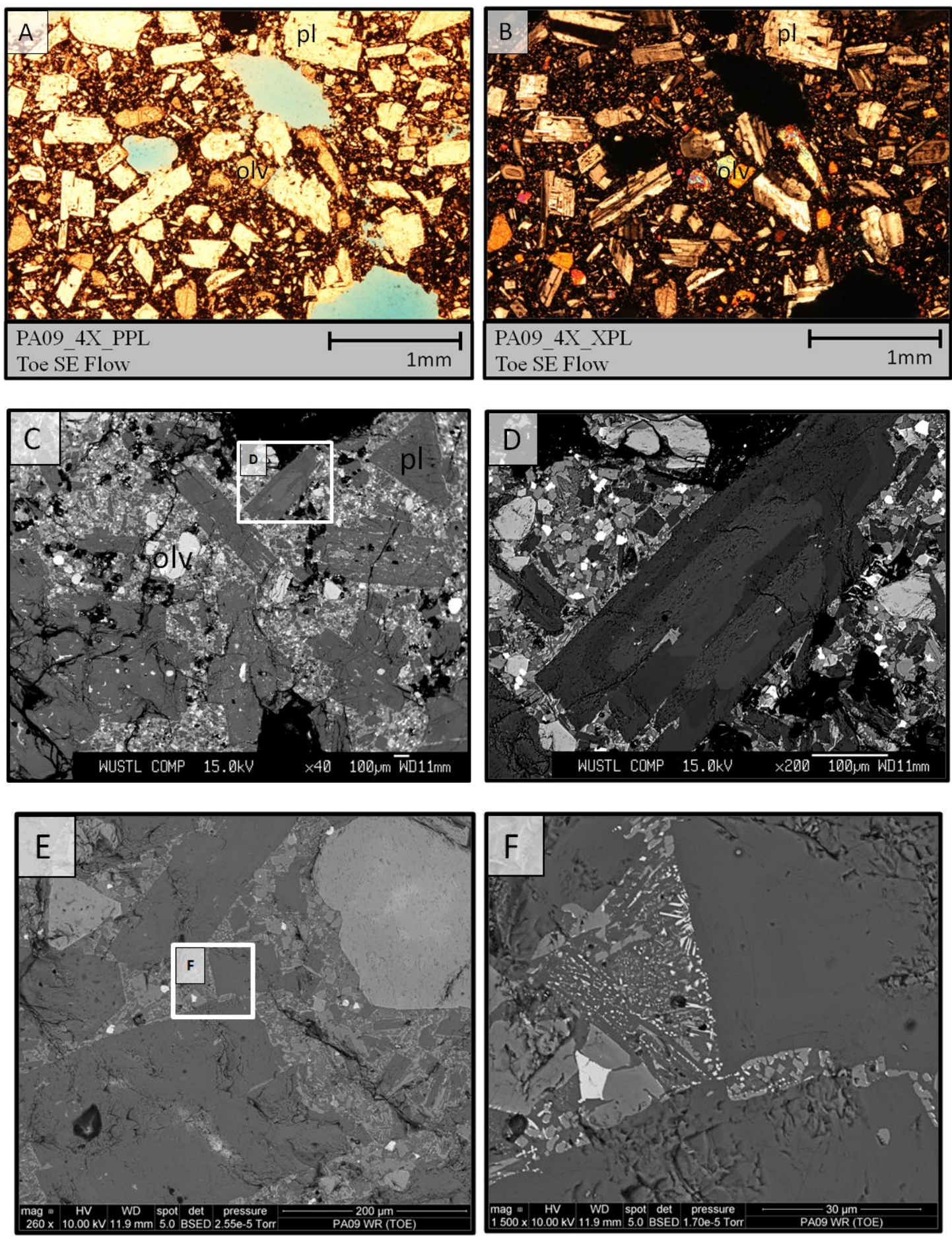

Figure 2.21. Toe from SE flow (PA09) optical images (A and B) and BSE images (C and D from JEOL WUSTL and E and F from Quanta UMC). Plagioclase (pl) and olivine (olv) phenocrysts, with entirely crystalline groundmass. 


\subsubsection{Petrographic Summary}

The combined density, vesicularity, and phase proportions calculated in the previous sections are provided in the following Table and in Figures 2.22-2.27.

Table 2.2. Density, bubble \%, and crystal \% for the natural samples erupted from Pacya in May 2010. Average pyconometry value in italics, used for samples that were not measured.

Geo= Geometric Density, Arch=Archimedean Density, and Pycno=Pycnometric density . Bub=Bubble, Phen=Phenocryts, Mic=Microcrystal, and Gl=Glass.

\begin{tabular}{|c|c|c|c|c|c|c|c|c|c|}
\hline $\begin{array}{c}\text { Sample } \\
\text { Name }\end{array}$ & $\begin{array}{c}\text { Geo } \\
\text { g/cm }\end{array}$ & $\begin{array}{l}\text { Arch } \\
\text { g/cm }{ }^{3}\end{array}$ & $\begin{array}{r}\text { Pycno } \\
\text { g/cm } \\
\end{array}$ & $\begin{array}{c}\varphi_{\mathrm{C}} \\
\text { Bub\% } \\
\end{array}$ & $\begin{array}{c}\varphi_{I} \\
\text { Bub\% } \\
\end{array}$ & $\begin{array}{c}\varphi_{\mathrm{T}} \\
\text { Bub\% } \\
\end{array}$ & $\begin{array}{c}\varphi_{\mathrm{P}} \\
\text { Phen\% }\end{array}$ & $\begin{array}{c}\varphi_{M} \\
\text { Mic\% } \\
\end{array}$ & $\begin{array}{r}\varphi_{\mathrm{gl}} \\
\mathrm{Gl} \% \\
\end{array}$ \\
\hline PA01 & - & 2.02 & 2.89 & - & - & - & 47.6 & $0-37.7$ & $14.7-52.4$ \\
\hline PA02 & 2.24 & 2.71 & 2.94 & 17.4 & 6.4 & 23.8 & - & - & - \\
\hline PA03 & 2.16 & 2.70 & 2.94 & 19.6 & 6.5 & 26.1 & - & - & - \\
\hline PA04 & 2.48 & 2.78 & 2.94 & 10.7 & 5.0 & 15.7 & - & - & - \\
\hline PA06 & 2.29 & 2.73 & 2.97 & 16.1 & 6.8 & 22.8 & 43.1 & 56.9 & 0.0 \\
\hline PA07 & 2.36 & 2.71 & 2.94 & 12.7 & 6.9 & 19.7 & - & - & - \\
\hline PA08 & 2.32 & 2.74 & 2.94 & 15.2 & 5.8 & 20.9 & - & - & - \\
\hline PA09 & 2.19 & 2.76 & 2.95 & 20.5 & 5.1 & 25.6 & 54.6 & 45.4 & 0.0 \\
\hline PA12 & 2.76 & 2.83 & 2.94 & 2.6 & 3.5 & 6.1 & 68.1 & 0.0 & 31.9 \\
\hline PA13 & 0.89 & 1.97 & 2.94 & 55.0 & 14.9 & 69.9 & - & - & - \\
\hline PA14 & 2.75 & 2.53 & 2.94 & 2.6 & 3.8 & 6.4 & - & - & - \\
\hline PA16 & 2.74 & 2.80 & 2.93 & 2.3 & 4.2 & 6.5 & 72.2 & $0-11.58$ & $16.2-27.8$ \\
\hline PA17 & 2.51 & 2.74 & 2.94 & 8.5 & 6.3 & 14.8 & - & - & - \\
\hline PA18 & 2.42 & 2.64 & 2.98 & 8.6 & 10.1 & 18.7 & - & - & - \\
\hline PA21 & 1.48 & 2.48 & 2.94 & 40.4 & 9.3 & 49.7 & 62.7 & 21.9 & 15.4 \\
\hline PA23 & 1.95 & 2.67 & 2.94 & 27.1 & 6.7 & 33.8 & 15.6 & $0-84.36$ & $0-84.36$ \\
\hline PA24 & 2.63 & 2.79 & 2.94 & 5.6 & 4.8 & 10.4 & - & - & - \\
\hline PA25 & 2.71 & 2.80 & 2.94 & 3.1 & 4.6 & 7.7 & - & - & - \\
\hline PA26 & 2.43 & 2.67 & 2.96 & 9.0 & 9.0 & 18.0 & 28.0 & 72.0 & 0.0 \\
\hline PA27 & 0.98 & 2.64 & 2.93 & 62.8 & 3.7 & 66.5 & 67.4 & 17.7 & 15.0 \\
\hline PA28 & 2.22 & 2.54 & 2.94 & 12.6 & 11.8 & 24.4 & - & - & - \\
\hline PA31 & 2.06 & 2.67 & 2.94 & 24.0 & 7.2 & 31.1 & - & - & - \\
\hline PA35 & 2.22 & 2.75 & 2.94 & 19.3 & 5.2 & 24.5 & 55.3 & 44.7 & 0.0 \\
\hline
\end{tabular}


Figure 2.22 shows the range of calculated density $\left(\mathrm{g} / \mathrm{cm}^{3}\right)$ using each method. There is little variation (less than 3\%) in the densities calculated using pycnometry, which led us to assign the average values to the samples that were not measured in the pycnometry for use in calculating $\phi_{\mathrm{T}}$ and $\phi_{\mathrm{C}}$. Considering the negligible difference between the dense rock values, the main difference in geometric and Archimedean density among samples in Figure 2.22 is due to varying vesicularity. With regards to geometric density, the variation is due to total bubbles $\phi_{\mathrm{T}}$, including connected $\phi_{\mathrm{C}}$ and isolated $\phi_{\mathrm{I}}$, that are included in the measurements (up to $\sim 70 \% \phi_{\mathrm{T}}$ for PA13). Variation in Archimedean density is smaller and due to only isolated bubbles $\phi_{\mathrm{I}}$ (up to $15 \% \phi_{\mathrm{I}}$ in PA13).

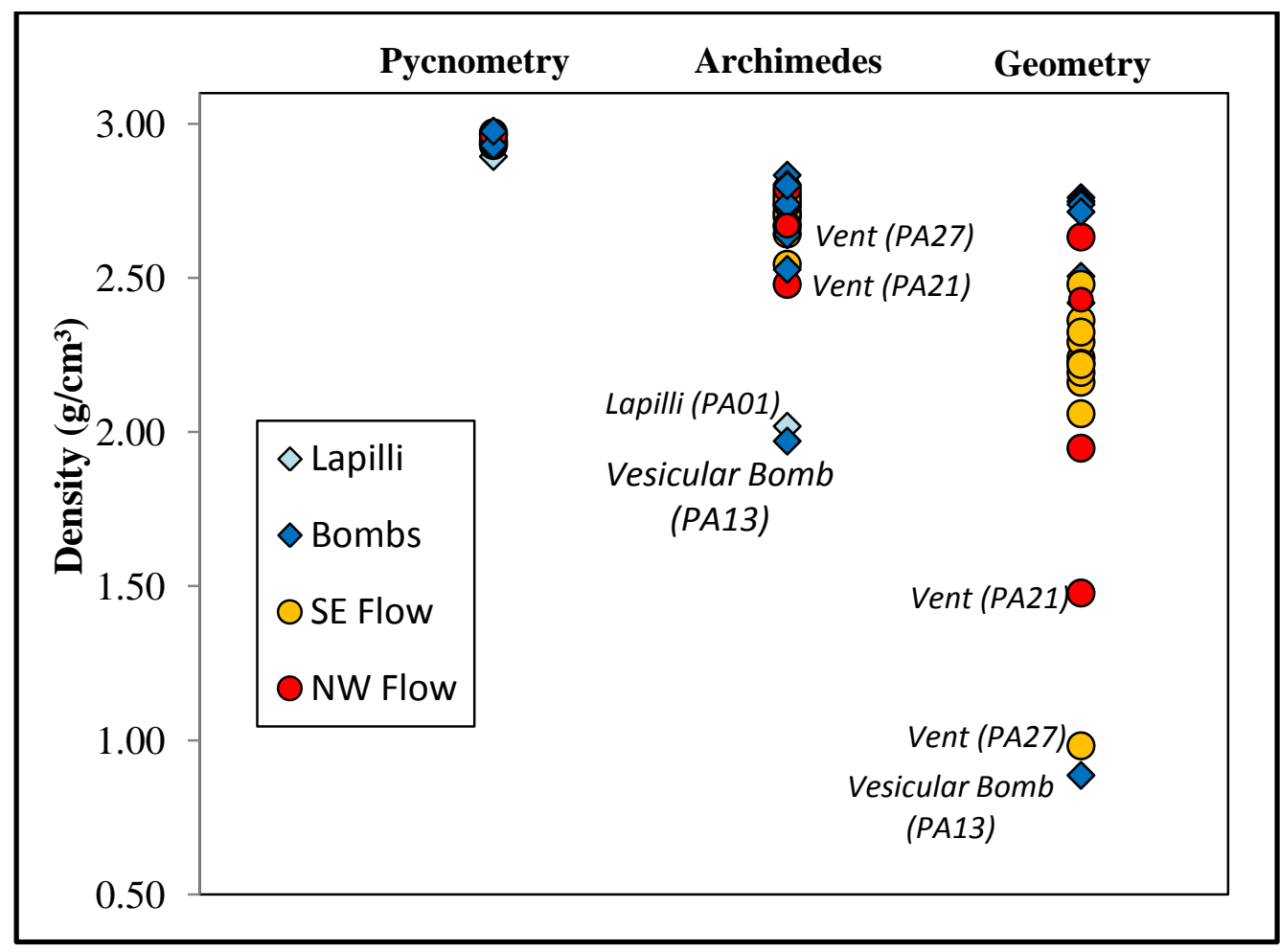

Figure 2.22. Density $\left(\mathrm{g} / \mathrm{cm}^{3}\right)$ for all measured samples divided on the basis of method used. 
Figure 2.23 shows total bubble $\%\left(\phi_{\mathrm{T}}\right)$ plotted for the measured samples in columns based on sample type. The vesicular bomb (PA13) and the vent for the SE flow (PA27) has the highest calculated $\phi_{\mathrm{T}}$. The vents of each flow have lower geometric densities and have higher $\phi_{\mathrm{T}}$ when compared to the rest of the flow samples, however, there only exist a spatial trend further down flow within the NW flow (If the dense PA24 is excluded). In the SE flow, the toe sample (PA09) plots among mid flow samples. Comparing the two flows in Figure 2.23 we see a wider spread in $\phi_{\mathrm{T}}$ for the NW flow samples compared to the SE flow samples which exhibit more clustered values. This can be attributed the presence of the dense block sample (PA24) and the fact that less samples were acquired in the NW flow resulting in less clustering.

We were unable to calculate geometric density for the lapilli sample (PA01) due to macroscopic heterogeneity, and thus were not able to calculate $\phi_{\mathrm{C}}$ or $\phi_{\mathrm{T}}$. We were however able to calculate these values for PA13, which based on macroscopic analysis, appears to be a larger lapilli sample, only grouped with the bombs based on its size. We can therefore consider PA01 to have similar $\phi_{\mathrm{T}}$ compared to PA13. Also, if we are to consider PA01 as a whole sample including ash and smaller lapilli fragments, the amount of $\phi_{\mathrm{T}}$ and $\phi_{\mathrm{C}}$ would be larger, being the most vesicular of any sample measured. 


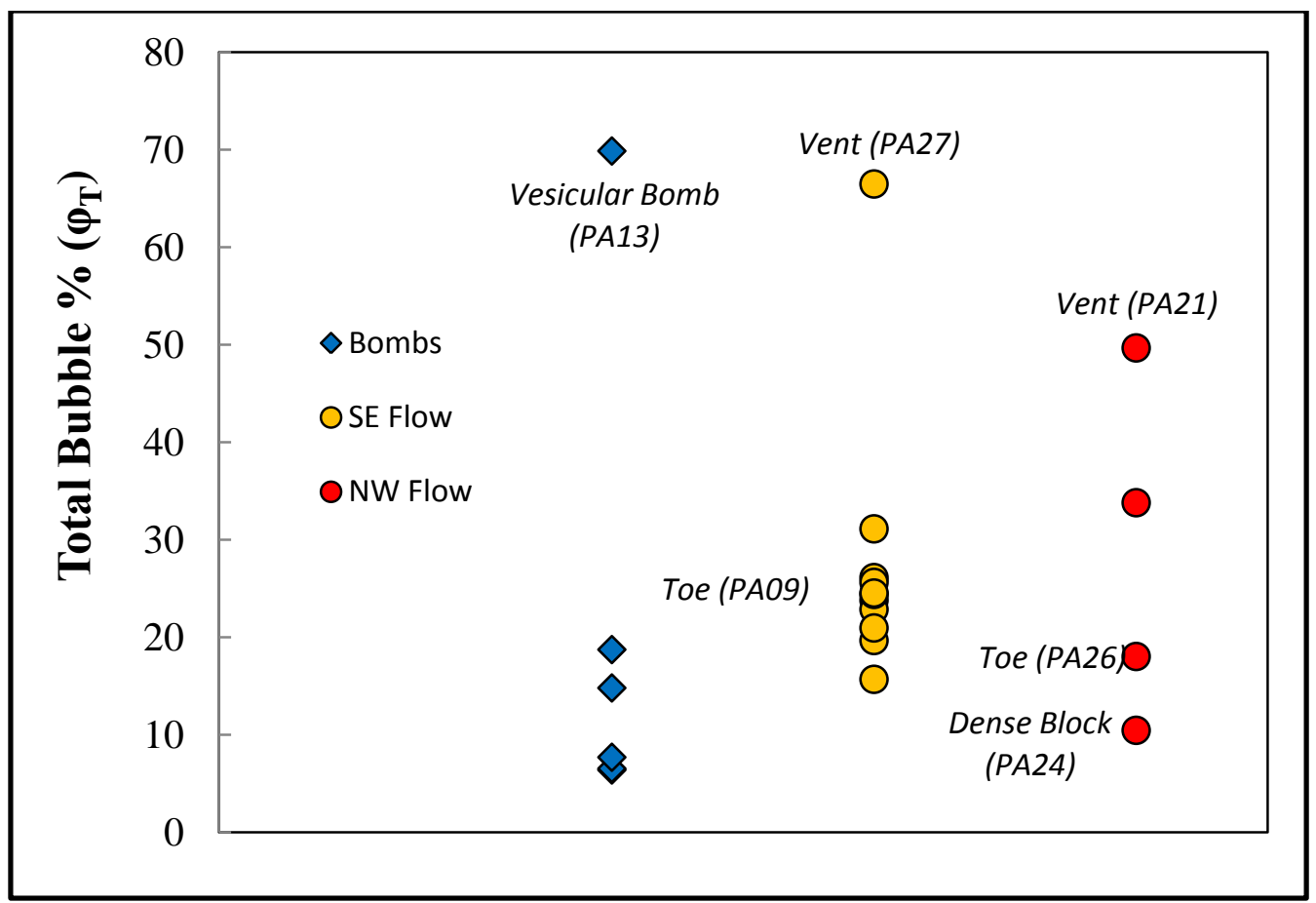

\section{Figure 2.23. Total Bubble\% $\left(\varphi_{\mathrm{T}}\right)$ for measured samples separated in columns based on sample type.}

Figure 2.24 shows isolated bubble $\%\left(\phi_{\mathrm{I}}\right)$ vs. total bubble $\%\left(\phi_{\mathrm{T}}\right)$. A 1:1 line is plotted to visualize where samples that contain only isolated bubbles would plot. Bomb samples (excluding PA13) plot closest to the 1:1 line, indicating the majority of bubbles within the samples are isolated. The two vent samples, and the vesicular bomb (PA13) plot further from the 1:1 line, indicating that compared to the other samples, they possess a higher proportion of connected bubbles $\left(\phi_{\mathrm{C}}\right)$. The mid and toe flow samples plot closer to the 1:1 line, indicating that they have a higher proportion of isolated bubbles compared to the vents. 


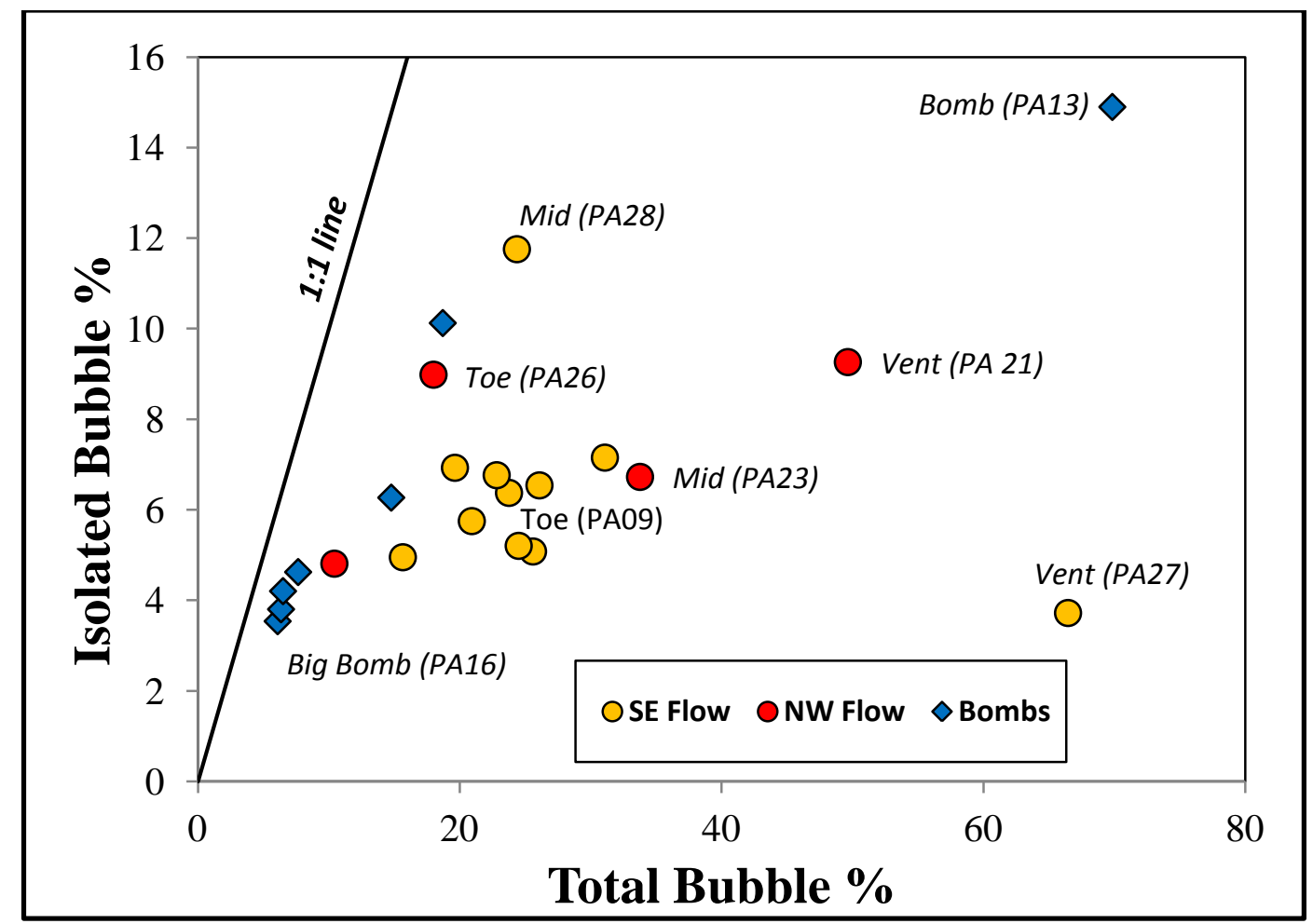

Figure 2.24. Isolated Bubble\% $\left(\varphi_{\mathrm{I}}\right)$ vs. Total Bubble\% $\left(\varphi_{\mathrm{T}}\right)$ for measured samples.

Figure 2.25 shows calculated phenocryst $\%\left(\phi_{\mathrm{P}}\right)$ for all samples calculated using 40x JEOL BSE images. Less data exists compared to the density and vesicularity results, as we did not acquire BSE image all samples, only those that best represent the group of collected samples. The vents of each flow and the bombs have relatively similar proportions of phenocrysts, between $63-72 \% \phi_{\mathrm{P}}$. The mid and toe flow samples of the NW flow have distinctively smaller proportions of phenocrysts compared to the mid and toe flow samples of the SE flow. Samples PA09 (toe) and PA35 (midflow) have nearly identical proportions of phenocrysts $\sim 55 \% \phi_{\mathrm{P}}$. The lapilli tephra sample yields $\sim 48 \% \phi_{\mathrm{P}}$. However, it is not accurate to simply use values from one sample fragment to estimate $\phi_{\mathrm{P}}$ for all collected sample, which includes many small fragments including ash sized 
particles. The 5\% error bars were calculated based on the average difference between $\phi_{\mathrm{P}}$ calculated using the higher and lower cutoff values within the histogram function of Photoshop.

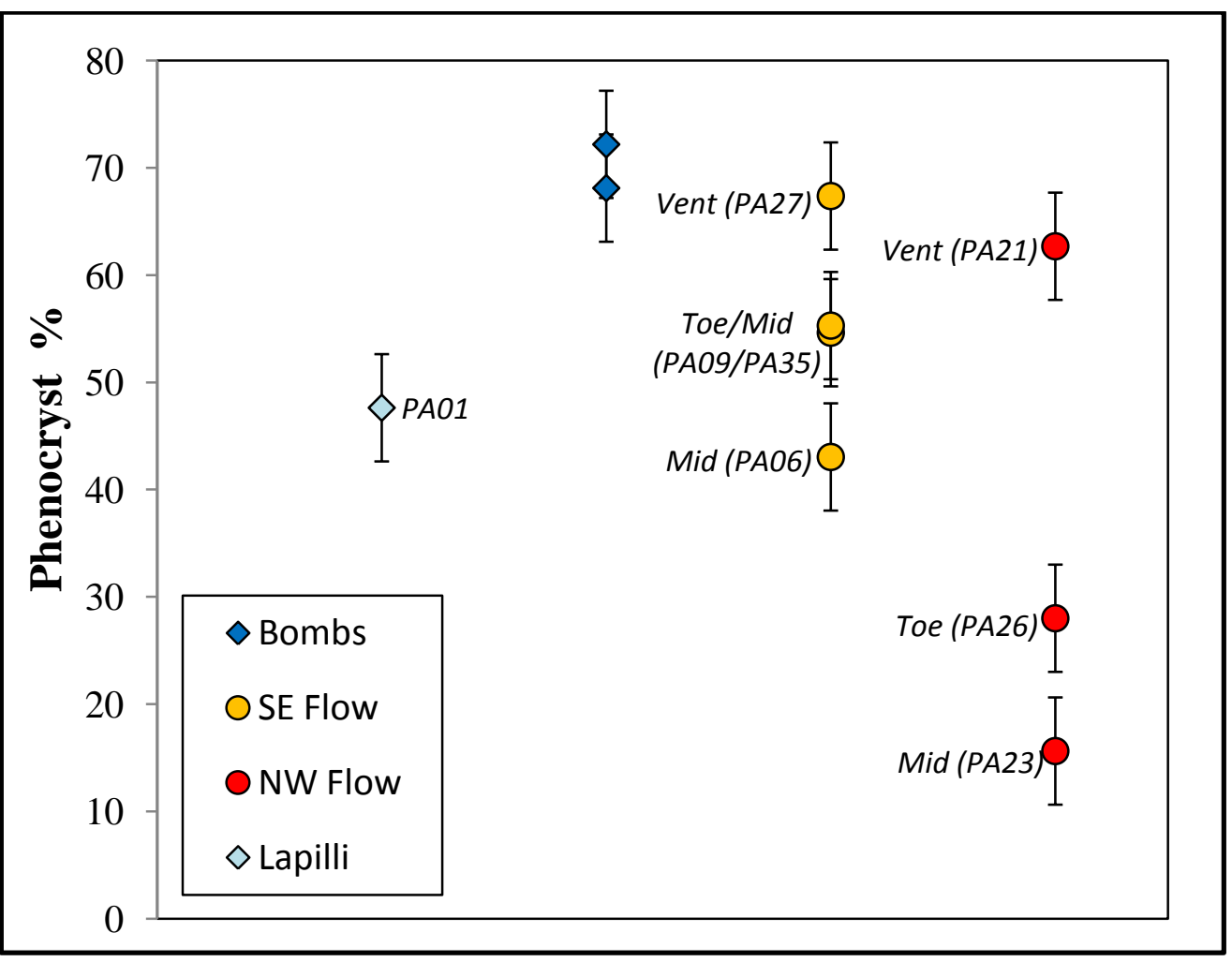

Figure 2.25. Phenocryst $\%\left(\varphi_{\mathrm{P}}\right)$ derived from 40x (JEOL) BSE images. Divided based on sample type.

Figure 2.26 shows calculated microcrystal $\%\left(\phi_{\mathrm{M}}\right)$ for all samples calculated using high magnification (>400x JEOL and >600x Quanta) BSE images. The range in $\phi_{M}$ between the flow samples is similar to the range in $\phi_{\mathrm{P}}$ in Figure 2.25. There is a range between $22-78 \% \phi_{M}$ from vent to toe within the NW flow, compared to $18-57 \% \phi_{M}$ in the SE flow. There is a similar proportion of $\phi_{\mathrm{M}}$ in the vent samples, which also agrees with $\phi_{\mathrm{P}}$ from Figure 2.25. The bomb and lapilli samples show a range in $\phi_{\mathrm{M}}$, which is 
much less in the bomb samples ranging from $0-12 \phi_{\mathrm{M}}$. This range is due to the fact that we were not able to differentiate between glass and microcrystals at the highest magnification used for PA12 (300x JEOL), thus yielding 0\% $\phi_{\mathrm{M}}$. PA16 was imaged at high magnification (>600X Quanta) and yielding $12 \% \phi_{\mathrm{M}}$ on the basis of the whole rock. The wider range within the lapilli tephra sample PA01 is derived from the variations in groundmass and glass within the samples imaged at high magnification (>400x JEOL and $>600 x$ Quanta). The higher value $\left(38 \phi_{\mathrm{M}}\right)$ is calculated in the portions with numerous microcrystals, and the zero value is from the location where only glass and microphenocrysts exist.

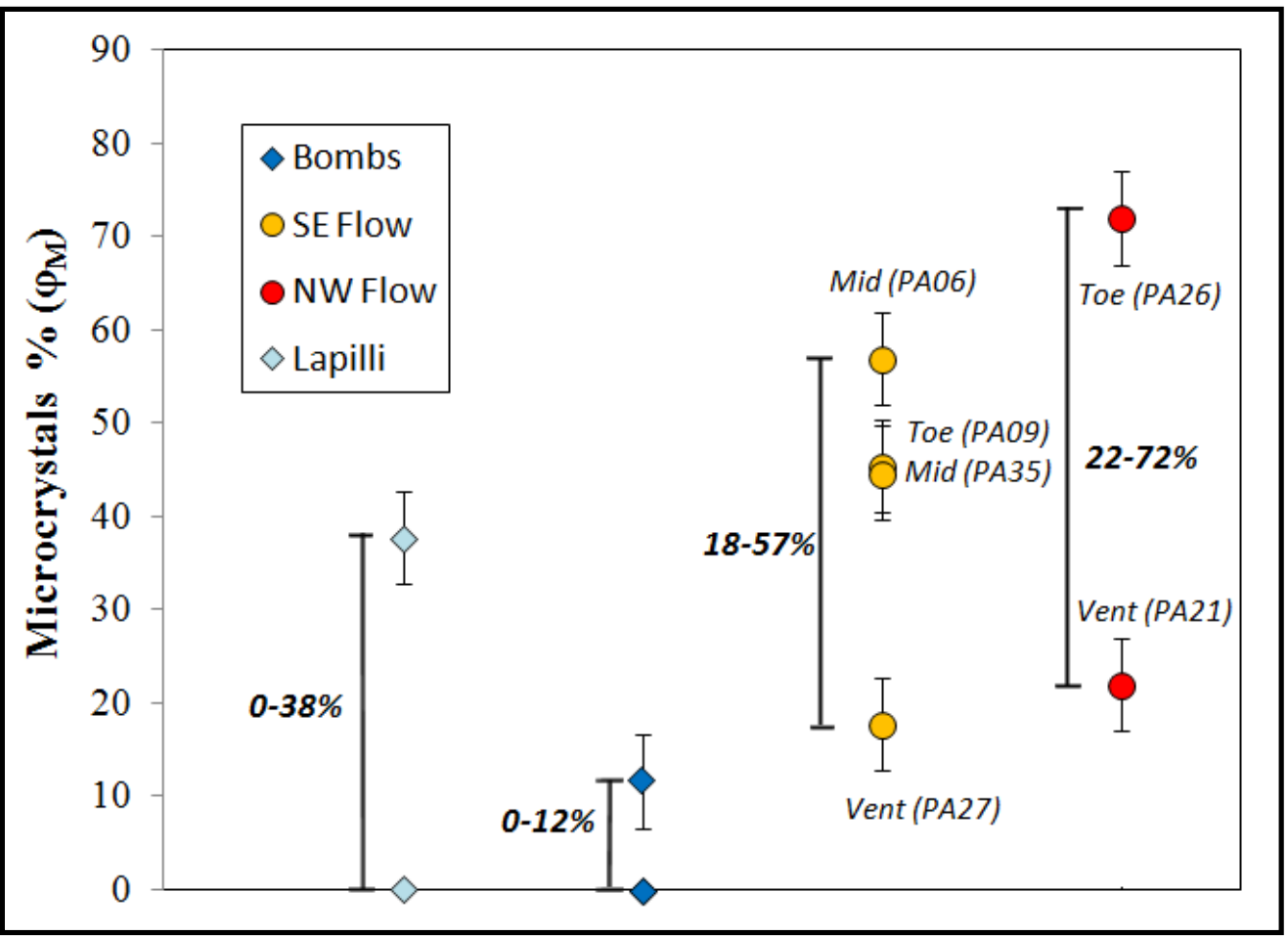

Figure 2.26. Microcrystal \% $\left(\varphi_{\mathrm{M}}\right)$ derived from high magnification JEOL and Quanta BSE images. Divided based on sample type. 
Figure 2.27 sums up all of the vesicularity and crystallinty measurements made on the flow samples, showing $\phi_{\mathrm{T}}, \phi_{\mathrm{P}}$, and $\phi_{\mathrm{M}}$ vs. distance from vent $(\mathrm{km})$. The dotted arrow lines indicate general trends that exist within each flow. Total bubble $\% \phi_{\mathrm{T}}$, decreases substantially from vent to toe. This is especially apparent in the $1^{\text {st }} \mathrm{km}$ of the SE flow, with the rest of the flow showing essentially no bubble loss as a function of distance from vent. Microcrystal $\% \phi_{\mathrm{M}}$ generally increased from vent to toe, with phenocryst $\% \phi_{\mathrm{P}}$ not exhbiting a coherent trend from vent to toe.

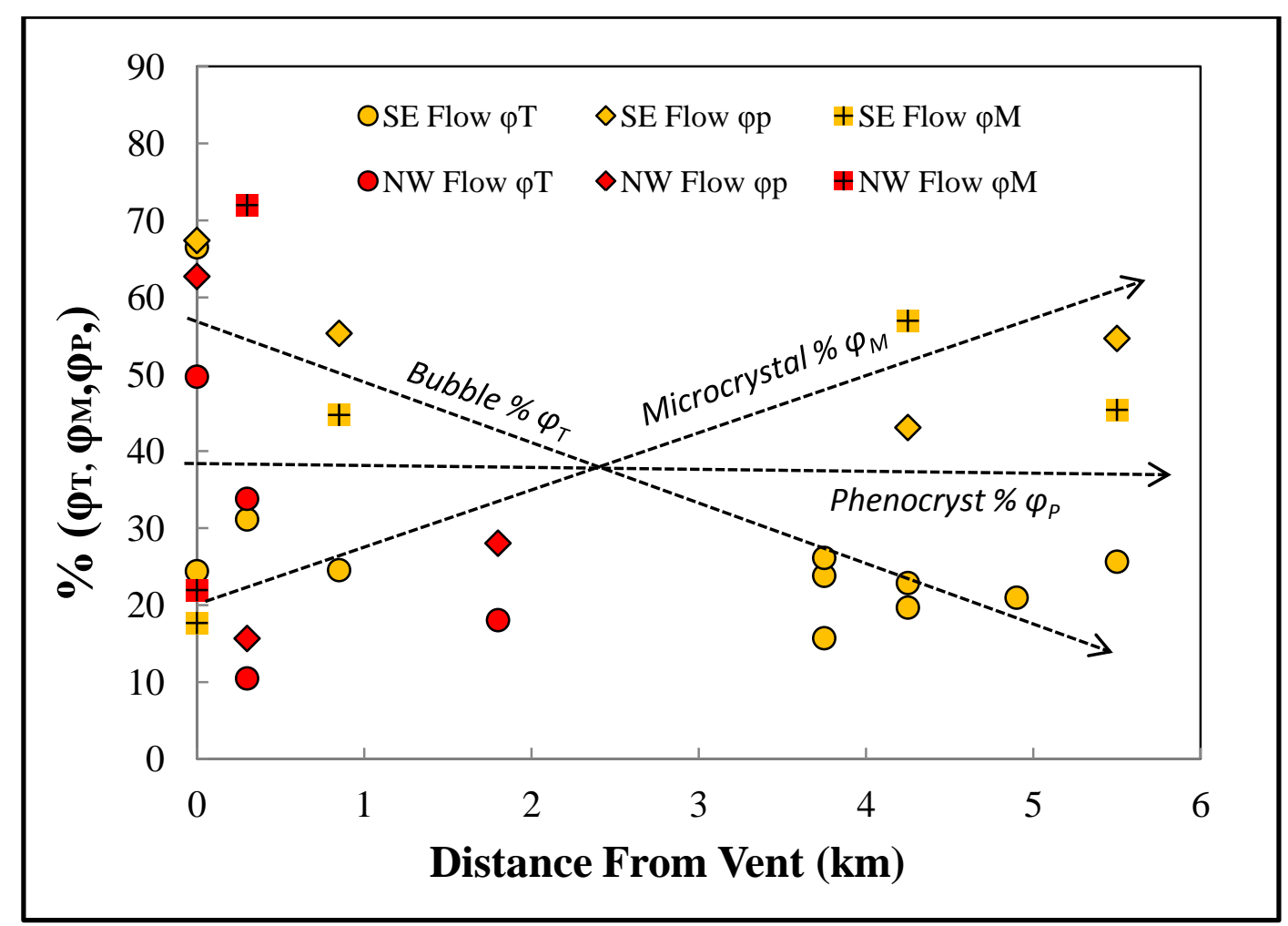

Figure 2.27. \% Total bubbles $\left(\varphi_{T}\right)$, Microcrystals $\left(\varphi_{M}\right)$, and Phenocrysts $\left(\varphi_{P}\right)$ vs. distance from the vent $(\mathrm{km})$ for the flow samples. 


\subsection{Chemistry}

Our petrographic analysis has provided some insight into the crystallization history within the magma chamber prior to and during eruption. However, more information may be obtained from chemical analyses, allowing for a more comprehensive interpretation of magma history within this eruption, which will be provided in the subsequent discussion section of this chapter.

Bulk rock chemistry was acquired for all rock samples to determine an approximate starting composition for erupted samples. The iron redox state of samples was measured to determine the ratio of $\mathrm{Fe}^{2+}$ to $\mathrm{Fe}^{3+}$ in each sample. Mineral and groundmass compositions were also acquired to determine composition of minerals and residual liquid.

\subsubsection{Bulk Rock Chemistry}

Samples were sent to ActLabs of Ancaster, Ontario for bulk rock chemical analysis. Each sample was pulverized using a Fe ring and puck mill in a Shatterbox. To facilitate pulverization, each large sample was cut into manageable chunks using the table saw, and was allowed to dry for 24 hours before use in the Shatterbox. Each sample was then run for approximately 2-6 minutes, with time variation dependent on the starting material. To verify that the total time of pulverization in the Fe ring and puck mill did not result in any variation in Fe contamination, one sample (PA35) was pulverized for both 2 minutes and 10 minutes. There was no noticeable time dependent contamination. The 4Litho code was chosen to perform Lithium Metaborate/Tetraborate Fusion - ICP and ICP/MS chemical analysis. ActLabs describes the method to begin with the dilution of 
fused samples, followed by analysis with a Perkin Elmer Sciex ELAN 6000, 6100 or 9000 ICP/MS. Three blanks and five controls (three before sample group and two after) are used for sample analysis with duplicates analyzed every 15 samples (ActLabs.com).

The bulk rock analysis data are provided in Table A-1in the appendix. The results are plotted in the Harker diagrams below in Figure 2.28, and in the TAS (Total Alkali vs. Silica) diagram in Figure 2.31 along with the liquid chemistry soon to be described. The diagrams in Figure 2.28 show that $\mathrm{Na}_{2} \mathrm{O}, \mathrm{K}_{2} \mathrm{O}$, and $\mathrm{Fe}_{2} \mathrm{O}_{3}(\mathrm{~T})$ wt $\%$ all increase with increasing $\mathrm{SiO}_{2}$ wt $\%$. $\mathrm{MgO}$ wt $\%$ shows little variation with increasing $\mathrm{SiO}_{2} \mathrm{wt} \%$. There is a spatial correlation to these trends when considering the flows samples and the distance they have traveled from vents. The flow samples in each diagram show increasing $\mathrm{SiO}_{2}$ wt $\%$ from vent to toe. This trend is also evident in Figure 2.31 and will be discussed in further detail at the end of the chapter. Figure 2.29 shows total alkalis $\left(\mathrm{Na}_{2} \mathrm{O}+\mathrm{K}_{2} \mathrm{O}\right.$ wt $\left.\%\right)$ vs. distance from the vent to further characterize this trend. The error bars represent average standard deviations of 0.05 calculated for $\mathrm{Na}_{2} \mathrm{O}$ and $\mathrm{K}_{2} \mathrm{O}$ measurements standards acquired by Actlabs. 

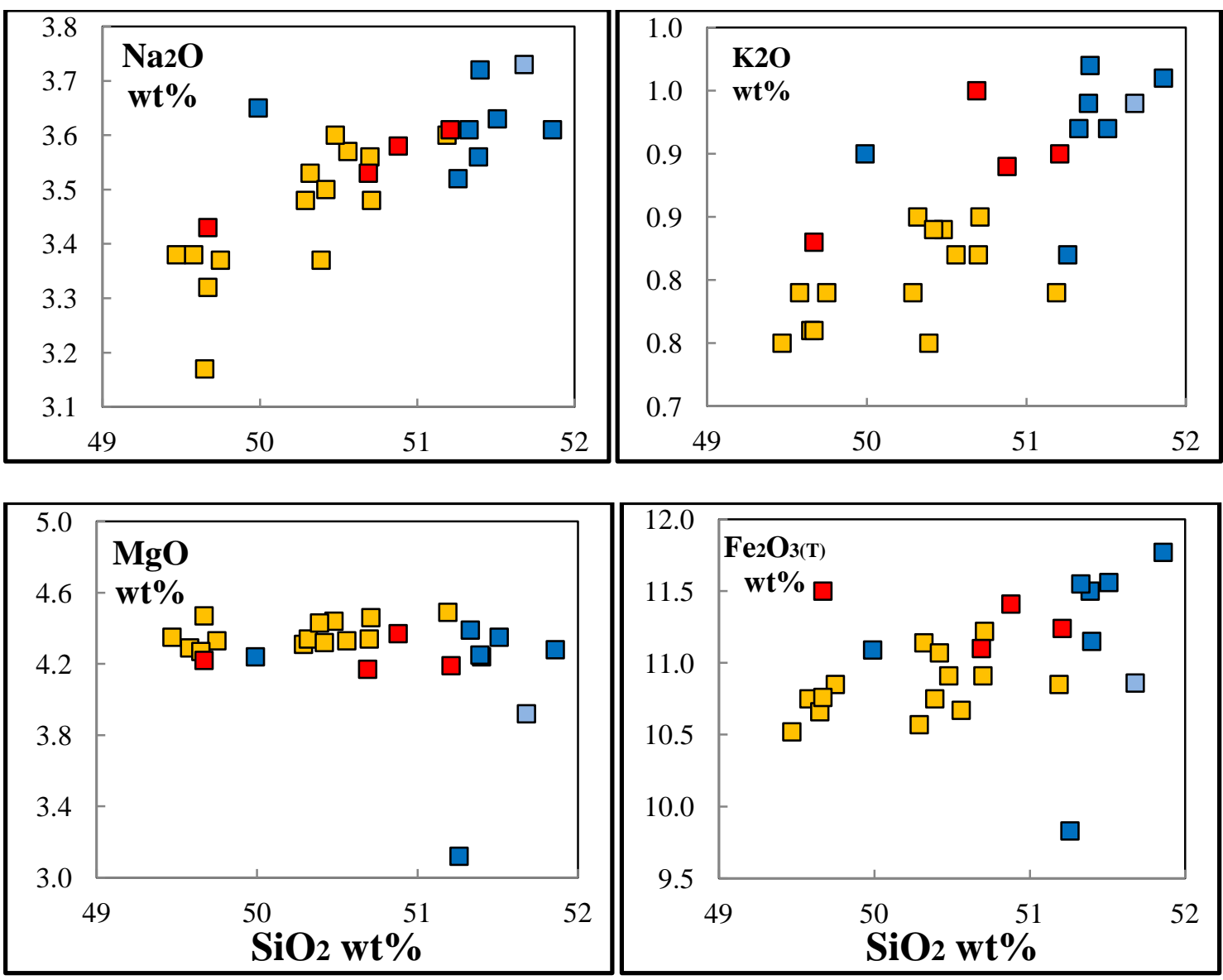

Figure 2.28. Harker diagrams for bulk rock chemical analyses. Wt \% used is in top right portion of each diagram, which are all plotted against $\mathrm{SiO}_{2} \mathrm{wt} \%$. SE flow samples (Orange squares), NW flow (Red squares), Lapilli (Light Blue), and Bombs (Blue). 


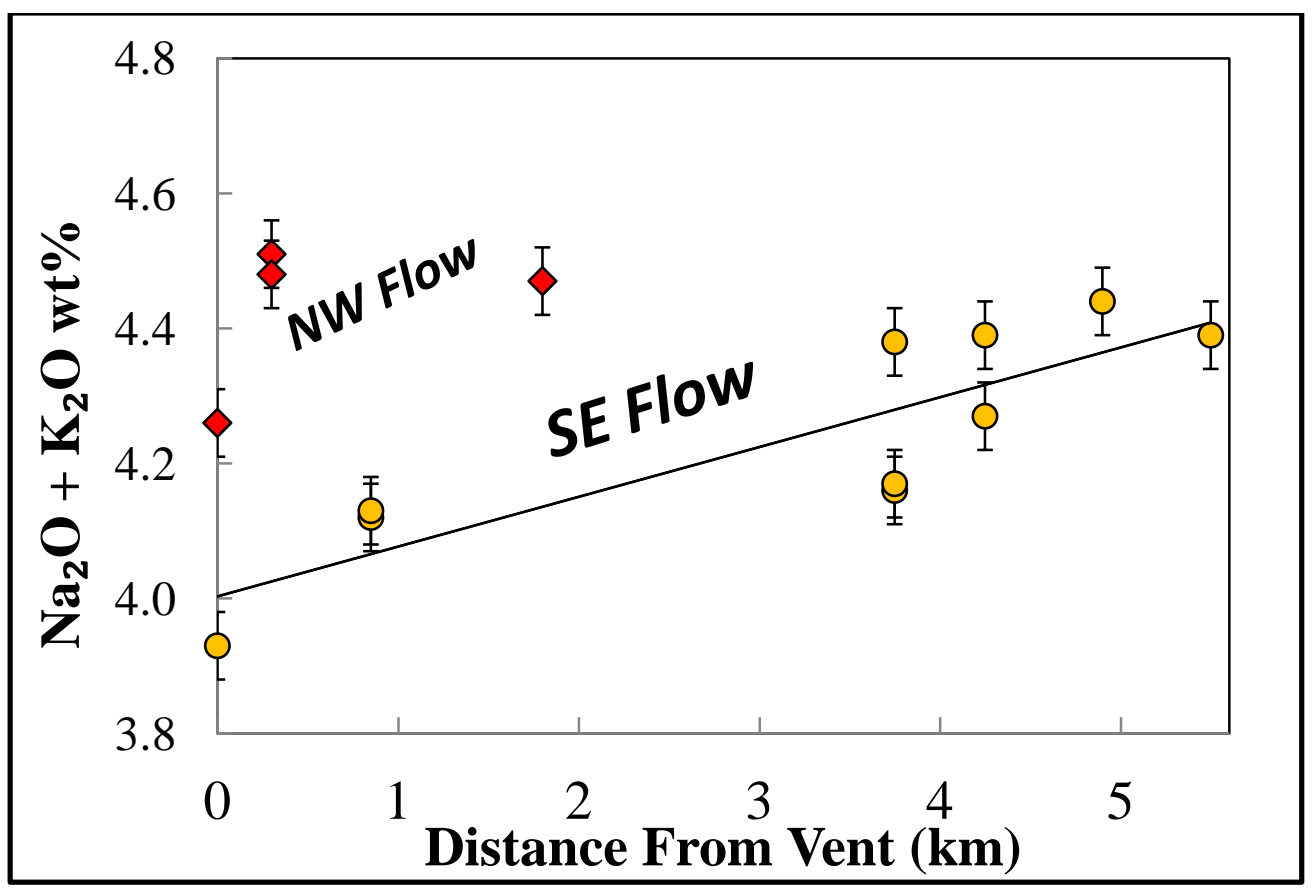

Figure 2.29. Total alkalis vs. distance from vent $(\mathrm{km})$. Trend is more noticeable in SE flow.

\subsubsection{Fe Redox}

The iron redox state of our natural samples was determined using UV/Vis spectroscopy. A Nanodrop1000 UV/Vis spectrometer is used to measure the absorbance values for solutions of varying color intensity dependent on Fe concentration. The procedure used is based on the method of Wilson (1960) and Schuessler et al. (2008) and has been refined by Alexander Sehlke. The method allows for the proportions of $\mathrm{Fe}^{2+}$ and $\mathrm{Fe}^{3+}$ to be calculated within a given sample. The amount of $\mathrm{Fe}^{2+}$ and $\mathrm{Fe}$ (total) are determined separately, and by simply subtracting $\mathrm{Fe}^{2+}$ from $\mathrm{Fe}$ (total) we get $\mathrm{Fe}^{3+}$. $\mathrm{Fe}$ standard solutions of known concentrations varying from 0-64 ppm and two USGS standards are used to determine and test our results respectively. 
The results of the Fe Redox experiments for our natural samples are shown in Figure 2.30 and Table A-2 in the appendix. FeO total (plotted in white) is the sum of both $\mathrm{FeO}$ (green) and $\mathrm{Fe}_{2} \mathrm{O}_{3}$ (red). The blank sample is run exactly as all other Fe bearing samples, and the zero value for our blank shown in Table A-2 ensures that no Fe contamination occurred during the experiment. Two USGS standards were also analyzed to check for accuracy. BIR1-a is an Icelandic Basalt with 2.06 wt $\% \mathrm{Fe}_{2} \mathrm{O}_{3}(+/-0.1)$ and 11.3 wt $\% \mathrm{Fe}_{2} \mathrm{O}_{3} \mathrm{~T}(+/-0.12)$. W-2a is a diabase sample from Centreville, Virginia with $8.34 \mathrm{wt} \% \mathrm{FeO}(+/-0.093), 1.53 \mathrm{wt} \% \mathrm{Fe}_{2} \mathrm{O}_{3}$ (+/- 0.87), and $10.83 \mathrm{wt} \% \mathrm{Fe}_{2} \mathrm{O}_{3} \mathrm{~T}$ (+/- 0.21). The measured USGS samples reproduce $\mathrm{FeO}$ wt $\%$ values within $+/-0.3 \mathrm{wt} \%$ and $\mathrm{Fe}_{2} \mathrm{O}_{3}$ values within +/- 0.05 wt $\%$. Table A-2 also shows values $\mathrm{Fe}_{2} \mathrm{O}_{3}(\mathrm{~T})$ and $\mathrm{FeO}(\mathrm{T})$ wt\%, with the (T) representing total $\mathrm{Fe}$ as either $\mathrm{Fe}_{2} \mathrm{O}_{3}$ or $\mathrm{FeO}$, measured using Actlabs and microprobe analyses respectively. The Actlabs data was acquired for the whole rock in powdered form, and matches values obtained from spectroscopy within $0.31 \mathrm{wt} \%$. The microprobe data was acquired from two remelts of the whole rock, and match values within $0.13 \mathrm{wt} \%$.

Looking at Figure 2.30 we see the total iron (as $\mathrm{FeO}$ ) is very similar for all samples at approximately $9.6 \mathrm{wt} \%$ (+/- 0.3). Most samples have $7.6 \mathrm{wt} \% \mathrm{FeO}(+/-0.5)$ and $\sim 2.3$ wt $\% \mathrm{Fe}_{2} \mathrm{O}_{3}(+/-0.3)$, which yields an atomic $\left(\mathrm{Fe}^{2+} / \mathrm{Fe}^{2+}+\mathrm{Fe}^{3+}\right)$ ratio of $\sim 0.77$. Samples PA01 and PA23 have $~ 5.7 \mathrm{wt} \% \mathrm{FeO}(+/-0.3)$ and $\sim 4.3$ wt $\% \mathrm{Fe}_{2} \mathrm{O}_{3}(+/-0.03)$, which yields an atomic $\left(\mathrm{Fe}^{2+} / \mathrm{Fe}^{2+}+\mathrm{Fe}^{3+}\right)$ ratio of $\sim 0.57$. We can use some of the observations made in our petrographic analyses to explain the cause for this difference in oxidation with PA01 and PA23 compared to the rest of the samples. PA01 represents an 
assortment of ash a lapilli sized tephra fragments erupted during the explosive stage of the 2010 eruption. We noticed in the macroscopic analyses that PA01 contained some fragments that were distinctly more red than others. When sample PA23 was analyzed macroscopically a noticeable red portion was apparent when sliced in half as seen in Figure 2.16. With regards to PA01, when we pulverized the sample, we included all the ash fragments and the lapilli fragments to ensure that the bulk rock chemistry would best represent that of all acquired lapilli tephra. Also we included all samples and did not separate out more red fragments as differentiating between gray and red hues would be nearly impossible as there was not a distinct separation of two components, but rather a range of hues. Regarding PA23 we did attempt to only include the darker portion of the sample and excluded the red portion in the center (Figure 2.14) as we assumed it was not representative of the whole rock. Judging by the still apparently oxidized composition of the whole rock, it is still possible that microscopic oxidized fragments still existed within the rock, or gray fragments were also oxidized with red fragments representing very oxidized portions. The fragments could have been incorporated from oxidized portions of the vent as the sample erupted, or it could be due to post depositional weathering and oxidation, as could also be possible among all erupted samples. With regards to the tephra it could also be the result of increased oxidation during the flight of the sample after eruption. 


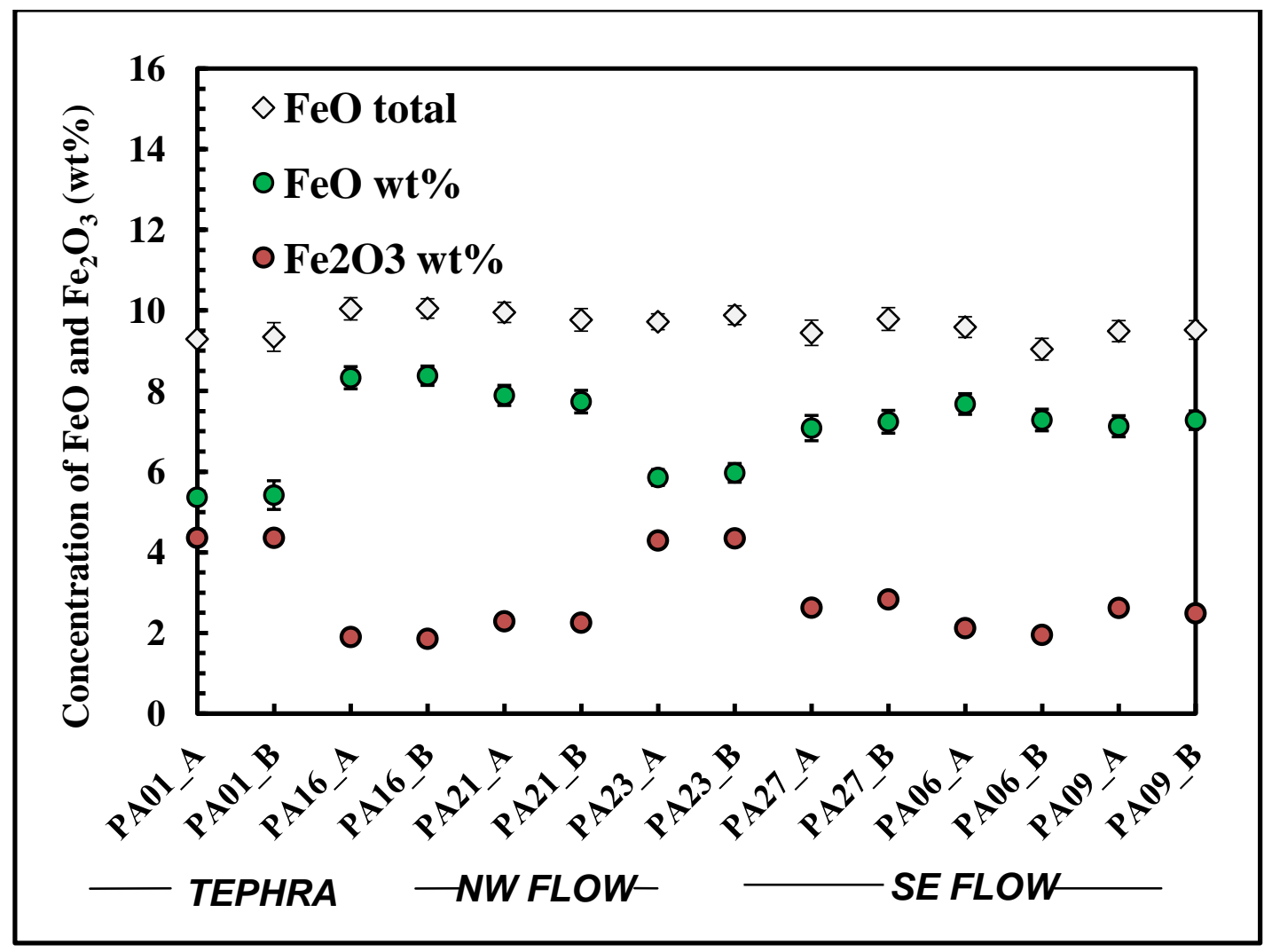

Figure 2.30. Concentration of $\mathrm{FeO}$ and $\mathrm{Fe}_{2} \mathrm{O}_{3}(w \mathrm{t} \%)$ for natural samples. Total iron expressed as $\mathrm{FeO}$.

\subsubsection{Mineral and Groundmass Chemistry}

Microanalysis of minerals and glass/groundmass of the samples were conducted with the JEOL microprobe at WUSTL. We used $5 \mu \mathrm{m}$ electron beams for everything except groundmass and glass where we generally used 1-2 $\mu \mathrm{m}$ electron beams. As determined in the petrography of our samples, the matrix of samples varies from glassy to microcrystalline, where the term glass is used to indicate portions of the samples that did not reveal any crystals at 400x (JEOL) or 600x (Quanta) in BSE images. Glassy matrices, were probed to determine liquid compositions at the time of eruption, although in some cases these areas exhibited microcrystals and/or undulatory compositional changes at 
much higher magnification. The results are provided in Table A-3 in the appendix, and within the following figures.

Figure 2.31 is a TAS (Total Alkali vs. Silica) diagram with the liquid chemistry of the natural samples (of those that exhibited glass at high magnification) and bulk rock analyses from Actlabs plotted. The liquid compositions range from basalt to andesite, with liquid composition being more silicic in more crystalline samples. The diagram shows that bulk rock analyses plot within the basalt field along a distinct line. The top right portion of the TAS diagram shows this trend in more detail. The samples generally exhibit increasing alkali and silica content as samples go from vent to toe, with toes bearing similar compositions to the tephra samples.

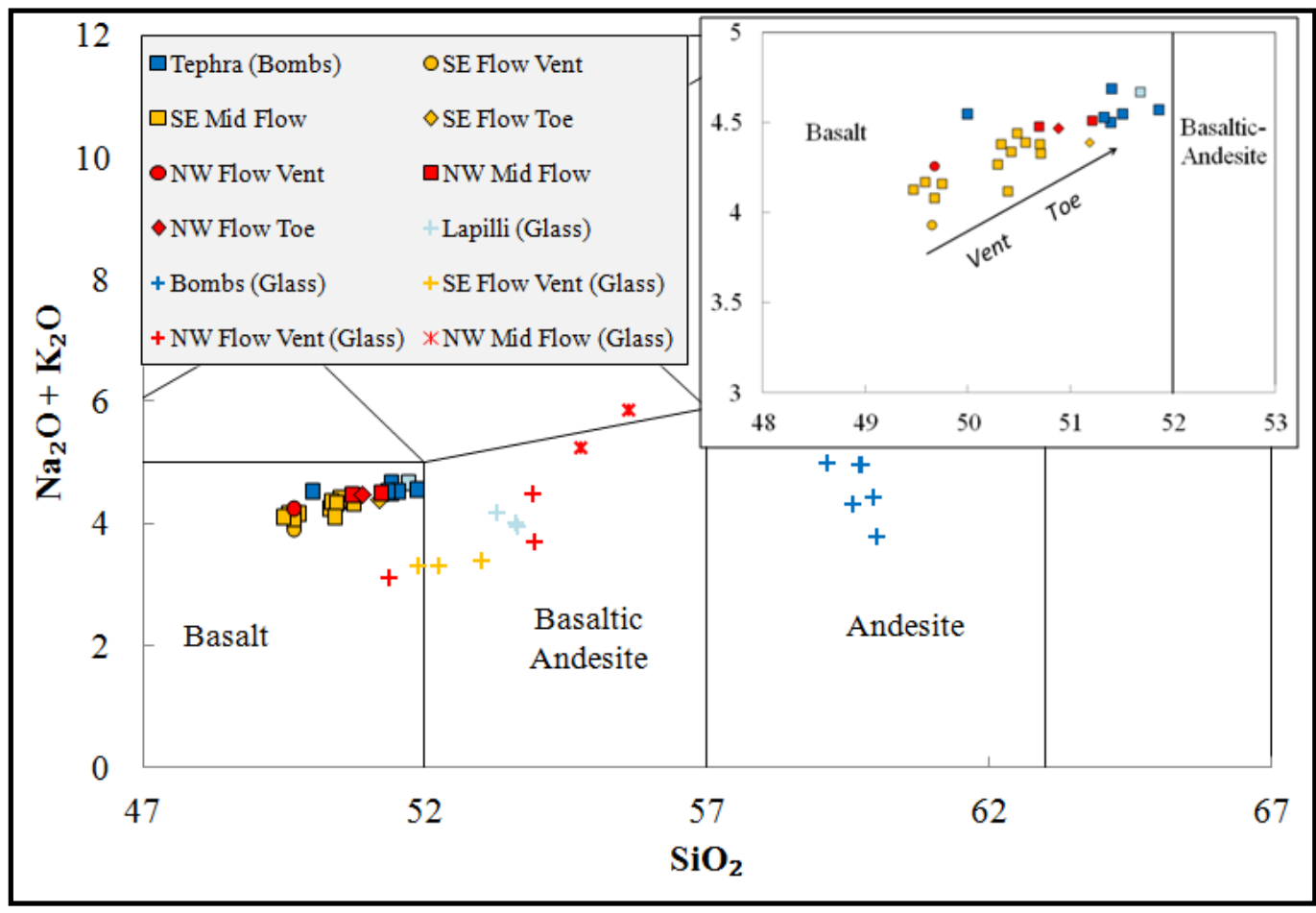

Figure 2.31. Total alkali vs. silica (TAS) diagram. Notice the trend of increasing alkali and silica from vent to toe. 
Plagioclase crystals are zoned from anorthite rich core to albite rich rim, so there is not a distinct compositional trend for Ca\# from vent to toe (Figure 2.32). There is however a compositional trend for Mg\# in olivine, with $\mathrm{Mg}$ rich olvines in vent samples to less magnesian olivines in toe samples (Figure 2.33). The trend is present in both flows, but more obvious in the SE flow. The bombs and lapilli tephra have the lowest calculated Mg\# of $\sim 54$.

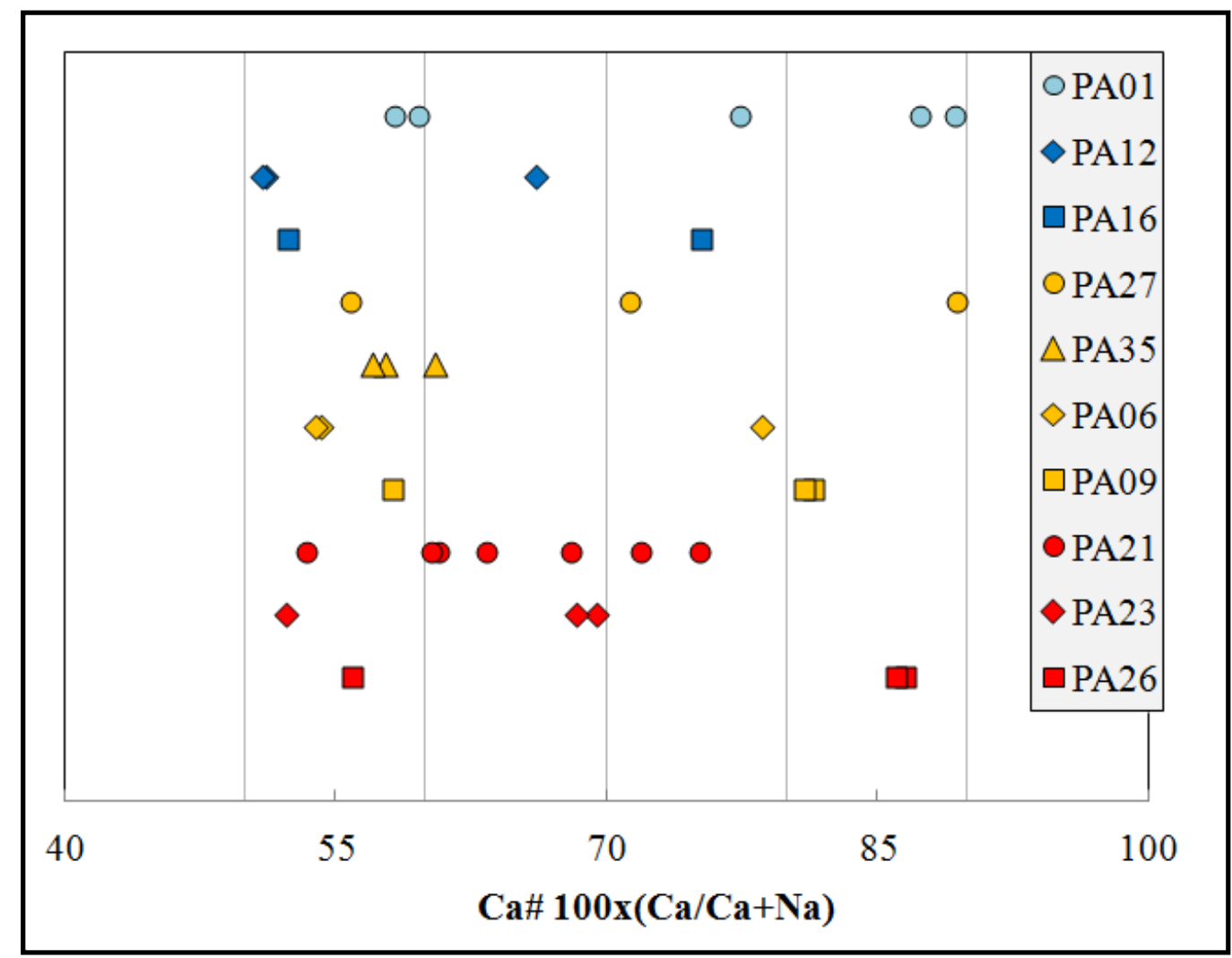

Figure 2.32. Plagioclase compositions based on Ca\# from microanalysis. Wide range in compositions is due to crystal zoning. 


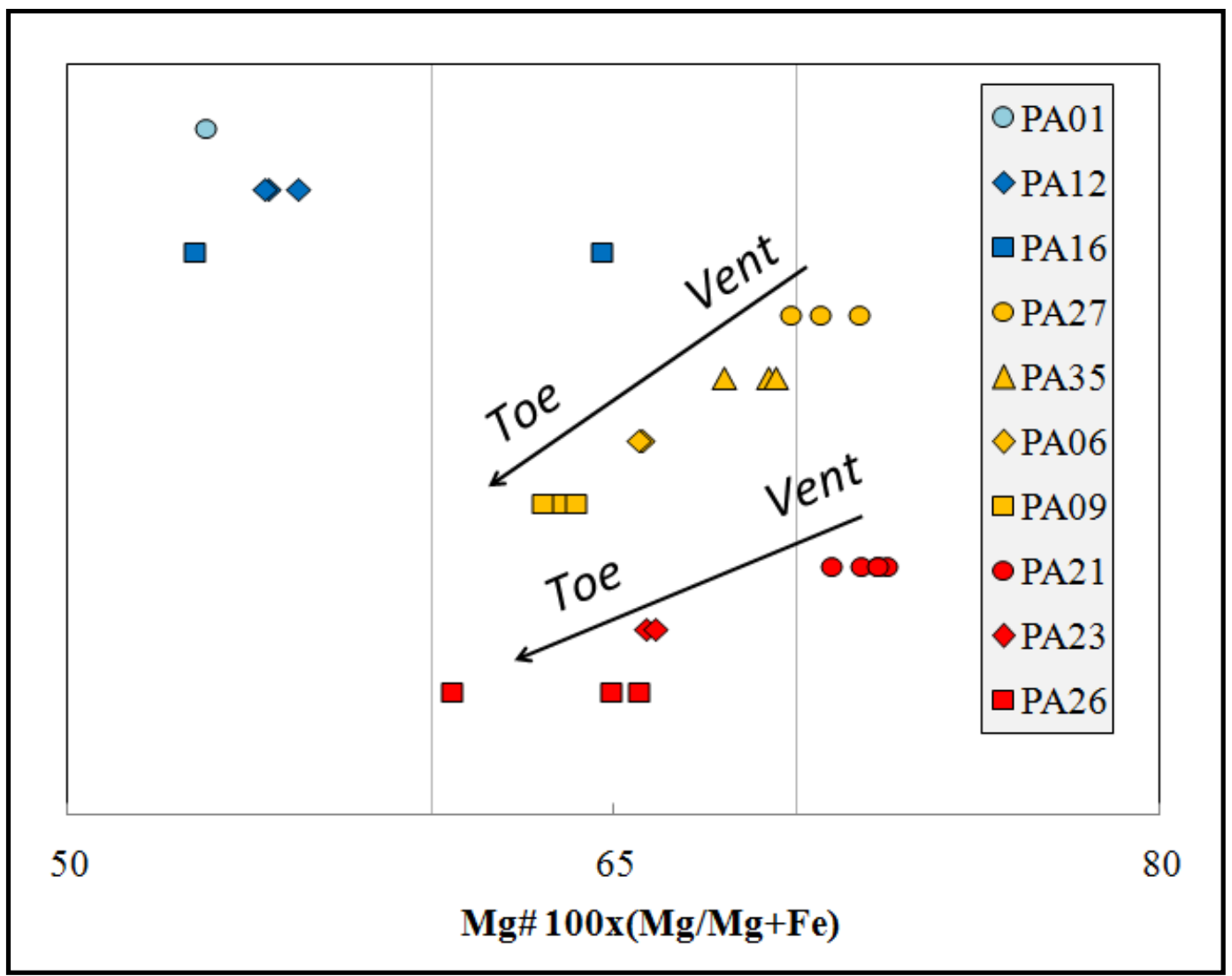

\section{Figure 2.33. Olivine compositions based on Mg\# from microanalysis. Lower Mg\# from vent to toe}

Crystal fractionation can potentially be quantified by plotting mineral, glass and bulk rock compositions in Harker diagrams. Figure 2.34 shows $\mathrm{MgO}$ wt $\%$ vs. $\mathrm{SiO}_{2}$ wt\% for the bulk rock analyses and the olivine, clinopyroxene, and glass phases. Olivine shows a distinct trend from vent to toe that is also evident in Figure 2.33. $\mathrm{SiO}_{2}$ decreases as $\mathrm{MgO}$ decreases for both olvine and clinopyroxene from vent to toe. $\mathrm{MgO}$ wt\% varies minimally in the bulk rock and glass analyses, with variation only in $\mathrm{SiO}_{2} \mathrm{wt} \%$ as was also evident in Figure 2.28 for the bulk rock analyses. The oxides are not shown as they simply would plot on the origin as they have essentially no $\mathrm{SiO}_{2}$ or $\mathrm{MgO}$. 


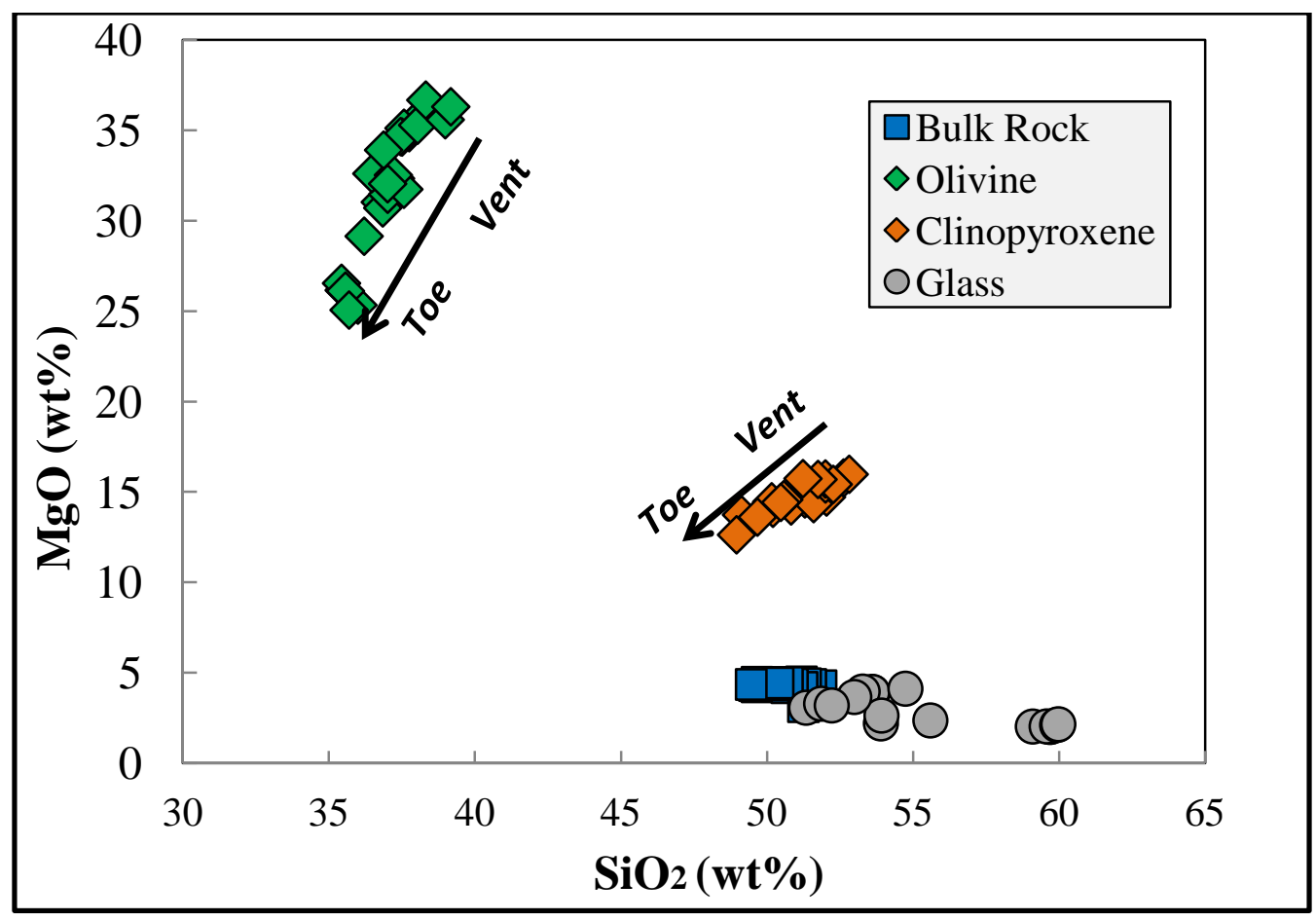

Figure 2.34. Bulk rock, glass, and mineral $\mathrm{MgO}$ wt\% vs $\mathrm{SiO}_{2}$ wt\%

Figure 2.35 shows the wide range in $\mathrm{CaO}$ wt\% within the glass due to the fractionation of clinopyroxene (diopside) and/or plagioclase (anorthite). Clinopyroxene is not obviously zoned, and has less variation in $\mathrm{CaO}$ and $\mathrm{SiO}_{2}$ compared to plagioclase. Olivine values are tied to the $\mathrm{x}$ axis as they do not contain any $\mathrm{CaO}$. The cluster of glass analyses at $\sim 60 \mathrm{wt} \% \mathrm{SiO}_{2}$ represents the bomb samples. The other values represent flow samples exhibiting a trend from vent to toe characterized by lower $\mathrm{SiO}_{2}$ and higher $\mathrm{CaO}$ for vent and up flow samples, and higher $\mathrm{SiO}_{2}$ and lower $\mathrm{CaO}$ for down flow and tephra samples. 


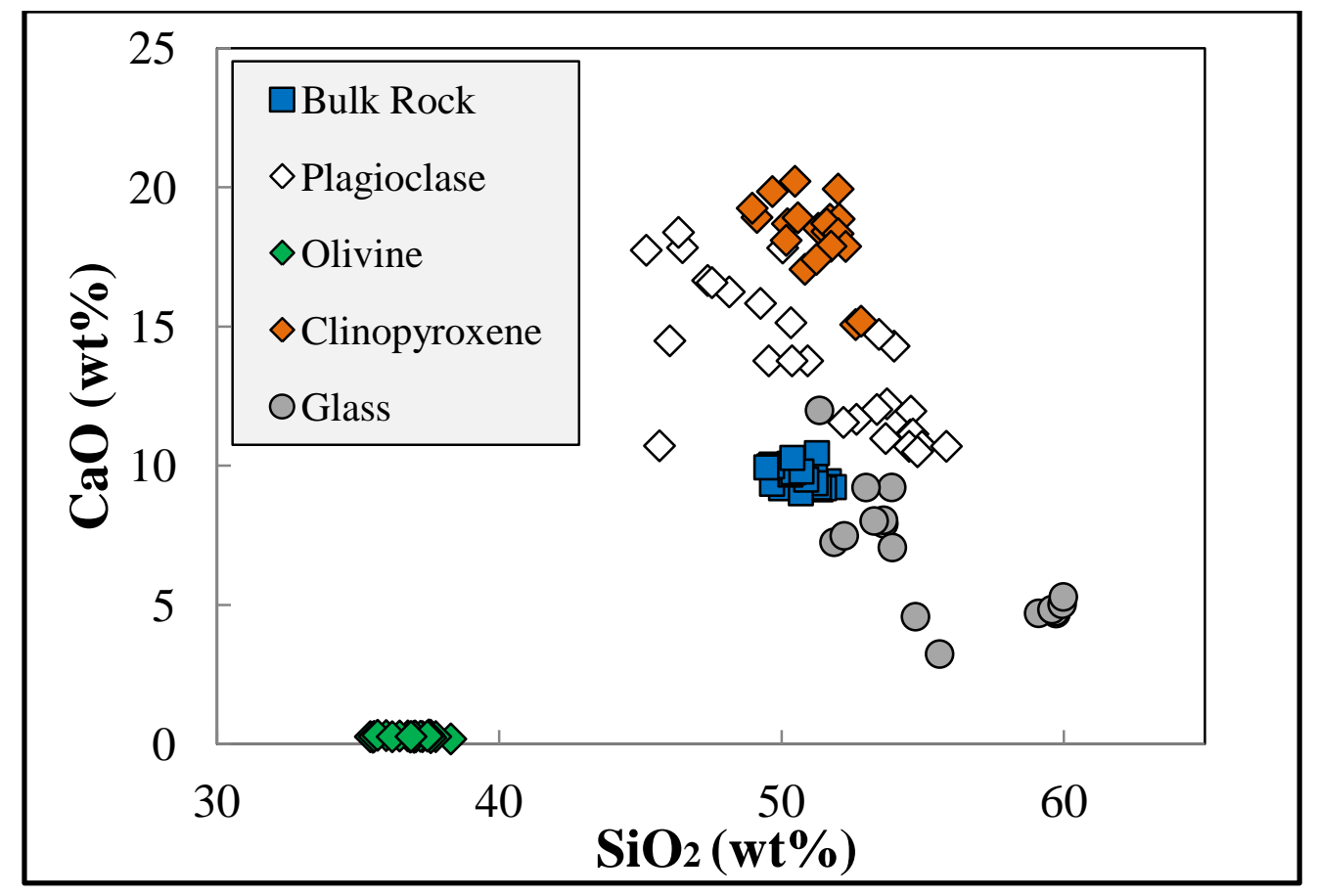

Figure 2.35. Bulk rock, glass, and mineral $\mathrm{CaO}$ vs. $\mathrm{SiO}_{2}$ wt\%

The $\mathrm{MgO}$ content of the liquid can be used with the equation

$$
\mathrm{T}\left({ }^{\circ} \mathrm{C}\right)=26.3 \mathrm{MgO}^{l i q}+994.4^{\circ} \mathrm{C}
$$

by Putirka (2008) to calculate the eruption temperature of samples with glass phases. We calculated eruption temperatures for two bomb samples, both vent samples, and the. Results are presented in the Table 2.3 in order of increasing eruption temperature. This equations only works for systems saturated in olivine, as the $\mathrm{MgO} \mathrm{wt} \%$ present in the liquid is controlled by the extent of olivine crystallization in a system that is olivine saturated. Putirka (2008) states that the equation calculates eruption temperature within $+/-71^{\circ} \mathrm{C}$. Considering the error, we cannot accurately compare the eruption temperatures 
of the samples. There is another equation presented by Putirka (2008), however, it requires $\mathrm{H}_{2} \mathrm{Owt} \%$ to be known, for which we do not have accurate estimates.

\begin{tabular}{c|c|c|c}
\hline $\begin{array}{c}\text { Sample } \\
\text { Type }\end{array}$ & $\begin{array}{c}\text { Sample } \\
\text { Name }\end{array}$ & $\begin{array}{c}\text { MgO wt\% } \\
\text { wt\% }\end{array}$ & $\begin{array}{c}\text { Eruption T } \\
{ }^{\circ} \mathbf{C}\end{array}$ \\
\hline Bomb & PA12 & 2.06 & 1049 \\
Bomb & PA16 & 2.12 & 1050 \\
Vent & PA21 & 2.63 & 1064 \\
Vent & PA27 & 3.44 & 1085 \\
Tephra & PA01 & 3.96 & 1099 \\
\hline
\end{tabular}

Table 2.3. Eruption temperatures calculated using $\mathrm{MgO}$ wt $\%$ of liquid using equation 2.3 by Putirka (2008).

\subsection{Petrographic Conclusions}

Using results from the macro and microscopic observations, along with our chemical analyses, inferences can be made regarding crystallization history both within the magma chamber prior to eruption, and within the eruption products during emplacement.

The distribution of plagioclase and olivine phenocrysts relative to glassy and/or microcrystalline groundmass in our optical and BSE images, suggest that these two phases were the first to exist in the magma chamber, followed by clinopyroxene and titano-magnetite crystallization.

Zoning present within the plagioclase crystals can be used to infer thermal history within the chamber as crystals grew. Calcic cores are indicative of high temperature plagioclase crystallization, where sodic rims are indicative of relatively lower temperature crystallization. The presence of oscillatory zoned plagioclase crystals (Figure 
2.20 D), provide evidence of either magma chamber convection, or periods of magma cooling and subsequent injections of hotter, more mafic magma (Ginibre et al. (2007). Plagioclase crystals with large calcic cores, and relatively thinner sodic rims (Figures $2.5 \mathrm{C}, 2.9 \mathrm{C}$, and $2.10 \mathrm{E}$ ), suggest that there was a relatively stable period of high temperatures where the plagioclase initially crystallized. It is likely that a combination of these processes occurred in the magma chamber.

Microphenocryst growth could be associated with the recharge events that possibly led to the oscillatory zoning in the plagioclase. In some samples it is also possible that microphenocrysts were derived from broken fragments of larger phenocrysts (Figure $2.17 \mathrm{C}$ ). However, zoning is evident in some microphenocrysts, suggesting that they spent some time in oscillating temperature conditions prior to and/or during eruption.

Microcrystal crystals present within samples that exhibit some glassy areas (tephra and vents) likely grew during ascent and rapid cooling of the rock. The flow samples do however, exhibit crystalline groundmass, likely a result of slow cooling as heat was sustained in the flows. In Dr. Rudiger Wolf's chronology of the events culminating in the May $27^{\text {th }}$ eruption, he estimates that flows remained active for at least 2 weeks, which would allow for continued crystallization during slow cooling within the flow.

The zoning within our plagioclase crystals provides evidence of a thermal gradient within the chamber that would allow for magma convection. Our chemical 
analyses provide further evidence of this phenomena. Vent to toe chemical trends have been observed within the bulk rock and phase analyses. Regarding the bulk rock analyses, the increasing alkali and silica content with distance correspond to an increasingly more mafic material erupted over time, assuming that the toe includes early erupted material. Later stages within a single eruption producing more mafic material are a common occurrence at other volcanoes, including Fuego volcano, Guatemala (Blake and Ivey 1986, Chesner and Halsor 1997). Pinkerton et al. (2007) provides a comprehensive description of processes occurring in magma chambers that can lead to compositional gradients. These compositional gradients occur as melt cools in contact with the wall rock, and begins to crystallize minerals. The minerals are moved throughout the chamber through thermal convection and can be separated by contrast in density. Over time the more mafic/heavy magma sinks to the bottom of the chamber with the more silicic/lighter magma concentrating at the top. This chemical gradient is further represented by the phase analyses showing $\mathrm{Mg}$ rich olivine and pyroxene likely derived from a deeper portion of the magma chamber erupting over time.

We still need to address several questions concerning the May 2010 eruption. Firstly, we need to provide an explanation regarding the chemistry of the tephra samples relative to the flow samples. Figure 2.31 shows that the tephra samples plot with the highest $\mathrm{SiO}$ wt\%, suggesting that they were removed from the magma chamber before the toe samples. However, Dr. Wolf observed flow activity 7-10 days before the main eruption producing the tephra samples. Considering the consistency between the bulk rock and phase chemistry suggesting a chemically layered magma chamber, what is the 
reason for this contradiction? Secondly, we observe a wide range of crystallinity in the samples from vent to toe. Flow samples, which exhibit fully crystalline groundmass, have traveled up to 5.5 . $\mathrm{km}$ from the vent. What is the viscosity of these crystalline magmas at various temperatures? Furthermore, is the textural variation between the groundmass of flows and lapilli tephra a compositional or thermally derived feature?

A series of high temperature experiments have been developed and implemented with the aim of answering these questions by assessing the rheology of the magma at various degrees of undercooling and crystallization. The experimental results will be used to both test models that calculate magma viscosity as a function of crystal fraction, and to create a hypothetical model for the May 2010 eruption. 


\section{CHAPTER 3- EXPERIMENTAL WORK}

\subsection{Overview}

This chapter first introduces a variety of high temperature experimental techniques that were used to explore the rheology of magmas at Pacaya, including viscosity measurements of our lava samples, their remelts (liquids), and partially crystalline remelts (magmas). The results are then described, and used to test current models that calculate magma viscosity. In chapter 4, the results will be applied to better understand magma flow and generation during the May 2010 eruption of Pacaya.

\section{2 Introduction to Viscometry Techniques}

Two techniques were used to measure viscosity over greater than ten orders of magnitude $\left(0.4-10^{13} \mathrm{~Pa} \mathrm{~s}\right)$ and over a temperature range from $650^{\circ} \mathrm{C}$ to nearly $1600^{\circ} \mathrm{C}$.

A Theta Industries Rheotronic III 1000C Parallel Plate (PP) Viscometer (Figure 3.1) was used to investigate subliquidus rheology on magmas or supercooled liquids at viscosities from $10^{8}$ to $10^{13} \mathrm{~Pa} \mathrm{~s}$ at temperatures between $\sim 650^{\circ} \mathrm{C}$ and greater than $1000^{\circ} \mathrm{C}$. The PP viscometer measures the uniaxial strain rate resulting from an applied normal load, and viscosity can then be calculated as the ratio of stress over strain rate using the general expression

$$
\eta(P a s)=\frac{m g h^{2}}{3 V \delta h / \delta t}
$$

where $m$ equals the mass of the applied load $(\mathrm{kg}), g$ equals the acceleration due to gravity $\left(\mathrm{m} / \mathrm{s}^{2}\right), V$ equals the volume of the sample $\left(\mathrm{m}^{3}\right), h$ equals the height of the sample used, and $t$ equals time (s) (Dingwell 1995). The factor of three accounts for deformation 
occurring in three directions, converting a longitudinal viscosity to a volumetric viscosity (Gent 1960). Figure 3.2 shows a more detailed schematic and image of the sample location in the PP viscometer.

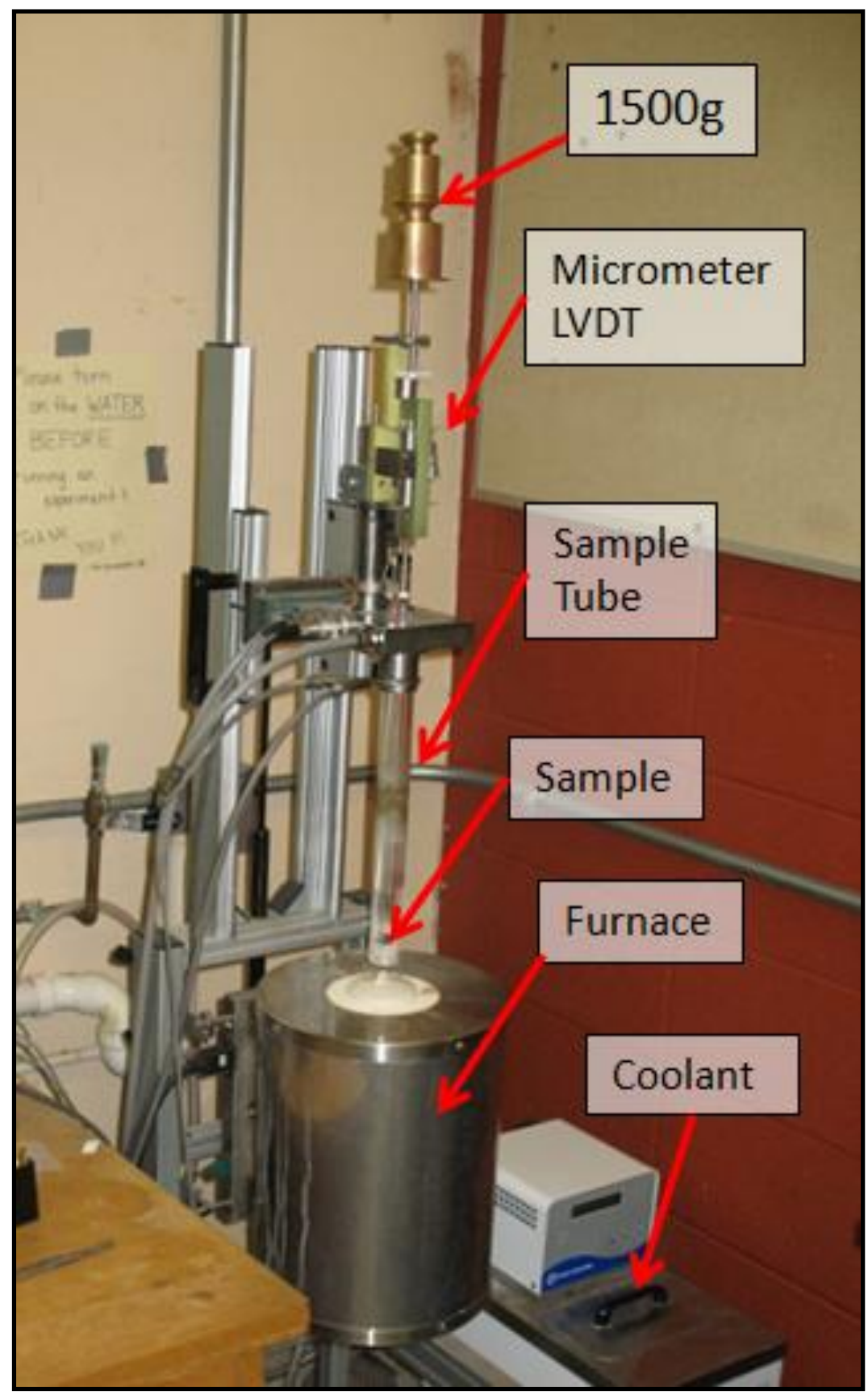

Figure 3.1. PP viscometer set up. 


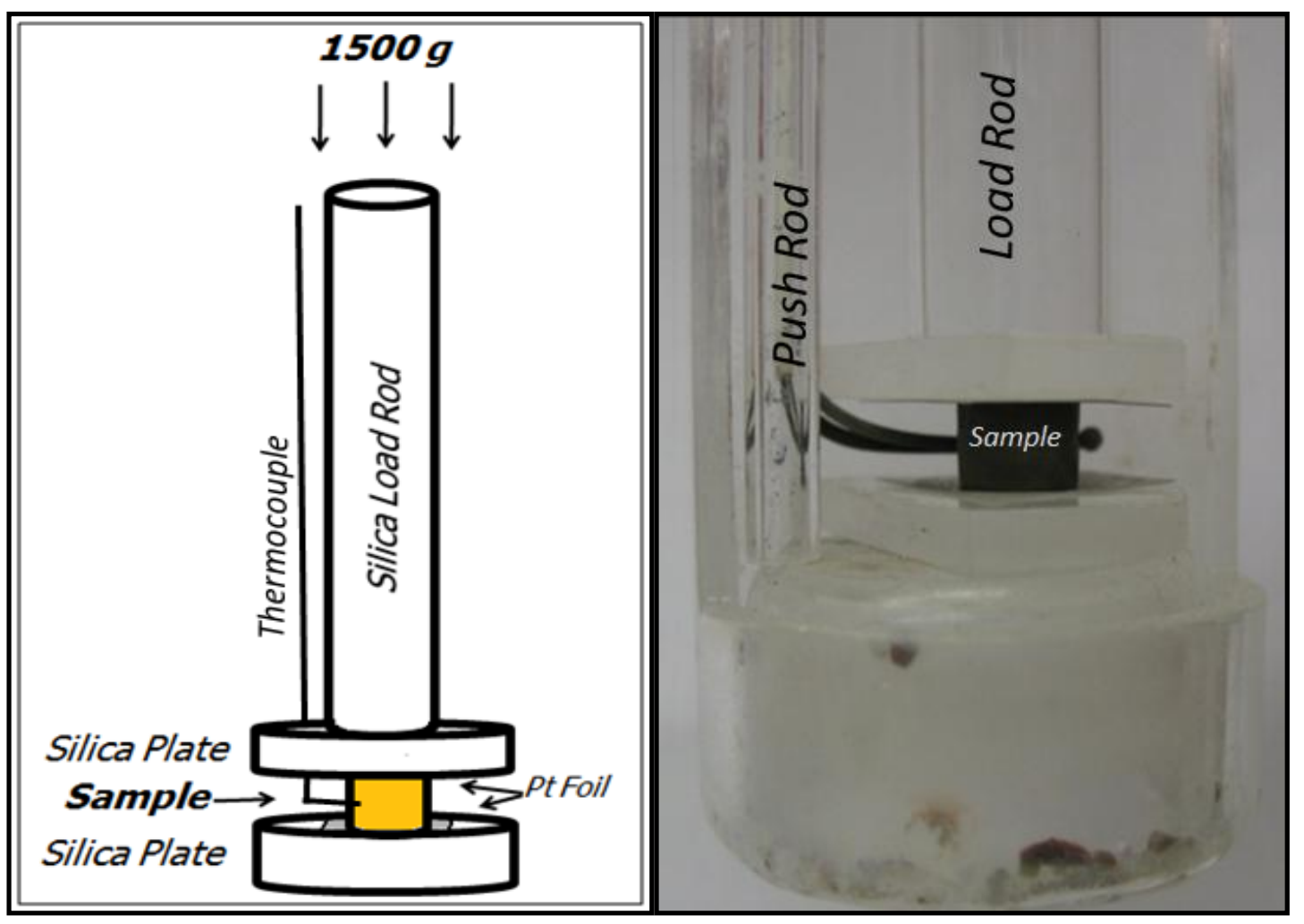

Figure 3.2. Generalized schematic and close up of sample location and components. Load road is $1.2 \mathrm{~cm}$ in diameter.

Samples are drilled using diamond coated Starlite bits with the drill press, and are polished symmetrically on each side using carbide grit paper. The sample rests in the sample holder tube between two silica plates and two pieces of platinum foil to avoid adhesion with the plate. A K type thermocouple (from Omega) is positioned behind and touching the sample through the duration of the experiment. The thin silica push rod next to the sample remains stationary and is used along with the linear variable displacement transducer (LVDT) to measure the deformation of the sample. The LVDT measures how much the sample deforms relative to the stationary push rod every few seconds, at an interval determined by the operator, and this information is recorded in a data file. The 
data filed is subsequently processed using Excel $^{\circledast}$. Given the history of sample height over time, we can then calculate viscosity with Equation 3.1 and relate it to temperature.

NIST standard borosilicate samples (717a) of known viscosity were measured to test the accuracy of the PP viscometer. Measurements on three samples match the certified values with a root-mean-square-deviation of $0.12 \log$ units, with all measurements falling slightly below the official values. The offered TVF equation has a stated accuracy of $+/-0.1 \log$ units.

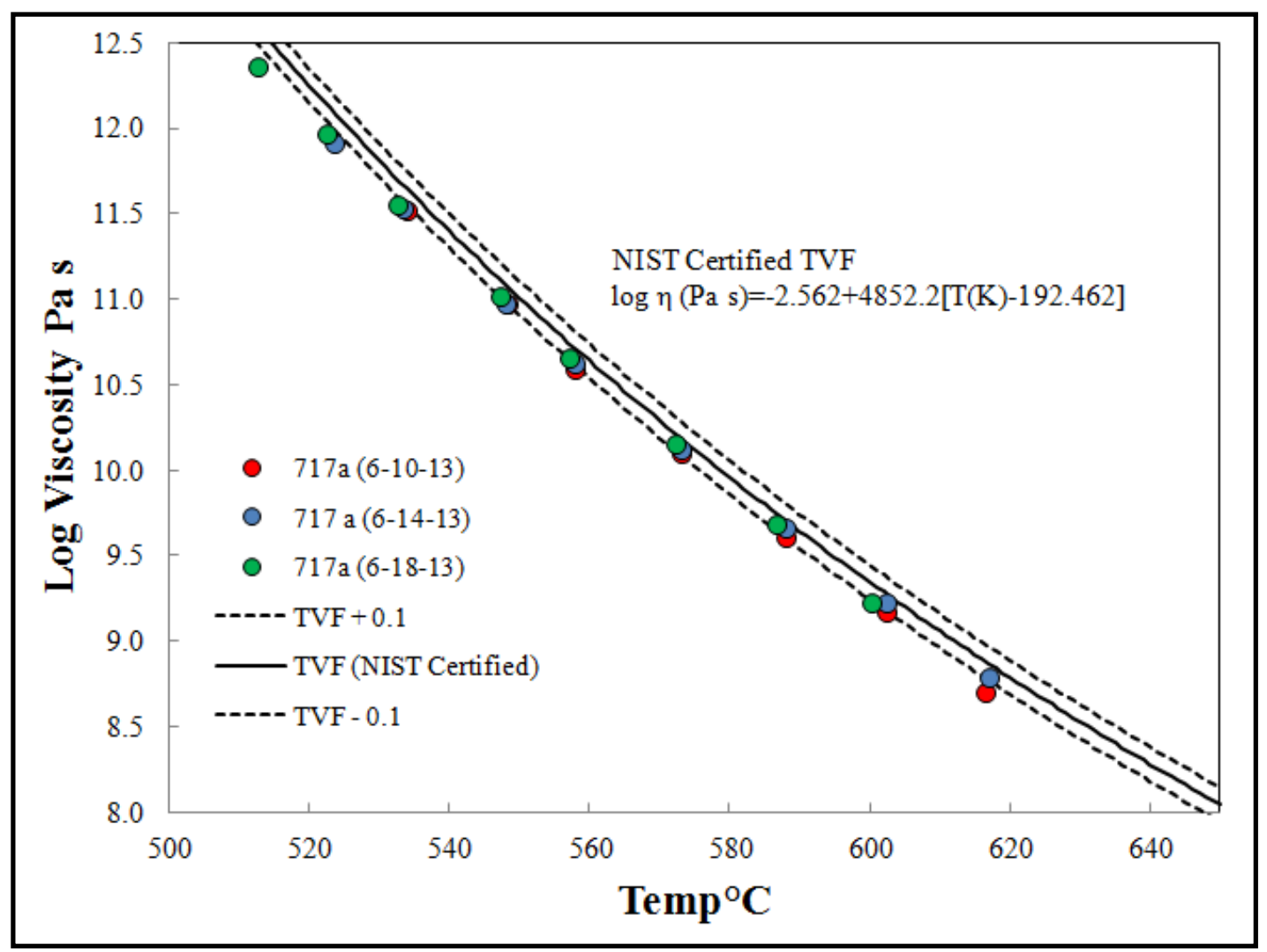

Figure 3.3. NIST standard 717a results for 3 experiments.

A Theta Industries Rheotronic II 1600C Rotating Viscometer, with a Brookfield HBDV-III Ultra measuring head, was used to investigate super- and sub-liquidus 
rheology at viscosities between 0.4 and $10^{3} \mathrm{~Pa} \mathrm{~s}$ at temperatures between $<1200^{\circ} \mathrm{C}$ to $\sim 1600^{\circ} \mathrm{C}$. Figure 3.4 shows the set up and a basic schematic of the concentric cylinder (CC) viscometer. Approximately $100 \mathrm{~g}$ of samples is placed into a cylindrical $\mathrm{Pt}_{90} \mathrm{Rh}_{10}$ crucible and is this lowered into the furnace being held stationary by three alumina rods. The furnace is then slowly heated at $20^{\circ} \mathrm{C} / \mathrm{min}$ to approximately $1350^{\circ} \mathrm{C}$. At $1350^{\circ} \mathrm{C}$ the sample is completely molten and the stirring rod begins rotating at 30rpm before being lowered approximately $2 \mathrm{~cm}$ into the melt. This value is precisely determined using the micrometer attached to the measuring head. The stirring rod is made of alumina and is fitted with a Pt-Rh sleeve to eliminate any alumina contamination of the melt. It is imperative that the rod remains in the center and greater than $1 \mathrm{~cm}$ from the bottom to avoid any edge effects with the crucible walls. After ensuring that the rod remains stable in the center, we can then begin acquiring viscosity data. A motor which is calibrated with a spring within the measuring head rotates the stirring rod. The melt exerts a viscous drag on the rod as it spins, and the measuring head records the torque needed to achieve a particular angular velocity, which can be varied between 0.1 to $250 \mathrm{rpm}$. The measuring head records data throughout the experiment at time intervals determined by the user. This data can then be used to calculate stress $(\sigma)$ and shear strain rate $\left(d \gamma / d_{t}\right)$ using the following relationships

$$
\begin{gathered}
\sigma=\frac{\tau}{\left(2 \pi R_{b}^{2} L\right)} \\
d_{\gamma} / d_{t}=\frac{2 \omega R_{c}^{2}}{\left(R_{c}^{2}-R_{b}^{2}\right)}
\end{gathered}
$$


Where $\tau$ is the torque applied by the measuring head, $\omega$ is the angular velocity, $L$ is the length of the stirring rod immersed into the melt, $R_{b}$ is the radius of the stirring rod, and $\mathrm{R}_{\mathrm{c}}$ is the inner diameter of the crucible. Viscosity $(\eta)$ can then be calculated by

$$
\eta(\operatorname{Pas})=\frac{\sigma}{d_{\gamma} / d_{t}}
$$

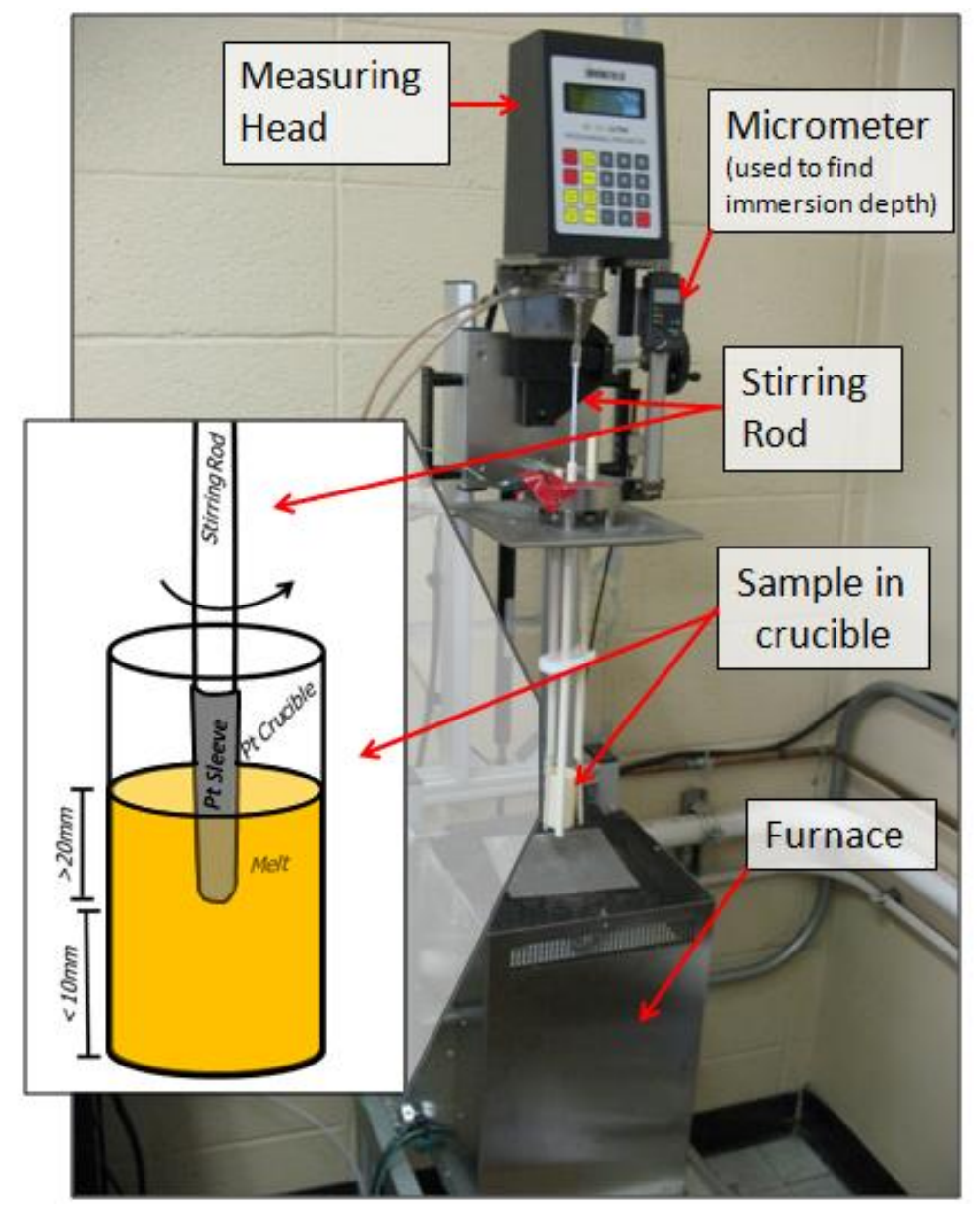

Figure 3.4. CC viscometer set up and detailed schematic.

The $\mathrm{CC}$ viscometer is calibrated with a Brookfield standard oil of known viscosity (12240 $\mathrm{mPa} \mathrm{s})$ at room temperature. When the viscometer was then used to measure the 
oil as an unknown, it recovered the certified values within $0.001 \log$ units. Getson and Whittington (2007) also checked the accuracy of the viscometer by measuring NIST certified soda-lime silicate glass 717a. Their experiments recovered values within 0.012 $\log$ units for $717 \mathrm{a}$ at temperatures between $850-1500^{\circ} \mathrm{C}$. The uncertainties of all test experiments are within the values listed in the NIST standard certificate as +/- $0.1 \log$ units.

Viscosity is not typically measured between the viscosity temperature ranges accessible to the CC and PP viscometers as crystallization occurs in this subliquidus region. This region is however of great importance, as natural magmas spend most of their history at subliquidus temperatures.

\subsection{Liquid Viscosity}

To understand the rheology of the erupted materials, we must first understand the rheology of the liquid, free of both crystals and bubbles. At least $200 \mathrm{~g}$ of homogenous and crystal free remelt were needed to begin these rheology experiments. Sample PA09 (from the toe of the SE Flow) was chosen as it well represents the bulk rock chemistry of all erupted samples (Figure 2.18) and it was a voluminous sample.

PA09 was remelted in a $\mathrm{Pt}_{90} \mathrm{Rh}_{10}$ crucible in two separate batches for approximately $2 \mathrm{hrs}$ each at $1500^{\circ} \mathrm{C}$ using an MHI Z18-40 box furnace. Each batch was then quenched into a glass by pouring onto a copper plate. After cooling, the glasses from each batch were first broken into pieces and then mixed together. The broken pieces were then placed into a Fe ring and puck mill Shatterbox and were pulverized for 
approximately 60-90 seconds. The powder was then removed from the Shatterbox and placed back into the crucible and remelted for another hour at $1500^{\circ} \mathrm{C}$. The process was repeated once more to ensure chemical homogeneity between the two melt batches. This was verified by analyzing samples from each batch using the electron microprobe at WUSTL, which show identical values with analytical uncertainty (Table A-3 in appendix).

One core was drilled from each of the melt batches (G1-B1 and G1-B2) and was used to conduct the first experiments using the PP viscometer. The experimental design was identical for each sample. Each experiment began with gradually heating the sample up from room temperature at $20^{\circ} \mathrm{C} / \mathrm{min}$ to approximately $720^{\circ} \mathrm{C}$. The sample would then dwell at this temperature until at least 10 um of deformation occurred past the initial $\sim 100$ um of deformation needed to account for the existence of any wedge due to nonparallel form. For any given temperature segment, at least $10 \mu \mathrm{m}$ of deformation is preferred to obtain a precise viscosity measurement, although at highest viscosities measured at least $5 \mu \mathrm{m}$ is acceptable. Temperature is then decreased in $20^{\circ} \mathrm{C}$ increments allowing for deformation at each increment. The lowest temperature measured was approximately $660^{\circ} \mathrm{C}$, corresponding to a viscosity of $10^{11.7} \mathrm{~Pa}$ s. Following measurement at the lowest temperature, repeat measurements were made at the same set of temperatures. These repeat measurements are made to determine if the sample underwent partial crystallization during the experiment, which would cause an increase in viscosity over time. 
The data from G1-B1 and G1-B2 are plotted against inverse temperature in Figure 3.5 and the quantitative results are provided in Table 3.1 in order of measurement. Both G1-B1 and G1-B2 share nearly identical viscosity values. The increase in viscosity between the first and second measurements may indicate that minor crystallization likely occurred during the measurement. After the experiment the samples were investigated at high magnification (>1000X JEOL) using back scatter electron imaging and did not reveal any perceptible micro-crystals. Any crystallization that occurred must therefore be on the submicron scale.

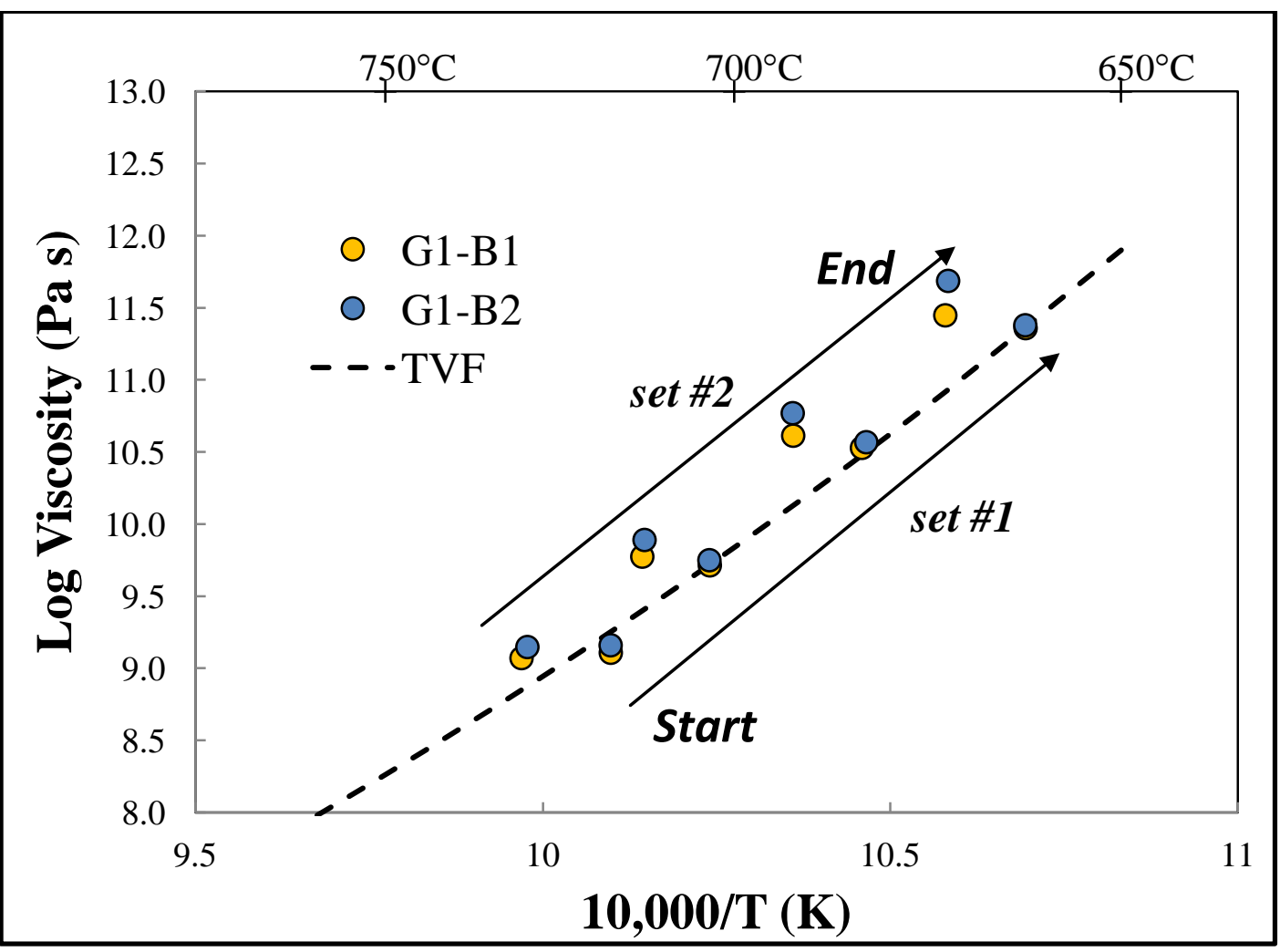

Figure 3.5. Low temperature remelt viscosity values measured with PP viscometer. 
Table 3.1. PP liquid viscosity data. Data provided in order of measurement.

\begin{tabular}{c|c|c|c}
\hline \multicolumn{2}{c|}{ G1-B1 } & \multicolumn{2}{c}{ G1-B2 } \\
\hline $\begin{array}{c}\text { Temp } \\
{ }^{\circ} \mathbf{C}\end{array}$ & $\begin{array}{c}\text { Log Visc } \\
\text { Pa s }\end{array}$ & $\begin{array}{c}\text { Temp } \\
{ }^{\circ} \mathbf{C}\end{array}$ & $\begin{array}{c}\text { Log Visc } \\
\text { Pa s }\end{array}$ \\
\hline 717 & 9.11 & 717 & 9.16 \\
703 & 9.71 & 703 & 9.75 \\
683 & 10.53 & 682 & 10.57 \\
662 & 11.36 & 662 & 11.38 \\
730 & 9.07 & 729 & 9.15 \\
713 & 9.77 & 712 & 9.89 \\
692 & 10.61 & 692 & 10.77 \\
672 & 11.45 & 672 & 11.69 \\
\hline
\end{tabular}

Superliquidus viscosity was then measured on the remelted material using the $\mathrm{CC}$ viscometer. The experiment starts as described in the methods section. After the stirring rod is lowered into the melt, temperature is increased at $20^{\circ} \mathrm{C} / \mathrm{min}$ to approximately $1600^{\circ} \mathrm{C}$, which is the maximum temperature used in the experiment. The rotation rate of the rod is increased to $250 \mathrm{rpm}$ and the sample is held at this temperature and rpm until stable torque readings are observed. This step is repeated at both $240 \mathrm{rpm}$ and $230 \mathrm{rpm}$. This is done to ensure that calculated viscosity values are independent of strain rate, which should be the case for Newtonian fluids such as silicate melts. If no significant variation exists between the values calculated with each rpm, they are simply averaged. Following the measurement at $1600^{\circ} \mathrm{C}$ the temperature is then decreased by $25^{\circ} \mathrm{C}$ and measurements are made at three rpm values once more. This is repeated every $25^{\circ} \mathrm{C}$ and the rpm used are gradually decreased to account for increasing viscosity with decreasing temperature. 
Superliquidus viscosity data are given in Table 3.2 and are plotted on an Arrhenian diagram in Figure 3.6. At approximately $1240^{\circ} \mathrm{C}$ torque only remains stable for approximately 20 minutes during the experiment before gradually increasing. This is due to crystallization occurring as the liquidus was crossed somewhere between 1260 and $1240^{\circ} \mathrm{C}$. Following the lowest temperature measurements, the temperature is then increased to approximately $1500^{\circ} \mathrm{C}$ where measurements are made following the same steps as before to check for instrument drift. Nearly identical viscosity values were measured.

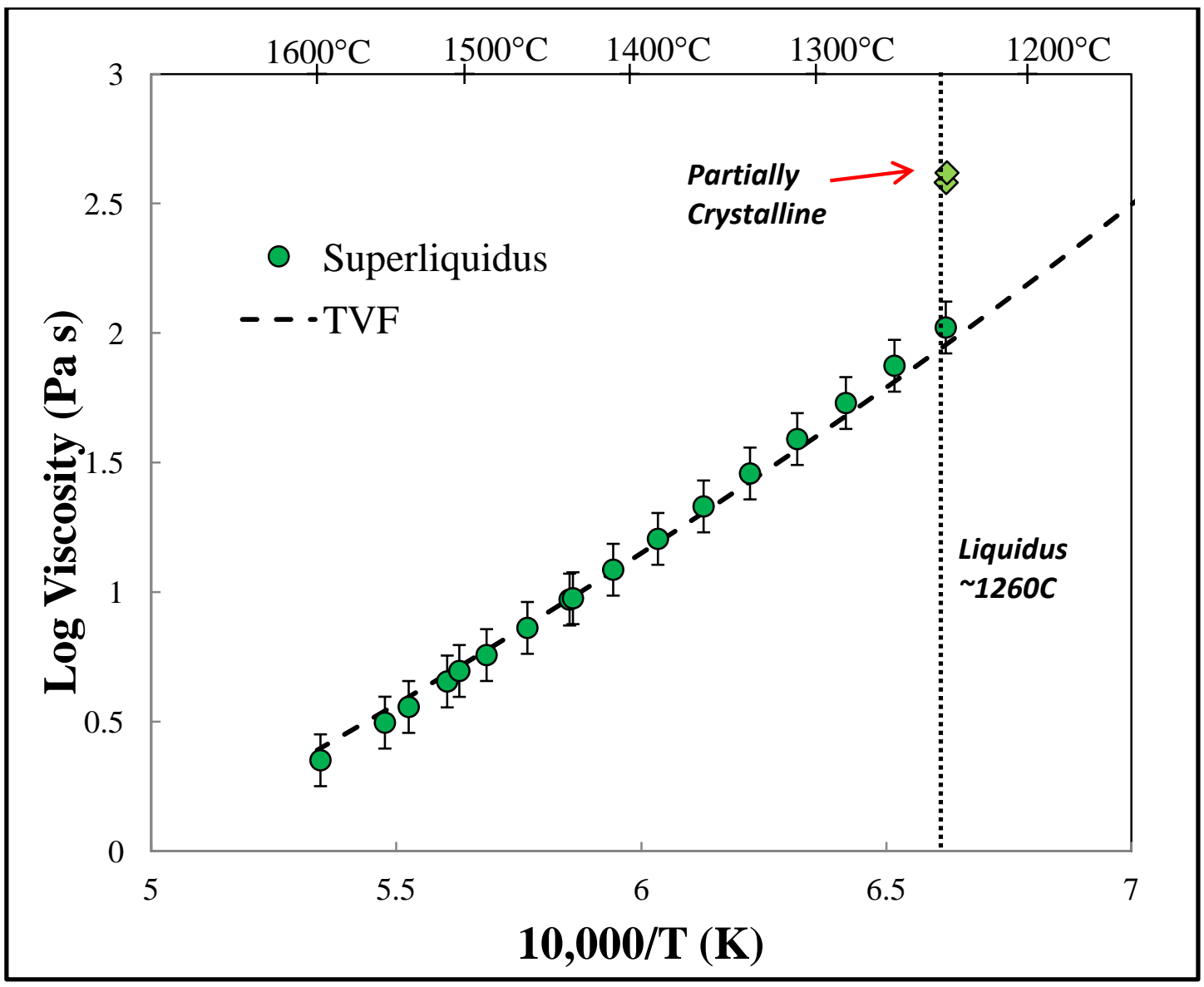

Figure 3.6. High temperature remelt viscosity values measured with $\mathrm{CC}$ viscometer. 
Table 3.2. CC liquid viscosity data. Each row represents averaged values at each temperature segment. Data is provided in order of measurement.

\begin{tabular}{c|c|c|c|c|c|c}
\hline $\begin{array}{c}\text { Temp } \\
{ }^{\circ} \mathbf{C}\end{array}$ & rpm & $\begin{array}{c}\text { Torque \% } \\
\text { Dyne cm }\end{array}$ & $\begin{array}{c}\text { Torque \% } \\
\mathbf{N ~ m}\end{array}$ & $\begin{array}{c}\text { Stress } \\
\text { Pa }\end{array}$ & $\begin{array}{c}\text { Strain } \\
\text { rate }\left(\mathbf{s}^{-1}\right)\end{array}$ & $\begin{array}{c}\text { Log Visc } \\
\text { Pa s }\end{array}$ \\
\hline 1597 & 245 & 3.95 & $2.3 \times 10^{-4}$ & 116.74 & 52.05 & 0.35 \\
1553 & 250 & 5.63 & $3.2 \times 10^{-4}$ & 166.39 & 53.11 & 0.50 \\
1537 & 240 & 6.21 & $3.6 \times 10^{-4}$ & 183.62 & 50.99 & 0.56 \\
1511 & 240 & 7.79 & $4.5 \times 10^{-4}$ & 230.27 & 50.99 & 0.65 \\
1486 & 230 & 9.43 & $5.4 \times 10^{-4}$ & 279.05 & 48.86 & 0.76 \\
1461 & 230 & 12.01 & $6.9 \times 10^{-4}$ & 355.29 & 48.86 & 0.86 \\
1435 & 230 & 15.45 & $8.9 \times 10^{-4}$ & 457.06 & 48.86 & 0.97 \\
1409 & 220 & 19.27 & $1.1 \times 10^{-3}$ & 569.90 & 46.74 & 1.09 \\
1384 & 220 & 25.34 & $1.5 \times 10^{-3}$ & 749.58 & 46.74 & 1.21 \\
1359 & 210 & 32.29 & $1.9 \times 10^{-3}$ & 954.94 & 44.61 & 1.33 \\
1334 & 210 & 43.26 & $2.5 \times 10^{-3}$ & 1279.63 & 44.61 & 1.46 \\
1309 & 200 & 55.95 & $3.2 \times 10^{-3}$ & 1654.77 & 42.49 & 1.59 \\
1285 & 190 & 73.22 & $4.2 \times 10^{-3}$ & 2165.85 & 40.37 & 1.73 \\
1261 & 165 & 88.58 & $5.1 \times 10^{-3}$ & 2620.11 & 35.05 & 1.87 \\
1237 & 119 & 90.07 & $5.2 \times 10^{-3}$ & 2664.20 & 25.38 & 2.02 \\
1503 & 220 & 7.83 & $4.5 \times 10^{-4}$ & 231.59 & 46.70 & 0.70 \\
\hline
\end{tabular}

The results from both the high and low temperature experiments are combined in Figure 3.7. To interpret the liquid viscosity values within the liquidus range that is not measured, the data were fitted to a Tammann-Vogel-Fulcher equation of the form

$$
\log \eta=A+B /(T-C)
$$

where $T$ is temperature in $\mathrm{K}$ and $A, B$, and $C$ are adjustable parameters (Vogel 1921). The parameters used were determined using the solver function in Excel $^{\circledR}$ to minimize the root-mean-square-deviation along the line connecting the points to zero. 
Figure 3.6 also shows viscosity calculated using the model of Giordano et al. 2008 which slightly underestimates viscosity at high temperatures, and slightly overestimates viscosity at low temperatures, confirming the need to measure samples.

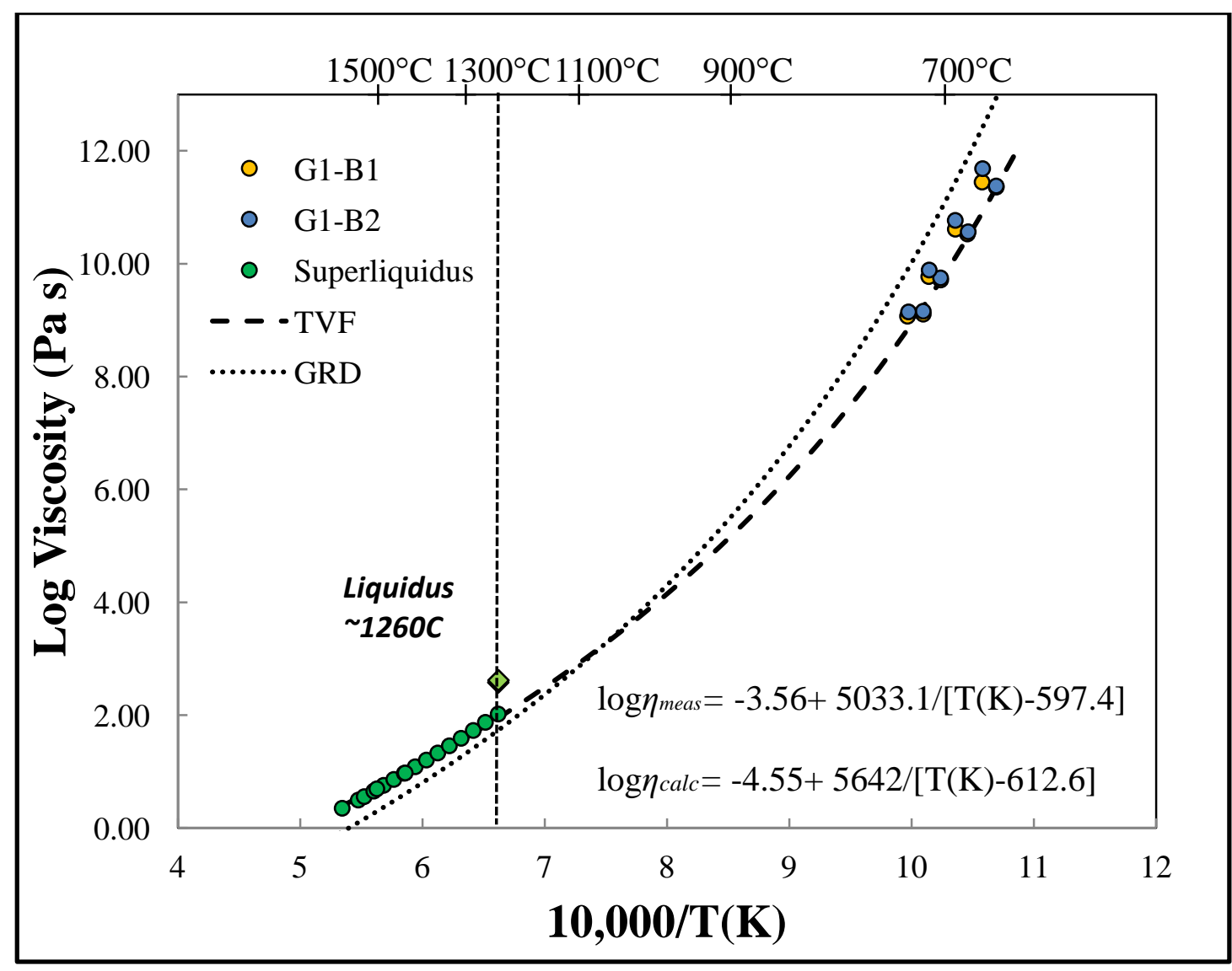

Figure 3.7. All remelt viscosity and the calculated TVF line and parameter values

\subsection{Magma Viscosity at Subliquidus Conditions}

Subliquidus experiments were conducted using both the PP and CC viscometers. The PP viscometer was used first to measure the viscosity of the naturally crystalline lava samples at high temperatures near $1000^{\circ} \mathrm{C}$. The $\mathrm{CC}$ viscometer was then used to measure viscosity at various temperatures near the liquidus $\left(\sim 1200-1260^{\circ} \mathrm{C}\right)$ and relatively high 
strain rates $\left(0.2-5.1 \mathrm{~s}^{-1}\right)$. Variations in dwell time and temperature used produced samples with six different crystal fractions, and strain rate was varied during the experiment to determine if there is any strain rate dependence on viscosity within the partially crystalline samples. Cores from each of these experiments were then measured using the PP viscometer to obtain the viscosity of samples with the same crystal fraction at lower

temperatures $\left(\sim 700-1000^{\circ} \mathrm{C}\right)$ and strain rates $\left(4.8 \times 10^{-8}-5.8 \times 10^{-5} \mathrm{~s}^{-1}\right)$. Finally, the parallel plate viscometer was used to partially crystallize 5 samples by approaching the liquidus from below and allowing initially glassy samples to sit at $\sim 950^{\circ} \mathrm{C}$ at dwell times between 0-120min in the furnace before measurement. The results and further details for each set of experiments will now be provided.

\subsubsection{Viscosity of the Natural Samples}

The first step in measuring magma viscosity was to measure the naturally crystalline samples using the PP viscometer. Only five cores were used in the experiments (two flow samples, PA26 and two cores of PA09, and two bomb samples, PA16 and PA18). Each core was polished to have parallel faces before measurement following the same procedures for previous PP experiments. A typical experiment consisted of a beginning stage of heating at $20^{\circ} \mathrm{C} / \mathrm{min}$ until the desired temperature was reached. All samples remained effectively rigid during the heating process until the maximum temperature was approached. Samples would typically undergo only $30-40 \mu \mathrm{m}$ of thermal expansion during the heating process. The experiments were then held isothermally between $40-90 \mathrm{hrs}$ at the maximum temperature of the PP viscometer $\left(\sim 1000^{\circ} \mathrm{C}\right)$. 
The furnace thermocouple showed relatively constant values of $1000^{\circ} \mathrm{C}$ during measurement; however the sample thermocouple consistently measured $\sim 30^{\circ} \mathrm{C}$ less than furnace values. It was later determined that the thermocouple being used was not calibrated for accurate temperature readings greater than $980^{\circ} \mathrm{C}$. We then used a thicker gauge thermocouple, which maintained accuracy to $1080^{\circ} \mathrm{C}$, to measure values within the sample chamber to $1000^{\circ} \mathrm{C}+/-10^{\circ} \mathrm{C}$. Considering the initial uncertainty with the temperature readings, we can assume based on the reading from the new thermocouple, that temperatures during the previous experiments were likely within $+/-10^{\circ} \mathrm{C}$ of $1000^{\circ} \mathrm{C}$.

In an ideal experiment the sample would deform at least $100 \mu \mathrm{m}$ before measuring viscosity to ensure that faces were perfectly parallel (length variations were always measured less than $100 \mu \mathrm{m})$. Following the initial $100 \mu \mathrm{m}$ displacement we would then begin calculating viscosity after every 1 um of deformation, essentially calculating a rolling viscosity for the length of the experiment at maximum temperature. Our samples proved to be too viscous to execute the experiments as originally planned. None of the samples deformed $100 \mu \mathrm{m}$. We still calculated viscosity points for the duration of the experiment, but starting after just $30-40 \mu \mathrm{m}$ of deformation. Total shortening in the experiments generally did not exceed $60 \mu \mathrm{m}$ total, which is only slightly larger than thermal expansion from room temperature to $\sim 1000^{\circ} \mathrm{C}$.

Calculated viscosity values are plotted vs. time (s) in Figure 3.8. We see within all samples an initial steep increase in viscosity over time, with viscosity increasing to a relatively steady state around $10^{13} \mathrm{~Pa}$ for the remainder of the experiment. Deformation 
could be the result of compacting bubbles or fracture compaction. Similar experiments were conducted on lava samples from Fuego Volcano, Guatemala by senior thesis student Thäis Magaldi (Whittington et al. 2013). The initial deformation within those experiments is also attributed to fracture and bubble displacement. After $\sim 72$ hours, maximum shortening did exceed $100 \mu \mathrm{m}$, after which viscosity reached a similar steady state value around $10^{13} \mathrm{~Pa}$ s. Based on the results from the cores samples we conclude that the lavas at Pacaya would be effectively rigid at temperatures greater than $1000^{\circ} \mathrm{C}$.

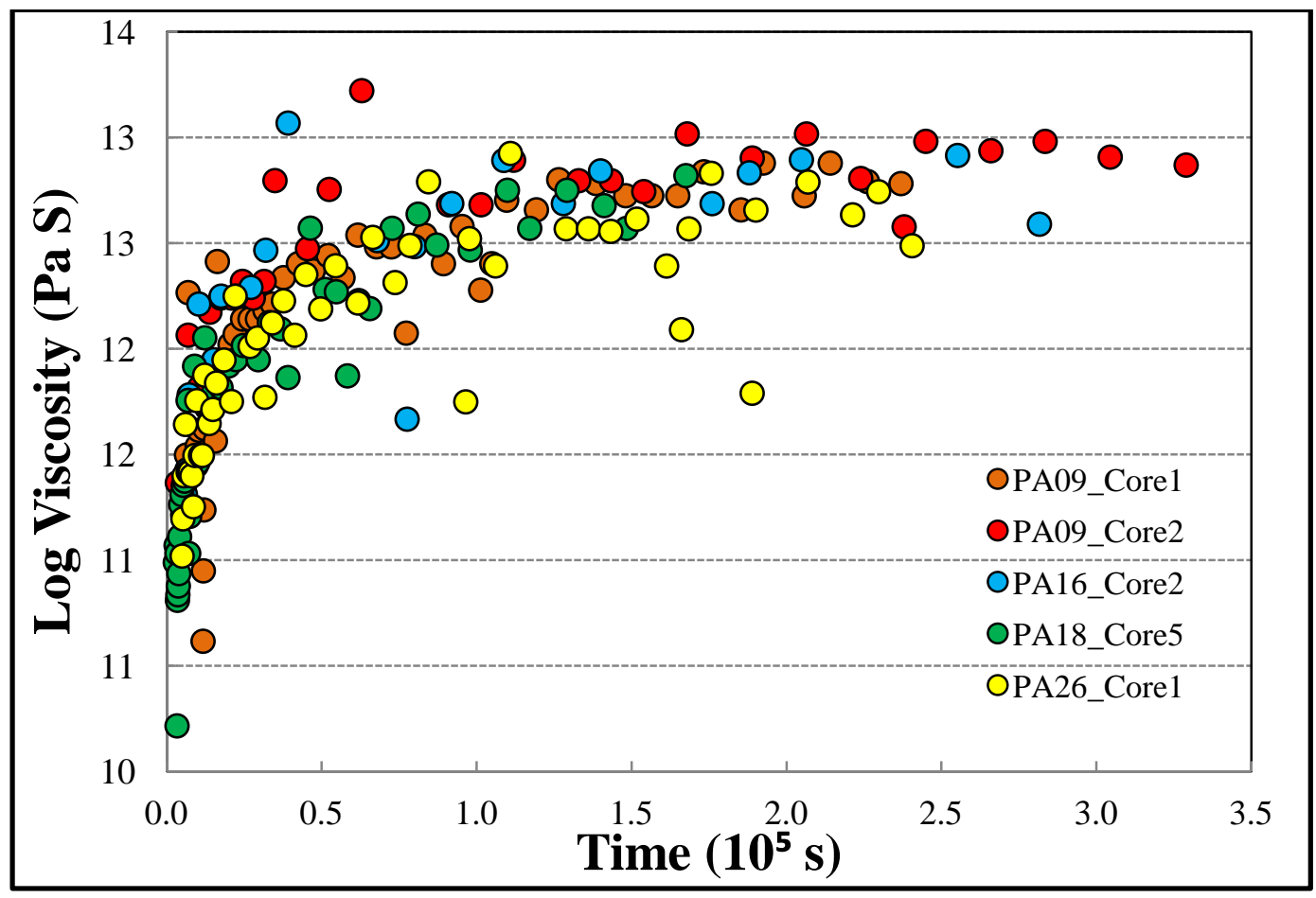

Figure 3.8. Isothermal viscosities of the natural samples at $\sim 1000^{\circ} \mathrm{C}$ using the $\mathrm{PP}$ viscometer.

\subsubsection{High Temperature Magma Viscosity of the Partially Crystalline Remelts}

The CC viscometer was used to measure the apparent viscosity of partially crystallized samples at fixed temperatures between $1207-1255^{\circ} \mathrm{C}$. The PA09 remelt was 
used in 6 experiments, each with different subliquidus target temperatures within this range. The experimental procedure was similar to that of Vona et al. (2011). Each experiment started similarly to the liquid viscosity CC measurements, with temperature initially being ramped up to approximately $1350^{\circ} \mathrm{C}$, followed by locating the top of the melt and then lowering the rotor into the melt. Following this step, each experiment would spent $2-3$ hours measuring superliquidus viscosity at $1500-1550^{\circ} \mathrm{C}$ until torque values remained constant and calculated viscosity values match those previously calculated to within $0.04 \log$ units. Following the attainment of stable readings, temperature was decreased at $20^{\circ} \mathrm{C} /$ minute until the target temperature for each experiment was reached. The sample was then held at the target temperature for up to 30 hrs with the spindle rotating at $30 \mathrm{rpm}$ (or as close to $30 \mathrm{rpm}$ as the program would allow). Two experiments ended prematurely, one due to maximum torque being exceeded, and the other to test the effects of dwell time on resulting crystal fraction.

Results are shown in Figure 3.9. All experiments showed a small viscosity increase over the first 30-60 minutes due to thermal equilibration, followed by a period of constant viscosity. This ranged between 30min to nearly 14 hours depending on the temperature of the experiment. This period was always followed by an abrupt increase as crystallization began. Viscosity in the lowest temperature experiment $\left(1207^{\circ} \mathrm{C}\right)$ never stabilized, increasing dramatically as a result of crystallization, which resulted in the experiment ending prematurely. Experiments at the next three dwell temperatures (1226, 1234 , and $1236^{\circ} \mathrm{C}$ ), did however show somewhat stable viscosity readings over the duration held at $30 \mathrm{rpm}$. The experiment held at $1234^{\circ} \mathrm{C}$ was ended early for comparison 
with the experiment held at essentially the same temperature $\left(1236^{\circ} \mathrm{C}\right)$ to determine if dwell time affected the amount of crystallization. The $1241^{\circ} \mathrm{C}$ experiment did show an initial stage of constant viscosity for approximately $14 \mathrm{hrs,} \mathrm{but} \mathrm{this} \mathrm{was} \mathrm{followed} \mathrm{by} \mathrm{a}$ later stage of steadily increasing viscosity with no second plateau attained. The $1255^{\circ} \mathrm{C}$ experiment essentially showed increasing viscosity for the entire length of the experiment. At the end of the experiment it was observed that melt had accumulated on the spindle, causing artificially high viscosity readings. This will be discussed in further detail in the following section.

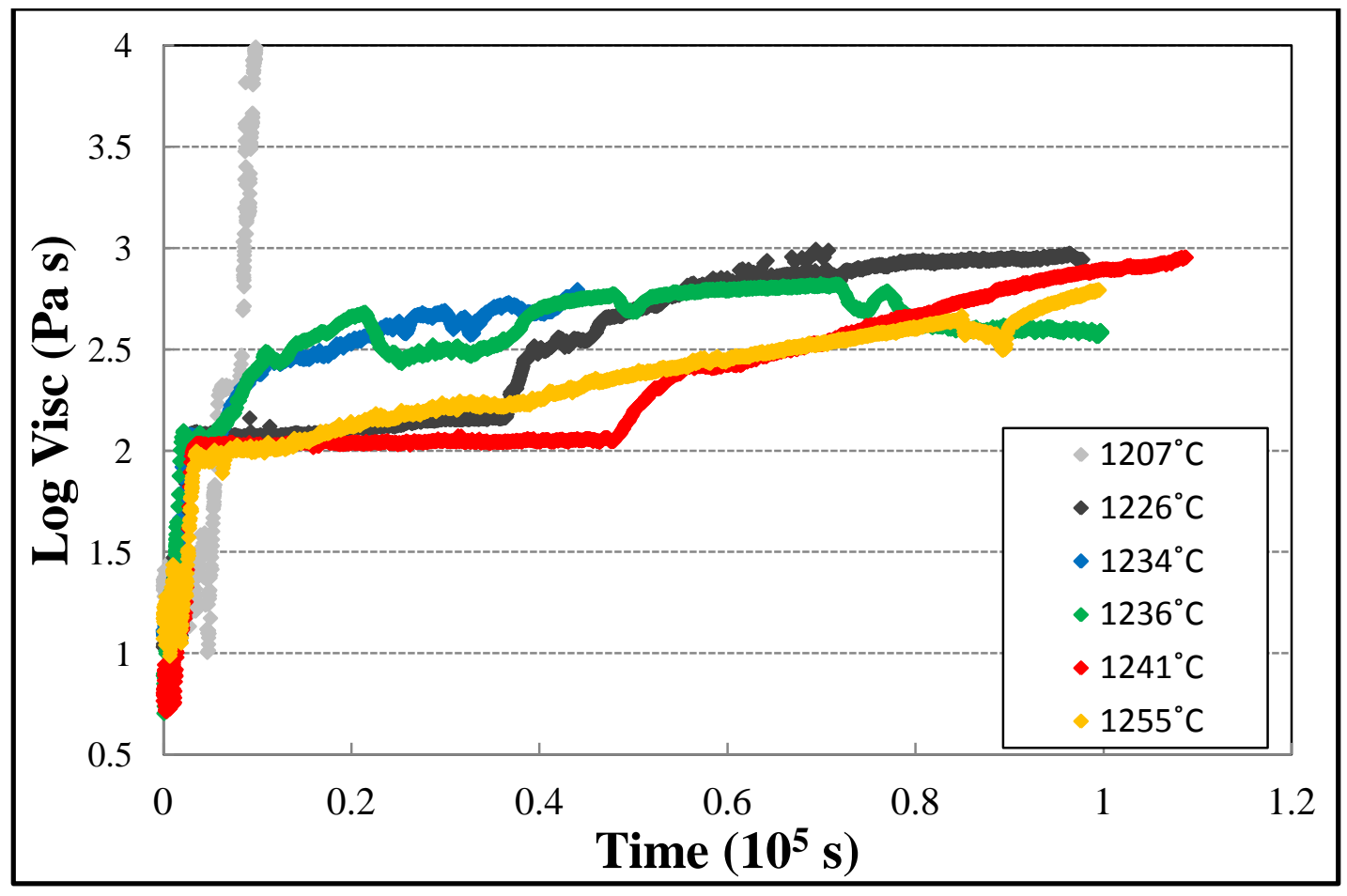

Figure 3.9. Calculated isothermal viscosity vs. time $\left(10^{5} \mathrm{~s}\right)$.

Following measurement at a constant $30 \mathrm{rpm}$, all experiments (except for $1207^{\circ} \mathrm{C}$ ) were subjected to varying rpm to determine the strain rate dependence of viscosity. The ideal experimental structure following measurement at $30 \mathrm{rpm}$ involved decreasing the 
rpm value to $20,10,5,3,2$, and 1 , with measurements being made for 10-15 minutes at each value until at least 5 minutes of stable torque readings were reached. Following measurement at the lowest rpm, the rpm was raised by the same increments, ending with a second measurement at $30 \mathrm{rpm}$. The program used to control the measuring head proved to have difficulty maintaining constant $\mathrm{rpm}$, and/or matching rpm values from previous measurements, so the ideal experimental program was not always achieved.

After measurements were made at, or near, $30 \mathrm{rpm}$ for the second time, the rotor was removed from the melt, then the crucible was removed from the furnace and quenched in water to essentially freeze in the crystal fraction and texture that was present during measurement. After the crucible and sample reached room temperature we drilled out the top $2 \mathrm{~cm}$ of the sample using the drill press and a diamond coated $\sim 2.5 \mathrm{~cm}$ diameter Starlite drill bit. $2 \mathrm{~cm}$ depth was used as this is the immersion depth of the spindle, and it is over this depth that viscosity was measured. A piece from the $\sim 2.5 \mathrm{~cm}$ core was polished and mounted to a slide using the same method as the natural samples for making microprobe sections. Cores were also drilled from the top $2 \mathrm{~cm}$ for use in PP experiments that will be described in section 3.5.3.

To begin another experiment, we would first need to remelt the sample to attain a crystal free glass, and potentially add more material to compensate for sample removed for imaging and PP viscosity experiments. The samples run for long durations $\left(1226^{\circ} \mathrm{C}\right.$, $1234^{\circ} \mathrm{C}, 1236^{\circ} \mathrm{C}, 1240^{\circ} \mathrm{C}$, and less so $1255^{\circ} \mathrm{C}$ ) became more oxidized throughout the experiment. Upon remelting at higher temperatures, the samples became more reduced. Starting around $1400^{\circ} \mathrm{C}$ the melt typically begins to release oxygen, causing bubbling, 
and on at least one occasion melt actually overflowed the crucible. To overcome this, we would need to remelt the samples in the box furnace by heating slowly at approximately $10^{\circ} \mathrm{C}$ every 20 minutes. Intermittently the melt was removed from the furnace and stirred by rotation of the crucible to release any oxygen bubbles that may have formed, and to check that the melt level has not increased to the point of overflow. These steps were repeated for each temperature segment until a max temperature of $1500^{\circ} \mathrm{C}$ was reached and no oxygen bubbles remained. It would typically take $2-3 \mathrm{hrs}$ to reach this point, after which our sample was ready for use in further $\mathrm{CC}$ subliquidus experiments.

The samples acquired after each experiment for use in microprobe analysis, were imaged with the Quanta at UMC. Four BSE images were acquired at 150X at different locations within each polished sample section to ensure that the determined crystal fractions would best represent that of the entire sample (Figures A-4 in the appendix). A single image from each set of four is provided in Figure 3.10. Crystal fractions were then calculated using the same method as the natural samples, except the Adobe Photoshop free hand tool was not needed as there was no need to differentiate between phenocrysts and microcrystals as all crystals were essentially in the same size range. We simply used the color select tool to highlight all phases of the same shade. We could then determine the relative proportions of each phase, including plagioclase, oxide, and glass within our samples. The calculated proportions of each phase are plotted against temperature in Figure 3.11. Figure 3.12 shows the results of calculated crystal proportions vs. temperature acquired using the MELTs software program (Ghiroso and Sack 1995). 


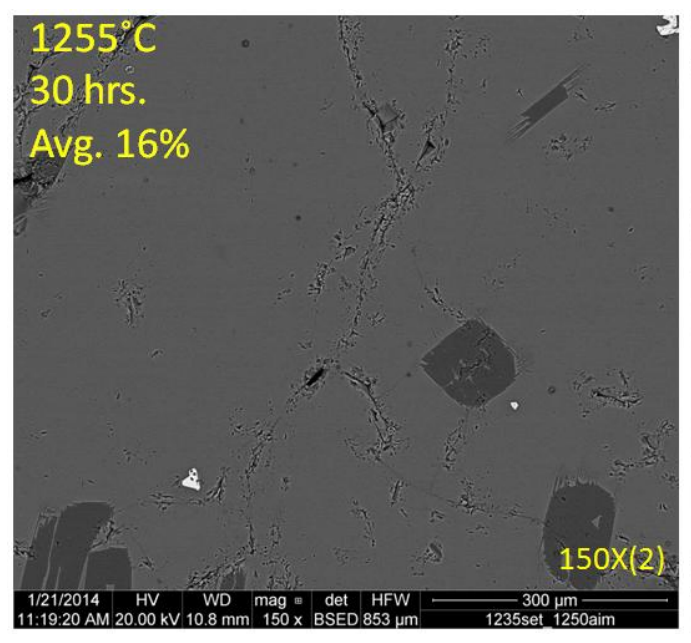

\section{$1241^{\circ} \mathrm{C}$ \\ 30 hrs.}

Avg. $26 \%$
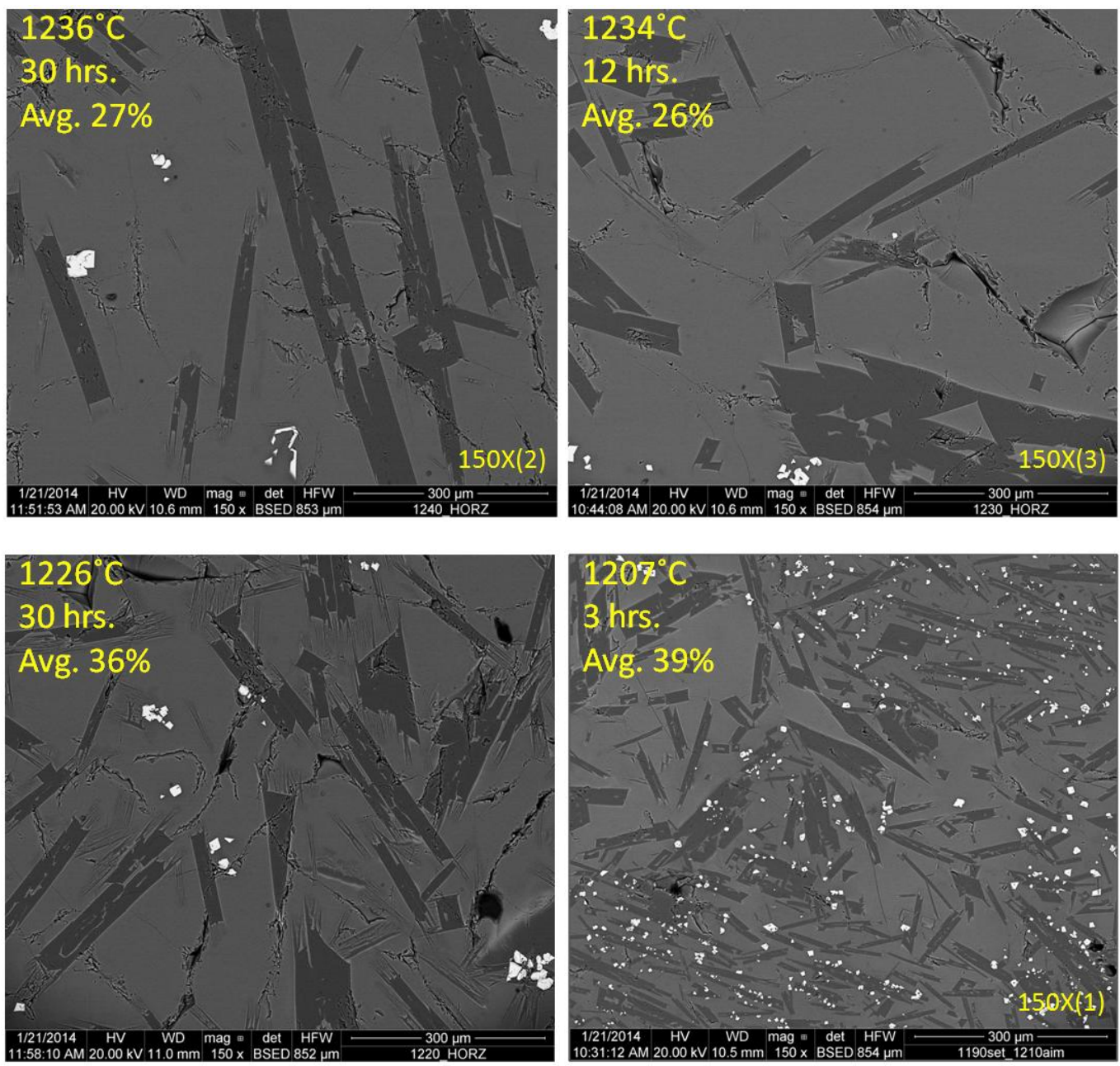

Figure 3.10. Low magnification BSE images of post CC experiments. Temperature, dwell time, and average crystal \% provided in each image. Additional images used for determining crystal \% provided in appendix. 


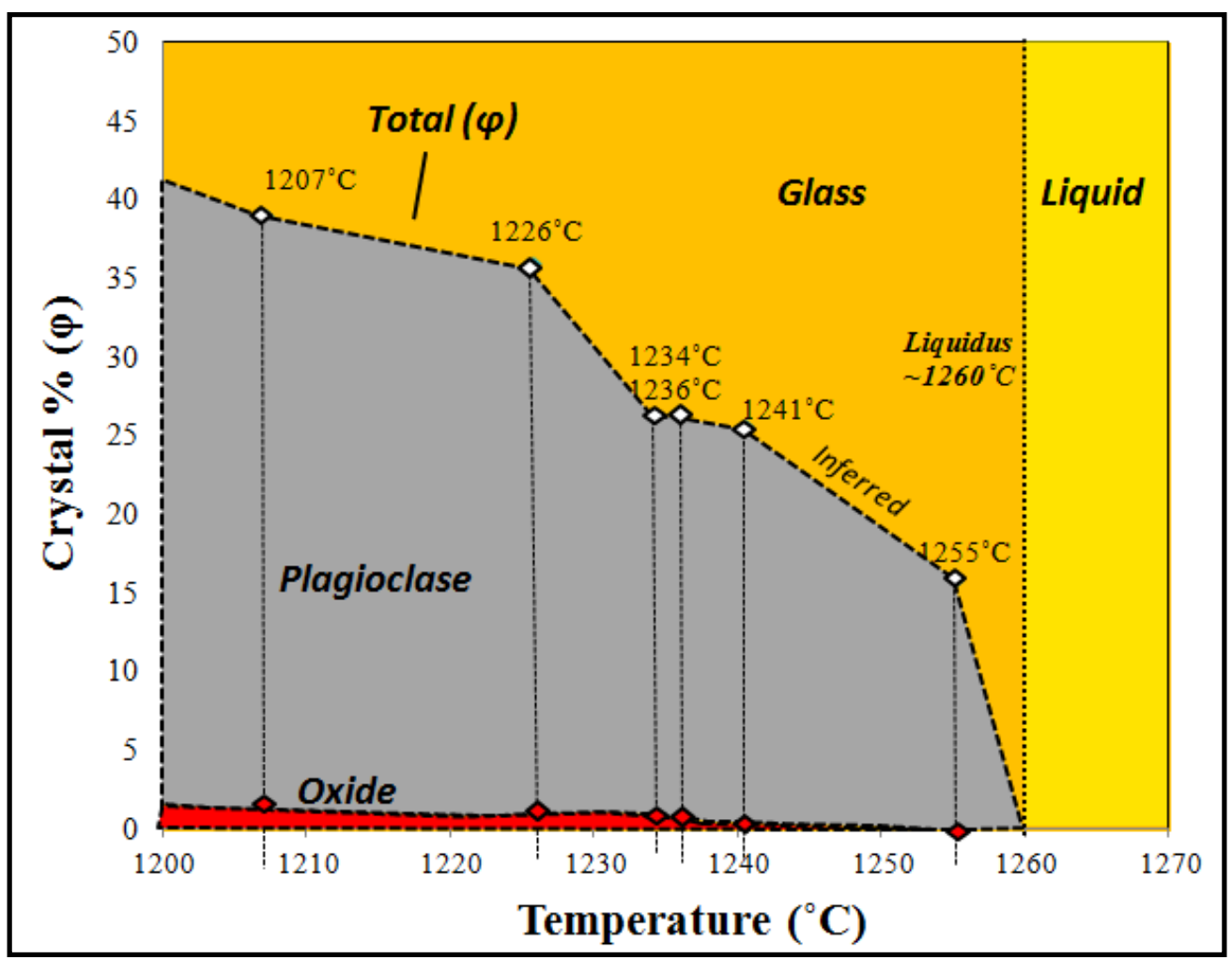

Figure 3.11. Crystal \% vs. Temperature for partially crystalline remelts.

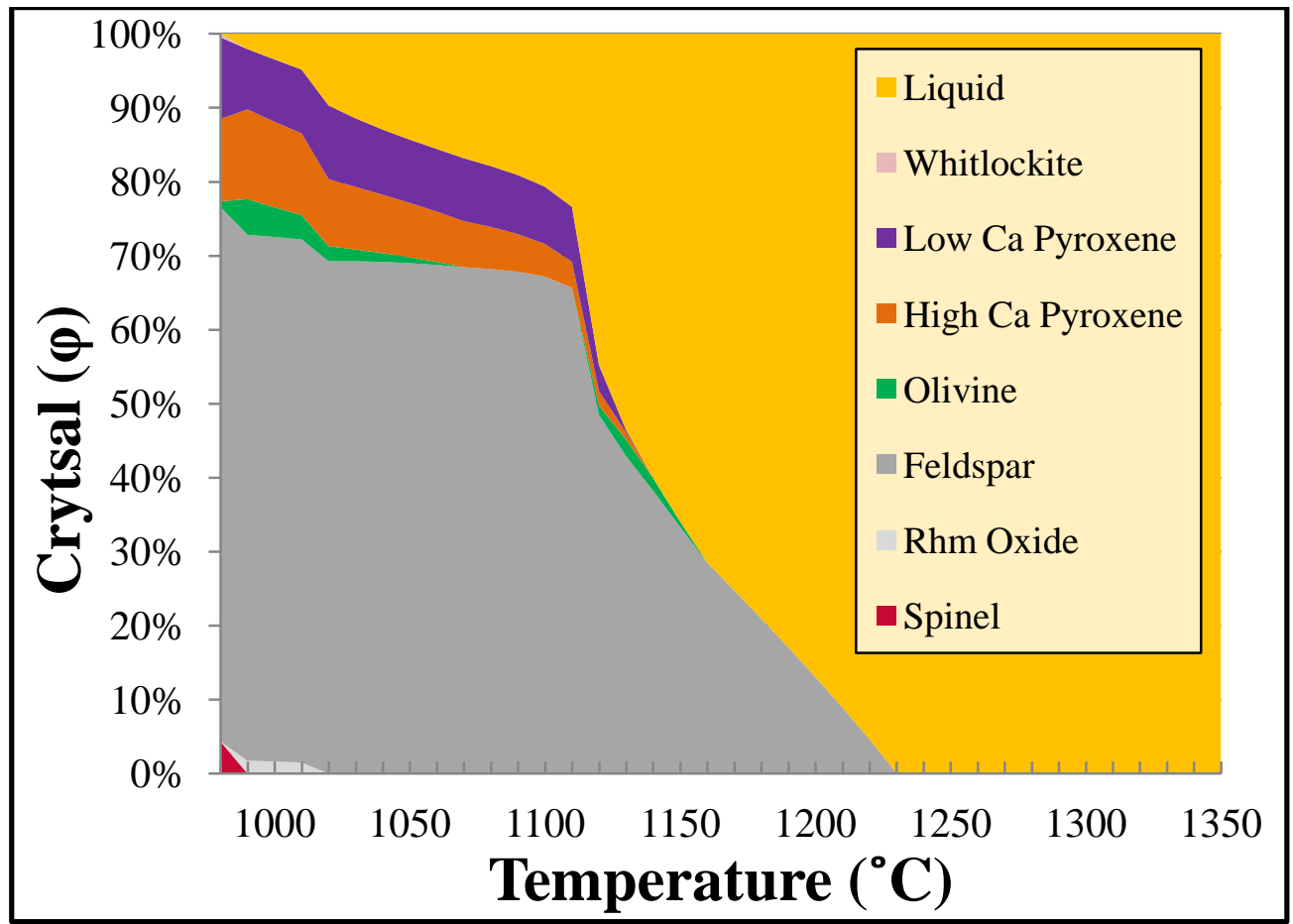

Figure 3.12. Crystal fraction vs. Temperature calculated using MELTs at QFM+1. Rhm oxide is Fe-Ti Oxide. 
The experiments successfully produced a range of crystal fractions from $~ 16-39 \%$ (Figure 3.11, Table 3.4). The minerals were dominantly plagioclase with less abundant $\mathrm{Fe}$ Oxide. The largest plagioclase minerals exceed $1 \mathrm{~mm}$ in length and rarely exceed 100um in width. Plagioclase crystals are commonly skeletal, and less commonly exhibit swallow tails, especially evident in $1226^{\circ} \mathrm{C}$ Figure 3.10 . Aspect ratios for the plagioclase crystals in each sample range from $\sim 4.1-10.1$ for the highest and lowest temperature experiments respectively. The oxide crystals generally range from 5-20um in size, however in the highest temperature experiments, where the oxides are less abundant, crystal size reaches $60 \mathrm{um}$. The oxide crystals have generally similar aspect ratios throughout all samples around 1.7. In general, the samples held at highest temperatures contain both the least, and the largest crystals, and samples at lower temperatures contain more abundant and smaller crystals. This is a result of crystal nucleation rates exceeding diffusion rates in the melt at low temperatures (Marsh 1998).

Most samples could be considered internally macroscopically homogenous with regards to crystal distribution, the exceptions being the highest and lowest temperatures used. The sample held at $1255^{\circ} \mathrm{C}$ is largely crystal free, with sparse large plagioclase crystals. The sample held at $1207^{\circ} \mathrm{C}$ is the most macroscopically heterogeneous of all the samples, with well defined areas of abundant plagioclase and Fe oxides, alternating with swathes of more glassy areas containing less abundant plagioclase and essentially no $\mathrm{Fe}$ oxides. An important observation to be made is that the experiments held at $1236^{\circ} \mathrm{C}$ and $1234^{\circ} \mathrm{C}$ exhibit nearly identical crystal percentages even considering that the dwell time for sample $1236^{\circ} \mathrm{C}$ was $30 \mathrm{hrs}$, more than twice that of $1234^{\circ} \mathrm{C}$. Although this is an 
isolated occurrence, and repeat experiments at different dwell times were not made, this suggests that crystal melt equilibrium can reached in less than 12 hours.
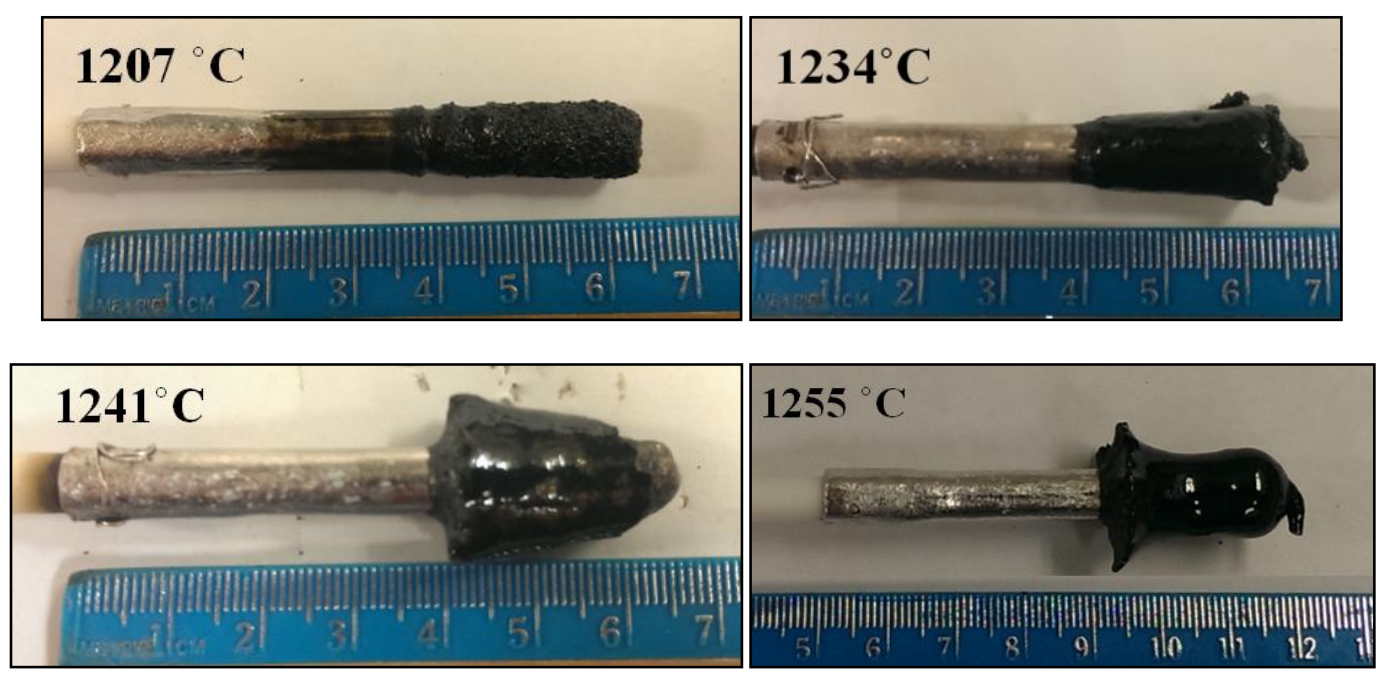

Figure 3.13. Melt accumulation on spindles, yielding artificially high stress values.

After removing the spindle from the melt we noticed variations in melt accumulation on the spindle, examples shown in Figure 3.13. Generally, the higher temperature of the experiment, the more melt accumulation on the spindle. As the radius of the spindle is used to calculate stress and strain rate by Equations 3.2, this substantially affects the calculated values. Especially the values calculated at the end of the experiment when strain rate was varied, and likely the duration where most accumulation was present. We then recalculated the viscosity based on the measured torque and rpm, but using the radius of the spindle plus the attached melt for $R_{b}$. The diameter of the spindle plus melt was measured several times and averaged to calculate the corrected $R_{b}$. The stress and strain rate data measured during the last portion of the experiments data are shown before and after correcting for spindle thickness in Figures 3.14 (A and B) along 
with the corresponding crystal \% values calculated from the BSE images in Figures 3.10 and Figures A-4 in the appendix.
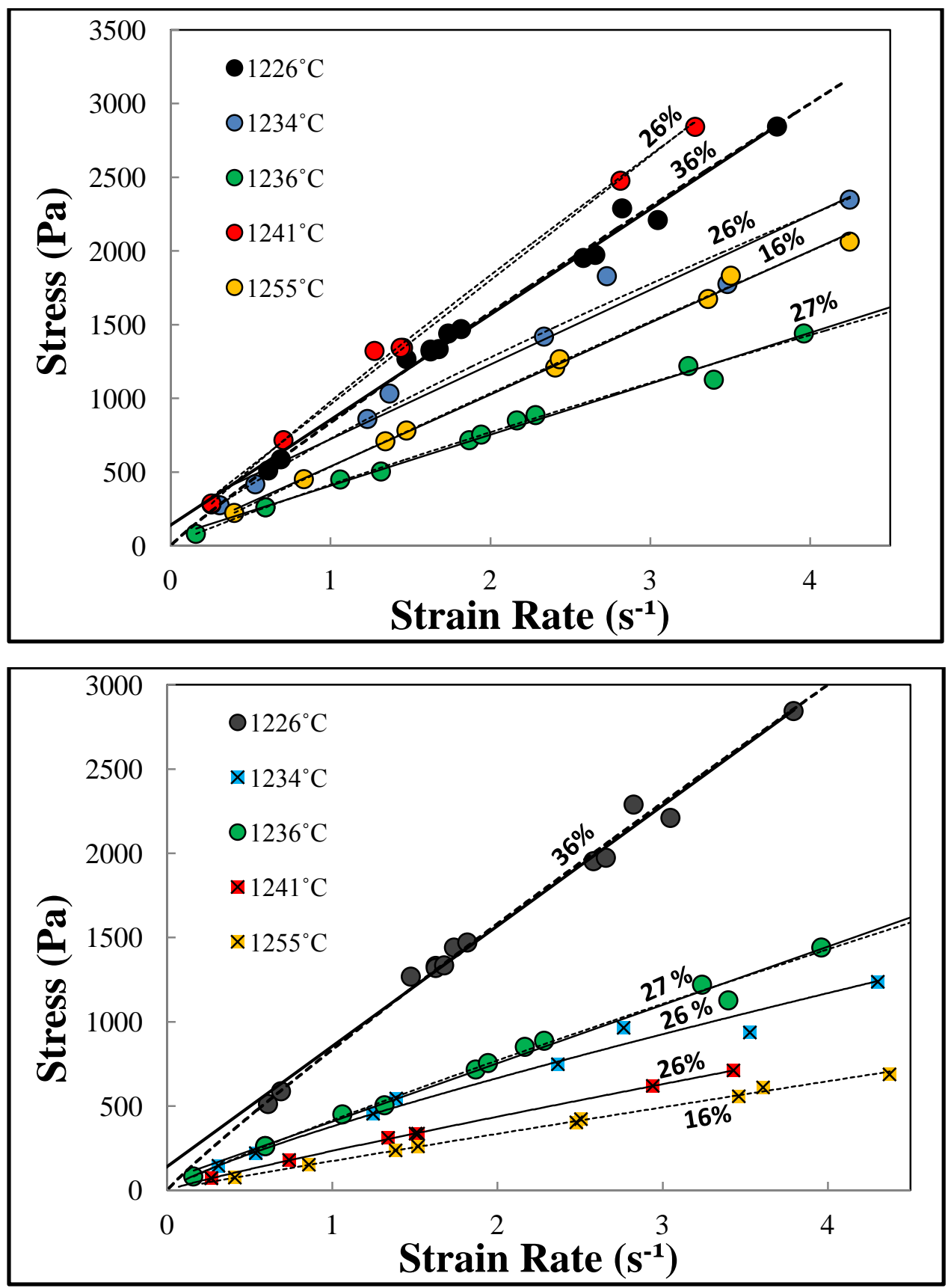

Figure 3.14. (A) Stress (Pa) plotted against Strain Rate $\left(\mathrm{s}^{-1}\right)$ using original spindle thickness. (B) Stress (Pa) plotted against Strain Rate $\left(\mathrm{s}^{-1}\right)$ " $\mathrm{x}$ " symbols represent values that were calculated using an increased spindle thickness due to melt accumulation. 
Figure 3.14 (A) shows the calculated stress and strain rate data using the actual radius of the spindle $(3.75 \mathrm{~mm})$. Given the dependence of stress on spindle radius as shown in Equation 3.2, it is obvious why anomalies exist. The samples held at 1234, 1241 , and $1255^{\circ} \mathrm{C}$ had measurable accumulations of melt on the spindle that result in artificially high stress values. We then substituted the measured radius of the spindle plus melt into the equation for stress allowing for the corrected values in Figure 3.14 (B). After recalculating stress and strain rate for the experiments with melt accumulation, the stress/ strain rate curves yield a correlation with crystal \%. The experiments marked with "x" symbols show shallower curves as calculated stress drops significantly with larger $R_{b}$. Strain rate increased minimally, and is hardly evident on the scale of the graph. There is a slight decrease in the slope of the lines as higher strain rates are reached, indicating a subtle shear thinning behavior of the partially crystalline samples. All of the lines converge near the origin of the graph suggesting that there is no detectable yield strength present in Pacaya lavas down to $\sim 1226^{\circ} \mathrm{C}$, although a linear extrapolation would suggest an apparent yield strength of $\sim 140 \mathrm{~Pa}$

Figures 3.15 and 3.16 show log viscosity, and log stress vs. log strain rate for the experiments to further express the shear thinning behavior evident in Figure 3.14, and to show how flow index can be measured. Once again, we show the original calculated values first followed by the corrected values for spindle thickness. 

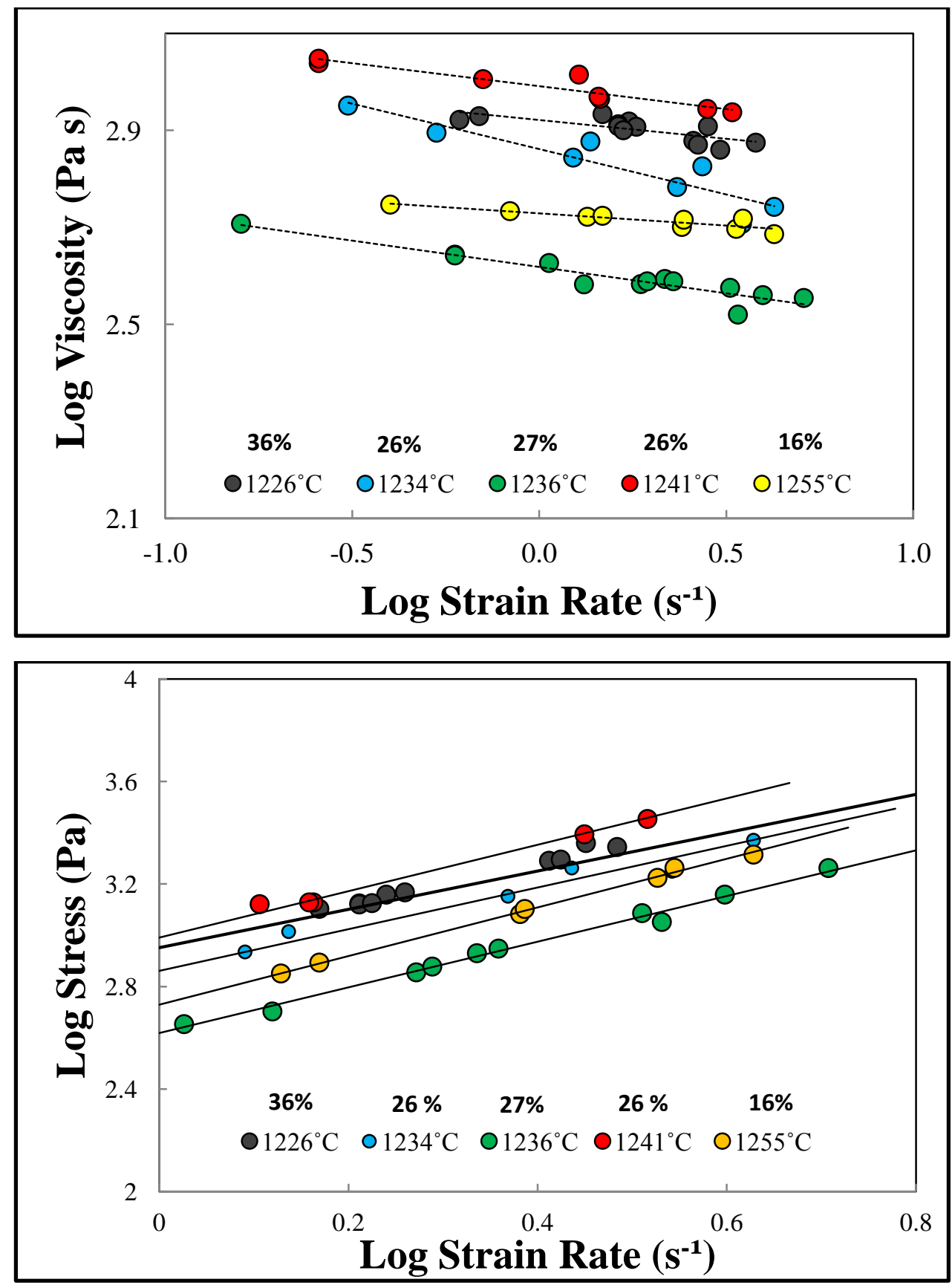

Figure 3.15. (A) Log Viscosity (Pa s) plotted against Log Strain Rate $\left(\mathrm{s}^{-1}\right)$, (B) Log stress (Pa) vs. Log Strain Rate $\left(\mathrm{s}^{-1}\right)$, both using the original value for spindle thickness. Slope of lines represent the flow index $(n)$ of the material. 

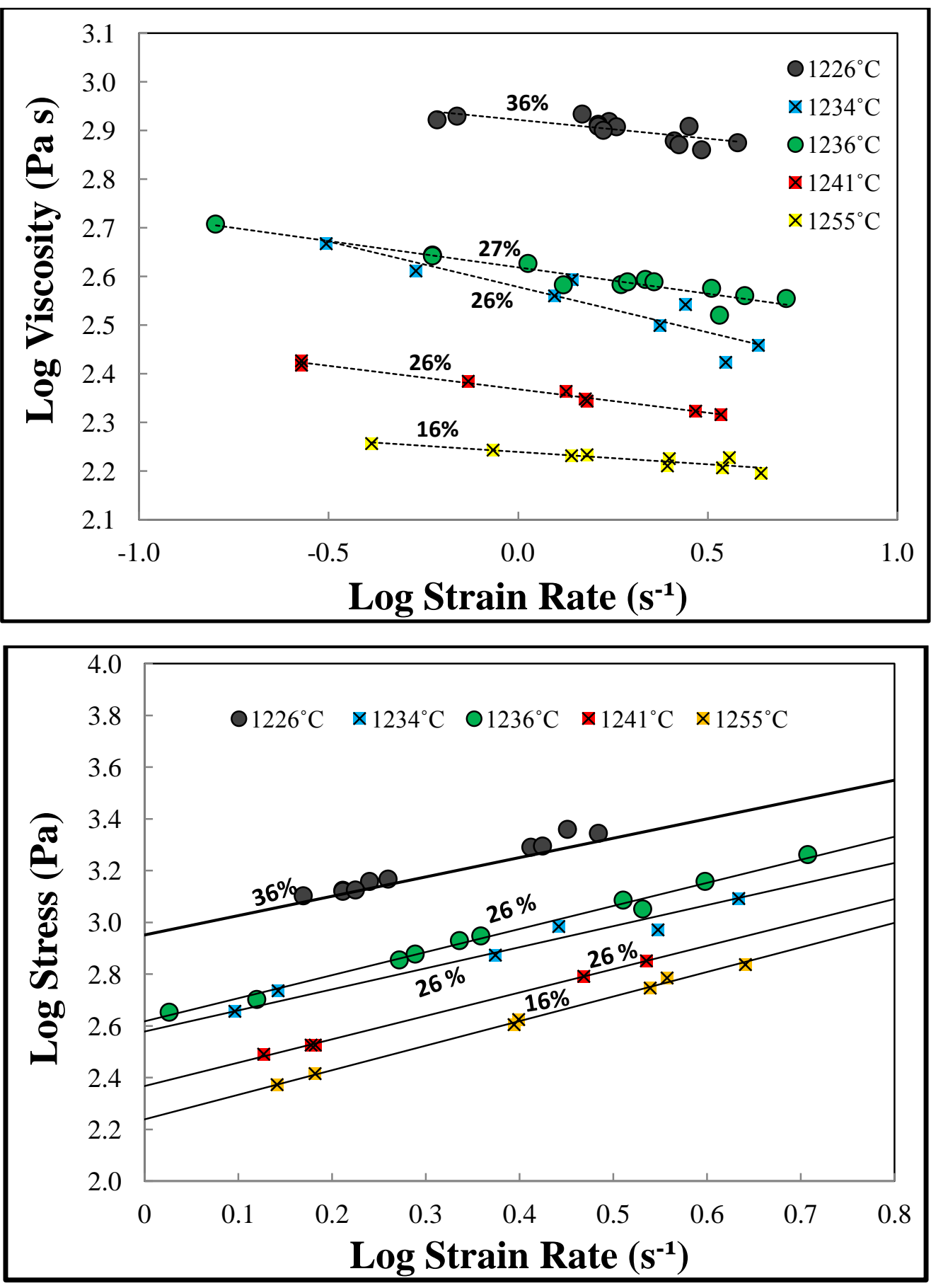

Figure 3.16. Log (A) Log Viscosity (Pa s) plotted against Log Strain Rate $\left(\mathrm{s}^{-1}\right)$, (B) Log stress (Pa) vs. Log Strain Rate $\left(\mathrm{s}^{-1}\right)$, using the corrected values for spindle thickness for the data with ' $x$ " symbols. Slope of lines represent the flow index $(n)$ of the material. 
A and B within Figures 3.15 and 3.16 are at the same scale to express the magnitude the spindle correction has on the resulting values. We refer to only Figure 3.16 from now on, as this figure provides the data we used. The shear thinning behavior is represented by the decreasing slope in Figure 3.16 (A), which corresponds to higher strain rates resulting in lower viscosities. The slope of Figure 3.16 (B) represent the flow index $(n)$ of the material. This experimental derived value will commonly be referred to as 'measured n', and will be used in the modeling section to compare against calculated values for $n$. Table 3.4 shows the slope values (measured $\mathrm{n}$ ) for corresponding temperature and crystal $\varphi$. Measured $n$ value of 1 , would correspond to a perfectly Newtonian fluid. Values $<1$ then exhibit non-Newtonian, shear thinning behavior, that is a result of crystal \%, and aspect ratio of crystals (Mader et al. 2013). Measured $n$ values decrease greater with higher crystal \%, providing further evidence of the shear thinning behavior in Figures 3.14(B), and in $3.16(\mathrm{~B})$.

Table 3.3. Slope of $\log$ stress (Pa ) vs. $\log$ strain rate $\left(\mathrm{s}^{-1}\right)$ as, at each temperature and crystal \%. Values represent the measured flow index $(n)$ of the magma.

\begin{tabular}{c|c|c}
\hline $\begin{array}{c}\text { Temp } \\
{ }^{\circ} \mathbf{C}\end{array}$ & Slope & $\begin{array}{c}\text { Crystal } \\
\text { \% }\end{array}$ \\
\hline 1226 & 0.742 & 35.4 \\
1234 & 0.814 & 26.2 \\
1236 & 0.891 & 26.0 \\
1241 & 0.906 & 25.3 \\
1255 & 0.950 & 15.8 \\
\hline
\end{tabular}

\subsubsection{Low Temperature Magma Viscosity of the Partially Crystalline Remelts}

One core was drilled from each of the partially crystalline remelts from the CC experiments for use in the PP viscometer. The viscosity of each core was measured at 4-6 
temperature segments following the same experimental procedures as outlined in the liquid viscosity section. The dwell time and range of temperatures was dependent on the degree of crystallization in the samples measured. It has already been confirmed that there exists a relatively heterogeneous distribution of crystals in the post-CC samples (Figure 3.10 and Figures A-4 in appendix) especially in samples $1207^{\circ} \mathrm{C}$ and $1255^{\circ} \mathrm{C}$. Considering that the cores drilled only represent a small portion $(4-7 \mathrm{~mm})$ diameter of the $\sim 25 \mathrm{~mm}$ core drilled for imaging, it is likely that the crystal fraction in any given core will not exactly match the fractions determined using electron microscopy. Additional microcrystal crystallization can also occur during PP measurement. For this reason each post-PP core was imaged with BSE after the experiments to compare with the results of the BSE images from the post-CC experiment samples, and to obtain accurate crystal percentages for direct correlation with the PP results. Density was also measured for the cores using the geometric and Archimedean methods both before and after experiments.

PP data from these experiments are shown in Figure 3.17. Crystal $\varphi$ estimates are derived from the BSE images shown in Figure 18 and Figures A-5 in the appendix. Before and after density are provided in Figure 3.31. The difference in crystal $\varphi$ estimates between the imaged post-PP and post-CC experiments are shown in Figure 3.19.

Based on the estimated crystal $\varphi$ there is an overall trend of increasing viscosity with crystal $\varphi$ in Figure 3.17. The original remelts (G1-B1and G1-B2) are plotted along with the liquid TVF line representing a melt with $0 \%$ crystal $\varphi$. Samples 1236,1241 , and $1255^{\circ} \mathrm{C}$ all plot on essentially the same line, with only a $\sim 4 \%$ difference in crystal $\varphi$ between the samples. Sample $1234^{\circ} \mathrm{C}$ yields a higher viscosity with a higher crystal $\varphi$ of 
34\%. The $1207^{\circ} \mathrm{C}$ experiment appears to violate the trend, but the core drilled for use in PP experiments was from a relatively glassy area compared to the rest of the sample, resulting in a lower crystal percent when compared to post-CC BSE images. The glass composition of the sample is more evolved than glass from higher temperature experiments, and this may have had a substantial impact on the viscosity. The anomalous nature of this experiment and the corresponding values for glass chemistry for this core along with the rest of the samples will be provided within Figures 3.22 and 3.23 in the next section. Sample $1226^{\circ} \mathrm{C}$ plots with highest viscosity and highest crystal $\varphi$ of $47 \%$.

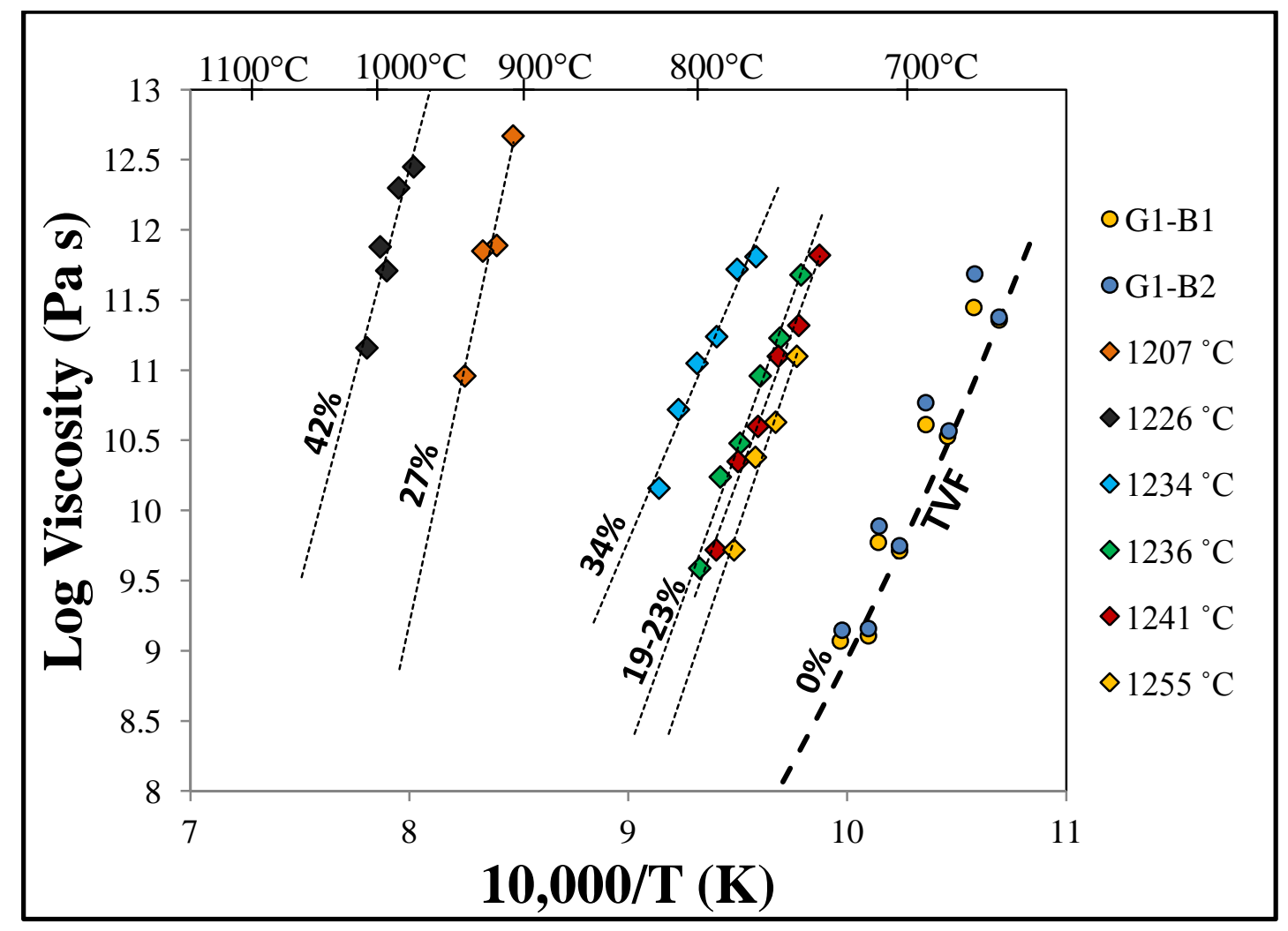

Figure 3.17. Low temperature magma viscosity measured with the PP viscometer. 

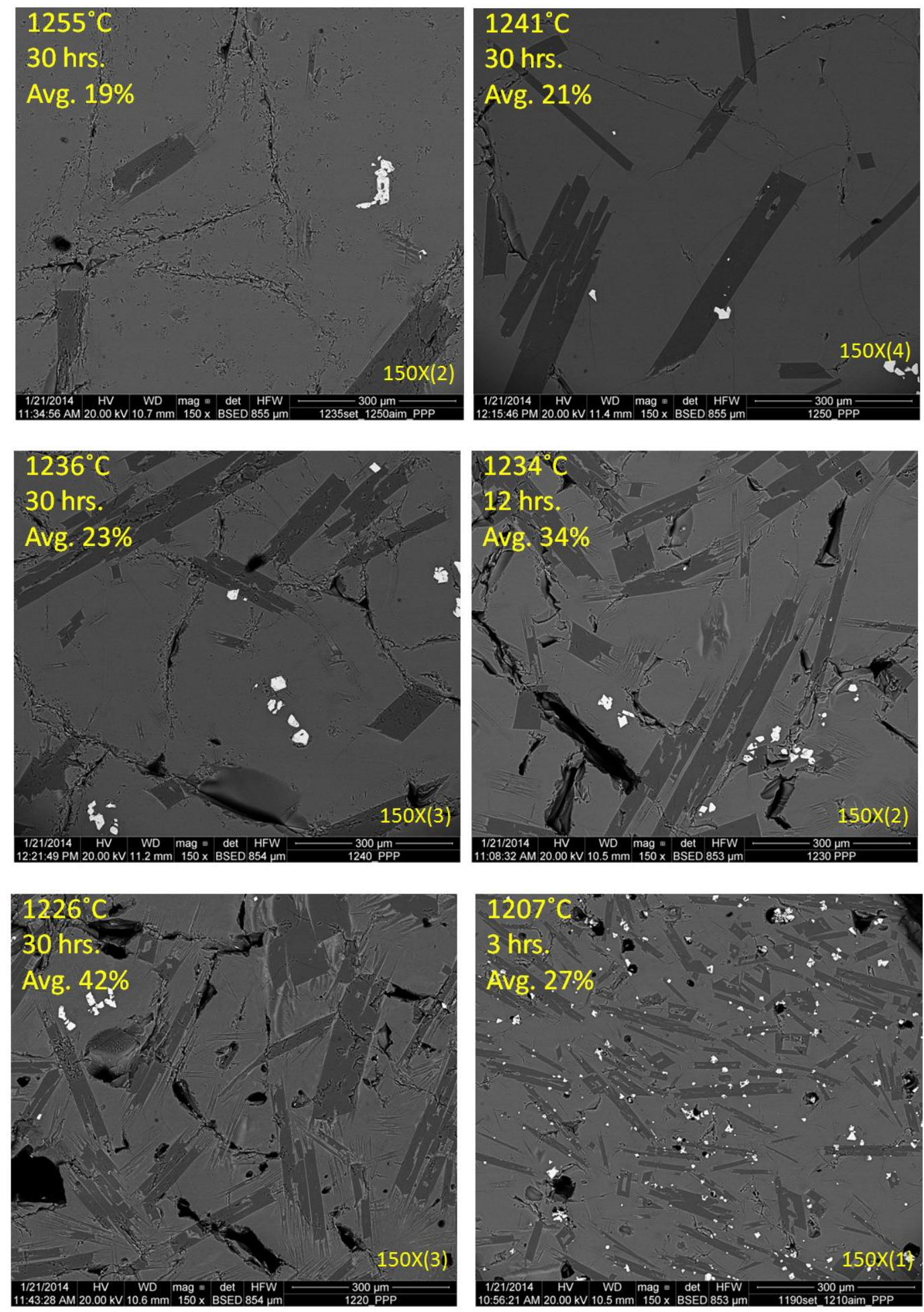

Figure 3.18. Low magnification BSE images of post PP experiments. Temperature, dwell time, and average crystal \% provided in each image. Additional images used for determining crystal \% provided in appendix. 
The post-PP BSE images reveal the extent of micro-crystallization that occurred during measurement. Swallowtail plagioclase crystals are strong indicators of growth at high undercooling. Figure 3.19 depicts the evidence of swallowtail micro-crystals by comparing the post-PP BSE images to the post-CC BSE images of sample $1207^{\circ} \mathrm{C}$.
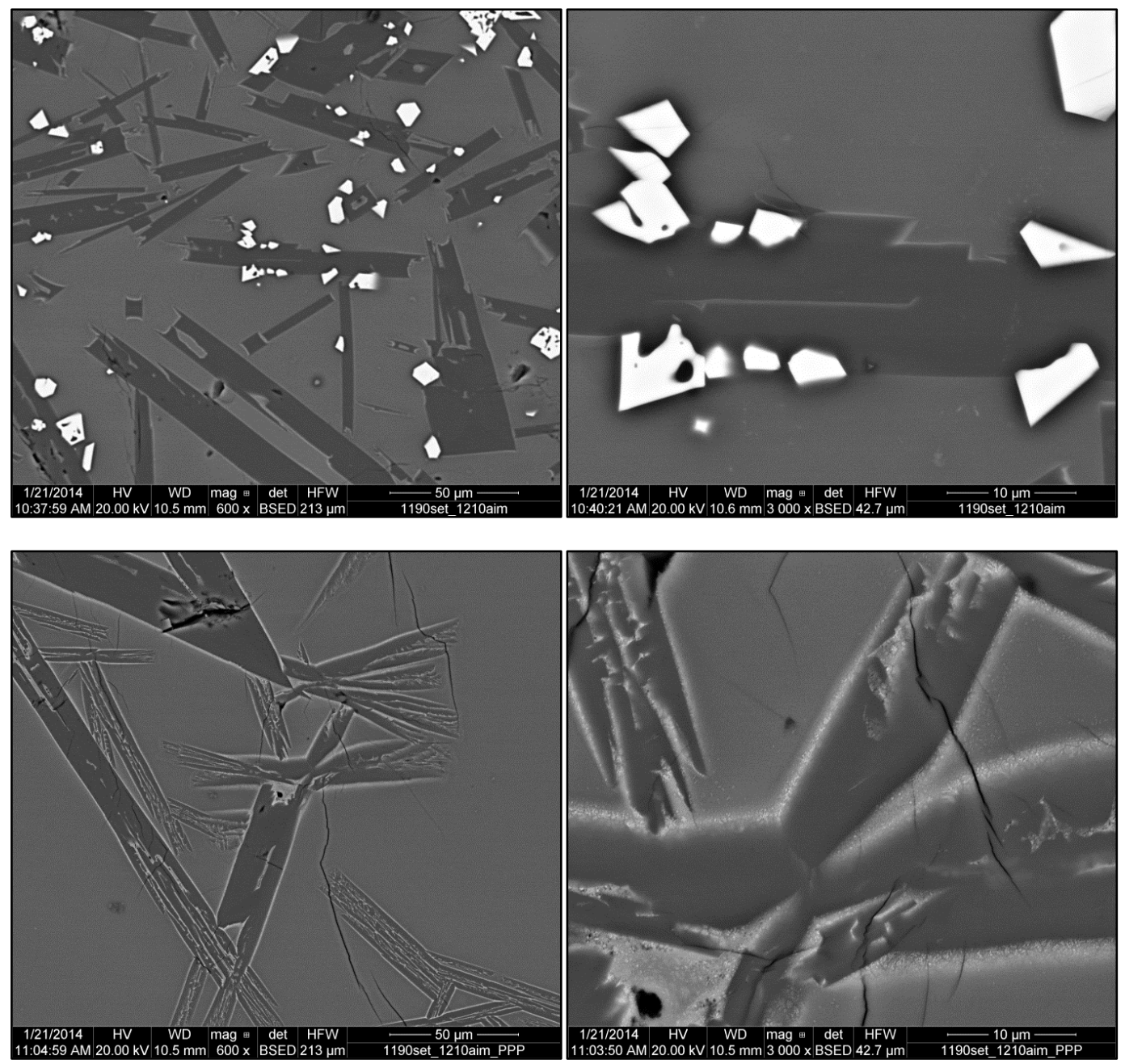

Figure 3.19. Upper BSE images show well defined crystal boundaries within the PCC sample held at $1207^{\circ} \mathrm{C}$. The lower BSE images show evidence of micro-crystallization that occurred during PP viscosity measurement. 
An increase in density of approximately $10-90 \mathrm{~kg} / \mathrm{m}^{3}$ between the two measurements is shown in below in Figure 3.20. The increase is likely due to the microcrystallization shown in Figure 3.19. The before and after density measurements, along with the crystallization data for both the post-PP and post-CC experiments are shown in Table 3.4.

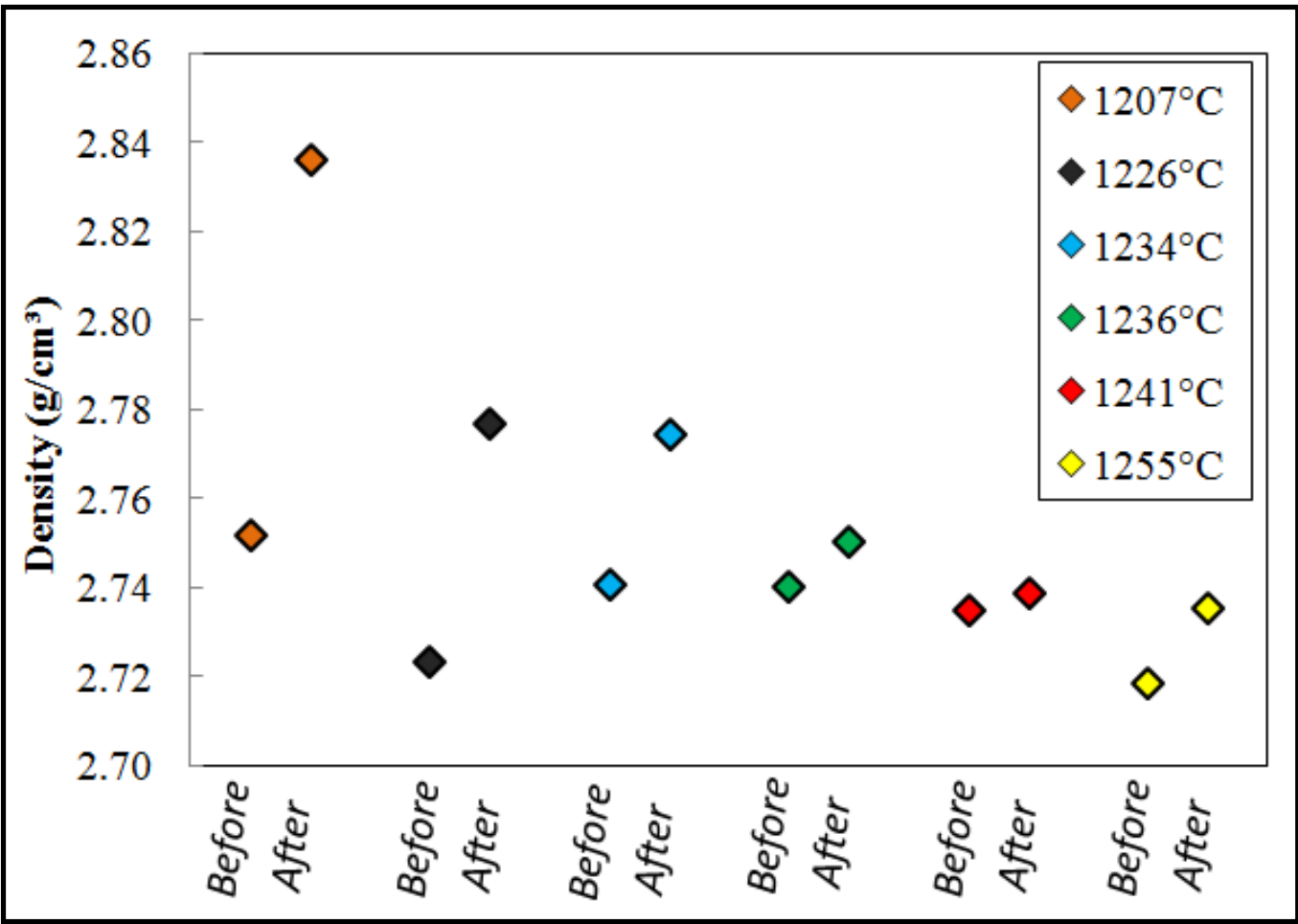

Figure 3.20. Density $\left(\mathrm{g} / \mathrm{cm}^{3}\right)$ measured before and after the PP experiments on the partially crystalline remelts. Analytical uncertainty is smaller than symbol size.

The difference between crystal $\varphi$ in Figure 3.21 should be attributed to heterogeneity between the sample, and not solely to microcrystalline growth. We have already established that heterogeneity exists within each post-CC sample throughout the four images used to approximate crystal $\varphi$, and therefore, must also exist between fragments used for imaging the post-CC samples, and the cores drilled for use in PP 100 
viscosity experiments. The error bars on the graph represent $5 \%$ uncertainty within our crystal fraction estimates, calculated from the standard deviation between crystal fractions calculated between each of the four BSE images used for both the post-CC and post-PP experiments.

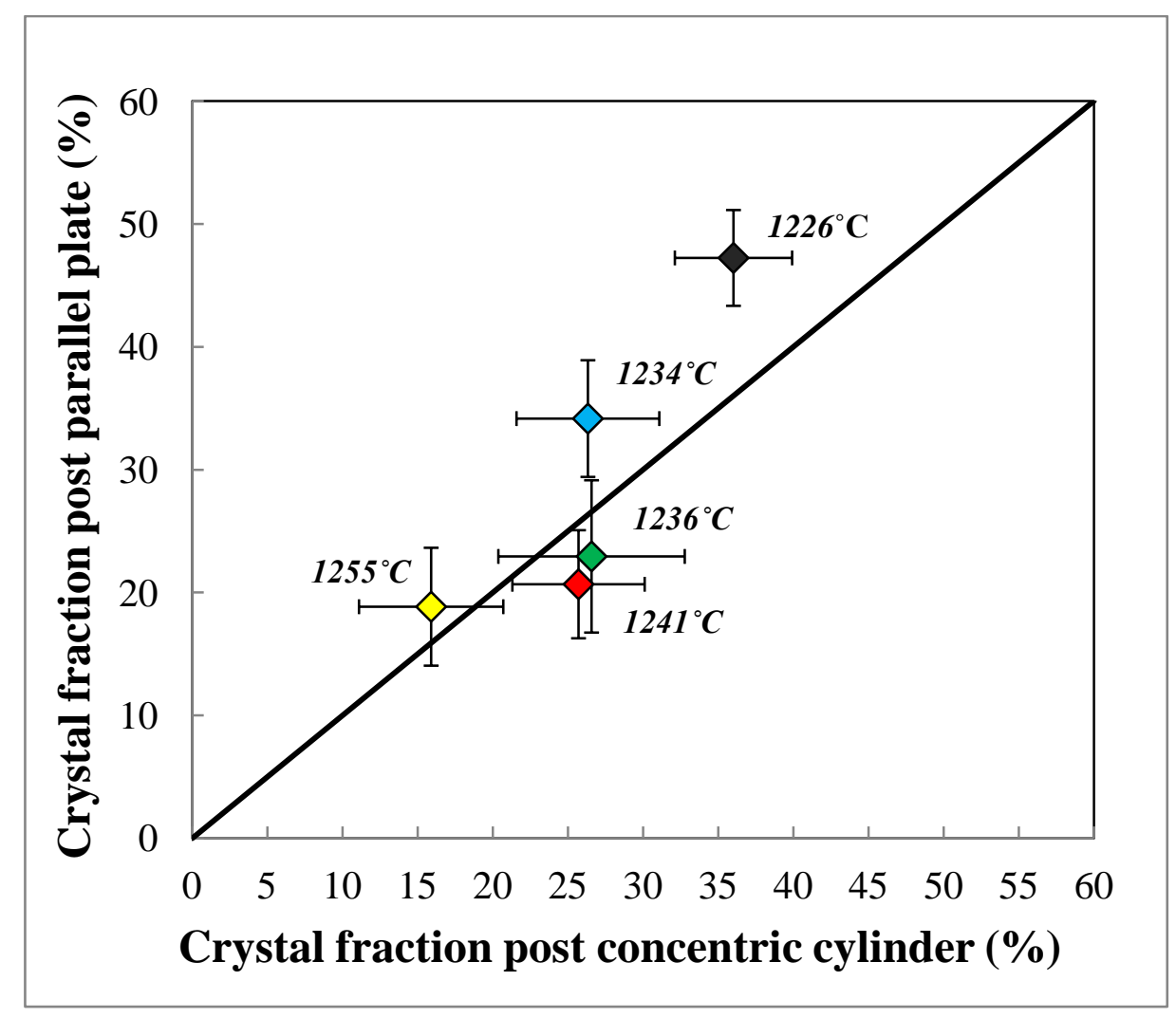

Figure 3.21. Crystal fraction from post-PP experiments plotted against crystal fraction from post-CC experiments. Error bars vary for each sample and are derived from standard deviations provided in tables A-4 and A-5 in the appendix. 
Table 3.4. Corresponding crystal \% and density for the samples used in both the $\mathrm{CC}$ and PP experiments.

\begin{tabular}{c|c|c|c|c|c}
\hline Post-CC & \multicolumn{5}{|c}{} \\
\hline $\begin{array}{c}\text { Temp } \\
{ }^{\circ} \mathbf{C}\end{array}$ & $\begin{array}{c}\text { Plag } \\
\text { \% }\end{array}$ & $\begin{array}{c}\text { Oxide } \\
\text { \% }\end{array}$ & $\begin{array}{c}\text { Glass } \\
\mathbf{\%}\end{array}$ & $\begin{array}{c}\text { Total } \\
\mathbf{\%}\end{array}$ & $\begin{array}{c}\text { Density } \\
\mathbf{g} / \mathbf{c m}^{\mathbf{3}}\end{array}$ \\
\hline 1207 & 37.7 & 1.4 & 60.8 & 39.2 & 2.75 \\
1226 & 35.3 & 0.8 & 64.0 & 36.0 & 2.72 \\
1234 & 25.4 & 0.9 & 73.7 & 26.4 & 2.74 \\
1236 & 25.6 & 1.0 & 73.4 & 26.6 & 2.74 \\
1241 & 25.4 & 0.3 & 74.3 & 25.7 & 2.74 \\
1255 & 15.8 & 0.2 & 84.1 & 15.9 & 2.72 \\
\hline
\end{tabular}

\begin{tabular}{c|c|c|c|c|c|c}
\hline Post-PP & \multicolumn{7}{|c}{} \\
\hline $\begin{array}{c}\text { Temp } \\
{ }^{\circ} \mathbf{C}\end{array}$ & $\begin{array}{c}\text { Plag } \\
\boldsymbol{\%}\end{array}$ & $\begin{array}{c}\text { Oxide } \\
\boldsymbol{\%}\end{array}$ & $\begin{array}{c}\text { 3rd phase } \\
\mathbf{\%}\end{array}$ & $\begin{array}{c}\text { Glass } \\
\mathbf{\%}\end{array}$ & $\begin{array}{c}\text { Total } \\
\mathbf{\%}\end{array}$ & $\begin{array}{c}\text { Density } \\
\mathbf{g} / \mathbf{c m}^{\mathbf{3}}\end{array}$ \\
\hline 1207 & 26.9 & 0.3 & 0.0 & 72.8 & 27.2 & 2.84 \\
1226 & 45.2 & 1.3 & 0.8 & 52.8 & 47.2 & 2.78 \\
1234 & 33.2 & 1.0 & 0.0 & 65.8 & 34.2 & 2.77 \\
1236 & 22.1 & 0.8 & 0.0 & 77.1 & 22.9 & 2.75 \\
1241 & 20.0 & 0.7 & 0.0 & 79.3 & 20.7 & 2.74 \\
1255 & 18.7 & 0.1 & 0.0 & 81.2 & 18.8 & 2.74 \\
\hline
\end{tabular}

\subsubsection{Chemistry}

Samples from both the post-CC experiments and the post-PP experiments were cut and polished for analysis by electron microprobe at Wash U. All phases in each sample were probed at least 3 times depending on the size of the phases present, as we are limited by the size of the electron beam. The electron beam can be focused to $1 \mathrm{um}$, but some phases, especially those from the partially crystalline PP annealing experiments, were still too small to be analyzed. Data are provided in Tables A-6 in the appendix.

Glass compositions range from approximately 50-53 $\mathrm{SiO}_{2} \mathrm{wt} \%$ and from 3.9-4.7 $\mathrm{Na}_{2} \mathrm{O}+\mathrm{K}_{2} \mathrm{O}$ wt $\%$ (Figure 3.22). There are outliers to this trend that will be discussed 
shortly; however a general trend of increasing $\mathrm{SiO}_{2}$ and $\mathrm{Na}_{2} \mathrm{O}+\mathrm{K}_{2} \mathrm{O}$ wt $\%$ correlating with decreasing dwell temperature and increasing crystal percent is apparent. As both $\mathrm{Fe}$ and $\mathrm{Ti}$ are removed from the liquid to crystallize the Fe-Ti Oxides and as $\mathrm{Ca}$ and $\mathrm{Al}$ are removed from the melt to crystallize plagioclase, the relative proportion of $\mathrm{SiO}_{2}$ and total alkalis increase in the remaining liquid. There is also a noticeable variation between the glass compositions of post-CC (samples labeled with just temperature in figure) and postPP (samples labeled with PPP) samples, with alkali concentration in the liquid phase plotting slightly lower for post-PPP experiments (diamond symbols plotting beneath circle symbols of the same color). The starting remelts (G1-B1 and G1-B2) and final remelt agree with the general trend plotting to the left of the partially crystalline samples. There is only slight increase in alkalis, with essentially no change in $\mathrm{SiO}_{2} \mathrm{wt} \%$, between the initial and final remelts.

The anomalies in the diagram pertain to sample $1207^{\circ} \mathrm{C}$. From the BSE images of $1207^{\circ} \mathrm{C}$ in Figures 3.10 and 3.18 we see that the samples exhibit both crystalline and glassy areas. In Figure 3.22 analyses from these locations are labeled with (glassy area) at the end of the sample name to differentiate from analyses taken from within the more crystalline areas labeled with (xtals) after the sample name. Glass analyses from the crystalline area plot to the far right of the trend with approximately $53 \mathrm{wt} \% \mathrm{SiO}_{2}$ and 4.8 wt $\% \mathrm{Na}_{2} \mathrm{O}$, which agrees with the general trend previously described. However, glass analyses from the same sample, within the less crystalline and glassy area plot to the far left of the trend with approximately $50 \mathrm{wt} \% \mathrm{SiO}_{2}$ and $4.3 \mathrm{wt} \% \mathrm{Na}_{2} \mathrm{O}$, indicating very heterogeneous liquid chemistry. The $1207^{\circ} \mathrm{C}$ post-PP (PPP) experiments also exhibit the 
deficient alkalis around only $3 \mathrm{wt} \% \mathrm{Na}_{2} \mathrm{O}$, nearly $1 \mathrm{wt} \%$ lower compared to the other samples. The microscopic heterogeneity within this sample, regarding both liquid chemistry, and crystallinity, caused us to exclude this sample from the subsequent viscosity modeling results, as modeling requires homogenous liquid chemistry for calculating relative viscosity.

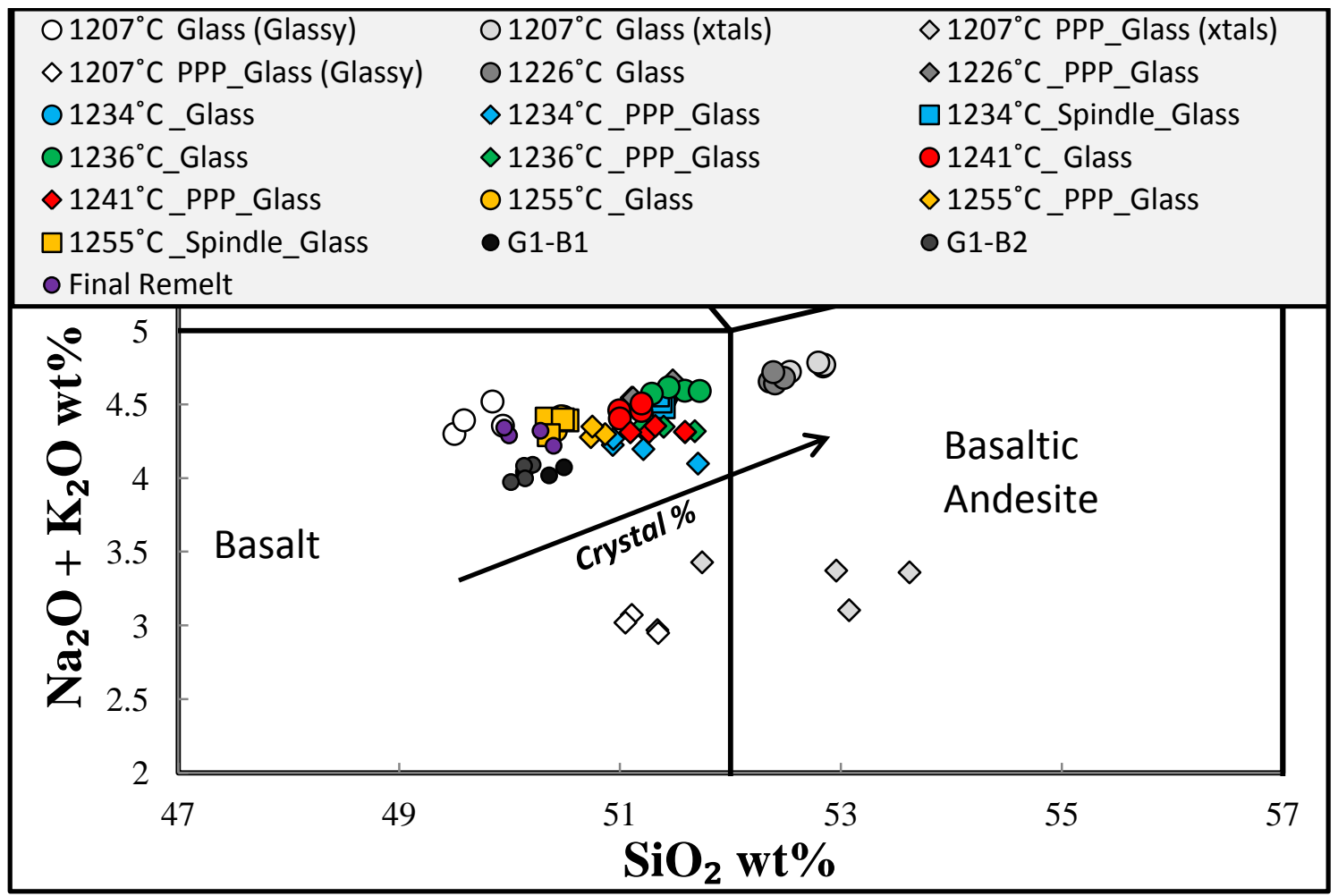

Figure 3.22. Glass compositions from microprobe analysis of all partially crystalline all PCC and PPP samples.

Figure 3.23 shows $\mathrm{CaO}$ wt $\%$ of plagioclase and glass compositions plotted against $\mathrm{SiO}_{2}$ wt \%. Figure 3.24 shows $\mathrm{Ca} \#(\mathrm{Ca} / \mathrm{Ca}+\mathrm{Na})$ plotted for each experiment. There is some overlap in the $\mathrm{Ca}$ content of plagioclases from higher to lower temperature, but a general trend of more anorthite rich plagioclase with higher temperature is apparent. 
Figure 3.23 also shows interstitial glass compositions with generally higher $\mathrm{SiO}_{2}$ wt\% and little change in $\mathrm{CaO}$ wt $\%$ at lower dwell temperatures. The variation is $\mathrm{SiO}_{2}$ is largely due to the precipitation of Fe oxides as described relative to the TAS diagram in Figure 3.22. The final and starting remelts for the experiments are also shown in Figure 3.20 for reference. The points plotting with less $\mathrm{SiO}_{2}$ are once again related to the anomalous results from the $1207^{\circ} \mathrm{C}$ sample.

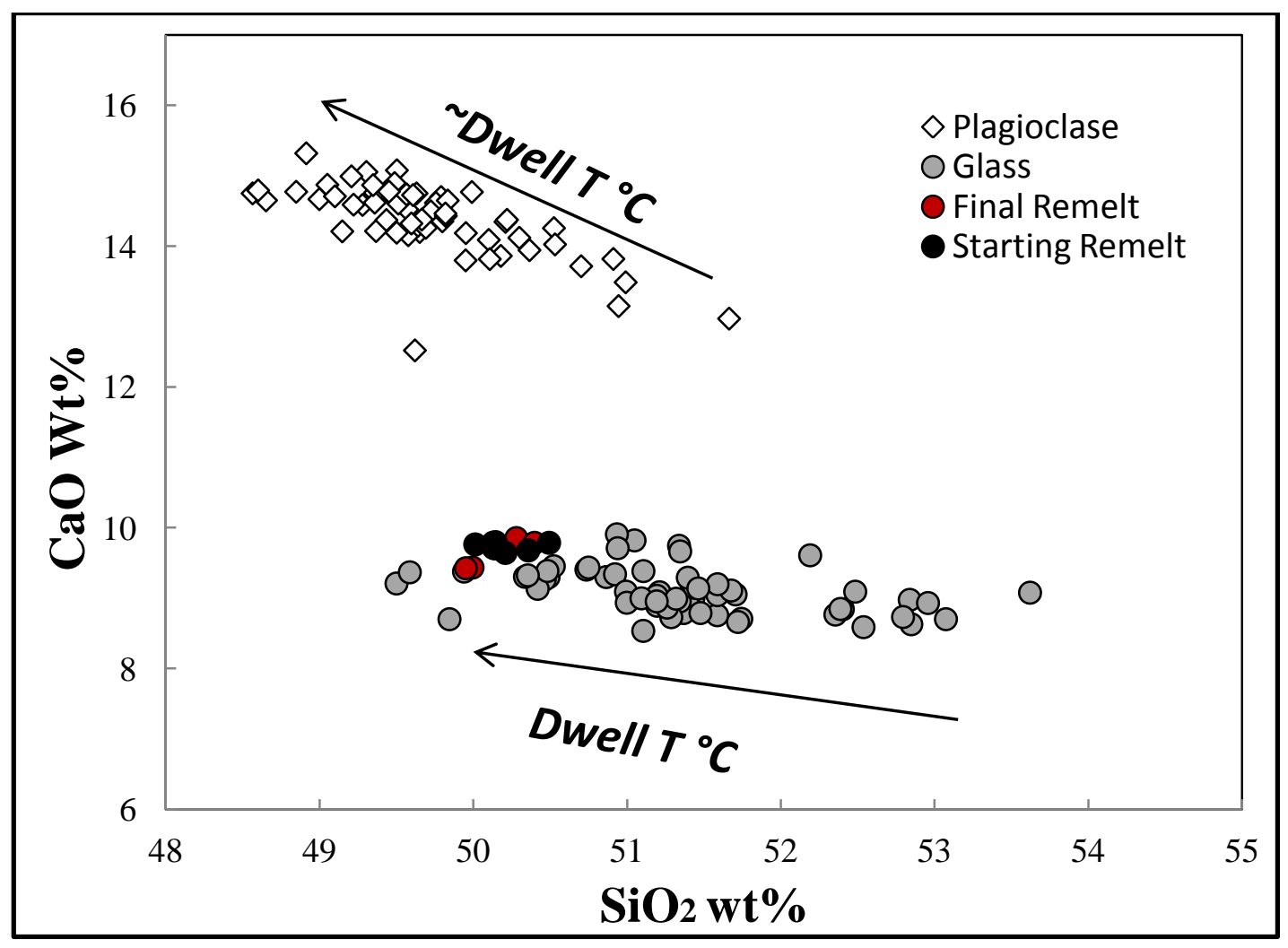

Figure 3.23. $\mathrm{CaO}$ wt \% of plagioclase and glass compositions plotted against $\mathrm{SiO}_{2}$ wt \%. 


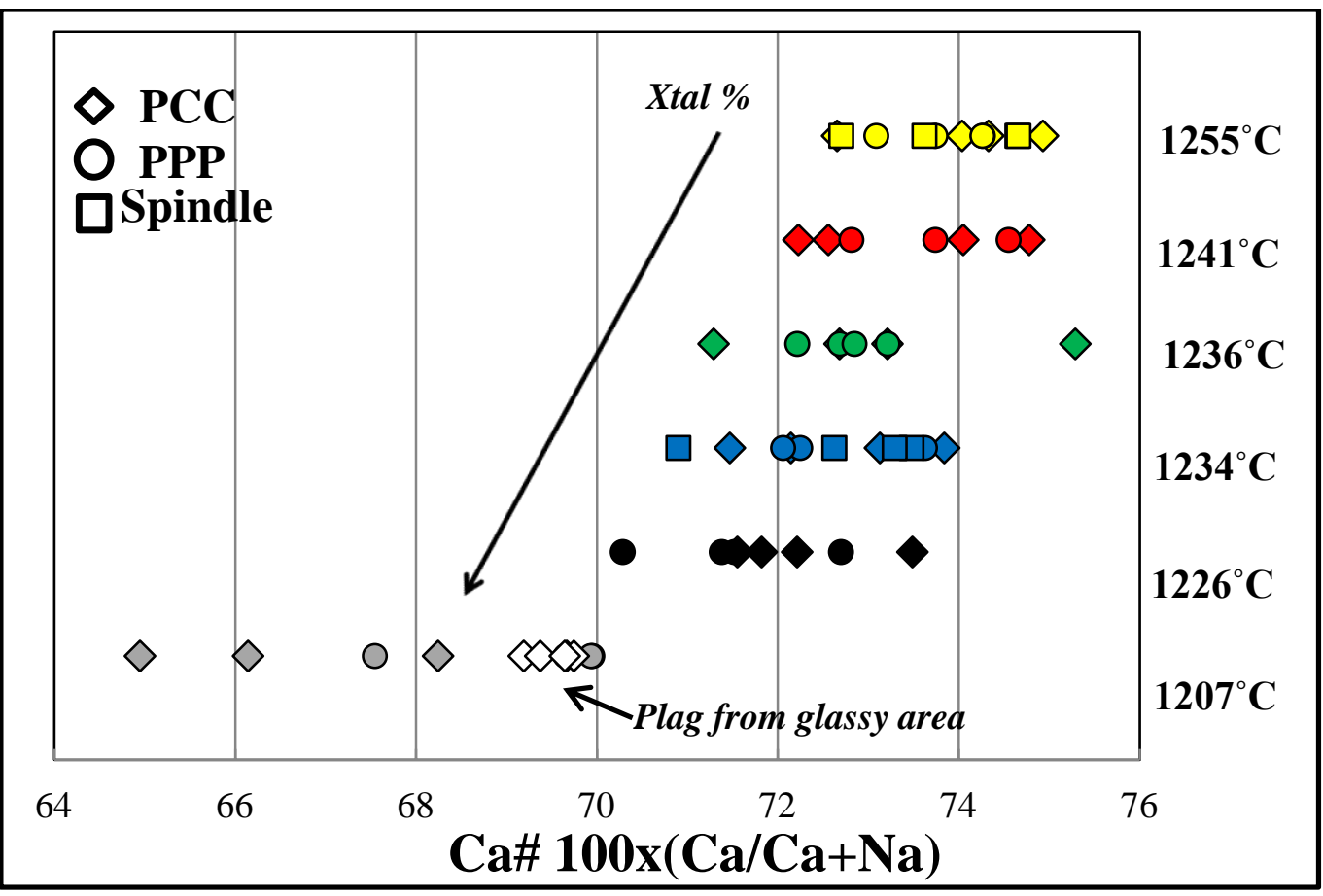

Figure 3.24. Ca\# for probed plagioclase compositions within the partially crystalline samples.

Figure 3.25 shows the Fe redox state of the partially crystalline remelts. The Fe redox state of these experiments was determined using the same method as described in Chapter 2 . The partially crystalline remelts are far more oxidized compared to our natural samples. Natural samples generally exhibit 1.8-2.8 wt $\% \quad \mathrm{Fe}_{2} \mathrm{O}_{3}$ with the relatively oxideized outliers (PA01, and PA23) exhibiting $~ 4.4 \mathrm{wt} \% \mathrm{Fe}_{2} \mathrm{O}_{3}$. The partially crystalline remelts are far more oxidized ranging from $~ 7.5-9.0$ wt $\% \mathrm{Fe}_{2} \mathrm{O}_{3}$. This is expected considering that the samples were remelted and crystallized in air.

The concentration of $\mathrm{FeO}$ and $\mathrm{Fe}_{2} \mathrm{O}_{3}$ within the partially crystalline samples is dependent on both temperature and time. Generally our higher temperature experiments are more oxidized and the lower temperature experiments are more reduced. Although 
the $1207^{\circ} \mathrm{C}$ sample is less oxidized than $1226^{\circ} \mathrm{C}$, it was also held at high temperature for less time ( $3 \mathrm{hrs}$. for $1207^{\circ} \mathrm{C}$ vs. $30 \mathrm{hrs}$. for $\left.1226^{\circ} \mathrm{C}\right)$.

The oxygen fugacity of a magmatic system dictates what minerals precipitate. Our natural samples contained plagioclase, olivine, clinopyroxene, and Fe-Ti oxides. Our partially crystalline remelts contained only plagioclase, and Fe-Ti oxide. The lack of olivine in experiments can be understood by considering the FMQ (Fayalite- MagnetiteQuartz,) mineral redox buffer,

$$
3 \mathrm{Fe}_{2} \mathrm{SiO}_{4}+\mathrm{O}_{2}=2 \mathrm{Fe}_{3} \mathrm{O}_{4}+3 \mathrm{SiO}_{2}
$$

This reaction shows that high $\mathrm{fO}_{2}$ in the system suppresses olivine, in favor of magnetite. In our case, instead of quartz precipitating, we have plagioclase.

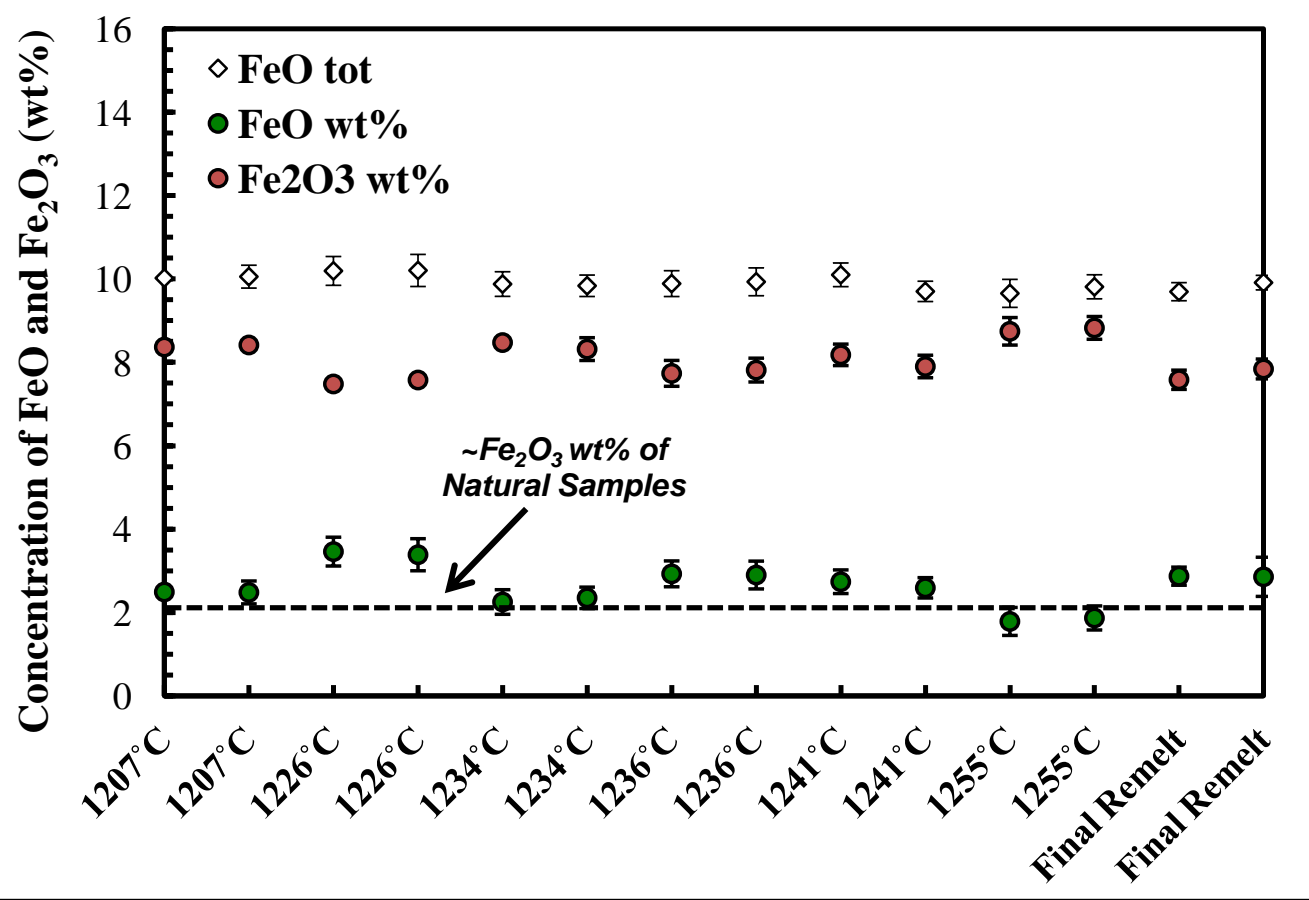

Figure 3.25. Concentration of $\mathrm{FeO}$ and $\mathrm{Fe}_{2} \mathrm{O}_{3}$ in the partially crystalline samples. 


\subsubsection{Low Temperature Crystallization Experiments}

To investigate the effects of crystallization at temperatures well below the liquidus, we conducted a set of annealing experiments using the PP viscometer. Five cores were drilled from the original PA09 remelt and were polished evenly using the standard techniques previously described. Each core was held at $\sim 950^{\circ} \mathrm{C}$ for a different dwell time. The typical load mass was removed during the heating part of the experiment and the $1000 \mathrm{~g}$ weight (instead of the usual 1500g) was only loaded after the annealing period, as we anticipated samples deforming rapidly at $\sim 950^{\circ} \mathrm{C}$. After the weight was added, we recorded deformation for between 15-250 seconds (resulting in shortening between 32-8 $\mu \mathrm{m}$ ) which was used to calculate a single isothermal viscosity point. Following measurement, the sample was removed rapidly from the furnace then quenched in water. The samples were then cut and polished for BSE imaging to determine the degree of crystallization.

The results are summarized in Figure 3.26. The experiments produced a range in crystal $\varphi$ from $\sim 42-78 \%$ and a range in viscosity from $10^{7.9}-10^{9.7} \mathrm{~Pa}$. The largest crystals to form only reach approximately 1 um in length, and were found in the longest duration experiment which was held at $950^{\circ} \mathrm{C}$ for $120 \mathrm{~min}$. The other crystal fractions from each experiment are shown in the BSE images within Figure 3.36 and are provided in Table 3.5 with corresponding viscosity. We were not able to obtain microprobe data on crystals or groundmass due to the very small crystal size, and thus the results from these experiments were not used in the subsequent viscosity modeling section. However, these 
results can still aid in interpreting the textures of the natural samples, and in assessing affect of crystal fraction on viscosity.

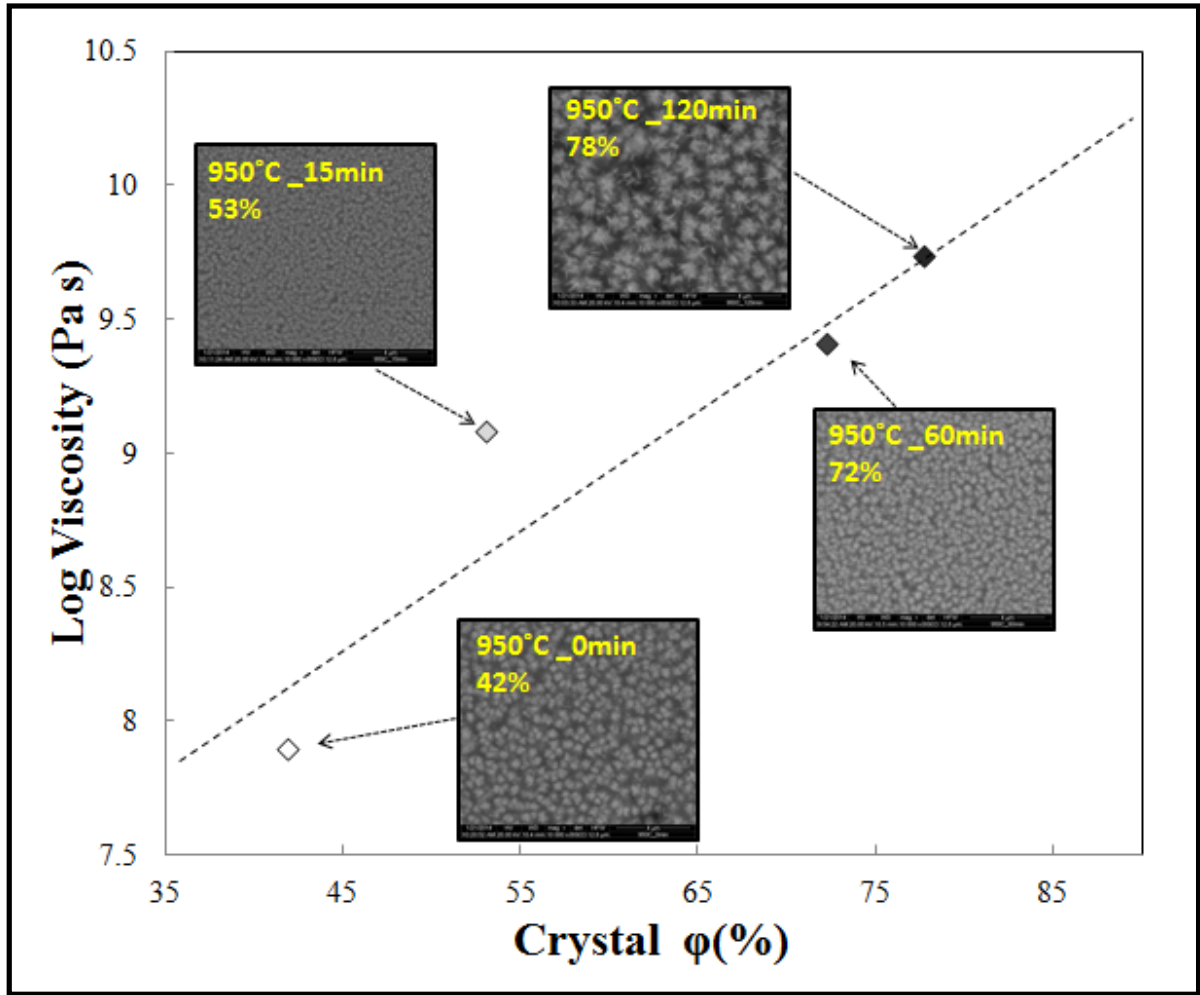

Figure 3.26. Log viscosity vs. crystal $\varphi \%$ for the isothermal annealing experiments. Each image is at the same magnification $(10000 \mathrm{X}$ Quanta), with $14 \mu \mathrm{m}$ representing the length of the image.

Table 3.5. Log viscosity and crystal volume fraction for isothermal annealing experiments at each dwell time and average temperature.

\begin{tabular}{c|c|c|c}
\hline $\begin{array}{c}\text { Avg. Temp } \\
{ }^{\circ} \mathbf{C}\end{array}$ & $\begin{array}{c}\text { Dwell Time } \\
\text { min }\end{array}$ & $\begin{array}{c}\text { Crystal } \\
\text { \% }\end{array}$ & $\begin{array}{c}\text { Log Visc } \\
\text { Pa s }\end{array}$ \\
\hline 943 & 120 & 78 & 9.74 \\
945 & 60 & 72 & 9.41 \\
945 & 15 & 53 & 9.08 \\
947 & 0 & 42 & 7.90 \\
\hline
\end{tabular}

\subsection{Measured Viscosity Summary}

Figure 3.27 shows viscosity data for all sub- and super-liquidus experiments plotted vs. inverse temperature. The dotted line, labeled TVF, represents the crystal free 
starting material for all subliquidus experiments. The grey circles at the top of line represent the PP experiments for the PA09 remelt, and the white circles represent the superliquidus CC experiments for the same remelt. The colored symbols correspond to the isothermal subliquidus $\mathrm{CC}$ experiments (in triangles), and the PP viscosity data acquired for those post-CC experiments. The colors of symbols correspond to the temperatures in the legend at the bottom right portion of the figure. Trend lines connect the low temperature PP experiments to the corresponding high temperature $\mathrm{CC}$ experiments, with the average crystal $\varphi \%$ calculated from post-CC and post-PP BSE images given next to the trend line. Remember from Figure 3.21 that there exists some heterogeneity between crystal fraction estimates of post-PP and post-CC experiments. When referring to both sets of experiments, we use the average values, which will also be used in the subsequent modeling section. The four square symbols aligned vertically in the middle of the figure represent the low temperature crystallization experiments. A detailed inset of these experiments with corresponding crystal $\varphi \%$ and dwell time is provided in the top left portion of the figure.

We see a coherent and expected trend of increasing viscosity with crystal $\varphi \%$ between crystal free melts, and the partially crystalline remelts marked with colored symbols. The trend lines between the PP and CC experiments allow for viscosity approximations at subliquidus temperatures. It is notable that the low temperature crystallization experiments, which produced between $42-80 \%$ crystals, all data plot beneath the $42 \%$ trend line for the $1226^{\circ} \mathrm{C}$ CC experiment. We were unable to attain chemical analyses of the crystals and or glass in the low temperature experiments, and are 
therefore unable to assess the degree to which changing residual melt composition may have affected viscosity in this case. The difference in viscosity could also be attributed to the shape, size, and number of the crystals between low and high temperature experiments (Figure 3.28). Both images are taken at the same magnification (3000X), and reveal a drastic difference in crystal size, shape, and number. It is likely the extreme textural difference between the low temperature and high temperate experiments causes the difference in viscosity. The effect of crystal shape on viscosity will be discussed in the following section.

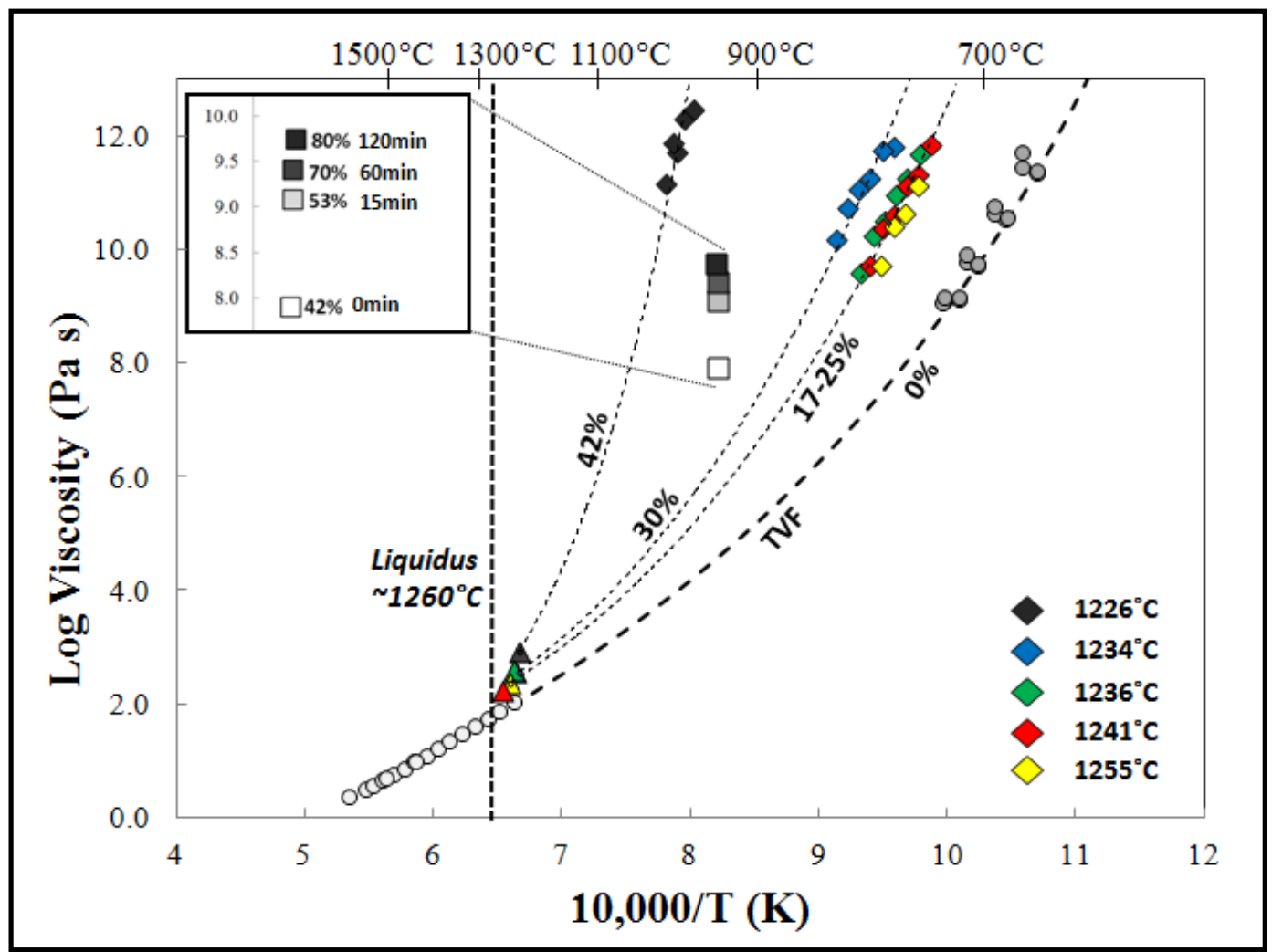

Figure 3.27. Log viscosity vs. 10000/T (K) for all partially crystalline remelts. White circles represent crystal free $\mathrm{CC}$ measurements, and grey circles represent crystal free PP experiments. See color legend for temperature of partially crystalline CC experiments (Triangles) and corresponding PP experiments (Diamonds). Inset to top left is detailed view of the isothermal PP experiments (white - grey boxes). 

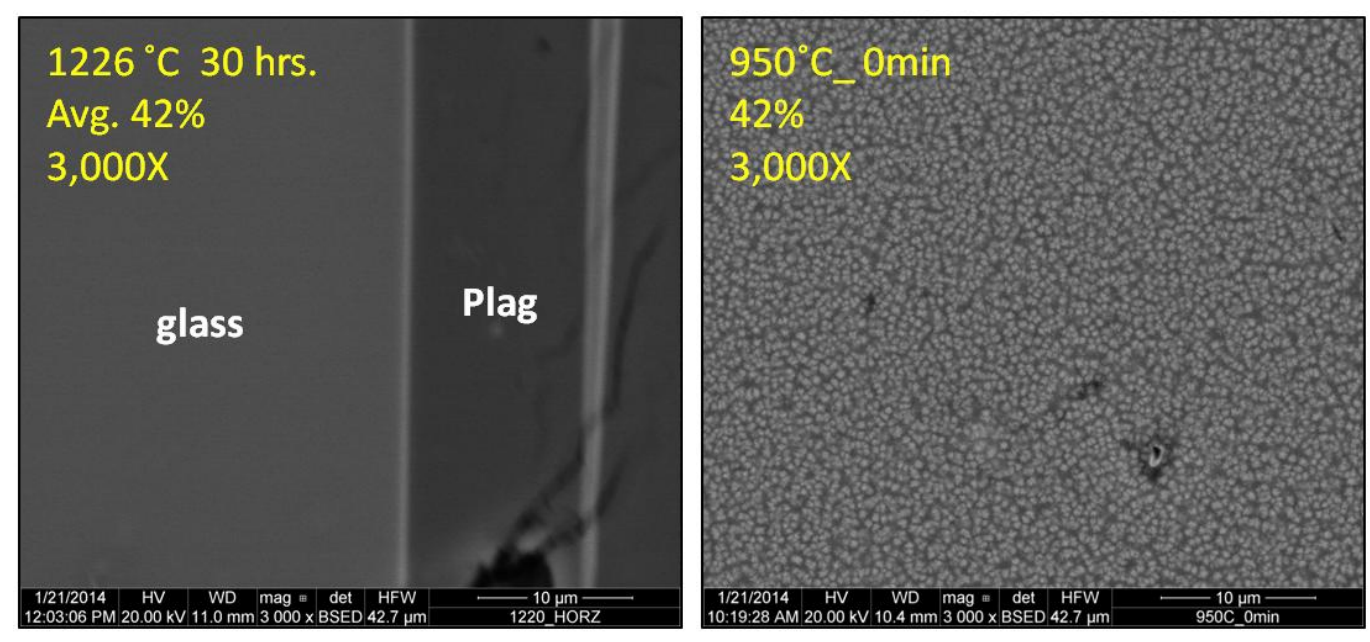

Figure 3.28. Post-CC BSE image of sample $1226^{\circ} \mathrm{C}$ (left) at same magnification of post-PP image of sample $950^{\circ} \mathrm{C} \_0 \mathrm{~min}$ for textural comparison.

\subsection{Modeling Magma Viscosity}

\subsubsection{Background}

We have successfully measured magma viscosity at high $\left(1226-1255^{\circ} \mathrm{C}\right)$ and low temperatures $\left(750-1008^{\circ} \mathrm{C}\right)$ using the $\mathrm{CC}$ and $\mathrm{PP}$ viscometers respectively. BSE imaging of the samples used in both sets of experiments have allowed us to estimate crystal fractions within the magma during measurement. The measured magma viscosity will be used to test current models that calculate magma viscosity.

Viscosity models are used to calculate relative viscosity $\left(\eta_{r}\right)$, which is equal to magma viscosity $\left(\eta_{\text {magma }}\right)$ over liquid viscosity $\left(\eta_{\text {liquid }}\right)$. Therefore, in order to calculate $\eta_{\text {magma }}$ from $\eta_{r}$ we must first know (or calculate) $\eta_{\text {liquid. }}$. We use the liquid viscosity model of Giordano et al. (2008) to calculate the viscosity of the interstitial liquid of our partially crystalline samples. We averaged the glass compositions from microprobe analysis for each temperature experiment between the post-CC and post-PP samples to calculate 
liquid viscosity for each crystal $\varphi \%$. The average liquid compositions are shown in Appendix Table A-4. Earlier in this chapter, we compared the accuracy of the Giordano et al. (2008) model to our measured liquid viscosity of the crystal free remelt. The model overestimates viscosity at low temperatures, and slightly underestimates viscosity at high temperatures. The significance of these discrepancies will be discussed after examining current models for magma (suspension) viscosity.

The first theoretical model for calculating suspension viscosity as a function of crystal fraction $(\varphi)$ was formulated by (Einstein 1906, 1911), who calculated relative viscosity $\left(\eta_{r}\right)$ by the equation

$$
\eta_{r}=1+B \varphi
$$

where $B$ is the Einstein coefficient, which is 2.5 for a monodisperse suspension of hard incompressible spheres (Einstein 1906, Roscoe 1952). Over 100 years of derivations and revisions have followed the original equation by Einstein with the attempt of creating an all-inclusive model that can accurately calculate magma viscosity. Mader et al. (2013) provide a comprehensive review of previous models for magma viscosity.

Of particular concern is to more accurately calculate magma viscosity at high crystal fractions. Rutgers (1962a,b) and Thomas (1965) found that Einstein's theory was only valid for crystal $\varphi<\sim 0.02$. When quantifying magma viscosity at higher crystal $\varphi$ it is then necessary to determine what the maximum packing fraction $\left(\varphi_{m}\right)$ of crystals can be within a liquid. $\varphi_{m}$ is calculated in the following equation 


$$
\varphi_{m}=\varphi_{m 1} \exp \left[-\frac{\left(\log _{10} r_{p}\right)^{2}}{2}\right]
$$

where $r_{p}$ represents the aspect ratio of particles in the liquid and $\varphi_{m 1}$ represents the maximum packing fraction for particles with $r_{p}=1$. The denominator is set equal to two based on the variance in the log-Gaussian function for rough particles represented in Figure 11 within Mader et al. (2013).

Costa et al. (2009) provide a model, revised from the model of Costa (2005), which is intended to account for high $\varphi$ values. $\eta_{r}$ is calculated by

$$
\eta_{r}\left(\varphi_{*}, \alpha, \delta, \xi\right)=\frac{1+\left(\frac{\varphi}{\varphi_{*}}\right)^{\delta}}{\left[1-F\left(\frac{\varphi}{\varphi_{*}} \xi, \gamma\right)\right]^{B \varphi_{*}}}
$$

where

$$
F=(1-\xi) \operatorname{erf}\left[\frac{\sqrt{\pi}}{2(1-\xi)} \frac{\varphi}{\varphi_{*}}\left(1+\frac{\varphi^{\alpha}}{\varphi_{*}^{\alpha}}\right)\right]
$$

$\varphi_{m}$ is replaced with $\varphi_{*}$, which is the "critical solid fraction" that results in an exponential increase in $\eta$. Empirical parameters $\alpha, \delta, \xi, \gamma$, and $\varphi *$ are controlled by deformation rate (Costa et al. 2009). When the $\varphi$ used is less than $\varphi_{*}$, Equation 3.6 reduces to

$$
\eta_{r}=\left(1-\frac{\varphi}{\varphi_{m}}\right)^{-B \varphi_{m}}
$$

derived by Krieger and Dougherty (1959). When $\varphi$ approaches 0 in Equation 3.6, it simplifies further to the Einstein equation (3.4). 
All of these models (3.4 -3.8) assume Newtonian behavior, but viscosity of crystal bearing melts is dependent on strain rate, as we have measured in our partially crystalline samples (Figure 3.20). Thus a model that addresses non-Newtonian behavior is needed to model the viscosity of crystal bearing melts. More recent studies by Ishibashi (2009) and Vona et al. (2011) suggest models including $\varphi_{m}, r_{p}$, and strain rate $(\gamma)$. Mader et al. (2013) present an algorithmic approach for calculating magma viscosity using the recent models, with a choice between three ways of calculating viscosity depending first on the values of $\varphi / \varphi_{m}$ and flow index $(n)$. Values for flow index can be obtained either empirically as the slope of $\ln$ stress vs. $\ln$ strain rate $(\gamma)$, providing sufficient measurements are available to make this calculation, or by the relationship obtained by Mueller et al. (2010):

$$
n=1-0.2 r_{p}\left(\frac{\varphi}{\varphi_{m}}\right)^{4}
$$

where $n$ is related to $r_{p}$ and $\varphi / \varphi_{m}$. This relationship can only be used when $\varphi / \varphi_{m} \leq 1$. In the following section we have calculated viscosity using both methods for comparison.

Mader et al. (2013) provide a flow chart by which to choose the best method for calculating $\eta$. They suggest first to determine if $\varphi / \varphi_{m}$ is less than 0.5 , and if it is then to simply calculate $\eta_{r}$ as a Newtonian fluid by

$$
\eta_{r}=K_{r}
$$

where $K_{r}$ is the relative consistency calculated by 


$$
K_{r}=\left(1-\frac{\varphi}{\varphi_{m}}\right)^{-2}
$$

For samples with $\varphi / \varphi_{m}$ greater than 0.5 , we then need to determine if the sample has a yield strength $\left(\tau_{0}\right)$ or not. Mader et al. (2013) suggest that samples with $\varphi / \varphi_{m}$ less than 0.8 do not possess a detectable yield strength, and $\eta_{r}$ can be calculated by the power law equation

$$
\eta_{r}=K_{r} \dot{\gamma}^{n-1}
$$

where $K_{r}$ is calculated using equation 3.11, $n$ is calculated using Equation 3.9 or by slope of measured $\ln$ stress vs $\ln \dot{\gamma}$, and the strain rate $(\dot{\gamma})$ at which viscosity is to be calculated. Equation 3.12 is to be used if $n$ is less than 0.9 and equation 3.10 if $n$ is greater than 0.9 .

For samples with $\varphi / \varphi_{m}$ greater than 0.8 we need to first determine the yield strength $\left(\tau_{0}\right)$. We used Figure 3.20 to approximate yield strength by linear extrapolation of the curves through the y axis. Stress $(\tau)$ can then be calculated by

$$
\tau=\tau_{0}+K \dot{\gamma}^{n}
$$

derived by Herschel and Bulkley (1926), where $K$ (consistency) is the stress required to deform the material at a strain rate of $1 \mathrm{~s}$. Once again $n$ can be calculated using Equation 3.9 or by the slope of $\ln$ stress vs. $\ln \gamma$. The apparent magma viscosity can then simply be calculated by dividing $\tau$ by $\gamma$. 


\subsubsection{Results}

The values for $n, K_{r}, K, \tau_{0}, \varphi, r_{p}$, and $\varphi / \varphi_{m}$ used for modeling are shown in Table 3.6 with the results of the modeling shown in Figures 3.38 and 3.39. The values for calculated viscosity using each of the methods are provided in Tables A-7- A-10 within the appendix.

Table 3.6 Properties for each sample used in calculating magma viscosity.

\begin{tabular}{c|c|c|c|c|c|c}
\hline Sample T $\left({ }^{\circ} \mathbf{C}\right)$ & $\mathbf{1 2 2 6}$ & $\mathbf{1 2 3 4}$ & $\mathbf{1 2 3 6}$ & $\mathbf{1 2 4 1}$ & $\mathbf{1 2 5 5}$ & \\
\hline Property & \multicolumn{5}{|c}{} & Units \\
\hline $\boldsymbol{\varphi}$ & 0.42 & 0.30 & 0.25 & 0.23 & 0.17 & - \\
$\boldsymbol{r} \boldsymbol{p}$ & 6.22 & 6.99 & 6.38 & 6.21 & 4.44 & - \\
$\boldsymbol{\varphi}_{\mathrm{m}}$ & 0.40 & 0.39 & 0.40 & 0.40 & 0.45 & - \\
$\boldsymbol{\varphi} / \boldsymbol{\varphi}_{\mathrm{m}}$ & 1.05 & 0.79 & 0.62 & 0.58 & 0.39 & - \\
$\boldsymbol{n}(\mathbf{c a l c})$ & - & 0.47 & 0.81 & 0.86 & 0.98 & - \\
$\boldsymbol{n}(\mathbf{m e a s})$ & 0.74 & 0.81 & 0.89 & 0.91 & 0.95 & - \\
$\boldsymbol{K} \boldsymbol{r}$ & 455 & 22 & 7 & 6 & 3 & - \\
$\boldsymbol{K}$ & 835 & 379 & 416 & 233 & 174 & - \\
$\boldsymbol{\tau} \mathbf{0}$ & 141 & 114 & 61 & 26 & 17 & $\mathbf{P a}$ \\
$\boldsymbol{\eta l} \boldsymbol{l i q}(\boldsymbol{G R D})$ & 108 & 76 & 79 & 68 & 46 & Pa s \\
\hline
\end{tabular}

Figure 3.29 shows calculated magma viscosities using the guidelines of Mader et al. (2013), using the calculated $n$ values from equation 3.9, plotted vs. measured magma viscosity. Sample $1226^{\circ} \mathrm{C}$ is not included in Figure 3.29 since $n$ cannot be calculated when $\varphi / \varphi_{m}$ is greater than 1 . Data from sample $1234^{\circ} \mathrm{C}, 1236^{\circ} \mathrm{C}$ and $1241^{\circ} \mathrm{C}$ yields $\varphi / \varphi_{m}$ $<0.8$ and $n<0.9$, meeting the criteria for power law modeling (equation 3.12) according to the guidelines of Mader et al. (2013). Sample $1255^{\circ} \mathrm{C}$ yields $\varphi / \varphi_{m}<0.5$, and $n>$ than 0.9, allowing treatment as a Newtonian fluid at high strain rates (e.g. for CC experiments) according to Mader et al. (2013). We used the power law equation (3.12) to calculate 
viscosity at low temperatures and low strain rates. Simply using the flow consistency $\left(K_{r}\right)$ would yield viscosity values $>$ than 6 orders of magnitude lower than measured values for this experiment.

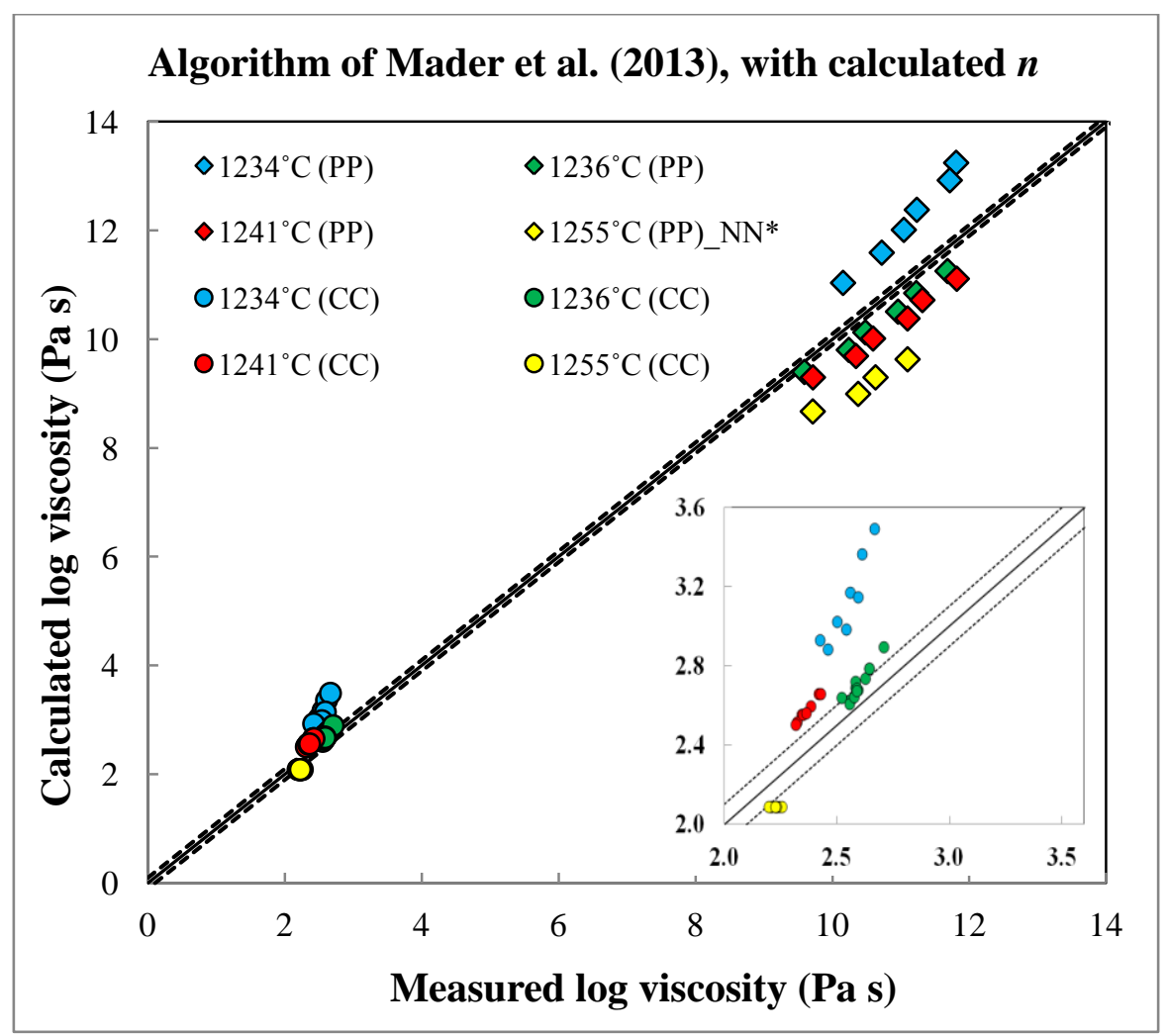

Figure 3.29. Calculated magma viscosity vs. measured magma viscosity. A close up of the high temperature $\mathrm{CC}$ values is provided in the lower right inset. All values calculated using the algorithm of Mader et al. (2013), excluding sample $1255^{\circ} \mathrm{C}$ (PP), which we used the nonNewtonian power law equation to calculate viscosity. Dotted lines represent $+/-0.1 \log$ units.

The resulting viscosities, calculated entirely following the recommended procedures of Mader et al. (2013) are noticeably in-accurate at low temperatures when compared to the measured results from the PP experiments (Figure 3.29). It underestimates values for all experiments, except for $1234^{\circ} \mathrm{C}$, which it over estimates. The model generally predicts values closer to measured values for the high temperature experiments. An enlarged view of this range in the bottom right of the figure provides a 
better view of the differences between calculated and measured values. The model over estimates viscosity for all samples, except for $1255^{\circ} \mathrm{C}$, which it underestimates. The difference between calculated and measured becomes greater at higher viscosities for all samples except $1255^{\circ} \mathrm{C}$ (Tables A-7).

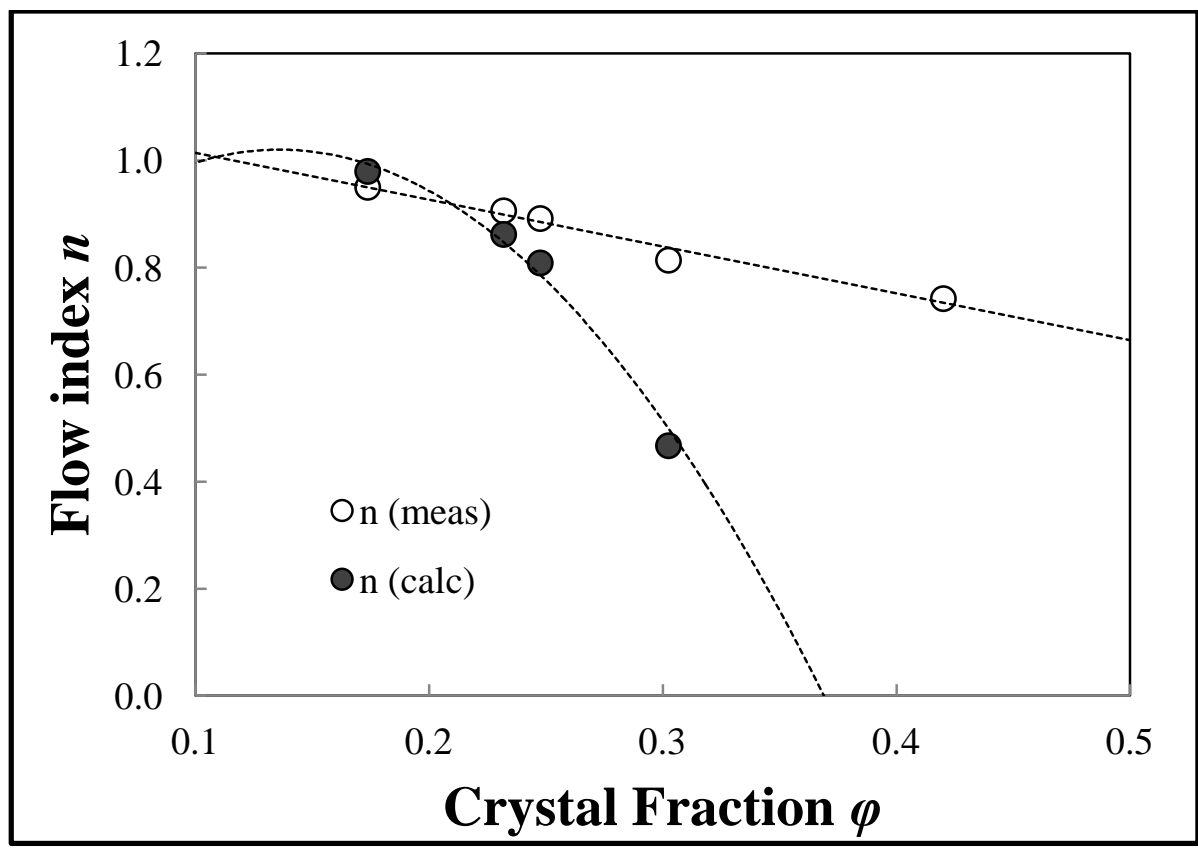

Figure 3.30. Flow index $(n)$ vs. crystal fraction. Measured values for $\boldsymbol{n}$ derived from slope of In stress vs. In strain rate. $n$ cannot be calculated for the highest crystal content.

Figure 3.30 shows calculated $n$ and measured $n$ values plotted against crystal fraction. The difference between the two becomes large at higher crystal fractions, potentially resulting in great differences in calculated viscosity. To better constrain the causes for inaccuracy in Figure 3.29, we recalculated viscosity using the guidelines of Mader et al. (2013) but this time using measured $n$. The results are shown in Figure 3.31. 


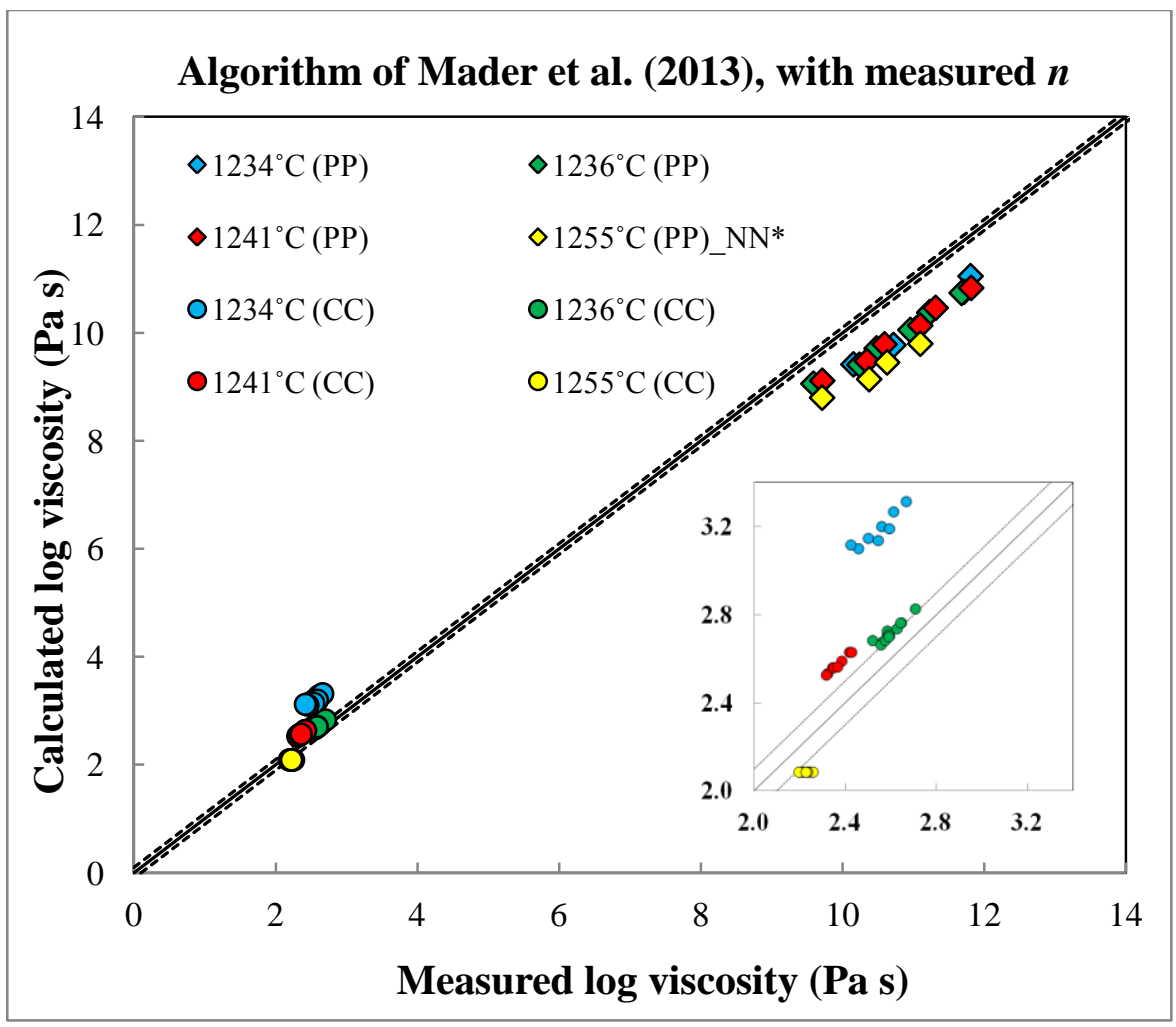

Figure 3.31. Calculated magma viscosity vs. measured magma viscosity, using Mader's guidelines with measured $n$.

Calculated viscosity values at high temperatures are again close to the measured values. At low temperatures the calculated values are all close to $0.5 \log$ unites lower that the measured values, although this is much better than before (Tables A-8).

Figure 3.32 shows calculated magma viscosities using only the Herschel Bulkley equation (3.13) with measured $n$. We used the yield strength values that we calculated with linear extrapolations through the $\mathrm{y}$ axis of Figure 3.14(B) to calculate stress using equation 3.13. We then divided stress by the strain rates measured in the $\mathrm{CC}$ viscometer. While this method yields consistently accurate data at high temperatures, most within 0.1 $\log$ units, all of the samples, except $1226^{\circ} \mathrm{C}$ begin on the $1: 1$ and begin to deviate at higher 
values. At low temperatures the model appears to be less accurate, with higher viscosities, and lower strain rates. At low temperatures the Herschel Bulkley equation severally underestimates viscosity by 3-4.3 log units (Tables A-9).

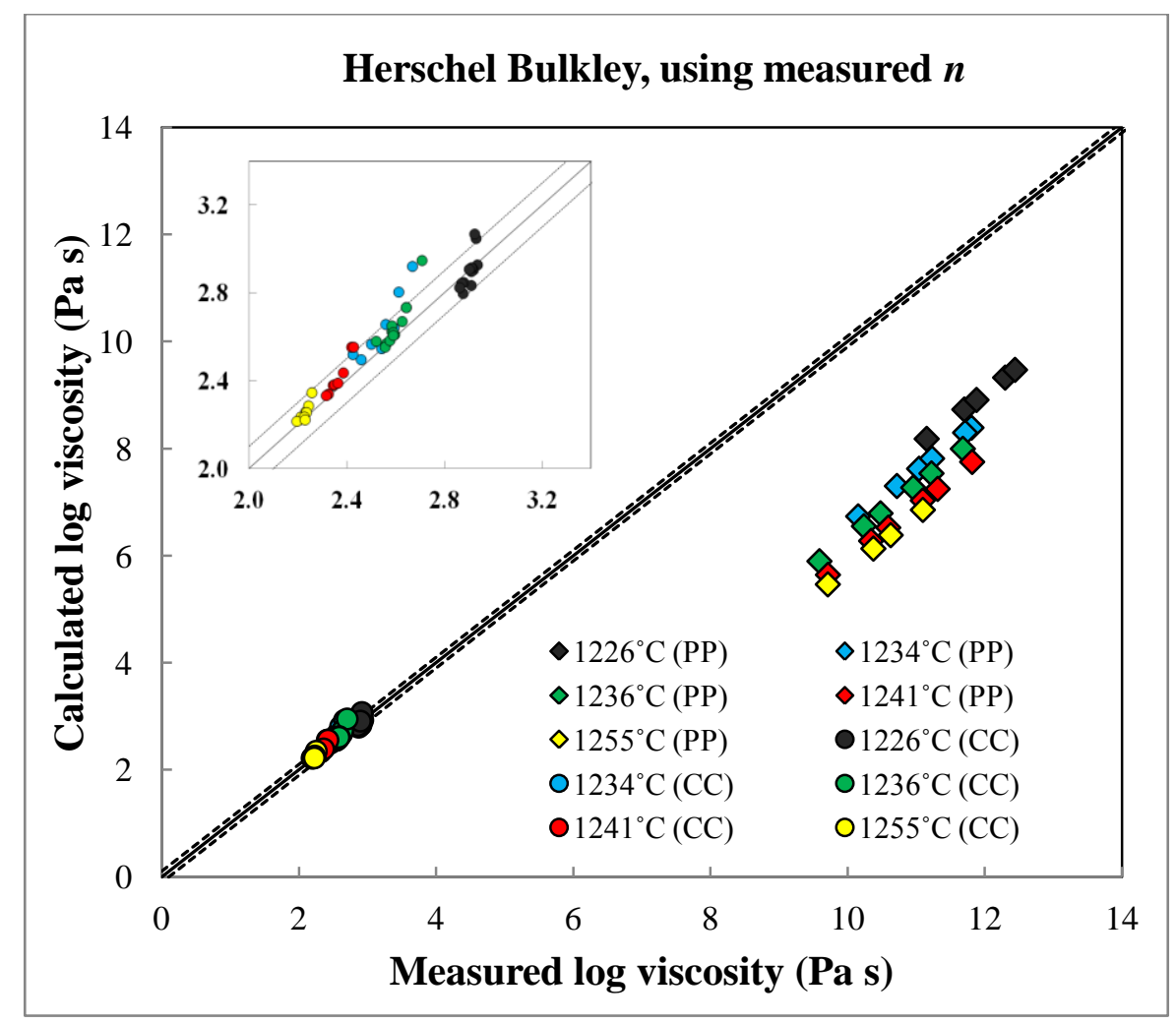

Figure 3.32. Calculated magma viscosity vs. measured magma viscosity using Herschel Bulkley equation (3.13). A close up of the high temperature CC values is provided in the top left inset.

For comparison, Figure 3.33 shows calculated and measured magma viscosities using only the non-Newtonian power law equation (3.12) and empirically derived $n$. The model is less accurate than the Herschel Bulkley model at high temperatures, appearing to be less accurate for samples with higher crystal fractions $\left(1226\right.$ and $\left.1234^{\circ} \mathrm{C}\right)$. It is how ever slightly more accurate for all samples, except $1226^{\circ} \mathrm{C}$, at low temperatures. 
Although calculated values are still generally off by $\sim 1 \log$ unit, with $1226^{\circ} \mathrm{C}$ off by $\sim 3$ $\log$ units (Tables A-8 and A-10).

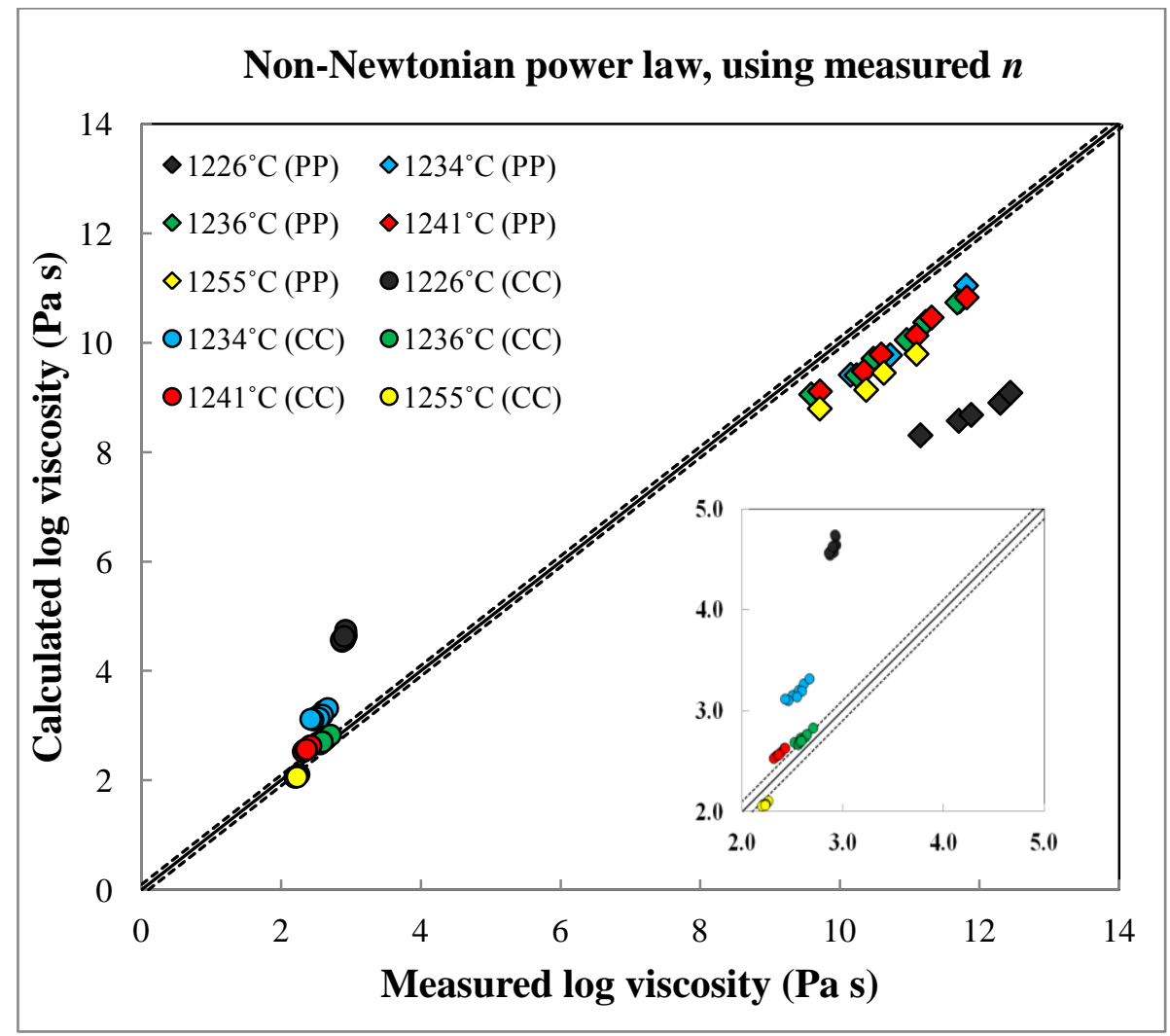

Figure 3.33. Calculated magma viscosity vs. measured magma viscosity using nonNewtonian power law equation (3.12). A close up of the high temperature $C C$ values is provided in the bottom right inset.

\subsubsection{Summary of Model Accuracy}

We determined the rmsd (root-mean-square deviation) between calculated and measured viscosity to help in summarizing the accuracy of each method used (Table 3.7). Explicitly using the algorithm of Mader et. al (2013), along with liquid viscosity of Giordano et al. (2008), and the calculated flow index (n) from the equation (3.9) of Mueller et al. (2010), yields a 0.305 rmsd at high temperatures compared to measured 
viscosity using the $\mathrm{CC}$ viscometer, and a 0.890 rmsd at lower temperatures compared to measured viscosity using the PP viscometer. When using measured $n$ from the slope of $\ln$ stress vs. ln strain rate, the rmsd values are only slightly further off at 0.326 and 0.918 for measured CC and PP data respectively. When comparing the data in Figures 3.29 and 3.31, we see the minimal difference between using calculated and measured $n$. We do however see a large change in the calculated viscosity for sample $1234^{\circ} \mathrm{C}$ at low temperatures. We also see a less discernible variance in the data at high temperatures. In Figure 3.29 we see a slight deviation from the 1:1 line at higher viscosities and smaller strain rates. Using measured $n$, seems to eliminate this effect, suggesting that using an empirical $n$ well better account for lower strain rates in the power law equation. When referencing the Mueller et. al (2010) for the formulation of equation 3.9, we find out that it is based on results of several experiments with monodisperse suspensions. Our samples contain polydisperse suspensions, likely contributing to the difference in between calculated and measured $n$. We see in Figure 3.30, that the calculated $n$ is affected more by crystal fraction, compared to measured $\mathrm{n}$, which produces a greater shear thinning effect, that what might actually be present in our samples. This is likely the result of our crystals containing both high aspect ratio plagioclase crystals and low aspect ratio $\mathrm{Fe}$ oxides. For this reason, we suggest not using equation 3.9 for flow index when calculating viscosity of a fluid with polydisperse suspensions. Only calculate viscosity if data is available for calculating $n$ from $\ln$ stress vs. ln strain rate. 
Table 3.7. Rmsd values for each method used. MDR represents values calculating using the algorithm of Mader et al. (2013).

\begin{tabular}{l|c|c}
\hline Method & rmsd & rmsd \\
\hline MDR w/ calc $\boldsymbol{n}$ & 0.305 & 0.890 \\
\hline MDR w/ emp $\boldsymbol{n}$ & 0.326 & 0.918 \\
\hline all NN w/ emp $\boldsymbol{n}$ & 0.915 & 1.604 \\
w/no 1226 & 0.328 & 0.918 \\
\hline all HB w/ emp $\boldsymbol{n}$ & 0.080 & 3.690 \\
\hline
\end{tabular}

Figure 3.33 shows essentially the same results as Figure 3.31 except includes the results of sample $1226^{\circ} \mathrm{C}$ and calculates sample $1255^{\circ} \mathrm{C}$ using the non-Newtonian power law equation, rather assuming Newtonian behavior as was done using Mader's algorithm. Rmsd values are provided in Table 3.7 and show values calculated both with and without $1226^{\circ} \mathrm{C}$ included. In no form of the model is sample $1226^{\circ} \mathrm{C}$ calculated to within even 1 $\log$ unit to measured viscosity at low temperatures. This sample yields a $\varphi / \varphi_{m}>1 . \varphi / \varphi_{m}$ plays a critical role in calculating viscosity as it is used to calculate $n$ (equation 3.9), and $K_{r}(3.11)$, which are used in all equations for calculating viscosity. Values of $\varphi / \varphi_{m}>1$ result in negative $n$ when calculated using equation 3.9, not allowing for viscosity to be calculated using Mader's algorithm, and furthermore result in unreasonably high values for $K_{r}$, yielding large underestimations of calculated viscosity when using empirically derived $n$.

Finally, Figure 3.32 shows the calculated values using only the Herschel Bulkley equation (3.13), which ironically yields the most accurate calculations at high temperatures with a rmsd of 0.080 , and the least accurate at low temperatures with a rmsd of 3.690 . 
Considering the results of all modeling, we would consider using these models only with caution. We suggest only using the model to calculate viscosities at high temperatures, and we suggest using the Herschel Bulkley equation along with measure $n$, if both yield strength, and stress/strain rate data is available. However, this seems to go contradict the intent of a viscosity model, as substantial measurements would be required to use it. Also, considering the inaccuracy at low temperatures, we must remember that magma viscosity is calculated from relative viscosity, which includes the liquid viscosity calculated by the Giordano model. If we refer to Figure 3.6, we see that the Giordano model over estimates liquid viscosity by 0.3 to greater than $2 \log$ units at lowest temperatures. However, as magma viscosity is calculated by multiplying calculated relative viscosity $\left(\eta_{r}\right)$ by liquid viscosity, if we were to use values from measured liquid viscosity (using the TVF in Figure 3.6), which are consistently less than values calculated using Giordano, our calculated magma viscosity values would be less than those already obtained. This would improve the agreement between calculated and measured viscosities for samples 1226 and $1234^{\circ} \mathrm{C}$, but would become worse for all other data. For this reason, relatively closer values obtained for 1226 and $1234^{\circ} \mathrm{C}$, would be only fortuitous and not represent an improvement in model accuracy. Inaccuracy at low temperatures is also related to strain rate, as Mader et al. (2013) states that the power law equation (3.12) does not work well at very low or very high strain rates, which is purely a function of the form of the equation. 


\section{CHAPTER 4-CONCLUSIONS}

\subsection{Summary of findings}

Pacaya volcano erupted explosively on May $27^{\text {th }} 2010$. Two lava flows erupted from opposing flanks of the volcano, and voluminous tephra (including ash size, up to lapilli and bomb sized fragments) was erupted from the NW side of the volcano, where an elongate fissure was formed. This eruption was unique compared to more recent eruptions, aside from being more explosive; the location of the new flows marks a change in the eruptive behavior at the volcano. In January 2012, we conducted field work at the volcano, and acquired samples of the various types of erupted material.

Our petrographic analyses in Chapter 2 revealed textural differences not only between flow and tephra samples, but also within the flow between vent and toe samples, and within individual lapilli. Tephra samples exhibit both glassy areas, and extremely microcrystalline areas, suggesting mingling of two different component magmas (Figure 2.5). Near vent samples exhibit a glassy groundmass, with few microcrystals evident only at high magnification, while samples from further down flow typically exhibit a very crystalline groundmass. These observations led to questions regarding the time-frame for forming these textures. We suggested that the largely glassy texture within the tephra was indicative of rapid ascent, eruption, and quenching. We suggested that the groundmass crystallization of the flow samples may have been the result of slower cooling either in the conduit, or within the flow following eruption. We questioned whether the time-scale of flow emplacement would be long enough to allow for down-flow samples to 
crystallize to the degree observed. Experimental work from Chapter 3 was partly aimed at answering these questions.

The chemical analyses in Chapter 2 revealed a trend of increasing $\mathrm{SiO}_{2} \mathrm{wt} \%$ in the bulk sample from vent to toe, with tephra samples generally more silicic than toe samples. This trend was tentatively attributed to chemical layering within the magma chamber, with less dense and more evolved magma concentrating at the top of the chamber (Blake and Ivey 1986). We propose that flow toes and tephra samples originated from near the top of the magma chamber, while and the near-vent samples, which must represent the very last products of the eruption, were tapped from deeper within the magma chamber. Microprobe analyses of minerals provide further evidence for this theory with more $\mathrm{Mg}$-rich olivine and clinopyroxene phenocrysts found in up-flow and near-vent samples. This simple description is somewhat at odds with the observation that the tephra samples erupted about 10 days after lave flow activity began. At the end of this chapter we present a model for the May 2010 eruption that can potentially reconcile all the observations.

In Chapter 3 we describe viscosity measurement of lava flow samples, which was $\sim 10^{13} \mathrm{~Pa} \mathrm{~s}$ at approximately $1000^{\circ} \mathrm{C}$. We concluded that these flow samples would be effectively rigid even at temperatures greater than $1000^{\circ} \mathrm{C}$. Based on these measurements we predict that the samples underwent significant amounts crystallization during the final stages of cooling after the sample traveled down flow. Very high (near-liquidus) temperatures can be maintained in the interior of basaltic lava flows, allowing some crystallization to occur within the time scale of flow activity, a maximum duration of 2-3 
weeks (Wolf, 2010). We conducted 6 isothermal subliquidus experiments to not only study the affect of crystallization on viscosity, but also to determine if substantial crystallization could occur on the time scale of flow activity. We produced a range of crystal fractions between approximately $17-42 \%$ in experiments that lasted between 3-30 hours, yielding similar textures to those seen in the lava flows, confirming that crystallization of the groundmass of down-flow could occur on the observed time scale of flow activity.

Low temperature (at or below the solidus) crystallization experiments at $950^{\circ} \mathrm{C}$ produced similar acicular textures present in the lapilli tephra on time scales between 0 and 120 minutes. We can combine the textures of crystals grown in high temperature and low temperature crystallization experiments, to explain the different textures of crystals within the lapilli. It is likely that the lapilli first underwent relatively slow cooling while in the magma chamber allowing for phenocryst and microphenocryst growth, and then experienced rapid cooling creating both the glassy and acicular microcrystals.

We measured the rheology of remelted lava samples with between $0 \%$ to $80 \%$ crystals. Our initial crystal-free remelt experiments measured liquid viscosity between $0.35-10^{11.7} \mathrm{~Pa} \mathrm{~s}$ at temperatures between $1600-680^{\circ} \mathrm{C}$. We used the results to fit a TVF equation, allowing the viscosity of the crystal-free melt to be interpolated at subliquidus temperatures. We tested the accuracy of the widely used Giordano et al. (2008) model, finding that it overestimated viscosity near the glass transition by as much as $2 \log$ units, but only under-estimated viscosity at high temperatures by less than $0.5 \log$ units. We measured crystal-bearing magma viscosity between $10^{2.2}-10^{2.9} \mathrm{~Pa} \mathrm{~s}$ at temperatures 
between $1255-1226^{\circ} \mathrm{C}$. Cores from the quenched post-CC experiments were then used to measure viscosity between $10^{9.7}-10^{12.5} \mathrm{~Pa}$ s at lower temperatures between $750-1000^{\circ} \mathrm{C}$. We were then able to interpolate between the measurements at high and low temperatures, allowing the viscosity of partially crystalline magma to be estimated at subliquidus temperatures. We used the results of these experiments to test current models that calculate the rheology of crystal bearing suspensions as a function crystal fraction.

Viscosity data using an algorithmic approach by Mader et al. (2013), including flow index $(n)$ calculated from an equation formulated by Mueller et al (2010), are within $\sim 0.3 \log$ units of measured values at high temperatures, and within only $\sim 0.9 \log$ units at low temperatures. As the flow index equation formulated by Mueller et al (2010) was derived through experiments on monodisperse suspensions, we approached using it with caution, as we measured viscosity of polydisperse suspensions. We used an empirically derived flow index (measured $n$ ) to further test the accuracy of the models, and found that a best fit is acquired at high temperatures within $0.1 \log$ units using the Herschel Bulkley equation, which requires yield strength to be measured. However data was sufficiently inaccurate at low temperatures, predicting viscosity greater than $1 \log$ units lower than measured. Considering the purpose for the model is to calculate viscosity with minimal empirical work, we conclude that accurate viscosity can only be determined through measurement. We suggest using the model only with caution at high temperatures, and not using the model at low temperatures and with low strain rates. 


\subsection{Petrologic Model}

Based on our petrographic and chemical analyses from Chapter 2, and our experimental work from Chapter 3, we propose a hypothetical model for the May 2010 eruption of Pacaya volcano (Figure 4.1).

We present two possible explanations for the chemical trend in the erupted samples. Firstly we can explain the more silicic tephra samples compared to the toe samples, by assuming that the toe samples do not actually represent the earliest erupted material. It is likely that the earliest erupted material, which tapped the uppermost and most silicic portion of the magma chamber was not sampled, and was likely overlain by later erupted material. In this scenario the timing of erupted products would agree with the chemical trend that we see, however further explanation is required to address the difference in eruptive behavior between flows and bombs.

We propose is that the uppermost and most silicic portion of the magma chamber became trapped under a plug in the main conduit, likely formed at the end of a previous eruption. Pressure could continue to build in the chamber, and volatiles could concentrate in the upper portion of the chamber and beneath the plug, while some magma could propagate through lateral conduits or fractures. If a path or fracture became available flows could migrate upward erupting at the NW and SE vents, which fall along a line that intersects the summit, Cerro Chino, and the most recently active vent from January 2014. Considering the evidence for this $\sim \mathrm{NW}-\mathrm{SE}$ trending fracture, which is the likely result of E-W extension in the region (Lyon-Caen et al. 2006), it is likely that multiple paths for magma flow exist in the subsurface. We know that the flows remained active for 7-10 
days before the violent strombolian eruption, which would allow for volatiles to concentrate beneath the plug and more pressure build up. Upon the plug rupturing, massive fragmentation could occur within the magma trapped beneath the plug, resulting in an explosive strombolian/vulcanian eruption, producing tephra with chemical signatures more silicic than flow samples. Gentler strombolian eruptions continued while the flows remained active for several days more, possibly erupting as degassed slugs created by temporary rheological barriers through which fresh magma bursts, as proposed for Stromboli (Gurioli et al. 2013).

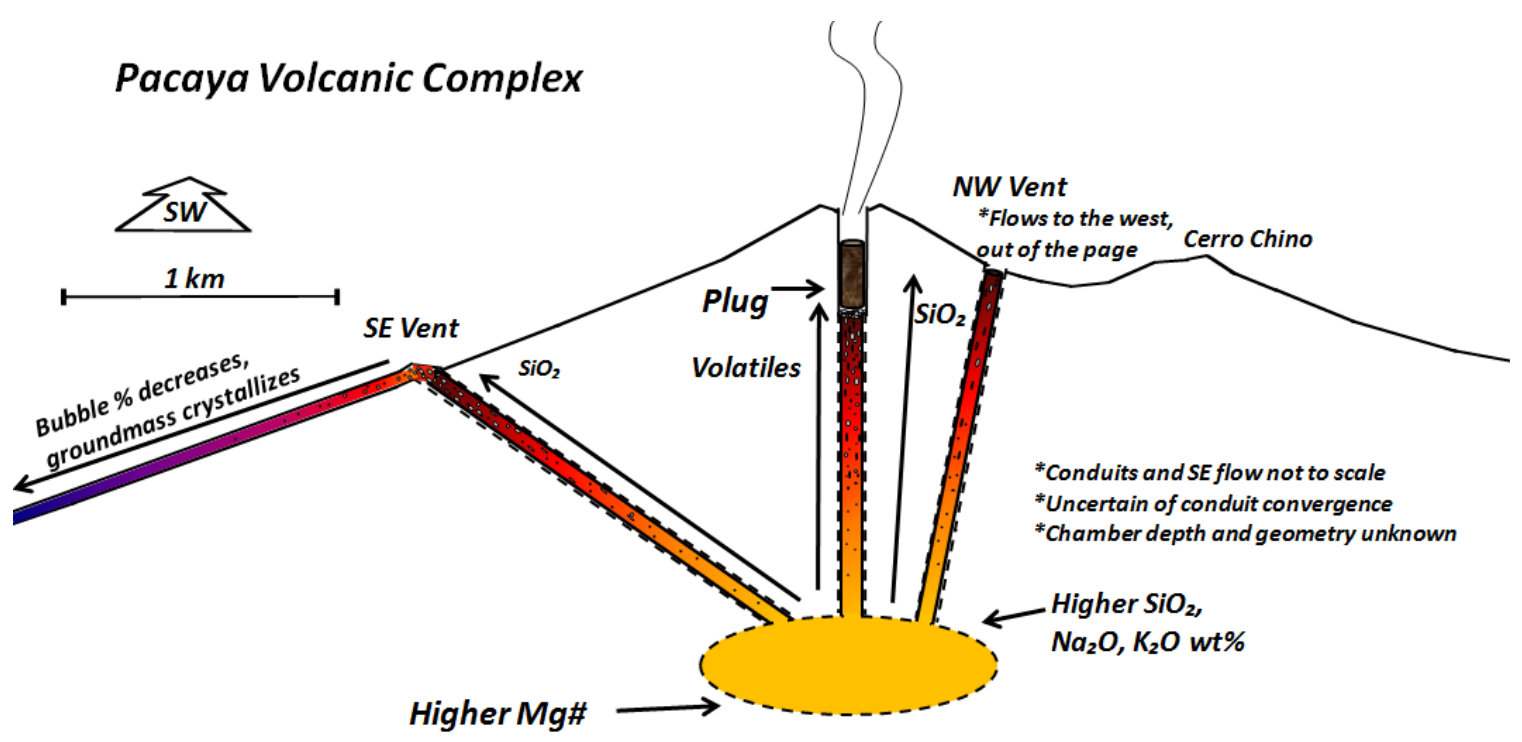

Figure 4.1. Conceptual model for Pacaya volcano prior to the May $27^{\text {th }}$ eruption. View is perpendicular to lineation of vents, with no vertical exaggeration. Material tapped from the upper magma chamber remains trapped under the plug building pressure, while the $\mathrm{SE}$ and NW flows remain active. Once the plug is fractured, the magma will fragment rapidly, forming ash, lapilli, and bombs. 


\subsection{Future Work}

While this study provides the framework for a comprehensive experimental approach for studying magma rheology, it could benefit from further field research and experimental work.

Future studies would benefit by acquiring fresh samples immediately after eruption. While this may pose a danger to the scientist that acquires the samples, it would provide a better constraint on the degree of crystallization in the chamber prior to eruption. All of our acquired samples have undergone cooling outside of the volcano and have crystallized differently depending on cooling rate subsequent to eruption. If we could gather a rock near the vent, or pieces of tephra, immediately after eruption, and quench the samples in water, we could essentially freeze in the crystal proportions present in the sample prior to eruption. We could then more accurately constrain the degree of crystallization within the chamber, and during ascent, and furthermore could calculate viscosity of the acquired sampled to estimate the rate of magma ascent.

More samples is usually better, at least in geological research. This was evident when comparing results between the SE and NW flows, as the additional samples acquired for the SE flow consistently revealed more definitive trends, allowing for outliers to be more easily identified. Future work would therefore benefit by acquiring plentiful samples from vent to toe.

With regards to experimental work, time limitations only allowed for 5-6 subliquidus experiments to be conducted. While we were able to produce 5-6 crystal 
fractions at different temperatures, we were only able to study the time-dependence of the crystallization between two experiments $\left(1234\right.$ and $\left.1236^{\circ} \mathrm{C}\right)$. Future work would benefit by conducting multiple experiments at the same temperature for different times to study this. Also, experimental data are always better when reproducibility is measured. Repeated experiments would test the reproducibility of all data, including the melt accumulation on spindles within subliquidus CC experiments.

Lastly, with regards to the magma modeling, further work is needed in constructing a model that can accurately calculate magma viscosity at low strain rates. While further calibration of the Giordano et al. (2008) model may provide more accurate liquid viscosity calculations at low temperatures, the presence of crystals and their variable influence at different strain rates is the single greatest source of uncertainty in calculating magma rheology. A new equation or recalibration of current models is needed to calculate non-Newtonian magma viscosity.

Ongoing work by Alexander Sehlke, and Arianna Soldati at the University of Missouri-Columbia, will provide information on the subliquidus magma rheology of a variety of terrestrial and extraterrestrial magmas. 


\section{REFERENCES}

Avard, G. \& Whittington, A. G. Rheology of arc dacite lavas: experimental determination at low strain rates. Bulletin of Volcanology 74, 1039-1056 (2012)

Bardintzeff, J.M., Deniel, C. Magmatic evolution of Pacaya and Cerro Chiquito volcanological complex, Guatemala. Bull. Volcanol. 54, 267-283 (1992)

Bau,Bohenberger, O.H., Los Focos Eruptivos Cuaternarios De Guatemala., Publicaciones Geológicas del ICAITI. Número II. P. 23-24 (1969)

Bolge, L. L., Carr, M. J., Milidakis, K. I., Lindsay, F. N. \& Feigenson, M. D. Correlating geochemistry, tectonics, and volcanic volume along the Central American volcanic front. Geochemistry, Geophysics, Geosystems 10, (2009)

Bouhifd, M. a. et al. Thermochemistry and melting properties of basalt. Contributions to Mineralogy and Petrology 153, 689-698 (2006)

Burkart, B., and Self, S. Extension and rotation of crustal blocks in northern Central America and effect on the volcanic arc, Geology, 13, 22-26, (1985)

Chesner, C.A., and Halsor. S.P. Geochemical trends of sequential lava flows from Meseta Volcano, Guatemala. Journal of Volcanology and Geothermal Research 78 (3-4): 221-237 (1997).

Cimarelli, C., Costa, a., Mueller, S. \& Mader, H. M. Rheology of magmas with bimodal crystal size and shape distributions: Insights from analog experiments. Geochemistry, Geophys. Geosystems 12, (2011).

Costa, A., Caricchi, L. \& Bagdassarov, N. A model for the rheology of particle-bearing suspensions and partially molten rocks. Geochemistry, Geophys. Geosystems 10, (2009).

Dingwell, D. B., Viscosity and anelasticity of melts. AGU Reference Shelf, 2, 209-217. (1995)

Dingwell, D.B., Transport properties of magmas: Diffusion and rheology. Elements 2, 281-286. (2006)

Einstein, A. Eine neue Bestimmung derMoleküldimensionen. Annals of Physics 19, 289306. (1906)

Einstein, A. Berichtigung $\mathrm{zu}$ meiner Arbeit: Eine neue Bestimmung der Moleküldimensionen. (1911)

Eggers, A. A. The geology and petrology of the Amatitlan quadrangle., Guatemala. Ph.D. thesis, Hanover, N.H., Dart- mouth College, pp 1-221. (1972) 
Fisher, R. 1961. Proposed classification of volcaniclastic sediments and rocks. Geol. Soc Amer.Bull., 72: 1409-1414

Gent, A.N. Theory of the parallel plate viscometer. British Journal of Applied Physics 11, 85-87 (1960).

Getson, J. M. \& Whittington, A. G. Liquid and magma viscosity in the anorthiteforsterite-diopside-quartz system and implications for the viscosity-temperature paths of cooling magmas. Journal of Geophysical Research 112, B10203 (2007).

Ghiorso, M. S., and Sack, R. O. "Chemical Mass Transfer in Magmatic Processes. IV. A Revised and Internally Consistent Thermodynamic Model for the Interpolation and Extrapolation of Liquid-Solid Equilibria in Magmatic Systems at Elevated Temperatures and Pressures." Contributions to Mineralogy and Petrology, v.119, pgs:197-212 (1995)

Ginibre, C. \& Kronz, A. Crystal Zoning as an Archive. 261-266 (2007).

Giordano, D., Russell, J.K., and Dingwell, D.B., Viscosity of Magmatic Liquids: A Model. Earth and Planetary Science Letters, v. 271, p. 123-134 (2008).

Gurioli, L., Colo', L., Bollasina, A., Harris, A., Whittington, A., and Ripepe, M., Dynamics of Strombolian Explosions: Inferences from field and laboratory studies of erupted bombs from Stromboli volcano, J. Geophys. Res. Solid Earth, 119, 1-27 (2013).

Herschel W. H. and Bulkley R. Konsistenzmessungen von Gummi-Benzollösungen. Kolloid Z. 39, 291-300 (1926).

Ishibashi, H. Non-Newtonian behavior of plagioclase-bearing basaltic magma: Subliquidus viscosity measurement of the 1707 basalt of Fuji volcano, Japan. Journal of Volcanology and Geothermal Research 181, 78-88 (2009).

Kitamura, S., Matías, O., Pacaya Volcano. Tephra Stratigraphic Approach to the Eruptive History of Pacaya Volcano, Guatemala. The Science Reports of the Tohku University $7^{\text {th }}$ Series Geograpy 45 (1995).

Krieger, I.M., Dougherty, T.J. A mechanism for non-Newtonian flowing suspensions of rigid spheres. Transactions. Society of Rheology 3, 137-152. (1959).

Lavallée, Y., Hess, K.-U., Cordonnier, B., Dingwell, D.B. Non-Newtonian rheologi- cal law for highly crystalline dome lavas. Geology 35, 843. (2007).

Lofgren, G.E. An experimental study of plagioclase crystal morphology: isothermal crystallization. American Journal of Science 274: 243-273 (1974)

Lyon-Caen, H., Barrier, E., Lasserre, C., Franco, A., Arzu, I., Chiquin, L., Chiquin, M., Duquesnoy, T.,. Flores O., Galicia, O., Luna, J., Molina, E., Porras, O., Requena, 
J., Robles, V., Romero, J., and Wolf, R. Kinematics of the North AmericanCaribbean-Cocos plates in Central America from new GPS measurements across the Polochic-Motagua fault system. Geophysical Research Letters 33, L19309 (2006).

Mader, H. M., Llewellin, E. W. \& Müller, S. P. The Rheology of Two-Phase Magmas: A Review and Analysis. Journal of Volcanology and Geothermal Research 257, 135-158 (2013).

Marsh, B. D. On the Interpretation of Crystal Size Distributions in Magmatic Systems. Journal of Petrology 39, 553-599 (1998).

Mueller, S., Llewellin, E.W., Mader, H.M., The rheology of suspensions of solid particles. Proceedings of the Royal Society 466, 1201-1228. (2010).

Pinkerton, H., Wilson, L., and Macdonald, R. The transport and eruption of magma from volcanoes : a review. Contemporary Physics, 43, 197-211 (2002).

Putirka, K. D. Thermometers and Barometers for Volcanic Systems. Rev. Mineral. Geochemistry 69, 61-120 (2008).

Roscoe, R. The viscosity of suspensions of rigid spheres. Journal of Applied Phys- ics 2, 267-269. (1952)

Rosenow, E., Bollasina, A., Chigna, G., and Whittington, A. Using xenoliths to investigate magma ascent: the May 2010 Strombolian eruption of Pacaya volcano, Guatemala. GSA Abstract (2013).

Rutgers I.R. Relative viscosity of suspensions of rigid spheres in Newtonian liquids. Rheol. Acta 2, 305-348. (1962a).

Rutgers I.R. Relative viscosity and concentration. Rheol. Acta 2, 305-348. (1962b).

Sato, H., Viscosity measurement of subliquidus magmas : 1707 basalt of Fuji volcano. Journal of Mineralogical and Petrological Sciences, 100, 133-142 (2005)

Schuessler J. A., Botcharnikov R. E., Behrens H., Misiti V. and Freda C. Oxidation state of iron in hydrous phono-tephritic melts. Am. Mineral. 93, 1493-1504 (2008)

Sisson, G.W. and Layne G. D., $\mathrm{H}_{2} \mathrm{O}$ in basalt and basaltic andesite glass inclusions from four subduction-related volcanoes. Earth and Planetary Science Letters. Volume 117, Issues 3-4, 619-635 (1993)

Vogel, D. H. Temperaturabhängigkeitsgesetz der Viskosität von Flüssigkeiten, Phys. Z., 22, 645-646 (1921). 
Vona, A., C. Romano, D.B. Dingwell, and D. Giordano (2011), The rheology of crystalbearing basaltic magmas from Stromboli and Etna. Geochim. Cosmochim. Acta, 75, 3214-3236.

Vona, A., C. Romano, D. Giordano, and Russell, J.K., The multiphase rheology of magmas from Monte Nuovo (Campi Flegrei, Italy), Chem. Geol., 346, 213-227 (2013)

Whittington, A.G., Magaldi,T., Calderas, A., Chigna, G., Escobar-Wolf, R., Lyons, J., Mathias, O., Robert, G., Seaman, S.,. Does magma rheology control eruption style? The case of Fuego, Guatemala. IAVCEI, Kagoshima, Japan. (2013)

Wilson, A. D., The micro-detrmination of ferrous iron in silicate melts by volumetric and colorimetric method. Analyst, 85, 823-827 (1960)

Wolf, R., E. The eruption of Volcán de Pacaya on May - June, 2010. Report in progress

Wunderman, R.L., and Rose, W.I., Amatitlán, an actively resurging caul- dron $10 \mathrm{~km}$ south of Guatemala City: Journal of Geophysical Research, v. 89, p. 8525-8539 (1984) 


\section{APPENDIX}

Table A-1. Bulk rock chemical analyses in wt\% from Actlabs. PA35 (2) is a duplicate sample of PA35, only was pulverized in the shatterbox for $\sim 8$ minutes longer.

\begin{tabular}{|c|c|c|c|c|c|c|c|c|c|c|c|c|}
\hline Sample & $\mathrm{SiO}_{2}$ & $\mathrm{Al}_{2} \mathrm{O}_{3}$ & $\mathrm{Fe}_{2} \mathrm{O}_{3}(\mathrm{~T})$ & MnO & MgO & $\mathrm{CaO}$ & $\mathrm{Na}_{2} \mathrm{O}$ & $\mathrm{K}_{2} \mathrm{O}$ & $\mathrm{TiO}_{2}$ & $\mathbf{P}_{2} \mathbf{O}_{5}$ & LOI & Total \\
\hline PA01 & 51.68 & 18.68 & 10.86 & 0.18 & 3.92 & 9.44 & 3.73 & 0.94 & 1.24 & 0.27 & -0.12 & 100.80 \\
\hline PA02 & 50.70 & 19.10 & 10.91 & 0.17 & 4.34 & 9.80 & 3.56 & 0.82 & 1.16 & 0.24 & -0.46 & 100.40 \\
\hline PA03 & 49.75 & 19.16 & 10.85 & 0.17 & 4.33 & 10.02 & 3.37 & 0.79 & 1.16 & 0.25 & -0.49 & 99.37 \\
\hline PA04 & 49.58 & 18.99 & 10.75 & 0.17 & 4.29 & 9.98 & 3.38 & 0.79 & 1.14 & 0.26 & -0.40 & 98.91 \\
\hline PA06 & 50.29 & 19.52 & 10.57 & 0.17 & 4.31 & 10.07 & 3.48 & 0.79 & 1.12 & 0.25 & -0.53 & 100.00 \\
\hline PA07 & 50.56 & 19.89 & 10.67 & 0.17 & 4.33 & 9.94 & 3.57 & 0.82 & 1.17 & 0.25 & -0.49 & 100.90 \\
\hline PA08 & 50.48 & 18.86 & 10.91 & 0.18 & 4.44 & 9.75 & 3.60 & 0.84 & 1.20 & 0.25 & -0.59 & 99.92 \\
\hline PA09 & 51.19 & 19.14 & 10.85 & 0.18 & 4.49 & 9.90 & 3.60 & 0.79 & 1.16 & 0.25 & -0.58 & 101.00 \\
\hline PA12 & 51.40 & 17.97 & 11.15 & 0.18 & 4.24 & 9.21 & 3.72 & 0.97 & 1.27 & 0.30 & -0.62 & 99.79 \\
\hline PA13 & 49.99 & 18.17 & 11.09 & 0.18 & 4.24 & 9.19 & 3.65 & 0.90 & 1.22 & 0.28 & -0.26 & 98.64 \\
\hline PA14 & 51.39 & 18.16 & 11.50 & 0.19 & 4.25 & 9.15 & 3.56 & 0.94 & 1.31 & 0.25 & -0.40 & 100.30 \\
\hline PA16 & 51.86 & 17.88 & 11.77 & 0.19 & 4.28 & 9.23 & 3.61 & 0.96 & 1.26 & 0.29 & -0.55 & 100.80 \\
\hline PA17 & 51.51 & 18.40 & 11.56 & 0.19 & 4.35 & 9.19 & 3.63 & 0.92 & 1.28 & 0.27 & -0.52 & 100.80 \\
\hline PA18 & 51.33 & 18.62 & 11.55 & 0.19 & 4.39 & 9.22 & 3.61 & 0.92 & 1.28 & 0.26 & -0.60 & 100.80 \\
\hline PA21 & 49.67 & 18.40 & 11.50 & 0.18 & 4.22 & 9.35 & 3.43 & 0.83 & 1.20 & 0.24 & -0.43 & 98.59 \\
\hline PA23 & 51.21 & 18.82 & 11.24 & 0.18 & 4.19 & 9.37 & 3.61 & 0.90 & 1.25 & 0.28 & -0.30 & 100.80 \\
\hline PA24 & 50.69 & 17.64 & 11.10 & 0.18 & 4.17 & 9.01 & 3.53 & 0.95 & 1.25 & 0.27 & -0.39 & 98.40 \\
\hline PA25 & 51.26 & 20.56 & 9.83 & 0.16 & 3.12 & 10.45 & 3.52 & 0.82 & 1.15 & 0.24 & -0.26 & 100.80 \\
\hline PA26 & 50.88 & 18.56 & 11.41 & 0.18 & 4.37 & 9.50 & 3.58 & 0.89 & 1.24 & 0.26 & -0.46 & 100.40 \\
\hline PA27 & 49.65 & 18.99 & 10.66 & 0.17 & 4.27 & 10.04 & 3.17 & 0.76 & 1.10 & 0.23 & -0.50 & 98.53 \\
\hline PA28 & 50.32 & 19.43 & 11.14 & 0.18 & 4.34 & 9.68 & 3.53 & 0.85 & 1.21 & 0.25 & -0.53 & 100.40 \\
\hline PA29 & 50.42 & 19.27 & 11.07 & 0.18 & 4.32 & 9.76 & 3.50 & 0.84 & 1.17 & 0.25 & -0.52 & 100.30 \\
\hline PA30 & 50.71 & 19.12 & 11.22 & 0.18 & 4.46 & 9.79 & 3.48 & 0.85 & 1.20 & 0.25 & -0.60 & 100.70 \\
\hline PA31 & 49.67 & 19.24 & 10.76 & 0.17 & 4.47 & 9.98 & 3.32 & 0.76 & 1.11 & 0.23 & -0.54 & 99.17 \\
\hline PA35 & 50.39 & 19.56 & 10.75 & 0.17 & 4.43 & 10.28 & 3.37 & 0.75 & 1.13 & 0.24 & -0.44 & 100.60 \\
\hline PA35 (2) & 49.47 & 19.23 & 10.52 & 0.17 & 4.35 & 9.94 & 3.38 & 0.75 & 1.09 & 0.23 & -0.48 & 98.66 \\
\hline
\end{tabular}


Table A-2. Concentration of $\mathrm{FeO}$ and $\mathrm{Fe}_{2} \mathrm{O}_{3}(w t \%)$ for natural samples. PA09 (BR) are data from bulk rock analyses from Actlabs. PA09 (B1 and B2) are microprobe analyses on remelts of the natural PA09 sample.

\begin{tabular}{l|cccccccc}
\hline Sample & FeO & & Fe2O3 & \multicolumn{3}{c}{ FeO(T) } & \multicolumn{3}{c}{ Fe2O3(T) } \\
Name & wt\% & $(+/-)$ & wt\% & $(+/-)$ & wt\% & $(+/-)$ & wt\% & $(+/-)$ \\
\hline blank & 0.00 & 0.00 & 0.00 & 0.00 & 0.00 & 0.00 & 0.00 & 0.00 \\
B1R-1a_A & 8.72 & 0.36 & 1.67 & 0.06 & 10.22 & 0.37 & 11.36 & 0.41 \\
B1R-1a_B & 8.61 & 0.28 & 1.74 & 0.05 & 10.17 & 0.30 & 11.30 & 0.33 \\
W-2a_A & 8.21 & 0.24 & 1.29 & 0.04 & 9.38 & 0.26 & 10.42 & 0.29 \\
W-2a_B & 8.26 & 0.25 & 1.28 & 0.04 & 9.41 & 0.27 & 10.46 & 0.30 \\
PA01_A & 5.37 & 0.28 & 4.36 & 0.15 & 9.29 & 0.32 & 10.32 & 0.36 \\
PA01_B & 5.42 & 0.20 & 4.36 & 0.12 & 9.34 & 0.25 & 10.38 & 0.28 \\
PA16_A & 8.33 & 0.27 & 1.90 & 0.06 & 10.04 & 0.29 & 11.16 & 0.32 \\
PA16_B & 8.38 & 0.26 & 1.86 & 0.05 & 10.05 & 0.28 & 11.17 & 0.32 \\
PA21_A & 7.89 & 0.23 & 2.29 & 0.06 & 9.95 & 0.26 & 11.06 & 0.29 \\
PA21_B & 7.74 & 0.32 & 2.25 & 0.08 & 9.77 & 0.34 & 10.85 & 0.38 \\
PA23_A & 5.86 & 0.27 & 4.29 & 0.14 & 9.72 & 0.32 & 10.80 & 0.35 \\
PA23_B & 5.97 & 0.24 & 4.35 & 0.13 & 9.88 & 0.29 & 10.98 & 0.32 \\
PA27_A & 7.08 & 0.27 & 2.63 & 0.08 & 9.45 & 0.30 & 10.50 & 0.34 \\
PA27_B & 7.24 & 0.25 & 2.83 & 0.08 & 9.79 & 0.29 & 10.88 & 0.32 \\
PA06_A & 7.68 & 0.23 & 2.12 & 0.06 & 9.59 & 0.26 & 10.65 & 0.29 \\
PA06_B & 7.28 & 0.31 & 1.95 & 0.07 & 9.04 & 0.33 & 10.05 & 0.37 \\
PA09_A & 7.13 & 0.28 & 2.62 & 0.09 & 9.49 & 0.31 & 10.54 & 0.34 \\
PA09_B & 7.28 & 0.26 & 2.49 & 0.07 & 9.52 & 0.29 & 10.58 & 0.32 \\
PA09(BR) & - & - & - & - & - & - & 10.85 & 0.08 \\
PA09 (B1) & - & - & - & - & 9.39 & 0.11 & - & - \\
PA09(B2) & - & - & - & - & 9.42 & 0.10 & - & - \\
\hline & & & & & & & &
\end{tabular}


Tables A-3. Microprobe analyses in wt \% for the natural rocks. Individual phases in the left column. The last two rows represent average glass composition and standard deviation among analyses. Some samples either don't have glass present, or have a relatively homogenous groundmass.

\begin{tabular}{|c|c|c|c|c|c|c|c|c|c|c|c|c|}
\hline \multicolumn{13}{|l|}{ A0 } \\
\hline Phase & $\mathrm{SiO}_{2}$ & $\mathrm{TiO}_{2}$ & $\mathbf{A l}_{2} \mathbf{O}_{3}$ & $\mathrm{Cr}_{2} \mathrm{O}_{3}$ & $\mathrm{FeO}$ & MnO & MgO & $\mathrm{CaO}$ & $\mathrm{Na}_{2} \mathrm{O}$ & $\mathrm{K}_{2} \mathrm{O}$ & $\mathbf{P}_{2} \mathbf{O}_{5}$ & Total \\
\hline $\mathrm{Plg}$ & 54.59 & 0.09 & 29.93 & 0.00 & 0.98 & 0.00 & 0.09 & 11.96 & 4.67 & 0.31 & 0.01 & 102.62 \\
\hline $\mathrm{Plg}$ & 46.50 & 0.00 & 34.83 & 0.01 & 0.61 & 0.00 & 0.04 & 17.83 & 1.41 & 0.06 & 0.01 & 101.29 \\
\hline $\mathrm{Plg}$ & 53.74 & 0.07 & 30 & & 0 & & 0 & 22 & & 0.30 & 3 & .98 \\
\hline $\mathrm{Plg}$ & 49.26 & 0.03 & 33.09 & 0.00 & 0.91 & 0.00 & 0.04 & 15.83 & 2.51 & 0.12 & 0.01 & 101.81 \\
\hline $\mathrm{Plg}$ & 46.36 & 0.00 & 35.77 & 0.02 & 0.57 & 0.01 & 0.04 & 18.38 & 1.20 & 0.03 & 0.00 & 102.37 \\
\hline Olv & 36.00 & 0.08 & 0.00 & 0.00 & 38.85 & 0.95 & 25.33 & 0.30 & 0.00 & 0.01 & 0.13 & 101.65 \\
\hline Ox & 0.00 & 11.89 & 3.95 & 0.07 & 74.46 & 0.38 & 4.10 & 0.06 & 0.01 & 0.01 & 0.00 & 94.92 \\
\hline Ox & 0.00 & 12.60 & 3.79 & 0.10 & 74.21 & 0.39 & 4.03 & 0.03 & 0.00 & 0.00 & 0.00 & 95.15 \\
\hline Glass & 53.51 & 1.94 & 14.71 & 0.01 & 12.65 & 0.27 & 3.94 & 7.99 & 2.59 & 1.45 & 0.46 & 99.52 \\
\hline stdev & 0.19 & 0.04 & 0.06 & 0.01 & 0.11 & 0.02 & 0.02 & 0.07 & 0.10 & 0.02 & 0.02 & \\
\hline
\end{tabular}

A-3 Continued.

\begin{tabular}{c|cccccccccccc}
\multicolumn{1}{l}{ PA06 } \\
\hline Phase & $\mathbf{S i O}_{2}$ & $\mathbf{T i O}_{2}$ & $\mathbf{A l}_{2} \mathbf{O}_{3}$ & $\mathbf{C r}_{2} \mathbf{O}_{3}$ & $\mathbf{F e O}$ & $\mathbf{M n O}$ & $\mathbf{M g O}$ & $\mathbf{C a O}$ & $\mathbf{N a}_{2} \mathbf{O}$ & $\mathbf{K}_{2} \mathbf{O}$ & $\mathbf{P}_{2} \mathbf{O}_{5}$ & Total \\
\hline Plg & 48.15 & 0.03 & 33.59 & 0.00 & 0.75 & 0.00 & 0.04 & 16.24 & 2.41 & 0.10 & 0.00 & 101.33 \\
Plg & 54.57 & 0.09 & 28.50 & 0.00 & 0.92 & 0.01 & 0.11 & 11.11 & 5.12 & 0.38 & 0.00 & 100.81 \\
Plg & 54.66 & 0.11 & 28.55 & 0.00 & 0.93 & 0.00 & 0.09 & 11.14 & 5.19 & 0.36 & 0.01 & 101.04 \\
Olv & 37.29 & 0.04 & 0.00 & 0.01 & 30.05 & 0.60 & 32.33 & 0.27 & 0.00 & 0.00 & 0.01 & 100.59 \\
Olv & 36.99 & 0.02 & 0.00 & 0.00 & 30.19 & 0.50 & 32.54 & 0.24 & 0.01 & 0.01 & 0.01 & 100.50 \\
Olv & 37.05 & 0.01 & 0.00 & 0.00 & 30.15 & 0.57 & 32.37 & 0.26 & 0.00 & 0.00 & 0.01 & 100.40 \\
Cpx & 51.31 & 0.87 & 2.28 & 0.00 & 11.74 & 0.38 & 14.61 & 18.53 & 0.37 & 0.01 & 0.03 & 100.13 \\
Cpx & 50.21 & 1.09 & 2.85 & 0.00 & 12.03 & 0.38 & 14.09 & 18.69 & 0.38 & 0.02 & 0.05 & 99.79 \\
Cpx & 49.14 & 1.54 & 3.42 & 0.01 & 12.07 & 0.40 & 13.73 & 18.92 & 0.47 & 0.03 & 0.11 & 99.83 \\
Glass & 60.32 & 1.42 & 14.95 & 0.00 & 9.03 & 0.22 & 0.53 & 3.13 & 4.87 & 3.49 & 1.04 & 99.02 \\
stdev & 1.21 & 0.42 & 1.12 & 0.00 & 1.34 & 0.03 & 0.08 & 0.21 & 1.50 & 0.52 & 0.23 & \\
\hline
\end{tabular}




\section{A-3 Continued.}

\begin{tabular}{c|cccccccccccc} 
PA09 \\
\hline Phase & $\mathbf{S i O}_{2}$ & $\mathbf{T i O}_{2}$ & $\mathrm{Al}_{2} \mathbf{O}_{3}$ & $\mathrm{Cr}_{2} \mathbf{O}_{3}$ & $\mathbf{F e O}$ & $\mathbf{M n O}$ & $\mathbf{M g O}$ & $\mathbf{C a O}$ & $\mathbf{N a}_{2} \mathbf{O}$ & $\mathbf{K}_{2} \mathbf{O}$ & $\mathbf{P}_{2} \mathbf{O}_{5}$ & Total \\
\hline Plg & 53.38 & 0.07 & 29.47 & 0.01 & 0.90 & 0.01 & 0.11 & 12.02 & 4.71 & 0.28 & 0.00 & 100.97 \\
$\mathrm{Plg}$ & 47.39 & 0.03 & 33.97 & 0.00 & 0.78 & 0.01 & 0.06 & 16.65 & 2.07 & 0.08 & 0.00 & 101.03 \\
$\mathrm{Plg}$ & 47.54 & 0.03 & 33.59 & 0.00 & 0.76 & 0.00 & 0.05 & 16.57 & 2.13 & 0.09 & 0.00 & 100.78 \\
$\mathrm{Olv}$ & 36.77 & 0.02 & 0.00 & 0.01 & 31.89 & 0.66 & 31.03 & 0.29 & 0.01 & 0.00 & 0.12 & 100.80 \\
Olv & 36.85 & 0.05 & 0.00 & 0.00 & 32.13 & 0.67 & 30.71 & 0.25 & 0.00 & 0.01 & 0.07 & 100.75 \\
Olv & 37.02 & 0.03 & 0.00 & 0.00 & 31.64 & 0.66 & 31.46 & 0.29 & 0.00 & 0.00 & 0.06 & 101.17 \\
Cpx & 51.72 & 0.79 & 1.95 & 0.00 & 11.55 & 0.36 & 14.76 & 18.85 & 0.35 & 0.02 & 0.02 & 100.39 \\
Cpx & 52.05 & 0.88 & 2.20 & 0.00 & 11.81 & 0.36 & 14.71 & 18.86 & 0.36 & 0.03 & 0.00 & 101.26 \\
Cpx & 51.62 & 0.80 & 1.86 & 0.00 & 11.76 & 0.39 & 14.66 & 18.41 & 0.33 & 0.01 & 0.00 & 99.83 \\
Ox & 0.00 & 13.75 & 3.37 & 0.10 & 73.98 & 0.45 & 3.33 & 0.00 & 0.02 & 0.01 & 0.00 & 95.01 \\
Gmass & 57.99 & 2.42 & 14.41 & 0.00 & 11.83 & 0.27 & 0.82 & 4.01 & 4.32 & 2.75 & 1.05 & 99.86 \\
stdev & 1.21 & 0.38 & 0.53 & 0.00 & 0.86 & 0.01 & 0.22 & 0.53 & 0.72 & 0.04 & 0.04 & \\
\hline
\end{tabular}

A-3. Continued.

\begin{tabular}{c|cccccccccccc} 
PA12 \\
\hline Phase & $\mathbf{S i O}_{2}$ & $\mathrm{TiO}_{2}$ & $\mathrm{Al}_{2} \mathbf{O}_{3}$ & $\mathrm{Cr}_{2} \mathbf{O}_{3}$ & $\mathbf{F e O}$ & $\mathbf{M n O}$ & $\mathbf{M g O}$ & $\mathbf{C a O}$ & $\mathbf{N a}_{2} \mathbf{O}$ & $\mathbf{K}_{2} \mathbf{O}$ & $\mathbf{P}_{2} \mathbf{O}_{5}$ & Total \\
\hline $\mathrm{Plg}$ & 54.98 & 0.10 & 27.85 & 0.00 & 1.04 & 0.01 & 0.10 & 10.70 & 5.57 & 0.35 & 0.01 & 100.72 \\
$\mathrm{Plg}$ & 50.93 & 0.06 & 30.85 & 0.01 & 0.92 & 0.01 & 0.07 & 13.77 & 3.85 & 0.18 & 0.02 & 100.67 \\
$\mathrm{Plg}$ & 54.52 & 0.12 & 27.68 & 0.00 & 1.14 & 0.02 & 0.09 & 10.50 & 5.52 & 0.38 & 0.01 & 100.00 \\
$\mathrm{Olv}$ & 35.53 & 0.03 & 0.00 & 0.01 & 37.37 & 0.80 & 26.15 & 0.24 & 0.01 & 0.00 & 0.00 & 100.16 \\
Olv & 35.44 & 0.02 & 0.01 & 0.00 & 36.69 & 0.73 & 26.54 & 0.27 & 0.03 & 0.00 & 0.05 & 99.77 \\
Olv & 35.58 & 0.05 & 0.00 & 0.01 & 37.44 & 0.76 & 26.10 & 0.27 & 0.00 & 0.01 & 0.05 & 100.28 \\
Cpx & 50.84 & 0.90 & 2.05 & 0.00 & 13.56 & 0.47 & 14.22 & 17.05 & 0.40 & 0.00 & 0.03 & 99.53 \\
Cpx & 48.97 & 1.59 & 3.55 & 0.00 & 13.36 & 0.36 & 12.63 & 19.25 & 0.49 & 0.00 & 0.04 & 100.24 \\
Cpx & 51.61 & 0.87 & 1.89 & 0.00 & 12.54 & 0.40 & 14.35 & 18.69 & 0.41 & 0.00 & 0.03 & 100.80 \\
Ox & 0.00 & 18.16 & 2.56 & 0.07 & 71.41 & 0.54 & 2.86 & 0.00 & 0.01 & 0.00 & 0.00 & 95.61 \\
Glass & 59.51 & 1.73 & 13.82 & 0.00 & 9.82 & 0.21 & 2.01 & 4.71 & 2.22 & 2.75 & 0.97 & 97.76 \\
stdev & 0.35 & 0.03 & 0.02 & 0.00 & 0.08 & 0.01 & 0.01 & 0.04 & 0.04 & 0.04 & 0.05 & \\
\hline
\end{tabular}




\section{A-3 Continued.}

PA16

\begin{tabular}{c|cccccccccccc}
\hline Phase & $\mathrm{SiO}_{2}$ & $\mathrm{TiO}_{2}$ & $\mathrm{Al}_{2} \mathbf{O}_{\mathbf{3}}$ & $\mathrm{Cr}_{\mathbf{2}} \mathbf{O}_{\mathbf{3}}$ & $\mathbf{F e O}$ & $\mathbf{M n O}$ & $\mathbf{M g O}$ & $\mathbf{C a O}$ & $\mathbf{N a}_{2} \mathbf{O}$ & $\mathbf{K}_{2} \mathbf{O}$ & $\mathbf{P}_{\mathbf{2}} \mathbf{O}_{5}$ & Total \\
\hline Plg & 49.56 & 0.07 & 32.25 & 0.03 & 0.87 & 0.00 & 0.08 & 15.13 & 2.72 & 0.14 & 0.04 & 100.87 \\
Plg & 55.85 & 0.10 & 28.38 & 0.00 & 1.02 & 0.00 & 0.09 & 10.71 & 5.31 & 0.37 & 0.00 & 101.82 \\
Olv & 35.70 & 0.05 & 0.00 & 0.00 & 38.85 & 0.70 & 25.06 & 0.32 & 0.00 & 0.01 & 0.02 & 100.71 \\
Olv & 37.58 & 0.00 & 0.00 & 0.02 & 30.92 & 0.61 & 31.73 & 0.31 & 0.00 & 0.01 & 0.05 & 101.22 \\
Cpx & 52.63 & 0.57 & 1.54 & 0.01 & 14.33 & 0.44 & 15.77 & 15.07 & 0.24 & 0.02 & 0.01 & 100.63 \\
Cpx & 52.82 & 0.62 & 1.59 & 0.01 & 13.90 & 0.51 & 15.97 & 15.19 & 0.28 & 0.00 & 0.00 & 100.90 \\
Glass & 59.84 & 1.78 & 13.97 & 0.00 & 10.56 & 0.20 & 2.10 & 5.05 & 2.44 & 1.74 & 0.96 & 98.62 \\
stdev & 0.22 & 0.03 & 0.15 & 0.00 & 0.04 & 0.03 & 0.06 & 0.23 & 0.32 & 0.03 & 0.04 & \\
\hline
\end{tabular}

\section{A-3 Continued.}

PA21

\begin{tabular}{c|cccccccccccc}
\hline Phase & $\mathbf{S i O}_{2}$ & $\mathrm{TiO}_{2}$ & $\mathrm{Al}_{2} \mathbf{O}_{3}$ & $\mathbf{C r}_{2} \mathbf{O}_{3}$ & $\mathbf{F e O}$ & $\mathbf{M n O}$ & $\mathbf{M g O}$ & $\mathbf{C a O}$ & $\mathbf{N a}_{2} \mathbf{O}$ & $\mathbf{K}_{2} \mathbf{O}$ & $\mathbf{P}_{2} \mathbf{O}_{5}$ & Total \\
\hline Plg & 52.72 & 0.08 & 30.09 & 0.00 & 0.79 & 0.04 & 0.10 & 12.64 & 4.46 & 0.25 & 0.01 & 101.18 \\
Plg & 50.45 & 0.02 & 31.48 & 0.00 & 0.75 & 0.00 & 0.07 & 14.17 & 3.63 & 0.16 & 0.01 & 100.76 \\
Plg & 52.65 & 0.09 & 29.67 & 0.00 & 0.78 & 0.03 & 0.13 & 12.49 & 4.48 & 0.27 & 0.02 & 100.59 \\
Plg & 49.04 & 0.08 & 32.68 & 0.00 & 0.96 & 0.03 & 0.19 & 15.53 & 2.81 & 0.10 & 0.00 & 101.42 \\
Plg & 54.06 & 0.08 & 28.38 & 0.00 & 1.05 & 0.03 & 0.12 & 11.10 & 5.29 & 0.31 & 0.02 & 100.44 \\
Plg & 49.58 & 0.08 & 32.43 & 0.00 & 0.81 & 0.00 & 0.11 & 15.03 & 3.20 & 0.09 & 0.01 & 101.33 \\
Olv & 38.05 & 0.07 & 0.05 & 0.00 & 25.76 & 0.47 & 35.28 & 0.31 & 0.00 & 0.01 & 0.06 & 100.07 \\
Olv & 38.64 & 0.03 & 0.02 & 0.00 & 24.80 & 0.43 & 36.17 & 0.24 & 0.00 & 0.00 & 0.00 & 100.33 \\
Olv & 38.33 & 0.03 & 0.00 & 0.02 & 24.81 & 0.46 & 36.67 & 0.24 & 0.00 & 0.00 & 0.02 & 100.58 \\
Olv & 38.99 & 0.06 & 0.03 & 0.02 & 24.95 & 0.48 & 35.58 & 0.30 & 0.05 & 0.02 & 0.17 & 100.65 \\
Olv & 39.18 & 0.06 & 0.04 & 0.00 & 24.86 & 0.46 & 36.30 & 0.31 & 0.02 & 0.01 & 0.13 & 101.37 \\
Glass & 53.06 & 2.66 & 12.56 & 0.00 & 13.68 & 0.27 & 2.63 & 9.42 & 1.99 & 1.78 & 0.57 & 98.63 \\
stdev & 1.48 & 0.30 & 0.86 & 0.01 & 0.50 & 0.05 & 0.43 & 2.47 & 1.04 & 0.63 & 0.05 & \\
\hline
\end{tabular}




\section{A-3 Continued.}

PA23

\begin{tabular}{c|cccccccccccc}
\hline Phase & $\mathbf{S i O}_{2}$ & $\mathbf{T i O}_{2}$ & $\mathbf{A l}_{2} \mathbf{O}_{\mathbf{3}}$ & $\mathbf{C r}_{2} \mathbf{O}_{\mathbf{3}}$ & $\mathbf{F e O}$ & $\mathbf{M n O}$ & $\mathbf{M g O}$ & $\mathbf{C a O}$ & $\mathbf{N a}_{2} \mathbf{O}$ & $\mathbf{K}_{2} \mathbf{O}$ & $\mathbf{P}_{2} \mathbf{O}_{5}$ & Total \\
\hline Plg & 50.38 & 0.07 & 31.77 & 0.00 & 0.92 & 0.03 & 0.12 & 14.49 & 3.48 & 0.11 & 0.02 & 101.37 \\
Plg & 54.82 & 0.06 & 28.72 & 0.00 & 0.90 & 0.03 & 0.08 & 10.98 & 5.47 & 0.31 & 0.02 & 101.38 \\
Plg & 50.34 & 0.08 & 31.67 & 0.01 & 0.92 & 0.01 & 0.10 & 14.29 & 3.61 & 0.15 & 0.00 & 101.18 \\
Olv & 36.97 & 0.04 & 0.02 & 0.00 & 30.15 & 0.57 & 32.63 & 0.27 & 0.02 & 0.00 & 0.08 & 100.75 \\
Olv & 36.48 & 0.01 & 0.00 & 0.01 & 29.76 & 0.60 & 32.60 & 0.29 & 0.02 & 0.01 & 0.04 & 99.83 \\
Cpx & 50.17 & 0.97 & 2.48 & 0.01 & 12.21 & 0.36 & 14.45 & 18.09 & 0.41 & 0.01 & 0.02 & 99.17 \\
Cpx & 50.59 & 0.94 & 2.76 & 0.01 & 11.39 & 0.33 & 14.57 & 18.91 & 0.39 & 0.01 & 0.00 & 99.89 \\
Glass & 55.18 & 2.24 & 13.77 & 0.00 & 13.37 & 0.33 & 3.24 & 3.91 & 2.78 & 2.77 & 0.54 & 98.13 \\
stdev & 0.60 & 0.22 & 0.51 & 0.00 & 0.02 & 0.02 & 1.24 & 0.95 & 0.16 & 0.60 & 0.01 & \\
\hline
\end{tabular}

\section{A-3 Continued.}

\begin{tabular}{c|ccccccccccccc}
\multicolumn{1}{l}{ PA26 } \\
\hline Phase & $\mathbf{S i O}_{2}$ & $\mathrm{TiO}_{2}$ & $\mathrm{Al}_{2} \mathbf{O}_{\mathbf{3}}$ & $\mathrm{Cr}_{2} \mathbf{O}_{\mathbf{3}}$ & $\mathbf{F e O}$ & $\mathbf{M n O}$ & $\mathbf{M g O}$ & $\mathbf{C a O}$ & $\mathbf{N a}_{2} \mathbf{O}$ & $\mathbf{K}_{2} \mathbf{O}$ & $\mathbf{P}_{2} \mathbf{O}_{5}$ & Total \\
\hline Plg & 45.68 & 0.02 & 34.89 & 0.00 & 0.50 & 0.01 & 0.07 & 17.82 & 1.51 & 0.03 & 0.00 & 100.53 \\
Plg & 46.05 & 0.02 & 35.04 & 0.02 & 0.51 & 0.00 & 0.05 & 17.74 & 1.57 & 0.02 & 0.01 & 101.03 \\
Plg & 53.69 & 0.08 & 28.87 & 0.00 & 0.91 & 0.03 & 0.11 & 11.67 & 5.00 & 0.29 & 0.02 & 100.67 \\
Olv & 37.22 & 0.00 & 0.00 & 0.01 & 30.34 & 0.62 & 32.52 & 0.28 & 0.03 & 0.01 & 0.02 & 101.05 \\
Olv & 37.02 & 0.01 & 0.00 & 0.01 & 30.90 & 0.62 & 32.04 & 0.28 & 0.02 & 0.00 & 0.04 & 100.93 \\
Olv & 36.22 & 0.01 & 0.00 & 0.00 & 33.91 & 0.70 & 29.14 & 0.26 & 0.01 & 0.00 & 0.01 & 100.25 \\
Cpx & 52.01 & 0.65 & 1.89 & 0.03 & 9.96 & 0.33 & 15.44 & 19.94 & 0.35 & 0.00 & 0.01 & 100.62 \\
Cpx & 50.48 & 0.91 & 2.92 & 0.01 & 10.09 & 0.30 & 14.42 & 20.21 & 0.39 & 0.01 & 0.00 & 99.76 \\
\hline
\end{tabular}

\section{A-3 Continued.}

\begin{tabular}{|c|c|c|c|c|c|c|c|c|c|c|c|c|}
\hline Phase & $\mathrm{SiO}_{2}$ & $\mathrm{TiO}_{2}$ & $\mathbf{A l}_{2} \mathbf{O}_{3}$ & $\mathrm{Cr}_{2} \mathrm{O}_{3}$ & $\mathrm{FeO}$ & $\mathrm{MnO}$ & MgO & $\mathrm{CaO}$ & $\mathrm{Na}_{2} \mathrm{O}$ & $\mathbf{K}_{2} \mathbf{O}$ & $\mathbf{P}_{2} \mathbf{O}_{5}$ & Total \\
\hline Plg & 53.99 & 0.10 & 28.93 & 0.01 & 0.93 & 0.00 & 0.12 & 11.55 & 4.98 & 0.25 & 0.01 & 100.87 \\
\hline Plg & 50.05 & 0.03 & 31.93 & 0.00 & 0.79 & 0.00 & 0.09 & 14.72 & 3.22 & 0.17 & 0.03 & 101.03 \\
\hline Plg & 45.22 & 0.01 & 35.43 & 0.00 & 0.55 & 0.00 & 0.03 & 18.26 & 1.18 & 0.04 & 0.01 & 100.73 \\
\hline Olv & 38.29 & 0.03 & 0.00 & 0.00 & 25.33 & 0.45 & 36.00 & 0.18 & 0.00 & 0.00 & 0.00 & 100.29 \\
\hline Olv & 37.76 & 0.02 & 0.00 & 0.02 & 26.81 & 0.49 & 34.86 & 0.27 & 0.03 & 0.00 & 0.01 & 100.27 \\
\hline Olv & 37.58 & 0.05 & 0.01 & 0.01 & 26.03 & 0.48 & 35.11 & 0.23 & 0.01 & 0.01 & 0.02 & 99.54 \\
\hline Cpx & 52.01 & 0.76 & 1.91 & 0.04 & 11.21 & 0.37 & 15.71 & 18.34 & 0.29 & 0.02 & 0.00 & 100.65 \\
\hline Cpx & 52.28 & 0.72 & 1.71 & 0.00 & 12.14 & 0.39 & 15.41 & 17.88 & 0.27 & 0.01 & 0.01 & 100.81 \\
\hline Cpx & 49.68 & 1.32 & 3.52 & 0.00 & 11.28 & 0.30 & 13.60 & 19.85 & 0.40 & 0.02 & 0.00 & 99.97 \\
\hline Glass & 52.61 & 2.32 & 13.21 & 0.01 & 14.43 & 0.27 & 3.42 & 8.35 & 1.74 & 1.62 & 0.53 & 98.51 \\
\hline stdev & 0.55 & 0.17 & 0.19 & 0.01 & 1.74 & 0.00 & 0.33 & 1.23 & 0.19 & 0.25 & 0.03 & \\
\hline
\end{tabular}




\section{A-3 Continued.}

PA35

\begin{tabular}{c|cccccccccccc}
\hline Phase & $\mathbf{S i O}_{2}$ & $\mathbf{T i O}_{2}$ & $\mathrm{Al}_{2} \mathbf{O}_{3}$ & $\mathbf{C r}_{2} \mathbf{O}_{3}$ & $\mathbf{F e O}$ & $\mathbf{M n O}$ & $\mathbf{M g O}$ & $\mathbf{C a O}$ & $\mathbf{N a}_{2} \mathbf{O}$ & $\mathbf{K}_{2} \mathbf{O}$ & $\mathbf{P}_{2} \mathbf{O}_{5}$ & Total \\
\hline $\mathrm{Plg}$ & 52.66 & 0.07 & 29.35 & 0.00 & 0.82 & 0.01 & 0.08 & 12.00 & 4.79 & 0.26 & 0.01 & 100.06 \\
$\mathrm{Plg}$ & 52.20 & 0.09 & 29.94 & 0.00 & 0.89 & 0.02 & 0.13 & 12.71 & 4.52 & 0.19 & 0.00 & 100.68 \\
$\mathrm{Plg}$ & 53.46 & 0.06 & 29.31 & 0.01 & 0.85 & 0.00 & 0.09 & 11.88 & 4.88 & 0.32 & 0.00 & 100.86 \\
$\mathrm{Olv}$ & 37.52 & 0.02 & 0.03 & 0.01 & 27.42 & 0.48 & 34.63 & 0.33 & 0.01 & 0.01 & 0.01 & 100.46 \\
$\mathrm{Olv}$ & 37.46 & 0.02 & 0.00 & 0.00 & 27.17 & 0.52 & 34.65 & 0.29 & 0.02 & 0.00 & 0.04 & 100.16 \\
Olv & 36.88 & 0.03 & 0.00 & 0.01 & 28.45 & 0.50 & 33.90 & 0.27 & 0.02 & 0.00 & 0.02 & 100.09 \\
$\mathrm{Cpx}$ & 51.76 & 0.68 & 1.61 & 0.01 & 11.68 & 0.42 & 15.69 & 17.88 & 0.25 & 0.01 & 0.03 & 100.03 \\
Cpx & 51.24 & 0.67 & 1.79 & 0.00 & 12.18 & 0.38 & 15.73 & 17.41 & 0.26 & 0.01 & 0.01 & 99.68 \\
Gmass & 61.90 & 1.36 & 16.02 & 0.00 & 8.31 & 0.21 & 0.46 & 2.80 & 5.16 & 2.46 & 0.92 & 99.62 \\
stdev & 1.68 & 0.49 & 0.36 & 0.00 & 1.91 & 0.05 & 0.09 & 0.18 & 0.45 & 0.16 & 0.10 & \\
\hline
\end{tabular}

A-3. Initial remelt of PA09.

Batch 1

\begin{tabular}{c|cccccccccccc}
\hline Phase & $\mathrm{SiO}_{2}$ & $\mathrm{TiO}_{2}$ & $\mathrm{Al}_{2} \mathrm{O}_{3}$ & $\mathrm{Cr}_{2} \mathrm{O}_{\mathbf{3}}$ & $\mathbf{F e O}$ & $\mathrm{MnO}$ & $\mathrm{MgO}$ & $\mathbf{C a O}$ & $\mathrm{Na}_{2} \mathrm{O}$ & $\mathbf{K}_{2} \mathrm{O}$ & $\mathbf{P}_{2} \mathrm{O}_{5}$ & Total \\
\hline Glass & 50.28 & 1.14 & 19.68 & 0.01 & 9.39 & 0.17 & 4.40 & 9.76 & 3.26 & 0.79 & 0.24 & 99.12 \\
stdev & 0.18 & 0.01 & 0.07 & 0.00 & 0.11 & 0.02 & 0.04 & 0.06 & 0.02 & 0.01 & 0.02 & \\
\hline
\end{tabular}

\section{A-3. Initial remelt of PA09.}

Batch 2

\begin{tabular}{|c|c|c|c|c|c|c|c|c|c|c|c|c|}
\hline Phase & $\mathrm{SiO}_{2}$ & $\mathrm{TiO}_{2}$ & $\mathbf{A l}_{2} \mathbf{O}_{3}$ & $\mathrm{Cr}_{2} \mathrm{O}_{3}$ & $\mathrm{FeO}$ & MnO & MgO & $\mathrm{CaO}$ & $\mathrm{Na}_{2} \mathrm{O}$ & $\mathbf{K}_{2} \mathbf{O}$ & $\mathbf{P}_{2} \mathbf{O}_{5}$ & Total \\
\hline Glass & 50.12 & 1.16 & 19.75 & 0.00 & 9.42 & 0.18 & 4.40 & 9.71 & 3.22 & 0.82 & 0.27 & 99.05 \\
\hline stdev & 0.08 & 0.04 & 0.07 & 0.00 & 0.10 & 0.03 & 0.06 & 0.05 & 0.05 & 0.01 & 0.02 & \\
\hline
\end{tabular}



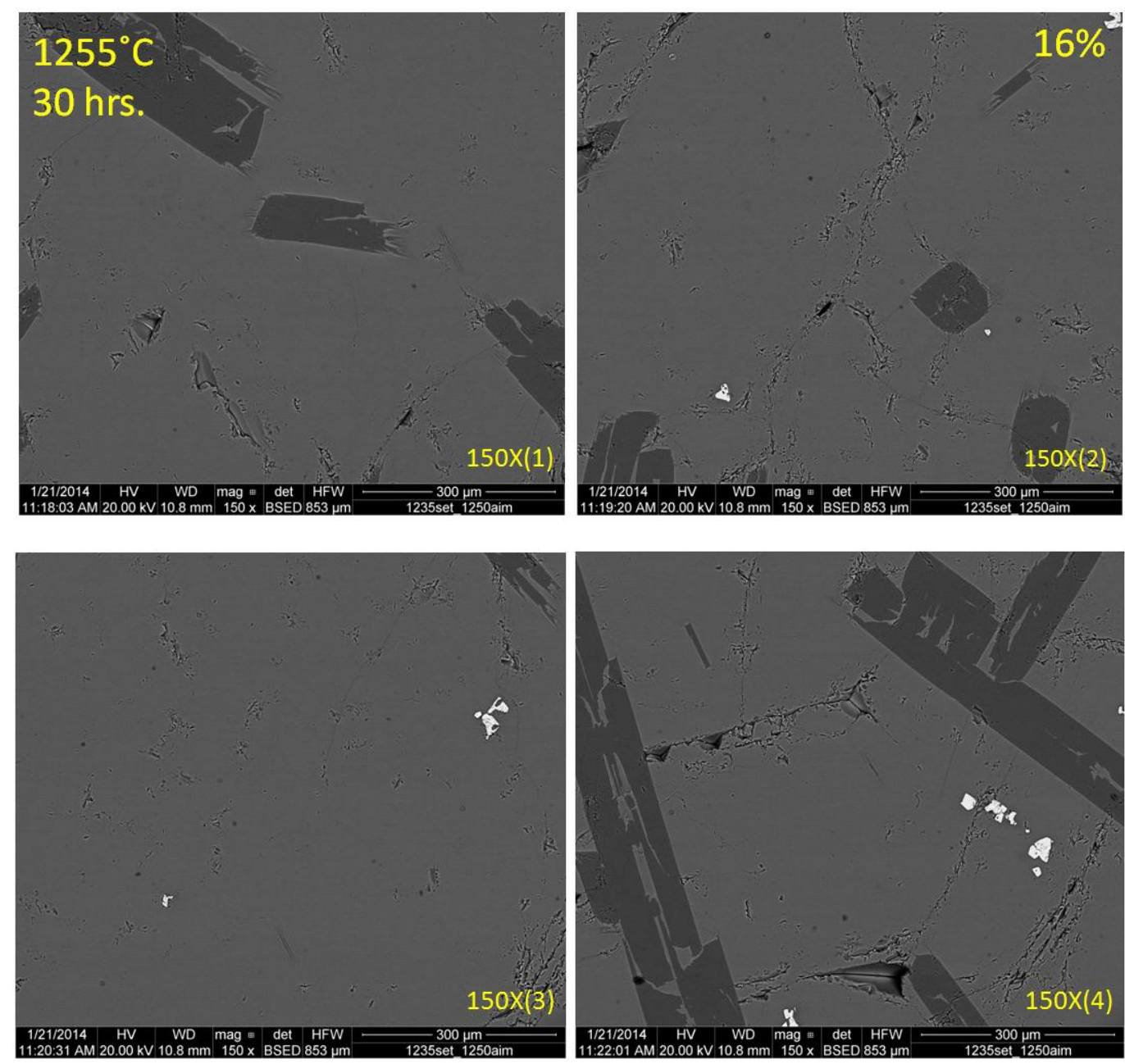

\begin{tabular}{|c|c|c|c|c|c|}
\hline \multicolumn{2}{|c|}{$1255^{\circ} \mathrm{C}$ (Post CC) } & \multirow[b]{2}{*}{$\begin{array}{c}\text { Glass } \\
\% \\
\end{array}$} & \multirow[b]{2}{*}{$\begin{array}{c}\text { Oxide } \\
\% \\
\end{array}$} & \multirow[b]{2}{*}{$\begin{array}{c}\text { Total Xtal } \\
\% \\
\end{array}$} & \multirow[b]{2}{*}{$\begin{array}{l}\text { Diff } \\
(+/-)\end{array}$} \\
\hline Image & $\begin{array}{c}\text { Plag } \\
\%\end{array}$ & & & & \\
\hline $150 X(1)$ & 20.5 & 79.5 & 0.0 & 20.5 & 6.0 \\
\hline $150 X(1)$ & 14.6 & 85.4 & 0.0 & 14.6 & \\
\hline $150 X(2)$ & 9.6 & 90.2 & 0.1 & 9.8 & 0.9 \\
\hline $150 X(2)$ & 10.5 & 89.3 & 0.1 & 10.7 & \\
\hline $150 \times(3)$ & 7.7 & 92.2 & 0.1 & 7.8 & 2.6 \\
\hline $150 \times(3)$ & 5.1 & 94.8 & 0.1 & 5.2 & \\
\hline $150 X(4)$ & 29.5 & 70.1 & 0.4 & 29.9 & 0.9 \\
\hline $150 X(4)$ & 28.6 & 71.0 & 0.3 & 29.0 & \\
\hline Avg. & 15.8 & 84.1 & 0.2 & 15.9 & 2.6 \\
\hline
\end{tabular}

Figures A-4 and Tables A-4. Low magnification BSE images of post CC experiment and corresponding crystal \% for each image. Difference column represents difference between high and low cut off values using Photoshop pixel counting method. Avg. of total xtal \% represents value used for whole sample. 

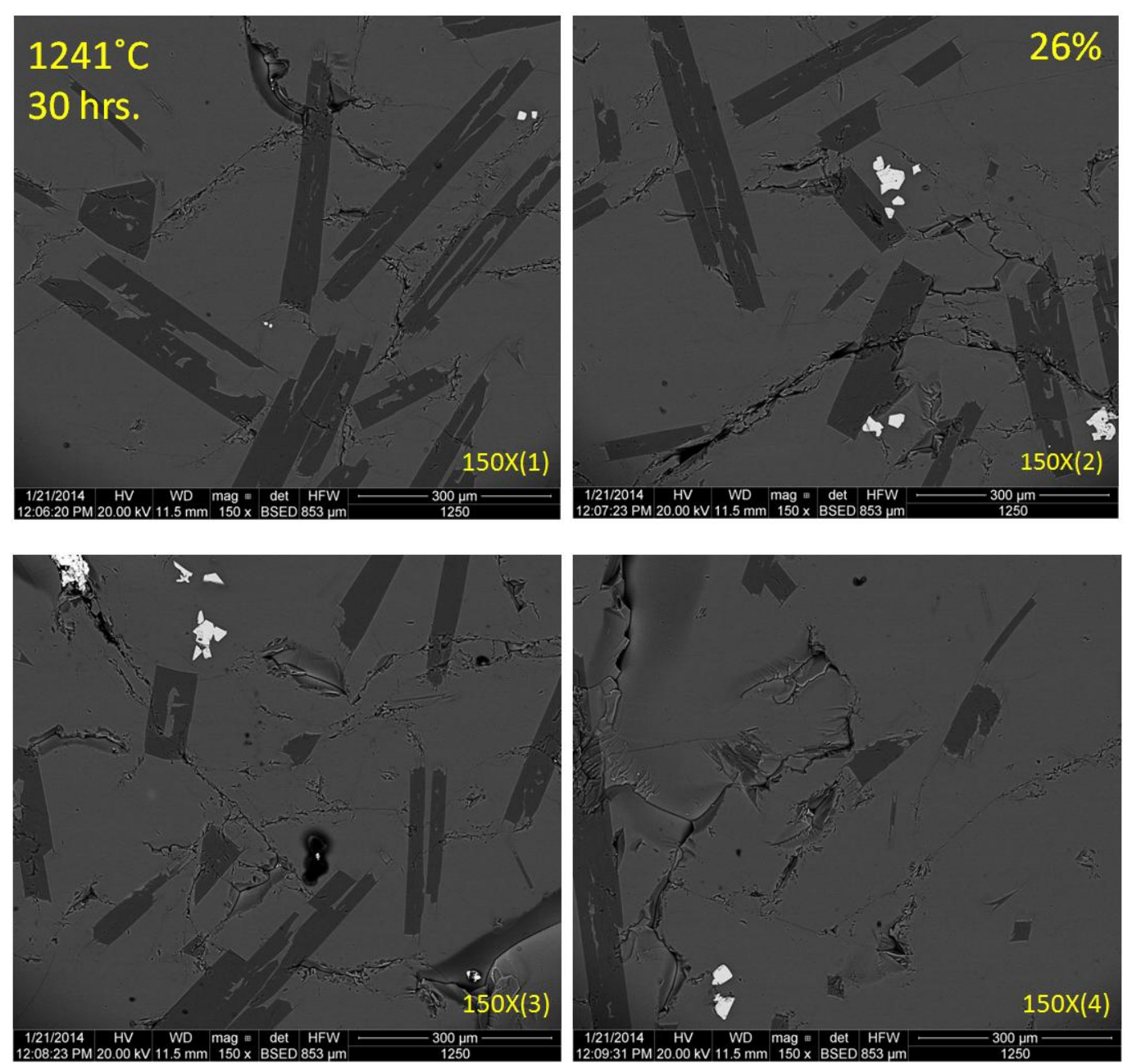

\begin{tabular}{c|c|c|c|c|c}
\hline \multicolumn{1241}{c}{$\mathbf{C}$ (Post CC) } & \multicolumn{4}{|c}{} \\
\hline Image & $\begin{array}{c}\text { Plag } \\
\%\end{array}$ & $\begin{array}{c}\text { Glass } \\
\%\end{array}$ & $\begin{array}{c}\text { Oxide } \\
\%\end{array}$ & $\begin{array}{c}\text { Total Xtal } \\
\%\end{array}$ & $\begin{array}{c}\text { Diff } \\
(+/-)\end{array}$ \\
\hline $150 X(1)$ & 32.4 & 67.5 & 0.1 & 32.5 & 3.4 \\
$150 X(1)$ & 35.9 & 64.1 & 0.0 & 35.9 & \\
$150 X(2)$ & 24.4 & 75.0 & 0.7 & 25.0 & 1.6 \\
$150 X(2)$ & 25.9 & 73.4 & 0.7 & 26.6 & \\
$150 X(3)$ & 23.5 & 76.2 & 0.4 & 23.8 & 2.1 \\
$150 X(3)$ & 25.6 & 74.1 & 0.3 & 25.9 & \\
$150 X(4)$ & 19.8 & 80.0 & 0.2 & 20.0 & 3.9 \\
$150 X(4)$ & 15.8 & 84.0 & 0.3 & 16.0 & \\
\hline Avg. & 25.4 & 74.3 & 0.3 & 25.7 & 2.7 \\
\hline
\end{tabular}

A-4 continued. 

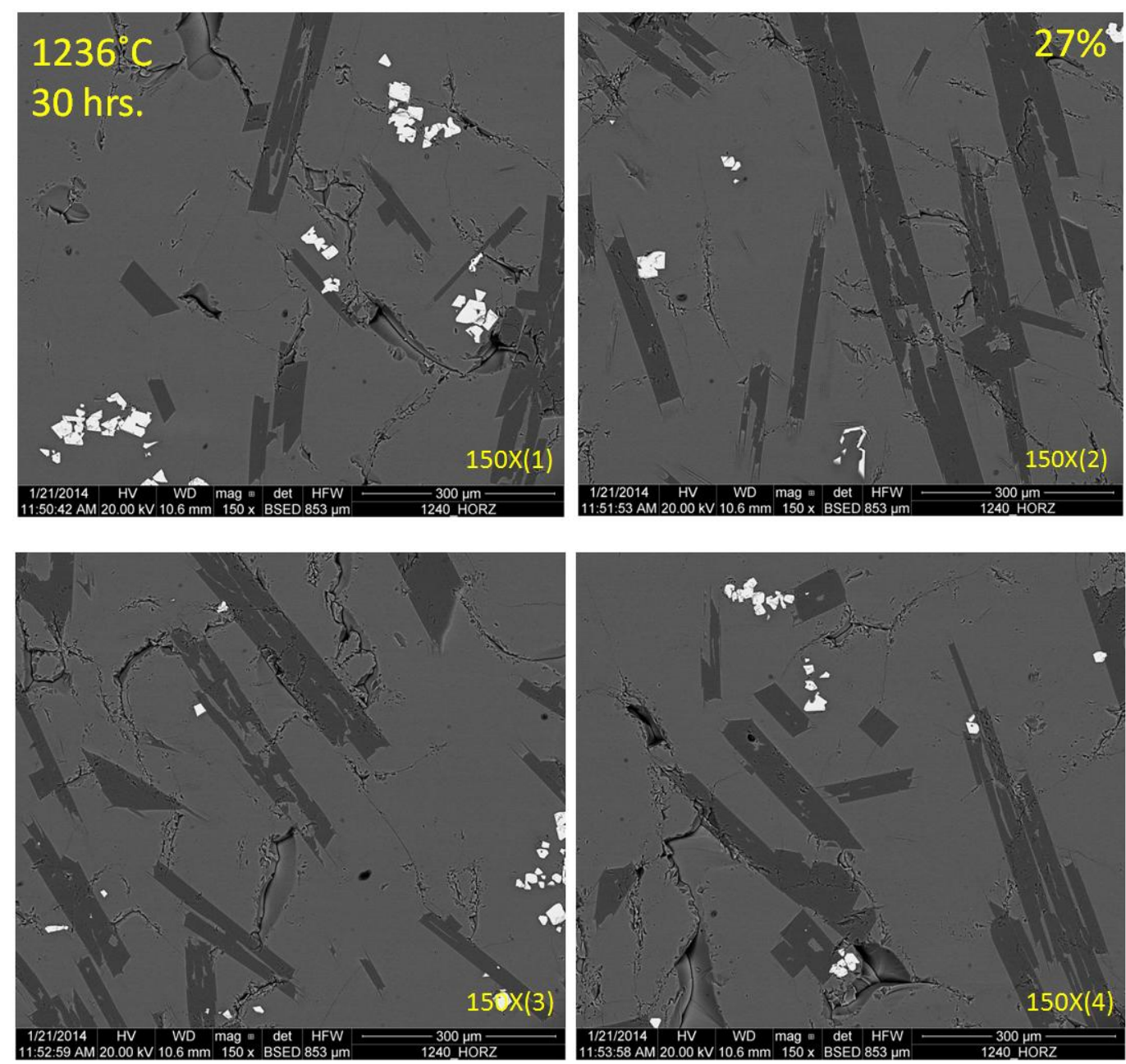

\begin{tabular}{c|c|c|c|c|c}
\hline \multicolumn{1236}{c}{$\mathbf{C}$ (Post CC) } & \multicolumn{4}{|c}{} \\
\hline Image & $\begin{array}{c}\text { Plag } \\
\%\end{array}$ & $\begin{array}{c}\text { Glass } \\
\%\end{array}$ & $\begin{array}{c}\text { Oxide } \\
\%\end{array}$ & $\begin{array}{c}\text { Total Xtal } \\
\%\end{array}$ & $\begin{array}{c}\text { Diff } \\
(+/-)\end{array}$ \\
\hline $150 X(1)$ & 19.7 & 78.2 & 2.1 & 21.8 & 1.0 \\
$150 X(1)$ & 18.7 & 79.2 & 2.1 & 20.8 & \\
$150 X(2)$ & 28.7 & 70.8 & 0.5 & 29.2 & 8.1 \\
$150 X(2)$ & 36.9 & 62.6 & 0.5 & 37.4 & \\
$150 X(3)$ & 24.7 & 74.6 & 0.7 & 25.4 & 1.8 \\
$150 X(3)$ & 26.6 & 72.7 & 0.7 & 27.3 & \\
$150 X(4)$ & 28.0 & 71.2 & 0.7 & 28.8 & 6.6 \\
$150 X(4)$ & 21.3 & 77.9 & 0.8 & 22.1 & \\
\hline Avg. & 25.6 & 73.4 & 1.0 & 26.6 & 4.4 \\
\hline
\end{tabular}

A-4 continued. 

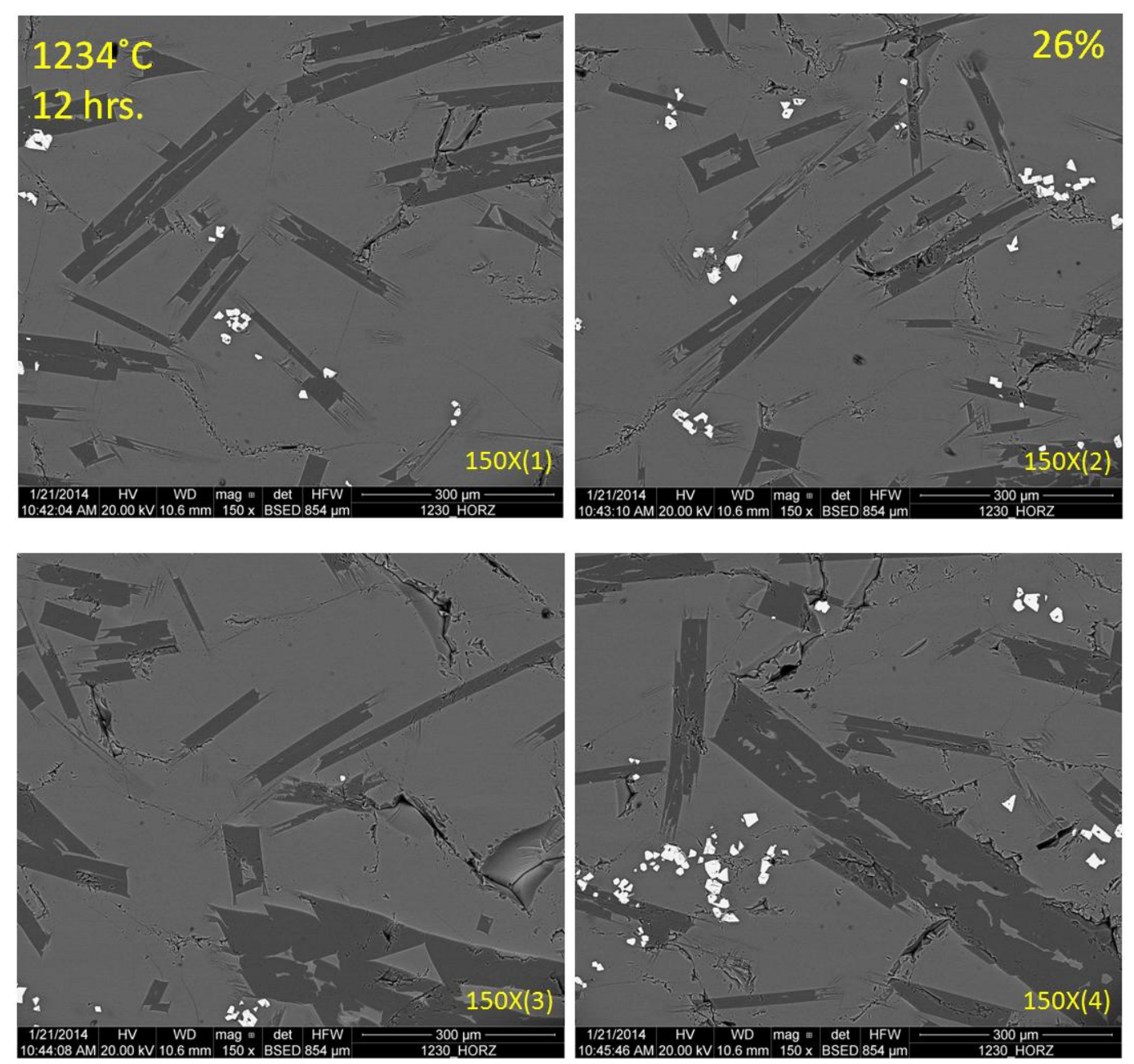

\begin{tabular}{|c|c|c|c|c|c|}
\hline \multicolumn{2}{|c|}{$1234^{\circ} \mathrm{C}$ (Post CC) } & \multirow[b]{2}{*}{$\begin{array}{c}\text { Glass } \\
\% \\
\end{array}$} & \multirow[b]{2}{*}{$\begin{array}{c}\text { Oxide } \\
\% \\
\end{array}$} & \multirow[b]{2}{*}{$\begin{array}{c}\text { Total Xtal } \\
\% \\
\end{array}$} & \multirow[b]{2}{*}{$\begin{array}{l}\text { Diff } \\
(+/-)\end{array}$} \\
\hline Image & $\begin{array}{c}\text { Plag } \\
\%\end{array}$ & & & & \\
\hline $150 \times(1)$ & 27.3 & 72.2 & 0.5 & 27.8 & 1.0 \\
\hline $150 X(1)$ & 26.3 & 73.2 & 0.5 & 26.8 & \\
\hline $150 X(2)$ & 20.7 & 78.1 & 1.2 & 21.9 & 1.4 \\
\hline $150 X(2)$ & 22.3 & 76.7 & 1.0 & 23.3 & \\
\hline $150 X(3)$ & 24.6 & 75.1 & 0.3 & 24.9 & 3.8 \\
\hline $150 X(3)$ & 28.3 & 71.3 & 0.3 & 28.7 & \\
\hline $150 \times(4)$ & 28.0 & 70.3 & 1.7 & 29.7 & 1.9 \\
\hline $150 X(4)$ & 26.0 & 72.2 & 1.8 & 27.8 & \\
\hline Avg. & 25.4 & 73.6 & 0.9 & 26.4 & 2.0 \\
\hline
\end{tabular}

A-4 continued. 

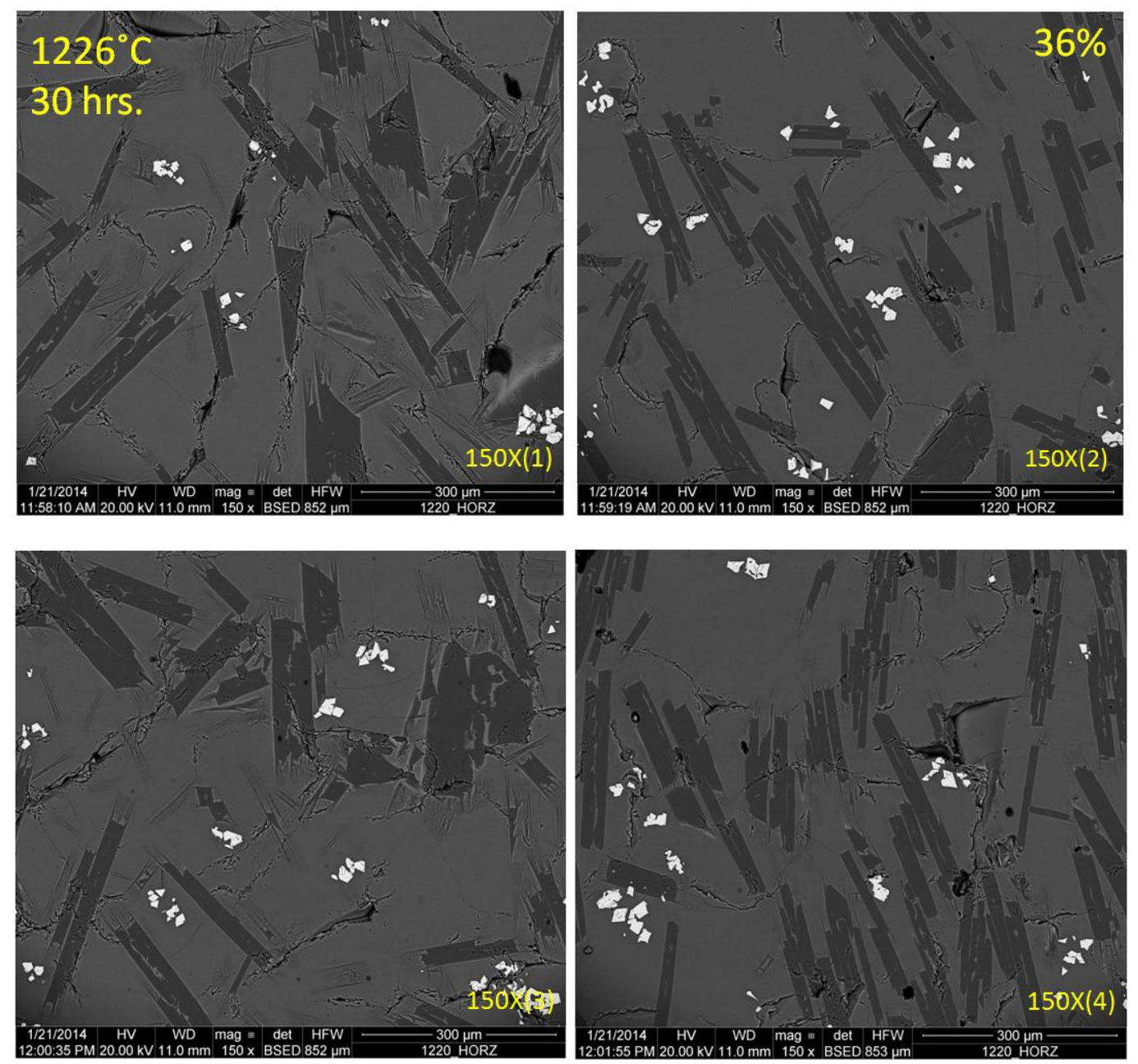

\begin{tabular}{|c|c|c|c|c|c|}
\hline \multicolumn{2}{|c|}{$1226^{\circ} \mathrm{C}$ (Post CC) } & \multirow[b]{2}{*}{$\begin{array}{c}\text { Glass } \\
\% \\
\end{array}$} & \multirow[b]{2}{*}{$\begin{array}{c}\text { Oxide } \\
\% \\
\end{array}$} & \multirow[b]{2}{*}{$\begin{array}{c}\text { Total Xtal } \\
\% \\
\end{array}$} & \multirow[b]{2}{*}{$\begin{array}{l}\text { Diff } \\
(+/-) \\
\end{array}$} \\
\hline Image & $\begin{array}{c}\text { Plag } \\
\%\end{array}$ & & & & \\
\hline $150 X(1)$ & 35.3 & 64.1 & 0.6 & 35.9 & 1.2 \\
\hline $150 X(1)$ & 34.1 & 65.3 & 0.5 & 34.7 & \\
\hline $150 \times(2)$ & 33.2 & 66.7 & 0.1 & 33.3 & 0.7 \\
\hline $150 \times(2)$ & 31.5 & 67.4 & 1.1 & 32.6 & \\
\hline $150 X(3)$ & 31.6 & 67.8 & 0.5 & 32.2 & 5.1 \\
\hline $150 X(3)$ & 36.2 & 62.7 & 1.1 & 37.3 & \\
\hline $150 \times(4)$ & 41.9 & 56.9 & 1.2 & 43.1 & 3.9 \\
\hline $150 X(4)$ & 38.2 & 60.8 & 1.0 & 39.2 & \\
\hline Avg. & 35.3 & 64.0 & 0.8 & 36.0 & 2.7 \\
\hline
\end{tabular}

A-4 continued. 

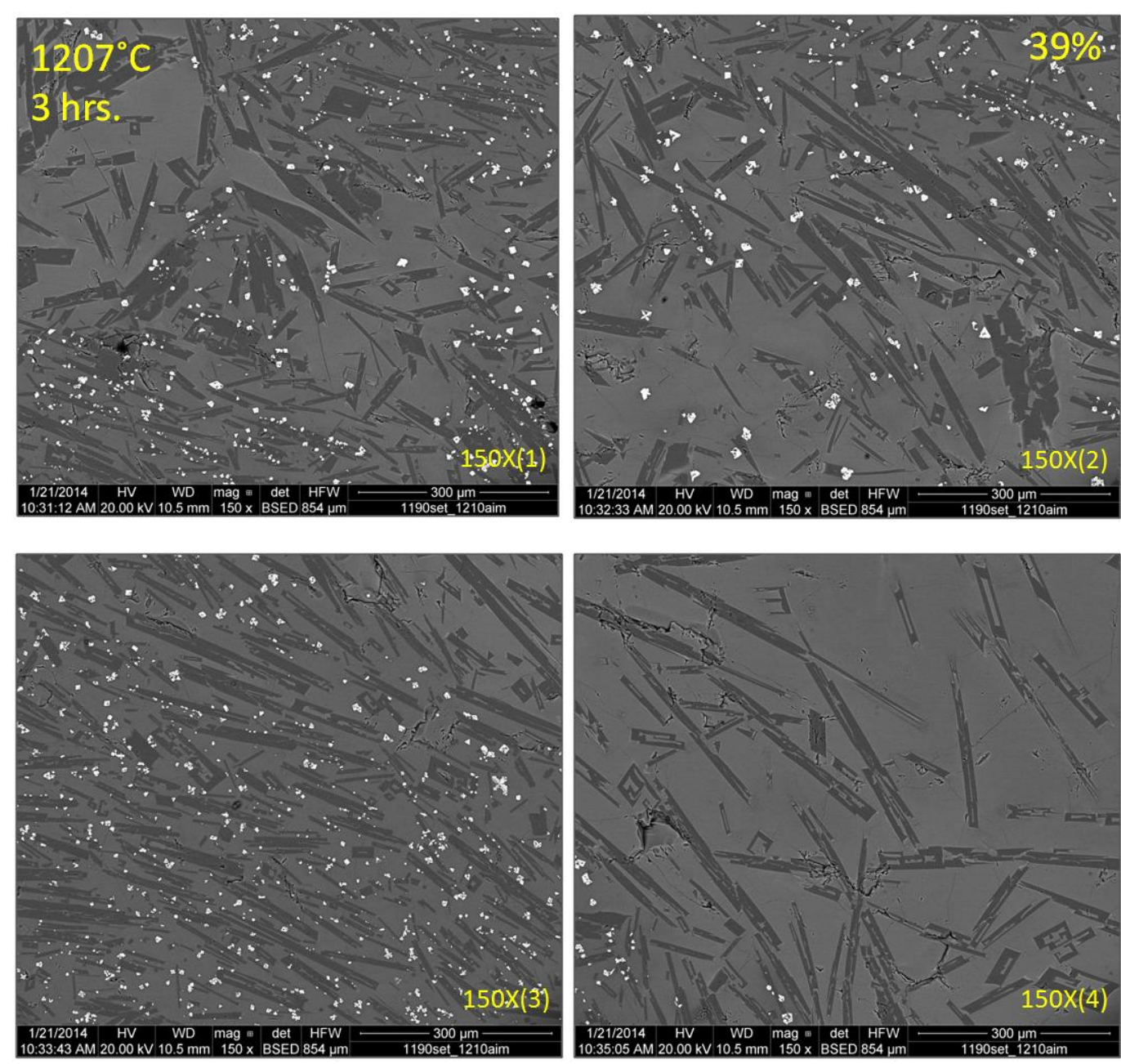

\begin{tabular}{|c|c|c|c|c|c|}
\hline \multicolumn{2}{|c|}{$1207^{\circ} \mathrm{C}$ (Post CC) } & \multirow[b]{2}{*}{$\begin{array}{c}\text { Glass } \\
\% \\
\end{array}$} & \multirow[b]{2}{*}{$\begin{array}{c}\text { Oxide } \\
\% \\
\end{array}$} & \multirow[b]{2}{*}{$\begin{array}{c}\text { Total Xtal } \\
\% \\
\end{array}$} & \multirow[b]{2}{*}{$\begin{array}{l}\text { Diff } \\
(+/-)\end{array}$} \\
\hline Image & $\begin{array}{c}\text { Plag } \\
\%\end{array}$ & & & & \\
\hline $150 \times(1)$ & 37.9 & 59.4 & 2.7 & 40.6 & 1.6 \\
\hline $150 X(1)$ & 40.3 & 57.8 & 1.8 & 42.2 & \\
\hline $150 X(2)$ & 42.9 & 55.2 & 1.9 & 44.8 & 5.5 \\
\hline $150 X(2)$ & 37.5 & 60.8 & 1.7 & 39.2 & \\
\hline $150 X(3)$ & 40.8 & 58.3 & 0.9 & 41.7 & 3.9 \\
\hline $150 X(3)$ & 43.6 & 54.4 & 2.0 & 45.6 & \\
\hline $150 \times(4)$ & 29.8 & 70.0 & 0.2 & 30.0 & 0.6 \\
\hline $150 X(4)$ & 29.1 & 70.7 & 0.2 & 29.3 & \\
\hline Avg. & 37.7 & 60.8 & 1.4 & 39.2 & 2.9 \\
\hline
\end{tabular}

A-4 continued. 

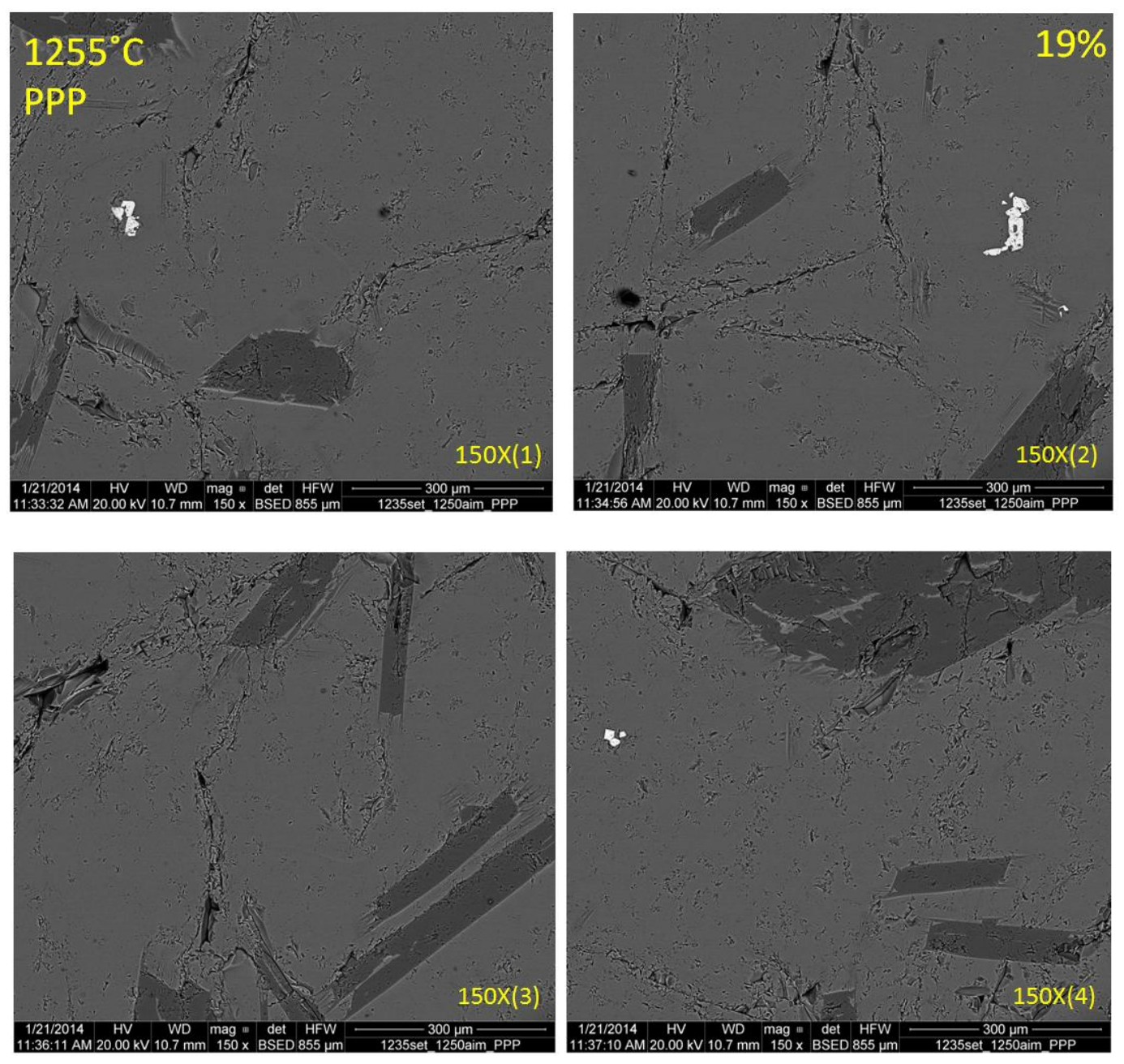

\begin{tabular}{|c|c|c|c|c|c|}
\hline \multicolumn{2}{|c|}{$1255^{\circ} \mathrm{C}$ (Post PP) } & \multirow[b]{2}{*}{$\begin{array}{c}\text { Glass } \\
\% \\
\end{array}$} & \multirow[b]{2}{*}{$\begin{array}{c}\text { Oxide } \\
\% \\
\end{array}$} & \multirow[b]{2}{*}{$\begin{array}{c}\text { Total Xtal } \\
\% \\
\end{array}$} & \multirow[b]{2}{*}{$\begin{array}{l}\text { Diff } \\
(+/-)\end{array}$} \\
\hline Image & $\begin{array}{c}\text { Plag } \\
\%\end{array}$ & & & & \\
\hline $150 X(1)$ & 15.8 & 84.0 & 0.2 & 16.0 & 0.8 \\
\hline $150 \times(1)$ & 15.0 & 84.8 & 0.2 & 15.2 & \\
\hline $150 X(2)$ & 18.0 & 81.7 & 0.3 & 18.3 & 4.6 \\
\hline $150 \times(2)$ & 13.4 & 86.3 & 0.3 & 13.7 & \\
\hline $150 \times(3)$ & 23.7 & 76.3 & 0.0 & 23.7 & 3.0 \\
\hline $150 \times(3)$ & 20.7 & 79.3 & 0.0 & 20.7 & \\
\hline $150 X(4)$ & 18.0 & 81.9 & 0.1 & 18.1 & 7.0 \\
\hline $150 \times(4)$ & 24.9 & 74.9 & 0.1 & 25.1 & \\
\hline Avg. & 18.7 & 81.2 & 0.1 & 18.8 & 3.8 \\
\hline
\end{tabular}

Figures A-5 and Tables A-5. Low magnification BSE images of post PP experiment and corresponding crystal \% for each image. Difference column represents difference between high and low cut off values using Photoshop pixel counting method. Avg. of total xtal \% represents value used for whole sample. 

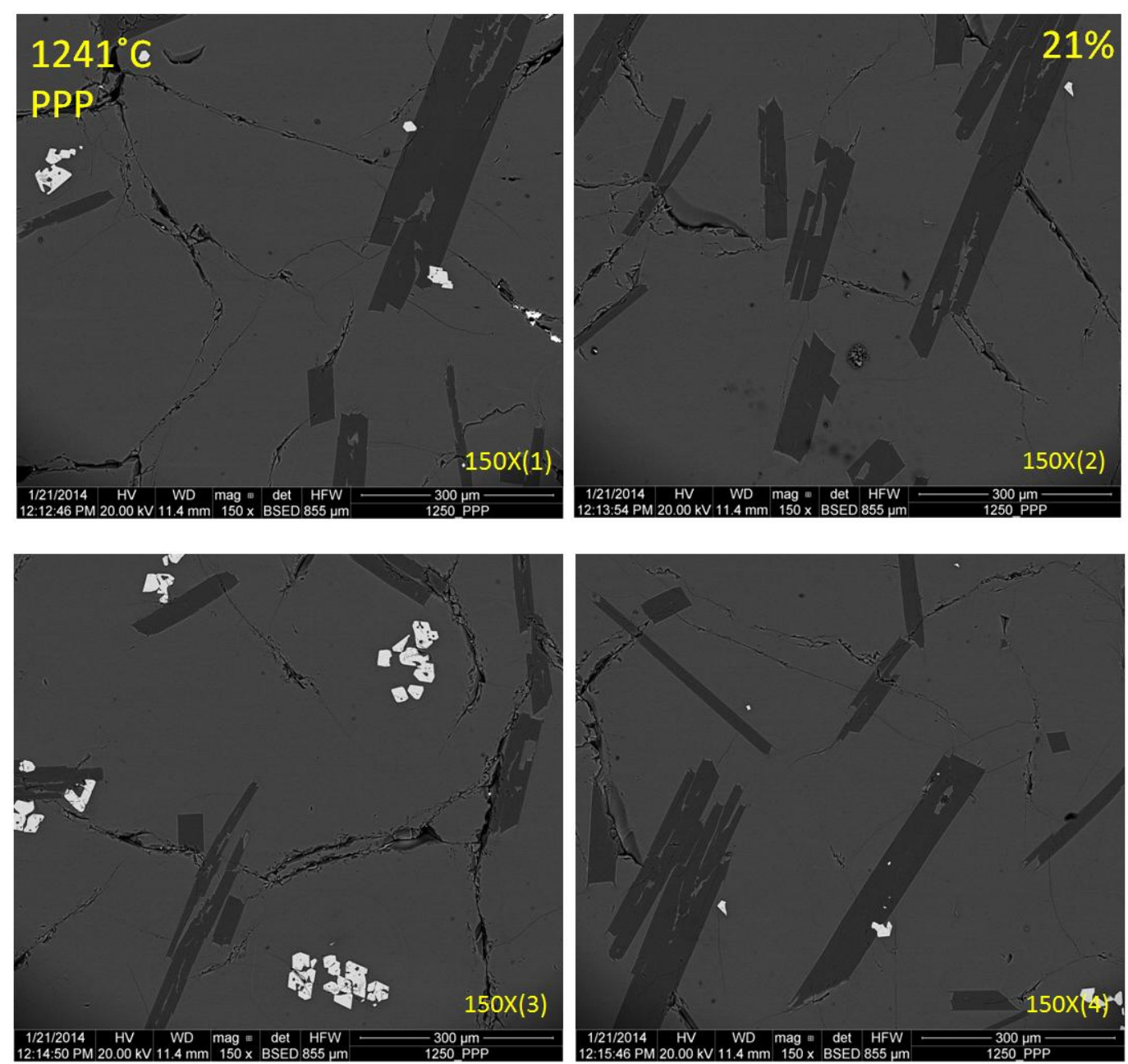

\begin{tabular}{|c|c|c|c|c|c|}
\hline \multicolumn{2}{|c|}{$1241^{\circ} \mathrm{C}$ (Post PP) } & \multirow[b]{2}{*}{$\begin{array}{c}\text { Glass } \\
\%\end{array}$} & \multirow[b]{2}{*}{$\begin{array}{c}\text { Oxide } \\
\% \\
\end{array}$} & \multirow[b]{2}{*}{$\begin{array}{c}\text { Total Xtal } \\
\% \\
\end{array}$} & \multirow[b]{2}{*}{$\begin{array}{l}\text { Diff } \\
(+/-)\end{array}$} \\
\hline Image & $\begin{array}{c}\text { Plag } \\
\%\end{array}$ & & & & \\
\hline $150 \times(1)$ & 15.7 & 83.8 & 0.5 & 16.2 & 5.2 \\
\hline $150 \times(1)$ & 21.0 & 78.6 & 0.5 & 21.4 & \\
\hline $150 \times(2)$ & 22.6 & 77.4 & 0.0 & 22.6 & 1.1 \\
\hline $150 \times(2)$ & 23.7 & 76.3 & 0.0 & 23.7 & \\
\hline $150 \times(3)$ & 18.4 & 79.8 & 1.8 & 20.2 & 2.2 \\
\hline $150 \times(3)$ & 16.0 & 81.9 & 2.1 & 18.1 & \\
\hline $150 \times(4)$ & 21.0 & 78.7 & 0.2 & 21.3 & 0.6 \\
\hline $150 \times(4)$ & 21.7 & 78.1 & 0.2 & 21.9 & \\
\hline Avg. & 20.0 & 79.3 & 0.7 & 20.7 & 2.3 \\
\hline
\end{tabular}

A-5 Continued. 

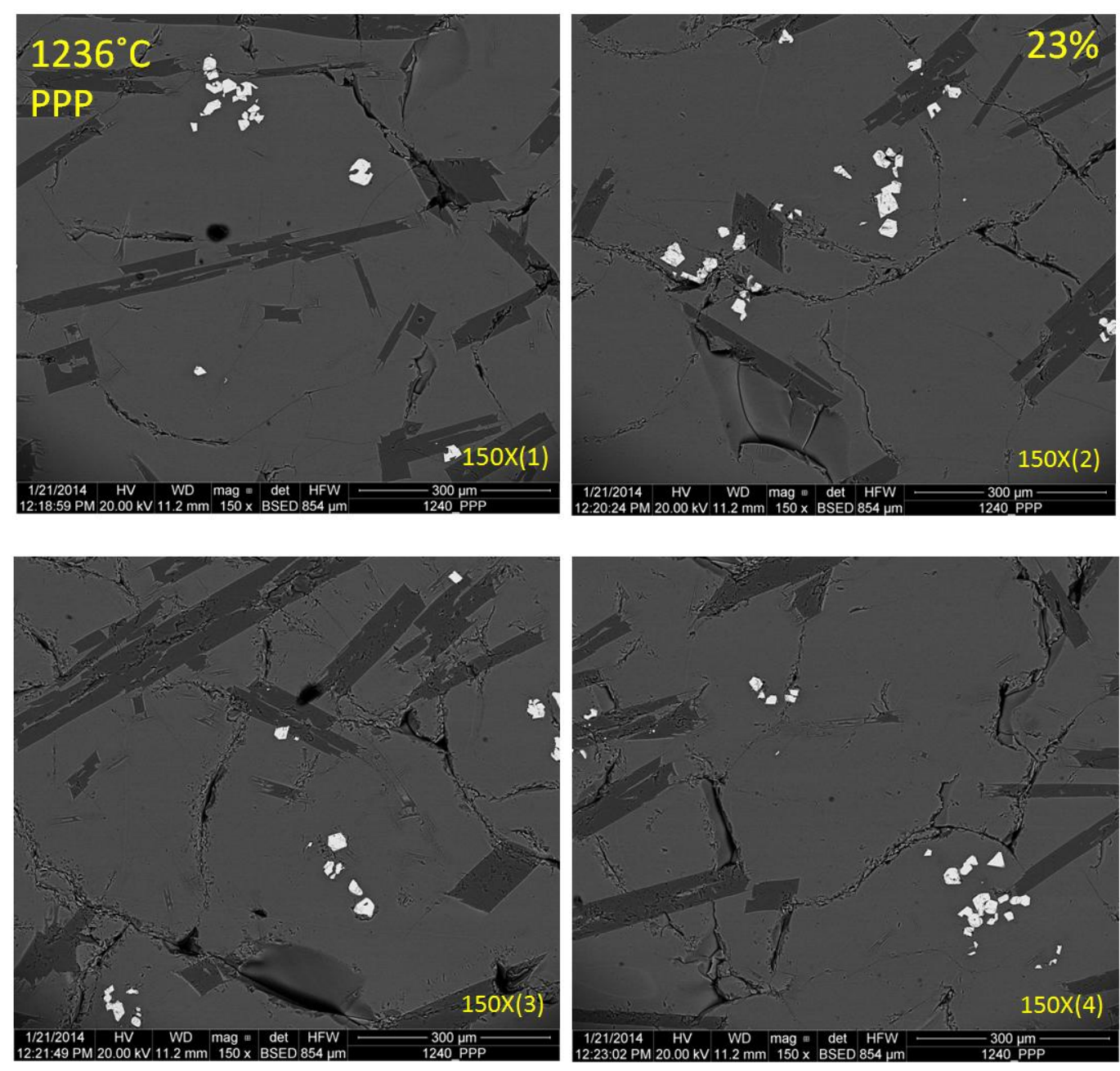

\begin{tabular}{|c|c|c|c|c|c|}
\hline \multicolumn{2}{|c|}{$1236^{\circ} \mathrm{C}$ (Post PP) } & \multirow[b]{2}{*}{$\begin{array}{c}\text { Glass } \\
\% \\
\end{array}$} & \multirow[b]{2}{*}{$\begin{array}{c}\text { Oxide } \\
\% \\
\end{array}$} & \multirow[b]{2}{*}{$\begin{array}{c}\text { Total Xtal } \\
\% \\
\end{array}$} & \multirow[b]{2}{*}{$\begin{array}{l}\text { Diff } \\
(+/-)\end{array}$} \\
\hline Image & $\begin{array}{c}\text { Plag } \\
\%\end{array}$ & & & & \\
\hline $150 \times(1)$ & 25.6 & 73.8 & 0.7 & 26.2 & 6.3 \\
\hline $150 \times(1)$ & 19.2 & 80.1 & 0.7 & 19.9 & \\
\hline $150 \times(2)$ & 15.6 & 83.3 & 1.1 & 16.7 & 0.9 \\
\hline $150 \times(2)$ & 14.8 & 84.2 & 1.0 & 15.8 & \\
\hline $150 \times(3)$ & 31.3 & 68.0 & 0.7 & 32.0 & 1.9 \\
\hline $150 \times(3)$ & 33.1 & 66.2 & 0.7 & 33.8 & \\
\hline $150 X(4)$ & 17.2 & 82.0 & 0.8 & 18.0 & 3.2 \\
\hline $150 \times(4)$ & 20.5 & 78.8 & 0.7 & 21.2 & \\
\hline Avg. & 22.1 & 77.1 & 0.8 & 22.9 & 3.1 \\
\hline
\end{tabular}

A-5 Continued. 

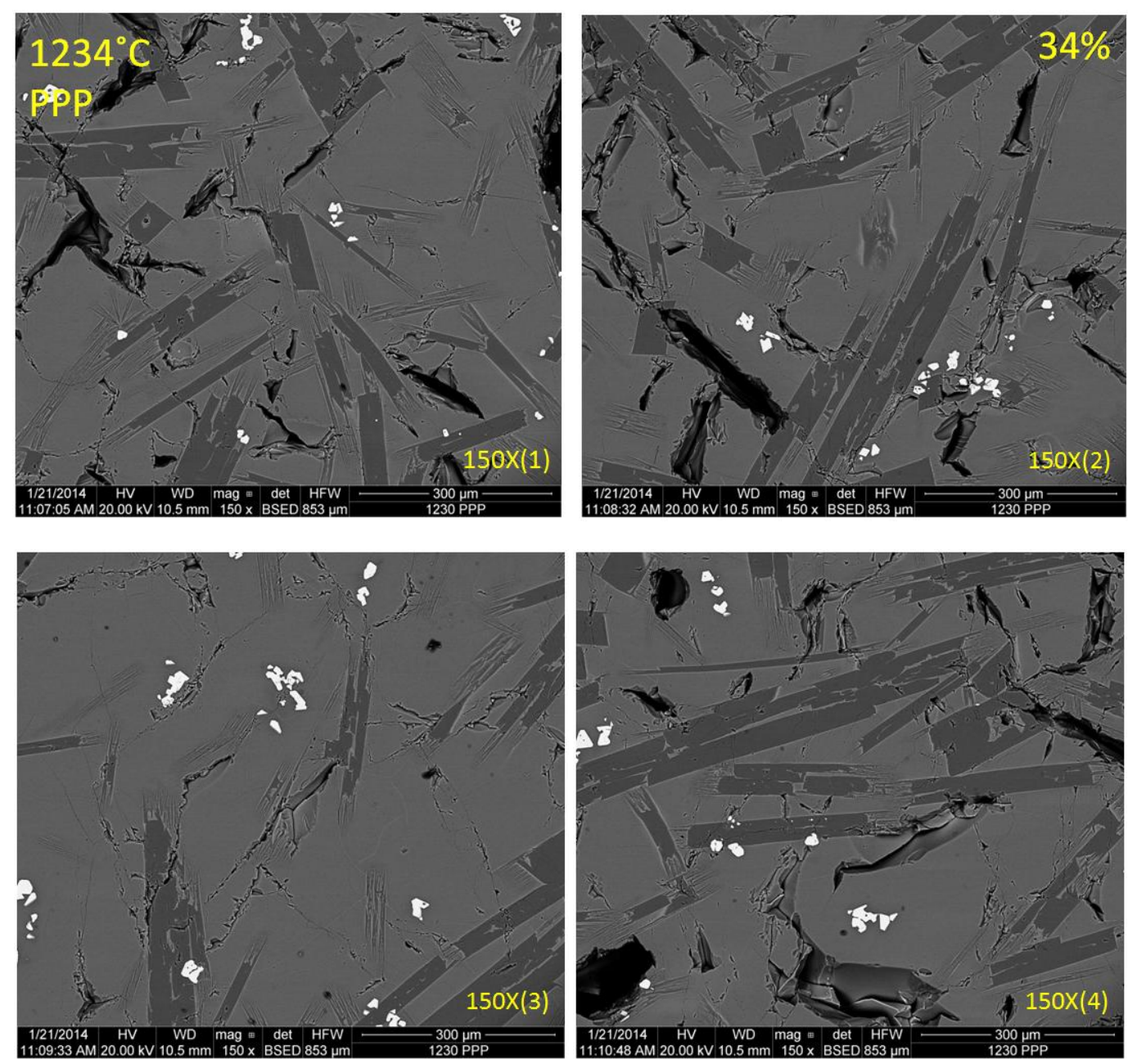

\begin{tabular}{|c|c|c|c|c|c|}
\hline \multicolumn{2}{|c|}{$1234^{\circ} \mathrm{C}$ (Post PP) } & \multirow[b]{2}{*}{$\begin{array}{c}\text { Glass } \\
\% \\
\end{array}$} & \multirow[b]{2}{*}{$\begin{array}{c}\text { Oxide } \\
\%\end{array}$} & \multirow[b]{2}{*}{$\begin{array}{c}\text { Total Xtal } \\
\% \\
\end{array}$} & \multirow[b]{2}{*}{$\begin{array}{l}\text { Diff } \\
(+/-)\end{array}$} \\
\hline Image & $\begin{array}{c}\text { Plag } \\
\%\end{array}$ & & & & \\
\hline $150 \times(1)$ & 32.3 & 67.0 & 0.7 & 33.0 & 1.2 \\
\hline $150 \times(1)$ & 33.6 & 65.8 & 0.6 & 34.2 & \\
\hline $150 \times(2)$ & 41.4 & 58.0 & 0.6 & 42.0 & 1.2 \\
\hline $150 \times(2)$ & 40.2 & 59.2 & 0.6 & 40.8 & \\
\hline $150 \times(3)$ & 20.8 & 78.1 & 1.1 & 21.9 & 5.5 \\
\hline $150 \times(3)$ & 26.3 & 72.6 & 1.1 & 27.4 & \\
\hline $150 \times(4)$ & 36.4 & 61.9 & 1.7 & 38.1 & 2.1 \\
\hline $150 \times(4)$ & 34.4 & 64.1 & 1.6 & 35.9 & \\
\hline Avg. & 33.2 & 65.8 & 1.0 & 34.2 & 2.5 \\
\hline
\end{tabular}

A-5 Continued. 

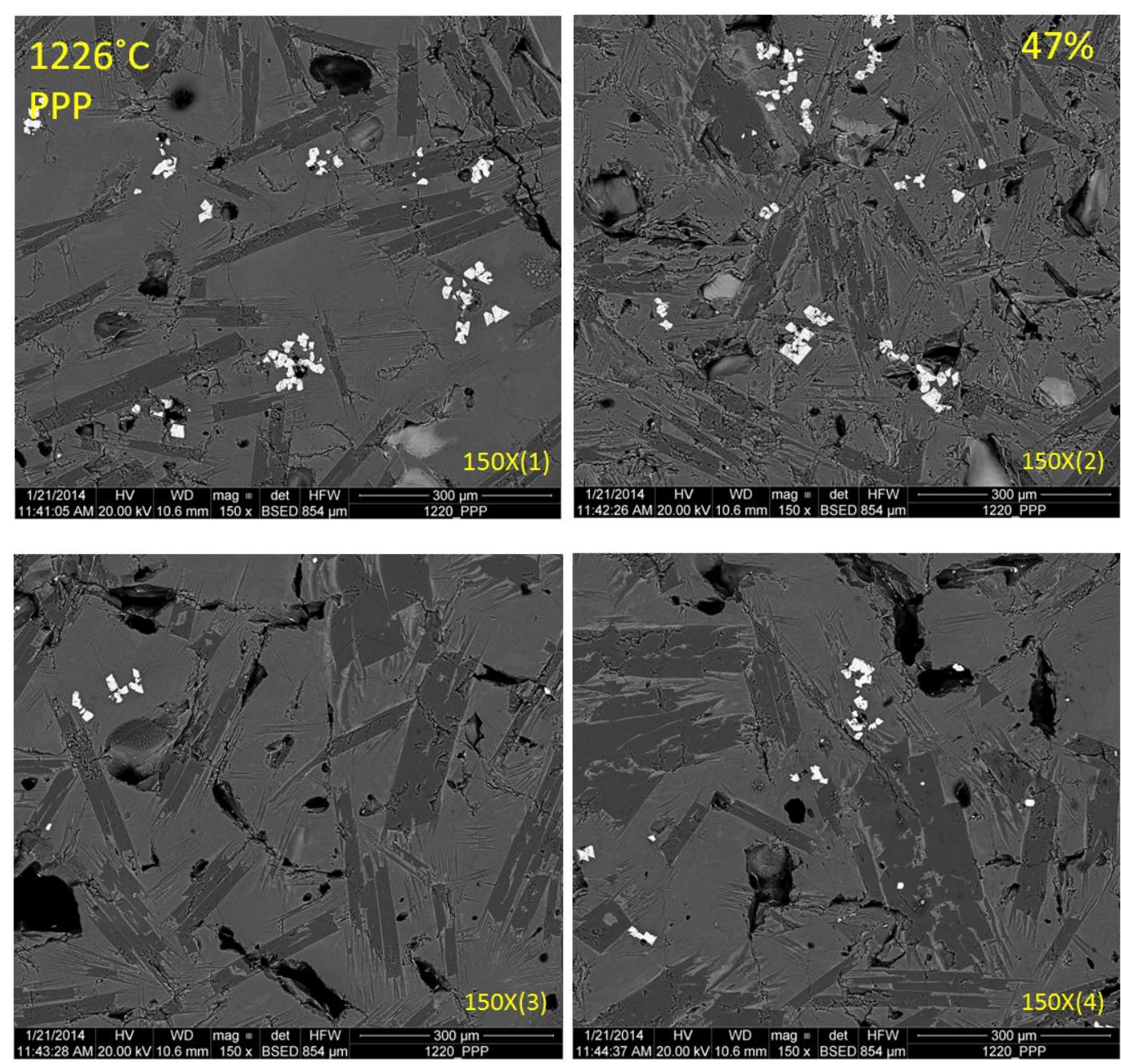

\begin{tabular}{c|c|c|c|c|c|c}
\hline \multicolumn{1}{l|}{$1226^{\circ} \mathrm{C}($ Post PP) } & \multicolumn{6}{|c}{} \\
\hline Image & $\begin{array}{c}\text { Plag } \\
\%\end{array}$ & $\begin{array}{c}\text { Glass } \\
\%\end{array}$ & $\begin{array}{c}\text { 3rd phase } \\
\%\end{array}$ & $\begin{array}{c}\text { Oxide } \\
\%\end{array}$ & $\begin{array}{c}\text { Total Xtal } \\
\%\end{array}$ & $\begin{array}{c}\text { Diff } \\
(+/-)\end{array}$ \\
\hline $150 \mathrm{X}(1)$ & 43.6 & 54.6 & 0.0 & 1.7 & 45.4 & 4.0 \\
$150 \mathrm{X}(1)$ & 39.7 & 58.6 & 0.0 & 1.7 & 41.4 & \\
$150 \mathrm{X}(2)$ & 42.8 & 52.0 & 3.0 & 2.2 & 48.0 & 5.7 \\
$150 \mathrm{X}(2)$ & 37.0 & 57.9 & 3.1 & 2.0 & 42.1 & \\
$150 \mathrm{X}(3)$ & 52.2 & 47.4 & 0.0 & 0.4 & 52.6 & 4.2 \\
$150 \mathrm{X}(3)$ & 48.0 & 51.6 & 0.0 & 0.4 & 48.4 & \\
$150 \mathrm{X}(4)$ & 49.9 & 49.2 & 0.0 & 0.8 & 50.8 & 1.3 \\
$150 \mathrm{X}(4)$ & 48.6 & 50.6 & 0.0 & 0.8 & 49.4 & \\
\hline Avg. & 45.2 & 52.8 & 0.8 & 1.3 & 47.2 & 3.8 \\
\hline
\end{tabular}

A-5 Continued. 

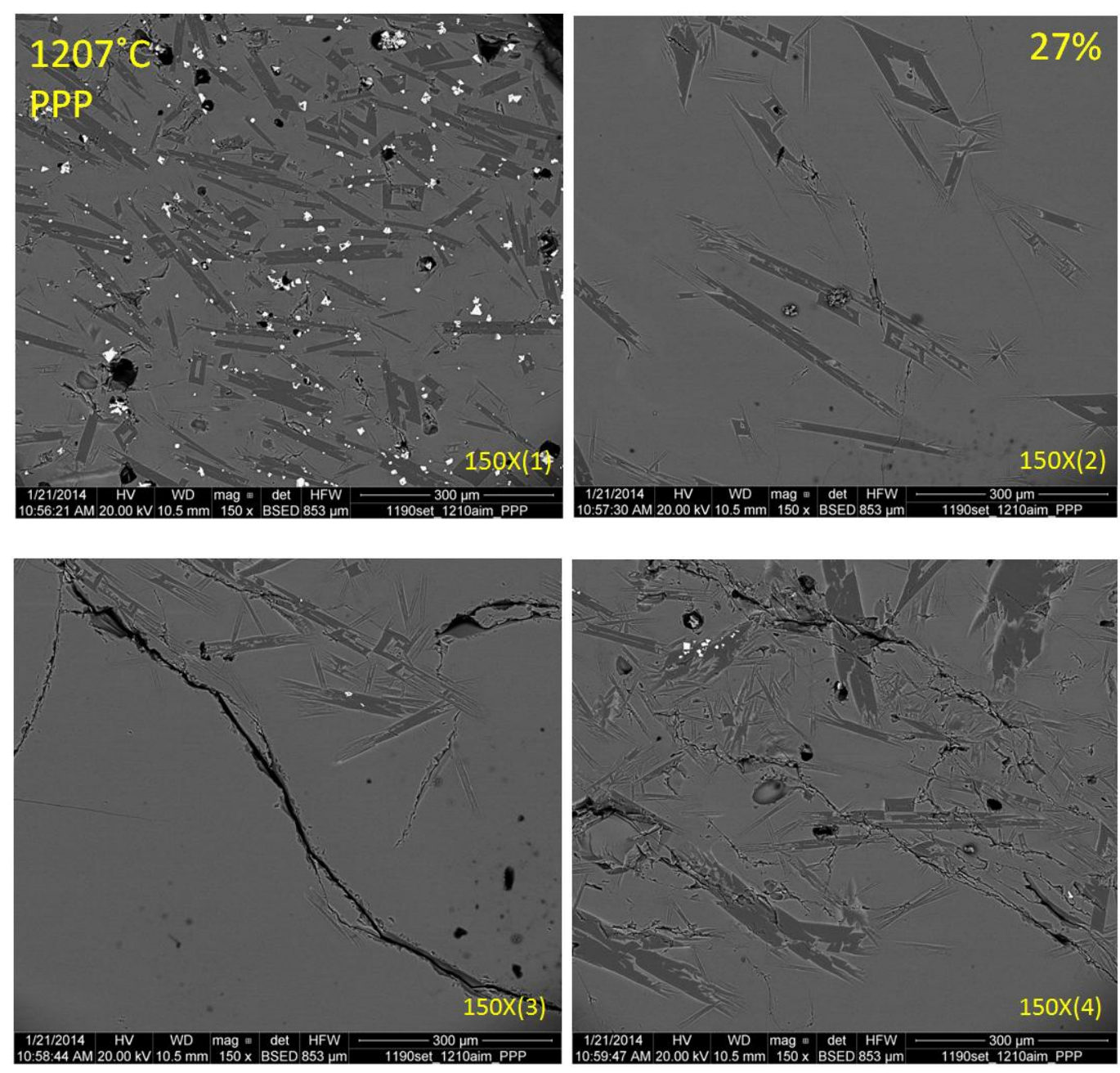

\begin{tabular}{c|c|c|c|c|c}
\hline $\mathbf{1 2 0 7}^{\circ} \mathbf{C}($ Post PP) & \multicolumn{4}{|c}{} \\
\hline Image & $\begin{array}{c}\text { Plag } \\
\%\end{array}$ & $\begin{array}{c}\text { Glass } \\
\%\end{array}$ & $\begin{array}{c}\text { Oxide } \\
\%\end{array}$ & $\begin{array}{c}\text { Total Xtal } \\
\%\end{array}$ & $\begin{array}{c}\text { Diff } \\
(+/-)\end{array}$ \\
\hline $150 X(1)$ & 40.7 & 59.2 & 0.1 & 40.8 & 2.4 \\
$150 X(1)$ & 41.3 & 56.8 & 1.9 & 43.2 & \\
$150 X(2)$ & 13.8 & 86.2 & 0.0 & 13.8 & 0.4 \\
$150 X(2)$ & 14.2 & 85.8 & 0.0 & 14.2 & \\
$150 X(3)$ & 21.5 & 78.4 & 0.0 & 21.6 & 2.6 \\
$150 X(3)$ & 19.0 & 81.0 & 0.0 & 19.0 & \\
$150 X(4)$ & 33.9 & 66.0 & 0.1 & 34.0 & 3.1 \\
$150 X(4)$ & 30.8 & 69.0 & 0.1 & 31.0 & \\
\hline Avg. & 26.9 & 72.8 & 0.3 & 27.2 & 2.1 \\
\hline
\end{tabular}

A-5 Continued. 
Tables A-6. Microprobe analyses in wt \% for the partially crystalline remelts. Individual phases in the left column. The last two rows represent average glass composition and standard deviation among analyses.

\begin{tabular}{c|cccccccccccc}
\multicolumn{10}{c}{$\mathbf{1 2 0 7}^{\circ} \mathbf{C}(\mathbf{P C C})$} \\
\hline Phase & $\mathbf{S i O}_{\mathbf{2}}$ & $\mathbf{T i O}_{\mathbf{2}}$ & $\mathbf{A l}_{\mathbf{2}} \mathbf{O}_{\mathbf{3}}$ & $\mathbf{C r}_{\mathbf{2}} \mathbf{O}_{\mathbf{3}}$ & $\mathbf{F e O}$ & $\mathbf{M n O}$ & $\mathbf{M g O}$ & $\mathbf{C a O}$ & $\mathbf{N a}_{\mathbf{2}} \mathbf{O}$ & $\mathbf{K}_{\mathbf{2}} \mathbf{O}$ & $\mathbf{P}_{\mathbf{2}} \mathbf{O}_{\mathbf{5}}$ & Total \\
\hline Plag & 50.95 & 0.09 & 28.77 & 0.00 & 2.80 & 0.03 & 0.18 & 13.15 & 3.67 & 0.15 & 0.00 & 99.78 \\
Plag & 51.67 & 0.10 & 28.41 & 0.00 & 2.93 & 0.00 & 0.17 & 12.97 & 3.82 & 0.18 & 0.01 & 100.25 \\
Plag & 50.70 & 0.09 & 29.07 & 0.01 & 2.87 & 0.02 & 0.17 & 13.71 & 3.48 & 0.15 & 0.04 & 100.33 \\
Plag & 50.10 & 0.13 & 29.13 & 0.00 & 2.86 & 0.03 & 0.15 & 14.09 & 3.35 & 0.16 & 0.05 & 100.05 \\
Glass & 52.76 & 1.55 & 16.17 & 0.00 & 8.70 & 0.22 & 5.72 & 8.73 & 3.62 & 1.14 & 0.35 & 98.96 \\
stdev & 0.15 & 0.03 & 0.07 & 0.01 & 0.08 & 0.03 & 0.06 & 0.17 & 0.05 & 0.03 & 0.02 & \\
\hline
\end{tabular}

\section{A-6 Continued.}

$1207^{\circ} \mathrm{C}(\mathrm{PPP})$

\begin{tabular}{c|cccccccccccc}
\hline Phase & $\mathbf{S i O}_{2}$ & $\mathbf{T i O}_{2}$ & $\mathbf{A l}_{2} \mathbf{O}_{\mathbf{3}}$ & $\mathbf{C r}_{2} \mathbf{O}_{\mathbf{3}}$ & $\mathbf{F e O}$ & $\mathbf{M n O}$ & $\mathbf{M g O}$ & $\mathbf{C a O}$ & $\mathbf{N a}_{2} \mathbf{O}$ & $\mathbf{K}_{2} \mathbf{O}$ & $\mathbf{P}_{2} \mathbf{O}_{5}$ & Total \\
\hline Plag & 49.95 & 0.11 & 29.45 & 0.00 & 2.90 & 0.00 & 0.17 & 13.80 & 3.28 & 0.13 & 0.04 & 99.83 \\
Plag & 50.99 & 0.10 & 28.74 & 0.00 & 3.20 & 0.03 & 0.20 & 13.49 & 3.54 & 0.16 & 0.03 & 100.48 \\
Plag & 50.18 & 0.09 & 29.95 & 0.00 & 2.77 & 0.00 & 0.16 & 13.86 & 3.25 & 0.14 & 0.03 & 100.42 \\
Plag & 50.30 & 0.09 & 29.40 & 0.01 & 2.81 & 0.05 & 0.16 & 14.12 & 3.31 & 0.13 & 0.02 & 100.41 \\
Ox & 0.00 & 1.14 & 8.98 & 0.07 & 77.61 & 0.62 & 10.46 & 0.24 & 0.00 & 0.02 & 0.00 & 99.14 \\
Ox & 0.00 & 1.11 & 8.92 & 0.10 & 78.60 & 0.70 & 9.76 & 0.21 & 0.01 & 0.02 & 0.00 & 99.42 \\
Ox & 0.00 & 1.10 & 9.28 & 0.09 & 76.67 & 0.61 & 11.02 & 0.18 & 0.03 & 0.02 & 0.03 & 99.03 \\
Glass & 52.85 & 1.47 & 17.35 & 0.00 & 9.91 & 0.20 & 5.46 & 8.85 & 2.05 & 1.27 & 0.31 & 99.72 \\
stdev & 0.79 & 0.05 & 0.32 & 0.00 & 0.52 & 0.05 & 0.01 & 0.18 & 0.11 & 0.04 & 0.03 & \\
\hline
\end{tabular}

A-6 Continued.

$1207^{\circ} \mathrm{C}$ (PCC_Glassy Area)

\begin{tabular}{c|cccccccccccc}
\hline Phase & $\mathbf{S i O}_{2}$ & $\mathbf{T i O}_{2}$ & $\mathbf{A l}_{2} \mathbf{O}_{3}$ & $\mathrm{Cr}_{2} \mathbf{O}_{3}$ & $\mathbf{F e O}$ & $\mathbf{M n O}$ & $\mathbf{M g O}$ & $\mathbf{C a O}$ & $\mathbf{N a}_{2} \mathbf{O}$ & $\mathbf{K}_{2} \mathbf{O}$ & $\mathbf{P}_{2} \mathbf{O}_{5}$ & Total \\
\hline Plag & 50.91 & 0.13 & 29.15 & 0.00 & 3.19 & 0.00 & 0.19 & 13.82 & 3.36 & 0.12 & 0.03 & 100.88 \\
Plag & 50.53 & 0.11 & 29.31 & 0.00 & 3.13 & 0.05 & 0.17 & 14.26 & 3.37 & 0.13 & 0.03 & 101.10 \\
Plag & 50.37 & 0.14 & 29.21 & 0.00 & 3.07 & 0.01 & 0.20 & 13.94 & 3.36 & 0.14 & 0.04 & 100.47 \\
Plag & 50.53 & 0.11 & 29.05 & 0.00 & 3.20 & 0.02 & 0.20 & 14.02 & 3.33 & 0.13 & 0.04 & 100.65 \\
Glass & 49.72 & 1.26 & 18.25 & 0.00 & 10.25 & 0.18 & 4.88 & 9.16 & 3.49 & 0.90 & 0.25 & 98.35 \\
stdev & 0.21 & 0.08 & 0.40 & 0.01 & 0.28 & 0.03 & 0.21 & 0.32 & 0.05 & 0.06 & 0.03 & \\
\hline
\end{tabular}


A-6 Continued.

${ }_{1207^{\circ} \mathrm{C}}$ (PPP_Glassy Area)

\begin{tabular}{l|cccccccccccc}
\hline Phase & $\mathbf{S i O}_{\mathbf{2}}$ & $\mathbf{T i O}_{\mathbf{2}}$ & $\mathrm{Al}_{\mathbf{2}} \mathbf{O}_{\mathbf{3}}$ & $\mathrm{Cr}_{2} \mathbf{O}_{\mathbf{3}}$ & $\mathbf{F e O}$ & $\mathbf{M n O}$ & $\mathbf{M g O}$ & $\mathbf{C a O}$ & $\mathbf{N a}_{2} \mathbf{O}$ & $\mathbf{K}_{\mathbf{2}} \mathbf{O}$ & $\mathbf{P}_{\mathbf{2}} \mathbf{O}_{\mathbf{5}}$ & Total \\
\hline Glass & 51.21 & 1.18 & 19.36 & 0.01 & 9.83 & 0.16 & 4.50 & 9.65 & 2.17 & 0.83 & 0.26 & 99.18 \\
stdev & 0.15 & 0.02 & 0.19 & 0.01 & 0.10 & 0.03 & 0.05 & 0.19 & 0.04 & 0.02 & 0.03 & \\
\hline
\end{tabular}

A-6 Continued.

$1226^{\circ} \mathrm{C}$ (PCC)

\begin{tabular}{c|cccccccccccc}
\hline Phase & $\mathbf{S i O}_{2}$ & $\mathrm{TiO}_{2}$ & $\mathrm{Al}_{2} \mathbf{O}_{\mathbf{3}}$ & $\mathrm{Cr}_{2} \mathbf{O}_{\mathbf{3}}$ & $\mathbf{F e O}$ & $\mathbf{M n O}$ & $\mathbf{M g O}$ & $\mathbf{C a O}$ & $\mathbf{N a}_{2} \mathbf{O}$ & $\mathbf{K}_{2} \mathbf{O}_{2}$ & $\mathbf{P}_{2} \mathbf{O}_{5}$ & Total \\
\hline Plag & 49.64 & 0.09 & 30.37 & 0.02 & 2.10 & 0.03 & 0.16 & 14.29 & 3.00 & 0.12 & 0.00 & 99.83 \\
Plag & 49.73 & 0.10 & 30.06 & 0.00 & 2.19 & 0.00 & 0.18 & 14.50 & 3.10 & 0.12 & 0.00 & 99.99 \\
Plag & 49.82 & 0.06 & 30.85 & 0.00 & 1.98 & 0.00 & 0.15 & 14.43 & 3.13 & 0.14 & 0.01 & 100.57 \\
Plag & 49.49 & 0.07 & 30.50 & 0.00 & 2.06 & 0.02 & 0.17 & 14.90 & 2.93 & 0.15 & 0.01 & 100.30 \\
Ox & 0.00 & 0.93 & 9.18 & 0.13 & 76.07 & 0.45 & 12.39 & 0.12 & 0.02 & 0.00 & 0.00 & 99.30 \\
Ox & 0.00 & 0.95 & 8.83 & 0.03 & 75.77 & 0.58 & 12.27 & 0.10 & 0.02 & 0.00 & 0.00 & 98.54 \\
Ox & 0.00 & 0.97 & 9.13 & 0.12 & 75.82 & 0.51 & 12.43 & 0.14 & 0.03 & 0.01 & 0.00 & 99.16 \\
Ox & 0.00 & 0.99 & 9.07 & 0.02 & 75.82 & 0.51 & 12.45 & 0.12 & 0.00 & 0.00 & 0.00 & 98.98 \\
Glass & 52.41 & 1.45 & 16.77 & 0.01 & 8.87 & 0.20 & 5.12 & 8.89 & 3.64 & 1.03 & 0.32 & 98.71 \\
stdev & 0.05 & 0.04 & 0.06 & 0.01 & 0.05 & 0.02 & 0.01 & 0.14 & 0.02 & 0.02 & 0.02 &
\end{tabular}

A-6 Continued.

$1226^{\circ} \mathrm{C}$ (PPP)

\begin{tabular}{c|cccccccccccc}
\hline Phase & $\mathrm{SiO}_{2}$ & $\mathrm{TiO}_{2}$ & $\mathrm{Al}_{2} \mathbf{O}_{\mathbf{3}}$ & $\mathrm{Cr}_{\mathbf{2}} \mathbf{O}_{\mathbf{3}}$ & $\mathbf{F e O}$ & $\mathbf{M n O}$ & $\mathbf{M g O}$ & $\mathbf{C a O}$ & $\mathbf{N a}_{2} \mathbf{O}$ & $\mathbf{K}_{2} \mathbf{O}_{2}$ & $\mathbf{P}_{2} \mathbf{O}_{5}$ & Total \\
\hline Plag & 50.11 & 0.06 & 30.33 & 0.01 & 2.00 & 0.05 & 0.14 & 13.82 & 3.19 & 0.12 & 0.02 & 99.84 \\
Plag & 49.37 & 0.06 & 30.37 & 0.00 & 2.01 & 0.01 & 0.15 & 14.21 & 3.09 & 0.12 & 0.02 & 99.40 \\
Plag & 49.84 & 0.10 & 30.50 & 0.00 & 2.21 & 0.05 & 0.15 & 14.65 & 3.00 & 0.13 & 0.02 & 100.63 \\
Plag & 49.95 & 0.09 & 30.42 & 0.01 & 2.09 & 0.04 & 0.16 & 14.19 & 3.10 & 0.14 & 0.02 & 100.21 \\
Ox & 0.00 & 1.37 & 9.71 & 0.12 & 78.79 & 0.63 & 9.11 & 0.21 & 0.03 & 0.02 & 0.00 & 99.98 \\
Ox & 0.00 & 1.13 & 9.80 & 0.12 & 78.23 & 0.57 & 9.37 & 0.11 & 0.00 & 0.01 & 0.00 & 99.35 \\
Ox & 0.00 & 1.24 & 10.15 & 0.12 & 79.30 & 0.52 & 8.35 & 0.16 & 0.00 & 0.00 & 0.00 & 99.84 \\
Glass & 51.48 & 1.46 & 17.44 & 0.01 & 10.41 & 0.21 & 4.98 & 8.54 & 3.77 & 1.02 & 0.29 & 99.60 \\
stdev & 0.21 & 0.06 & 0.13 & 0.01 & 0.62 & 0.04 & 0.08 & 1.09 & 0.37 & 0.04 & 0.04 & \\
\hline
\end{tabular}


A-6 Continued.

\begin{tabular}{|c|c|c|c|c|c|c|c|c|c|c|c|c|}
\hline Phase & $\mathrm{SiO}_{2}$ & $\mathrm{TiO}_{2}$ & $\mathrm{Al}_{2} \mathrm{O}_{3}$ & $\mathrm{Cr}_{2} \mathrm{O}_{3}$ & $\mathrm{FeO}$ & MnO & MgO & $\mathrm{CaO}$ & $\mathrm{Na}_{2} \mathrm{O}$ & $\mathbf{K}_{2} \mathbf{O}$ & $\mathbf{P}_{2} \mathbf{O}_{5}$ & Total \\
\hline Plag & 49.80 & 0.06 & 30.40 & 0.00 & 2.32 & 0.00 & 0.17 & 14.35 & 3.02 & 0.11 & 0.02 & 100.25 \\
\hline Plag & 49.48 & 0.07 & 31.12 & 0.00 & 2.12 & 0.05 & 0.14 & 14.71 & 2.84 & 0.11 & 0.00 & 100.64 \\
\hline Plag & 49.65 & 0.10 & 30.26 & 0.00 & 2.35 & 0.01 & 0.14 & 14.20 & 3.09 & 0.13 & 0.05 & 99.98 \\
\hline Plag & 49.63 & 0.09 & 30.79 & 0.00 & 2.23 & 0.01 & 0.12 & 14.75 & 2.96 & 0.12 & 0.02 & 100.72 \\
\hline Ox & 0.00 & 0.82 & 10.03 & 0.14 & 76.54 & 0.47 & 11.60 & 0.13 & 0.00 & 0.00 & 0.02 & 99.75 \\
\hline Ox & 0.00 & 0.79 & 10.38 & 0.18 & 75.03 & 0.49 & 11.57 & 0.20 & 0.01 & 0.02 & 0.00 & 98.65 \\
\hline Glass & 51.34 & 1.32 & 17.74 & 0.01 & 9.43 & 0.19 & 4.97 & 8.98 & 3.60 & 0.93 & 0.29 & 98.80 \\
\hline stdev & 0.10 & 0.02 & 0.03 & 0.00 & 0.12 & 0.03 & 0.02 & 0.06 & 0.01 & 0.03 & 0.01 & \\
\hline
\end{tabular}

\section{A-6 Continued.}

$1234^{\circ} \mathrm{C}$ (PPP)

\begin{tabular}{c|cccccccccccc}
\hline Phase & $\mathrm{SiO}_{2}$ & $\mathrm{TiO}_{2}$ & $\mathrm{Al}_{2} \mathbf{O}_{3}$ & $\mathrm{Cr}_{\mathbf{2}} \mathbf{O}_{\mathbf{3}}$ & $\mathbf{F e O}$ & $\mathbf{M n O}$ & $\mathbf{M g O}$ & $\mathbf{C a O}$ & $\mathbf{N a}_{2} \mathbf{O}$ & $\mathbf{K}_{2} \mathbf{O}_{2}$ & $\mathbf{P}_{2} \mathbf{O}_{5}$ & Total \\
\hline Plag & 49.15 & 0.08 & 30.36 & 0.00 & 2.51 & 0.00 & 0.17 & 14.21 & 2.98 & 0.10 & 0.00 & 99.57 \\
Plag & 49.50 & 0.08 & 30.66 & 0.01 & 2.10 & 0.05 & 0.14 & 15.08 & 2.95 & 0.12 & 0.00 & 100.70 \\
Plag & 52.21 & 1.28 & 18.97 & 0.00 & 9.13 & 0.08 & 3.34 & 10.64 & 4.04 & 0.40 & 0.32 & 100.41 \\
Plag & 49.22 & 0.08 & 29.74 & 0.00 & 2.41 & 0.00 & 0.17 & 14.59 & 3.09 & 0.12 & 0.00 & 99.42 \\
Ox & 0.00 & 0.81 & 10.78 & 0.16 & 75.38 & 0.53 & 12.01 & 0.19 & 0.01 & 0.02 & 0.01 & 99.88 \\
Ox & 0.00 & 0.81 & 10.87 & 0.17 & 74.63 & 0.54 & 12.02 & 0.12 & 0.03 & 0.01 & 0.00 & 99.20 \\
Ox & 0.00 & 0.82 & 10.54 & 0.17 & 75.55 & 0.41 & 11.91 & 0.16 & 0.01 & 0.01 & 0.02 & 99.60 \\
Ox & 0.00 & 0.80 & 10.52 & 0.12 & 75.35 & 0.45 & 11.99 & 0.17 & 0.02 & 0.02 & 0.01 & 99.45 \\
Glass & 51.20 & 1.29 & 17.74 & 0.02 & 9.77 & 0.23 & 4.96 & 9.44 & 3.25 & 0.94 & 0.31 & 99.15 \\
stdev & 0.36 & 0.03 & 0.13 & 0.01 & 0.14 & 0.01 & 0.01 & 0.43 & 0.11 & 0.05 & 0.02 & \\
\hline
\end{tabular}


A-6 Continued.

$1236^{\circ} \mathrm{C}$ (PCC)

\begin{tabular}{c|cccccccccccc}
\hline Phase & $\mathrm{SiO}_{2}$ & $\mathrm{TiO}_{2}$ & $\mathrm{Al}_{2} \mathbf{O}_{3}$ & $\mathbf{C r}_{2} \mathbf{O}_{3}$ & $\mathbf{F e O}$ & $\mathbf{M n O}$ & $\mathbf{M g O}$ & $\mathbf{C a O}$ & $\mathbf{N a}_{2} \mathbf{O}$ & $\mathbf{K}_{2} \mathbf{O}$ & $\mathbf{P}_{2} \mathbf{O}_{5}$ & Total \\
\hline Plag & 49.51 & 0.10 & 30.76 & 0.01 & 2.10 & 0.00 & 0.15 & 14.60 & 2.91 & 0.12 & 0.00 & 100.28 \\
Plag & 49.76 & 0.07 & 30.71 & 0.00 & 2.03 & 0.00 & 0.15 & 14.61 & 3.00 & 0.12 & 0.00 & 100.45 \\
Plag & 48.91 & 0.07 & 31.18 & 0.00 & 2.01 & 0.01 & 0.15 & 15.32 & 2.74 & 0.11 & 0.02 & 100.52 \\
Plag & 50.21 & 0.07 & 30.15 & 0.00 & 2.07 & 0.06 & 0.15 & 14.35 & 3.15 & 0.12 & 0.02 & 100.34 \\
Ox & 0.00 & 0.81 & 10.11 & 0.16 & 75.29 & 0.40 & 12.38 & 0.09 & 0.01 & 0.00 & 0.00 & 99.25 \\
Ox & 0.00 & 0.83 & 10.14 & 0.14 & 75.52 & 0.49 & 12.34 & 0.14 & 0.00 & 0.01 & 0.00 & 99.62 \\
Ox & 0.00 & 0.82 & 10.02 & 0.03 & 75.84 & 0.49 & 12.35 & 0.14 & 0.00 & 0.00 & 0.00 & 99.69 \\
Ox & 0.00 & 0.82 & 10.19 & 0.06 & 75.17 & 0.48 & 12.82 & 0.17 & 0.01 & 0.02 & 0.01 & 99.75 \\
Glass & 51.51 & 1.39 & 17.53 & 0.00 & 9.34 & 0.24 & 4.98 & 8.82 & 3.62 & 0.97 & 0.31 & 98.73 \\
stdev & 0.19 & 0.04 & 0.03 & 0.00 & 0.09 & 0.03 & 0.07 & 0.22 & 0.01 & 0.02 & 0.01 & \\
\hline
\end{tabular}

A-6 Continued.

\section{${ }^{1236^{\circ}}{ }^{\circ} \mathrm{C}$ (PPP)}

\begin{tabular}{c|cccccccccccc}
\hline Phase & $\mathrm{SiO}_{2}$ & $\mathrm{TiO}_{2}$ & $\mathrm{Al}_{2} \mathbf{O}_{3}$ & $\mathrm{Cr}_{2} \mathbf{O}_{3}$ & $\mathbf{F e O}$ & $\mathrm{MnO}$ & $\mathbf{M g O}$ & $\mathbf{C a O}$ & $\mathbf{N a}_{2} \mathbf{O}$ & $\mathbf{K}_{2} \mathrm{O}_{2}$ & $\mathbf{P}_{2} \mathbf{O}_{5}$ & Total \\
\hline Plag & 49.67 & 0.09 & 30.39 & 0.00 & 2.23 & 0.03 & 0.14 & 14.38 & 2.95 & 0.13 & 0.01 & 100.02 \\
Plag & 49.60 & 0.06 & 30.76 & 0.00 & 2.01 & 0.00 & 0.14 & 14.32 & 2.91 & 0.11 & 0.01 & 99.92 \\
Plag & 50.22 & 0.08 & 30.60 & 0.00 & 2.10 & 0.00 & 0.16 & 14.37 & 3.02 & 0.12 & 0.03 & 100.71 \\
Plag & 49.99 & 0.09 & 30.65 & 0.02 & 2.07 & 0.00 & 0.16 & 14.77 & 2.95 & 0.12 & 0.01 & 100.82 \\
Ox & 0.00 & 0.80 & 10.55 & 0.07 & 76.56 & 0.45 & 11.04 & 0.12 & 0.04 & 0.01 & 0.00 & 99.64 \\
Ox & 0.00 & 0.82 & 10.65 & 0.11 & 76.70 & 0.41 & 10.87 & 0.13 & 0.00 & 0.00 & 0.00 & 99.71 \\
Ox & 0.00 & 0.82 & 10.51 & 0.14 & 77.27 & 0.41 & 10.88 & 0.09 & 0.04 & 0.01 & 0.02 & 100.20 \\
Ox & 0.00 & 0.76 & 10.23 & 0.07 & 76.90 & 0.49 & 11.43 & 0.05 & 0.00 & 0.00 & 0.00 & 99.93 \\
Glass & 51.46 & 1.34 & 17.99 & 0.00 & 9.92 & 0.20 & 4.91 & 9.14 & 3.39 & 0.94 & 0.29 & 99.59 \\
stdev & 0.22 & 0.02 & 0.20 & 0.01 & 0.12 & 0.04 & 0.03 & 0.14 & 0.03 & 0.01 & 0.01 & \\
\hline
\end{tabular}


A-6 Continued.

\begin{tabular}{c|cccccccccccc}
\multicolumn{10}{c}{$\mathbf{1 2 4 1}^{\circ} \mathbf{C}(\mathbf{P C C})$} \\
\hline Phase & $\mathbf{S i O}_{2}$ & $\mathbf{T i O}_{2}$ & $\mathbf{A l}_{2} \mathbf{O}_{3}$ & $\mathbf{C r}_{2} \mathbf{O}_{3}$ & $\mathbf{F e O}$ & $\mathbf{M n O}$ & $\mathbf{M g O}$ & $\mathbf{C a O}$ & $\mathbf{N a}_{2} \mathbf{O}$ & $\mathbf{K}_{2} \mathbf{O}$ & $\mathbf{P}_{2} \mathbf{O}_{5}$ & Total \\
\hline Plag & 49.31 & 0.06 & 30.96 & 0.00 & 2.08 & 0.01 & 0.13 & 15.05 & 2.88 & 0.08 & 0.02 & 100.57 \\
Plag & 49.82 & 0.08 & 30.48 & 0.00 & 2.35 & 0.00 & 0.17 & 14.46 & 3.03 & 0.11 & 0.02 & 100.53 \\
Plag & 49.21 & 0.11 & 30.92 & 0.00 & 2.13 & 0.00 & 0.13 & 14.99 & 2.76 & 0.10 & 0.03 & 100.38 \\
Plag & 49.69 & 0.08 & 30.92 & 0.00 & 2.15 & 0.00 & 0.14 & 14.26 & 2.94 & 0.10 & 0.02 & 100.31 \\
Ox & 0.00 & 0.81 & 10.79 & 0.27 & 75.55 & 0.51 & 11.73 & 0.12 & 0.02 & 0.00 & 0.00 & 99.79 \\
Ox & 0.00 & 0.73 & 10.99 & 0.15 & 76.14 & 0.46 & 11.91 & 0.10 & 0.04 & 0.00 & 0.01 & 100.53 \\
Ox & 0.00 & 0.78 & 10.81 & 0.11 & 76.02 & 0.45 & 11.72 & 0.07 & 0.00 & 0.00 & 0.00 & 99.96 \\
Ox & 0.00 & 0.74 & 10.73 & 0.13 & 75.70 & 0.46 & 12.02 & 0.09 & 0.00 & 0.00 & 0.02 & 99.90 \\
Glass & 51.10 & 1.32 & 18.16 & 0.01 & 9.66 & 0.19 & 4.88 & 8.99 & 3.56 & 0.90 & 0.29 & 99.05 \\
stdev & 0.11 & 0.03 & 0.04 & 0.01 & 0.11 & 0.02 & 0.01 & 0.09 & 0.04 & 0.02 & 0.03 & \\
\hline
\end{tabular}

A-6 Continued.

\section{$1241^{\circ} \mathrm{C}$ (PPP)}

\begin{tabular}{c|cccccccccccc}
\hline Phase & $\mathbf{S i O}_{2}$ & $\mathbf{T i O}_{2}$ & $\mathbf{A l}_{2} \mathbf{O}_{3}$ & $\mathbf{C r}_{2} \mathbf{O}_{3}$ & $\mathbf{F e O}$ & $\mathbf{M n O}$ & $\mathbf{M g O}$ & $\mathbf{C a O}$ & $\mathbf{N a}_{2} \mathbf{O}$ & $\mathbf{K}_{2} \mathbf{O}$ & $\mathbf{P}_{2} \mathbf{O}_{5}$ & Total \\
\hline Plag & 49.10 & 0.09 & 31.23 & 0.00 & 2.12 & 0.03 & 0.13 & 14.71 & 2.74 & 0.10 & 0.04 & 100.29 \\
Plag & 49.45 & 0.06 & 30.24 & 0.00 & 2.45 & 0.02 & 0.15 & 14.78 & 3.01 & 0.11 & 0.05 & 100.32 \\
Plag & 49.35 & 0.09 & 30.96 & 0.00 & 2.18 & 0.03 & 0.14 & 14.87 & 2.89 & 0.10 & 0.01 & 100.62 \\
Plag & 49.62 & 0.28 & 27.53 & 0.02 & 3.27 & 0.00 & 0.82 & 12.52 & 3.20 & 0.25 & 0.05 & 97.56 \\
Ox & 0.00 & 0.80 & 10.80 & 0.11 & 75.37 & 0.46 & 11.86 & 0.18 & 0.02 & 0.00 & 0.00 & 99.60 \\
Ox & 0.00 & 0.75 & 10.44 & 0.20 & 75.86 & 0.48 & 11.50 & 0.13 & 0.00 & 0.00 & 0.00 & 99.36 \\
Ox & 0.00 & 0.80 & 10.45 & 0.14 & 75.31 & 0.52 & 11.70 & 0.09 & 0.00 & 0.00 & 0.00 & 99.02 \\
Ox & 0.00 & 0.79 & 10.54 & 0.16 & 75.70 & 0.48 & 11.80 & 0.10 & 0.00 & 0.02 & 0.01 & 99.59 \\
Glass & 51.32 & 1.34 & 17.82 & 0.01 & 9.86 & 0.19 & 4.88 & 8.97 & 3.42 & 0.90 & 0.29 & 98.99 \\
stdev & 0.21 & 0.04 & 0.26 & 0.01 & 0.06 & 0.04 & 0.05 & 0.08 & 0.03 & 0.02 & 0.03 & \\
\hline
\end{tabular}




\section{A-6 Continued.}

\begin{tabular}{c|cccccccccccc}
\multicolumn{1}{c}{$\mathbf{1 2 5 5}^{\circ} \mathbf{C}(\mathbf{P C C})$} \\
\hline Phase & $\mathbf{S i O}_{2}$ & $\mathbf{T i O}_{2}$ & $\mathbf{A l}_{2} \mathbf{O}_{3}$ & $\mathbf{C r}_{\mathbf{2}} \mathbf{O}_{\mathbf{3}}$ & $\mathbf{F e O}$ & $\mathbf{M n O}$ & $\mathbf{M g O}$ & $\mathbf{C a O}$ & $\mathbf{N a}_{\mathbf{2}} \mathbf{O}$ & $\mathbf{K}_{\mathbf{2}} \mathbf{O}$ & $\mathbf{P}_{\mathbf{2}} \mathbf{O}_{\mathbf{5}}$ & Total \\
\hline Plag & 49.05 & 0.05 & 30.81 & 0.01 & 2.22 & 0.02 & 0.14 & 14.87 & 2.84 & 0.09 & 0.04 & 100.16 \\
Plag & 48.65 & 0.05 & 31.21 & 0.01 & 2.19 & 0.03 & 0.14 & 14.65 & 2.67 & 0.09 & 0.01 & 99.72 \\
Plag & 49.50 & 0.08 & 29.91 & 0.00 & 2.53 & 0.00 & 0.15 & 14.19 & 2.91 & 0.12 & 0.00 & 99.39 \\
Plag & 48.57 & 0.06 & 31.02 & 0.00 & 2.13 & 0.00 & 0.14 & 14.75 & 2.78 & 0.09 & 0.00 & 99.53 \\
Ox & 0.00 & 0.69 & 11.88 & 0.27 & 73.31 & 0.53 & 12.99 & 0.07 & 0.00 & 0.00 & 0.00 & 99.75 \\
Ox & 0.00 & 0.65 & 11.90 & 0.25 & 73.27 & 0.50 & 13.30 & 0.09 & 0.02 & 0.00 & 0.00 & 100.00 \\
Ox & 0.00 & 0.61 & 12.04 & 0.26 & 72.35 & 0.48 & 13.38 & 0.14 & 0.02 & 0.01 & 0.00 & 99.31 \\
Ox & 0.00 & 0.62 & 11.83 & 0.34 & 72.60 & 0.59 & 12.92 & 0.15 & 0.02 & 0.02 & 0.01 & 99.10 \\
Glass & 50.45 & 1.27 & 18.50 & 0.01 & 9.90 & 0.17 & 4.64 & 9.21 & 3.52 & 0.87 & 0.29 & 98.81 \\
stdev & 0.04 & 0.03 & 0.07 & 0.00 & 0.08 & 0.03 & 0.02 & 0.08 & 0.03 & 0.02 & 0.02 & \\
\hline
\end{tabular}

A-6 Continued.

$1255^{\circ} \mathrm{C}$ (PPP)

\begin{tabular}{c|cccccccccccc}
\hline Phase & $\mathrm{SiO}_{2}$ & $\mathrm{TiO}_{2}$ & $\mathrm{Al}_{2} \mathbf{O}_{\mathbf{3}}$ & $\mathrm{Cr}_{2} \mathbf{O}_{\mathbf{3}}$ & $\mathbf{F e O}$ & $\mathbf{M n O}$ & $\mathbf{M g O}$ & $\mathbf{C a O}$ & $\mathbf{N a}_{2} \mathbf{O}$ & $\mathbf{K}_{2} \mathbf{O}$ & $\mathbf{P}_{2} \mathbf{O}_{5}$ & Total \\
\hline Plag & 49.36 & 0.08 & 30.86 & 0.00 & 2.16 & 0.03 & 0.15 & 14.76 & 2.79 & 0.09 & 0.01 & 100.30 \\
Plag & 49.36 & 0.10 & 30.62 & 0.01 & 2.30 & 0.02 & 0.19 & 14.62 & 2.94 & 0.12 & 0.00 & 100.28 \\
Plag & 48.85 & 0.06 & 30.65 & 0.00 & 2.22 & 0.04 & 0.13 & 14.77 & 2.79 & 0.10 & 0.00 & 99.61 \\
Plag & 49.57 & 0.08 & 30.78 & 0.00 & 2.15 & 0.02 & 0.17 & 14.74 & 2.86 & 0.11 & 0.03 & 100.49 \\
Glass & 50.82 & 1.24 & 18.45 & 0.00 & 10.04 & 0.18 & 4.71 & 9.37 & 3.42 & 0.88 & 0.26 & 99.36 \\
stdev & 0.09 & 0.03 & 0.04 & 0.00 & 0.06 & 0.06 & 0.03 & 0.06 & 0.02 & 0.01 & 0.02 & \\
\hline
\end{tabular}

\section{A-6 Continued.}

Final Remelt

\begin{tabular}{|c|c|c|c|c|c|c|c|c|c|c|c|c|}
\hline Phase & $\mathrm{SiO}_{2}$ & $\mathrm{TiO}_{2}$ & $\mathrm{Al}_{2} \mathrm{O}_{3}$ & $\mathrm{Cr}_{2} \mathrm{O}_{3}$ & $\mathrm{FeO}$ & $\mathrm{MnO}$ & MgO & $\mathrm{CaO}$ & $\mathrm{Na}_{2} \mathrm{O}$ & $\mathrm{K}_{2} \mathrm{O}$ & $\mathbf{P}_{2} \mathbf{O}_{5}$ & Total \\
\hline Glass & 50.16 & 1.18 & 19.45 & 0.02 & & 0.20 & 4.41 & 9.62 & 3.49 & 0.81 & 0.27 & \\
\hline stdev & 0.22 & 0.02 & 0.08 & 0.01 & 0.17 & 0.03 & 0.05 & 0.23 & 0.06 & 0.01 & 0.02 & \\
\hline
\end{tabular}


Tables A-7. Measured and Calculated magma viscosity using the algorithm of Mader et al. (2013) with calculated $n$. Results plotted in Figure 3.40.

\begin{tabular}{c|c|c|c}
\hline $\begin{array}{c}\text { Calculated } \boldsymbol{n} \\
(\mathbf{0 . 4 7 )}\end{array}$ & \multicolumn{2}{|c|}{$\mathbf{1 2 3 4}^{\circ} \mathbf{C}$} & $\boldsymbol{\varphi}=\mathbf{0 . 3 0}$ \\
NN Power Law (CC) & \\
\hline$\dot{\gamma}$ & $\begin{array}{c}\log \boldsymbol{\eta} \text { (meas) } \\
\text { Pa s }\end{array}$ & $\begin{array}{c}\log \boldsymbol{\eta} \text { (calc) } \\
\text { Pa s }\end{array}$ & $\begin{array}{c}\text { Diff } \\
(+/-)\end{array}$ \\
\hline $\mathbf{s}^{-1}$ & 2.50 & 3.02 & 0.52 \\
2.37 & 2.56 & 3.17 & 0.61 \\
1.25 & 2.61 & 3.37 & 0.75 \\
0.54 & 2.67 & 3.49 & 0.82 \\
0.31 & 2.59 & 3.15 & 0.55 \\
1.39 & 2.54 & 2.99 & 0.44 \\
2.77 & 2.46 & 2.88 & 0.43 \\
4.30 & 2.42 & 2.93 & 0.51 \\
3.53 & \multicolumn{3}{|c}{} \\
\hline
\end{tabular}

\begin{tabular}{c|c|c|c|c}
\hline \multicolumn{2}{c|}{$\begin{array}{c}\text { Calculated } n \\
(\mathbf{0 . 4 7 )}\end{array}$} & \multicolumn{2}{c|}{$\mathbf{1 2 3 4}^{\circ} \mathbf{C}$} & $\boldsymbol{\varphi}=\mathbf{0 . 3 0}$ \\
NN Power Law (PP) & \\
\hline $\begin{array}{c}\text { Temp } \\
{ }^{\circ} \mathbf{C}\end{array}$ & $\boldsymbol{\gamma}$ & $\begin{array}{c}\log \boldsymbol{\eta} \text { (meas) } \\
\text { Pa s }\end{array}$ & $\begin{array}{c}\log \boldsymbol{\eta}(\text { calc) } \\
\text { Pa s }\end{array}$ & $\begin{array}{c}\text { Diff } \\
(+/-)\end{array}$ \\
\hline 820.73 & $2 \times 10^{-5}$ & 10.16 & 11.04 & 0.88 \\
800.34 & $2.7 \times 10^{-6}$ & 11.05 & 12.01 & 0.96 \\
810.21 & $5.7 \times 10^{-6}$ & 10.72 & 11.59 & 0.87 \\
790.11 & $1.7 \times 10^{-6}$ & 11.24 & 12.38 & 1.14 \\
770.15 & $4.6 \times 10^{-6}$ & 11.81 & 13.24 & 1.43 \\
779.66 & $5.7 \times 10^{-6}$ & 11.72 & 12.92 & 1.21 \\
\hline
\end{tabular}


A-7 Continued.

\begin{tabular}{c|c|c|c}
\hline $\begin{array}{c}\text { Calculated } \boldsymbol{n} \\
(\boldsymbol{0 . 8 1})\end{array}$ & \multicolumn{2}{|c|}{$\mathbf{1 2 3 6}^{\circ} \mathbf{C}$} & $\boldsymbol{\varphi}=\mathbf{0 . 2 5}$ \\
\hline $\boldsymbol{\gamma}$ & NN Power Law (CC) & \\
\hline $\mathbf{s}^{-\mathbf{1}}$ & $\log \boldsymbol{\eta}$ (meas) & $\log \boldsymbol{\eta}$ (calc) & Diff \\
Pa s & Pa s & $(+/-)$ \\
\hline 3.40 & 2.52 & 2.64 & 0.12 \\
2.17 & 2.59 & 2.68 & 0.08 \\
1.87 & 2.58 & 2.69 & 0.11 \\
1.32 & 2.58 & 2.72 & 0.14 \\
1.06 & 2.63 & 2.74 & 0.11 \\
0.59 & 2.64 & 2.79 & 0.14 \\
0.59 & 2.64 & 2.79 & 0.14 \\
0.16 & 2.71 & 2.90 & 0.19 \\
1.94 & 2.59 & 2.69 & 0.10 \\
3.96 & 2.56 & 2.63 & 0.07 \\
5.10 & 2.55 & 2.61 & 0.05 \\
3.24 & 2.58 & 2.64 & 0.07 \\
2.28 & 2.59 & 2.67 & 0.08 \\
\hline
\end{tabular}

\begin{tabular}{|c|c|c|c|c|}
\hline \multicolumn{2}{|c|}{$\begin{array}{c}\text { Calculated } n \\
(0.81) \\
\end{array}$} & \multicolumn{2}{|c|}{$\begin{array}{c}1236^{\circ} \mathrm{C} \\
\text { NN Power Law (PP) }\end{array}$} & \multirow{2}{*}{$\begin{array}{c}\varphi=0.25 \\
\begin{array}{c}\text { Diff } \\
(+/-)\end{array}\end{array}$} \\
\hline $\begin{array}{c}\text { Temp } \\
{ }^{\circ} \mathrm{C} \\
\end{array}$ & $\begin{array}{c}\dot{\gamma} \\
\mathrm{s}^{-1}\end{array}$ & $\begin{array}{c}\log \text { n (meas) } \\
\text { Pa s } \\
\end{array}$ & $\begin{array}{c}\log \mathbf{n}(\text { calc) } \\
\text { Pa s }\end{array}$ & \\
\hline 798.92 & $7.8 \times 10^{-5}$ & 9.59 & 9.40 & 0.19 \\
\hline 778.17 & $9.9 \times 10^{-6}$ & 10.48 & 10.13 & 0.36 \\
\hline 788.24 & $1.7 \times 10^{-5}$ & 10.24 & 9.80 & 0.44 \\
\hline 758.42 & $1.8 \times 10^{-6}$ & 11.23 & 10.85 & 0.38 \\
\hline 768.07 & $3.3 \times 10^{-6}$ & 10.96 & 10.51 & 0.45 \\
\hline 748.26 & $6.2 \times 10^{-7}$ & 11.68 & 11.25 & 0.43 \\
\hline
\end{tabular}


A-7 Continued.

\begin{tabular}{c|c|c|c}
\hline $\begin{array}{c}\text { Calculated } \boldsymbol{n} \\
(\mathbf{0 . 8 6})\end{array}$ & \multicolumn{2}{|c|}{$\mathbf{1 2 4 1}^{\circ} \mathbf{C}$} & $\boldsymbol{\varphi}=\mathbf{0 . 2 3}$ \\
\hline $\boldsymbol{\gamma}$ & NN Power Law (CC) & \\
\hline $\mathbf{s}^{-\mathbf{1}}$ & $\log \boldsymbol{\eta}$ (meas) & $\begin{array}{c}\log \boldsymbol{\eta} \text { (calc) } \\
\text { Pa s }\end{array}$ & $\begin{array}{c}\text { Diff } \\
\text { Pa }\end{array}$ \\
\hline 1.52 & 2.34 & 2.55 & 0.21 \\
2.94 & 2.32 & 2.51 & 0.19 \\
3.43 & 2.32 & 2.50 & 0.19 \\
1.51 & 2.35 & 2.55 & 0.21 \\
0.74 & 2.38 & 2.60 & 0.21 \\
0.27 & 2.42 & 2.66 & 0.24 \\
0.27 & 2.43 & 2.66 & 0.23 \\
1.34 & 2.36 & 2.56 & 0.20 \\
\hline
\end{tabular}

\begin{tabular}{c|c|c|c|c}
\hline \multicolumn{2}{c|}{$\begin{array}{c}\text { Calculated } \boldsymbol{n} \\
(\mathbf{0 . 8 6})\end{array}$} & \multicolumn{2}{c|}{$\mathbf{1 2 4 1}{ }^{\circ} \mathbf{C}$} & $\boldsymbol{\varphi}=\mathbf{0 . 2 3}$ \\
NN Power Law (PP) & \\
\hline $\begin{array}{c}\text { Temp } \\
{ }^{\circ} \mathbf{C}\end{array}$ & $\boldsymbol{\gamma}$ & $\begin{array}{c}\log \boldsymbol{\eta} \text { (meas) } \\
\mathbf{s}^{-1}\end{array}$ & $\begin{array}{c}\log \boldsymbol{\eta} \text { (calc) } \\
\text { Pa s }\end{array}$ & $\begin{array}{c}\text { Diff } \\
\text { Pa s }\end{array}$ \\
\hline 790.33 & $5.8 \times 10^{-5}$ & 9.72 & 9.30 & 0.42 \\
769.16 & $7.7 \times 10^{-6}$ & 10.60 & 10.01 & 0.58 \\
779.17 & $1.4 \times 10^{-5}$ & 10.35 & 9.69 & 0.65 \\
749.35 & $1.5 \times 10^{-5}$ & 11.32 & 10.72 & 0.60 \\
759.19 & $2.4 \times 10^{-6}$ & 11.10 & 10.38 & 0.72 \\
739.55 & $4.5 \times 10^{-7}$ & 11.82 & 11.11 & 0.71 \\
\hline
\end{tabular}


A-7 Continued.

\begin{tabular}{|c|c|c|c|}
\hline $\begin{array}{c}\text { Calculated } n \\
(0.98)\end{array}$ & \multicolumn{2}{|c|}{$\begin{array}{c}1255^{\circ} \mathrm{C} \\
\text { Newtonian (CC) }\end{array}$} & $\varphi=0.17$ \\
\hline $\begin{array}{c}\dot{\gamma} \\
\mathrm{s}^{-1}\end{array}$ & $\begin{array}{c}\log \eta(\text { meas) } \\
\text { Pa s } \\
\end{array}$ & $\begin{array}{c}\log \eta(\text { calc) } \\
\text { Pa s } \\
\end{array}$ & $\begin{array}{l}\text { Diff } \\
(+/-)\end{array}$ \\
\hline 3.46 & 2.21 & 2.09 & 0.12 \\
\hline 2.48 & 2.21 & 2.09 & 0.12 \\
\hline 1.38 & 2.23 & 2.09 & 0.14 \\
\hline 0.86 & 2.24 & 2.09 & 0.15 \\
\hline 0.41 & 2.26 & 2.09 & 0.17 \\
\hline 1.52 & 2.23 & 2.09 & 0.14 \\
\hline 2.51 & 2.23 & 2.09 & 0.14 \\
\hline 4.38 & 2.20 & 2.09 & 0.11 \\
\hline 3.61 & 2.23 & 2.09 & 0.14 \\
\hline
\end{tabular}

\begin{tabular}{c|c|c|c|c}
\hline \multicolumn{2}{c|}{$\begin{array}{c}\text { Calculated } \boldsymbol{n} \\
(\mathbf{0 . 9 8 )}\end{array}$} & \multicolumn{2}{c|}{$\mathbf{1 2 5 5}^{\circ} \mathbf{C}$} & $\boldsymbol{\varphi}=\mathbf{0 . 1 7}$ \\
NN Power Law (PP) & \\
\hline $\begin{array}{c}\text { Temp } \\
{ }^{\circ} \mathbf{C}\end{array}$ & $\boldsymbol{\gamma}^{\mathbf{- 1}}$ & $\begin{array}{c}\log \boldsymbol{\eta} \text { (meas) } \\
\text { Pa s }\end{array}$ & $\begin{array}{c}\log \boldsymbol{\eta} \text { (calc) } \\
\text { Pa s }\end{array}$ & $\begin{array}{c}\text { Diff } \\
(+/-)\end{array}$ \\
\hline 781.19 & $5.8 \times 10^{-5}$ & 9.72 & 8.67 & 1.04 \\
760.52 & $7.0 \times 10^{-6}$ & 10.63 & 9.30 & 1.33 \\
770.44 & $1.3 \times 10^{-5}$ & 10.38 & 9.00 & 1.38 \\
750.29 & $2.4 \times 10^{-6}$ & 11.10 & 9.63 & 1.47 \\
\hline
\end{tabular}


Tables A-8. Measured and calculated magma viscosities using the algorithm of Mader et al. (2013) with measured $n$. Results in Figure 3.42. Values also used in Figure 3.45.

\begin{tabular}{|c|c|c|c|c|c|c|c|}
\hline \multirow{2}{*}{\multicolumn{2}{|c|}{$\begin{array}{c}\text { Measured } n \\
(0.81) \\
\gamma \\
\mathrm{s}^{-1} \\
\end{array}$}} & \multicolumn{4}{|c|}{$\begin{array}{c}1234^{\circ} \mathrm{C} \\
\text { NN Power Law (CC) }\end{array}$} & \multirow{2}{*}{\multicolumn{2}{|c|}{\begin{tabular}{|c}
$\varphi=0.30$ \\
$\begin{array}{c}\text { Accuracy } \\
(+/-)\end{array}$ \\
\end{tabular}}} \\
\hline & & \multicolumn{2}{|c|}{$\begin{array}{c}\log \eta(\text { meas) } \\
\text { Pa s }\end{array}$} & \multicolumn{2}{|c|}{$\begin{array}{c}\log \eta(\text { calc }) \\
\text { Pa s }\end{array}$} & & \\
\hline \multicolumn{2}{|c|}{2.37} & & 2.50 & & 3.15 & & 0.65 \\
\hline \multicolumn{2}{|c|}{1.25} & & 2.56 & & 3.20 & & 0.64 \\
\hline \multicolumn{2}{|c|}{0.54} & & 2.61 & & 3.27 & & 0.66 \\
\hline \multicolumn{2}{|c|}{0.31} & & 2.67 & & 3.32 & & 0.65 \\
\hline \multicolumn{2}{|c|}{1.39} & & 2.59 & & 3.20 & & 0.60 \\
\hline \multicolumn{2}{|c|}{2.77} & & 2.54 & & 3.14 & & 0.60 \\
\hline \multicolumn{2}{|c|}{4.30} & & 2.46 & & 3.10 & & 0.65 \\
\hline \multicolumn{2}{|c|}{3.53} & & 2.42 & & 3.12 & & 0.70 \\
\hline \multicolumn{3}{|c|}{$\begin{array}{c}\text { Measured } n \\
(0.81)\end{array}$} & \multicolumn{4}{|c|}{$\begin{array}{c}1234^{\circ} \mathrm{C} \\
\text { NN Power Law (PP) }\end{array}$} & $\varphi=0.30$ \\
\hline $\begin{array}{c}\text { Temp } \\
{ }^{\circ} \mathrm{C}\end{array}$ & \multicolumn{2}{|l|}{$\begin{array}{c}\dot{\gamma} \\
\mathrm{s}^{-1}\end{array}$} & \multicolumn{2}{|c|}{$\log \eta($ meas $)$} & \multicolumn{2}{|c|}{$\begin{array}{c}\log \eta(\text { calc }) \\
\text { Pa } s\end{array}$} & $\begin{array}{l}\text { Diff } \\
(+/-)\end{array}$ \\
\hline 820.73 & \multicolumn{2}{|c|}{$2 \times 10^{-5}$} & \multicolumn{2}{|l|}{10.16} & \multicolumn{2}{|l|}{9.42} & 0.74 \\
\hline 800.34 & \multicolumn{2}{|c|}{$2.7 \times 10^{-6}$} & \multicolumn{2}{|l|}{11.05} & \multicolumn{2}{|l|}{10.08} & 0.96 \\
\hline 810.21 & \multicolumn{2}{|c|}{$5.7 \times 10^{-6}$} & \multicolumn{2}{|l|}{10.72} & \multicolumn{2}{|l|}{9.77} & 0.95 \\
\hline 790.11 & \multicolumn{2}{|c|}{$1.7 \times 10^{-6}$} & \multicolumn{2}{|l|}{11.24} & \multicolumn{2}{|l|}{10.38} & 0.85 \\
\hline 770.15 & \multicolumn{2}{|c|}{$4.6 \times 10^{-6}$} & \multicolumn{2}{|l|}{11.81} & \multicolumn{2}{|l|}{11.05} & 0.76 \\
\hline 779.66 & \multicolumn{2}{|c|}{$5.7 \times 10^{-6}$} & \multicolumn{2}{|l|}{11.72} & 10.76 & & 0.96 \\
\hline
\end{tabular}


A-8 Continued.

\begin{tabular}{c|c|c|c}
\hline $\begin{array}{c}\text { Measured } \boldsymbol{n} \\
(\mathbf{0 . 8 9})\end{array}$ & \multicolumn{2}{|c|}{$\mathbf{1 2 3 6}^{\circ} \mathbf{C}$} & $\boldsymbol{\varphi}=\mathbf{0 . 2 5}$ \\
\hline $\boldsymbol{\gamma}$ & $\mathbf{l o g} \boldsymbol{\eta}$ (meas) & $\log \boldsymbol{\eta}$ (calc) & Diff \\
Pa s & $(+/-)$ \\
\hline $\mathbf{s}^{-\mathbf{1}}$ & Pa S & 2.69 & 0.16 \\
3.40 & 2.52 & 2.71 & 0.11 \\
2.17 & 2.59 & 2.71 & 0.13 \\
1.87 & 2.58 & 2.73 & 0.15 \\
1.32 & 2.58 & 2.74 & 0.11 \\
1.06 & 2.63 & 2.77 & 0.12 \\
0.59 & 2.64 & 2.77 & 0.12 \\
0.59 & 2.64 & 2.83 & 0.12 \\
0.16 & 2.71 & 2.71 & 0.12 \\
1.94 & 2.59 & 2.68 & 0.12 \\
3.96 & 2.56 & 2.67 & 0.11 \\
5.10 & 2.55 & 2.69 & 0.11 \\
3.24 & 2.58 & 2.70 & 0.11 \\
2.28 & 2.59 & &
\end{tabular}

\begin{tabular}{c|c|c|c|c}
\hline \multicolumn{2}{c|}{$\begin{array}{c}\text { Measured } \boldsymbol{n} \\
(\boldsymbol{0 . 8 9})\end{array}$} & \multicolumn{2}{c|}{$\mathbf{1 2 3 6}^{\circ} \mathbf{C}$} & $\boldsymbol{\varphi}=\mathbf{0 . 2 5}$ \\
NN Power Law (PP) & \\
\hline $\begin{array}{c}\text { Temp } \\
{ }^{\circ} \mathbf{C}\end{array}$ & $\boldsymbol{\gamma}$ & $\begin{array}{c}\log \boldsymbol{\eta} \text { (meas) } \\
\text { Pa s }\end{array}$ & $\begin{array}{c}\log \boldsymbol{\eta} \text { (calc) } \\
\text { Pa s }\end{array}$ & $\begin{array}{c}\text { Diff } \\
(+/-)\end{array}$ \\
\hline 798.92 & $7.8 \times 10^{-5}$ & 9.59 & 9.06 & 0.54 \\
778.17 & $9.9 \times 10^{-6}$ & 10.48 & 9.71 & 0.77 \\
788.24 & $1.7 \times 10^{-5}$ & 10.24 & 9.41 & 0.83 \\
758.42 & $1.8 \times 10^{-6}$ & 11.23 & 10.37 & 0.86 \\
768.07 & $3.3 \times 10^{-6}$ & 10.96 & 10.05 & 0.91 \\
748.26 & $6.2 \times 10^{-7}$ & 11.68 & 10.74 & 0.95 \\
\hline
\end{tabular}


A-8 Continued.

\begin{tabular}{c|c|c|c}
\hline $\begin{array}{c}\text { Measured } \boldsymbol{n} \\
(\mathbf{0 . 9 1 )}\end{array}$ & \multicolumn{2}{|c|}{$\mathbf{1 2 4 1}^{\circ} \mathbf{C}$} & $\boldsymbol{\varphi}=\mathbf{0 . 2 3}$ \\
\hline $\boldsymbol{\gamma}$ & $\log \boldsymbol{\eta}$ (meas) & $\log \boldsymbol{\eta}$ (calc) & Diff \\
Pa s & $(+/-)$ \\
\hline $\mathrm{s}^{-1}$ & Pa s & 2.56 & 0.22 \\
1.52 & 2.34 & 2.53 & 0.21 \\
2.94 & 2.32 & 2.53 & 0.21 \\
3.43 & 2.32 & 2.56 & 0.21 \\
1.51 & 2.35 & 2.59 & 0.21 \\
0.74 & 2.38 & 2.63 & 0.21 \\
0.27 & 2.42 & 2.63 & 0.21 \\
0.27 & 2.43 & 2.57 & 0.20 \\
1.34 & 2.36 & \multicolumn{3}{|c}{}
\end{tabular}

\begin{tabular}{c|c|c|c|c}
\hline \multicolumn{2}{c|}{$\begin{array}{c}\text { Measured } \boldsymbol{n} \\
(\mathbf{0 . 9 1})\end{array}$} & \multicolumn{2}{c|}{$\mathbf{1 2 4 1}^{\circ} \mathbf{C}$} & $\boldsymbol{\varphi}=\mathbf{0 . 2 3}$ \\
NN Power Law (PP) & \\
\hline $\begin{array}{c}\text { Temp } \\
{ }^{\circ} \mathbf{C}\end{array}$ & $\boldsymbol{\gamma}$ & $\begin{array}{c}\text { log } \boldsymbol{\eta} \text { (meas) } \\
\text { Pa s }\end{array}$ & $\begin{array}{c}\log \boldsymbol{\eta} \text { (calc) } \\
\text { Pa s }\end{array}$ & $\begin{array}{c}\text { Diff } \\
(+/-)\end{array}$ \\
\hline 790.33 & $5.8 \times 10^{-5}$ & 9.72 & 9.11 & 0.61 \\
769.16 & $7.7 \times 10^{-6}$ & 10.60 & 9.79 & 0.81 \\
779.17 & $1.4 \times 10^{-5}$ & 10.35 & 9.48 & 0.87 \\
749.35 & $1.5 \times 10^{-5}$ & 11.32 & 10.46 & 0.85 \\
759.19 & $2.4 \times 10^{-6}$ & 11.10 & 10.13 & 0.97 \\
739.55 & $4.5 \times 10^{-7}$ & 11.82 & 10.83 & 0.99 \\
\hline
\end{tabular}


A-8 Continued.

\begin{tabular}{c|c|c|c}
\hline $\begin{array}{c}\text { Measured } \boldsymbol{n} \\
(\mathbf{0 . 9 5 )}\end{array}$ & \multicolumn{2}{|c|}{$\mathbf{1 2 5 5}^{\circ} \mathbf{C}$} & $\boldsymbol{\varphi}=\mathbf{0 . 1 7}$ \\
Newtonian (CC) & \\
\hline $\boldsymbol{\gamma}$ & $\begin{array}{c}\log \boldsymbol{\eta} \text { (meas) } \\
\text { Pa s }\end{array}$ & $\begin{array}{c}\log \boldsymbol{\eta}(\mathbf{c a l c}) \\
\text { Pa } \mathbf{~}\end{array}$ & $\begin{array}{c}\text { Diff } \\
(+/-)\end{array}$ \\
\hline 3.46 & 2.21 & 2.09 & 0.12 \\
2.48 & 2.21 & 2.09 & 0.12 \\
1.38 & 2.23 & 2.09 & 0.14 \\
0.86 & 2.24 & 2.09 & 0.15 \\
0.41 & 2.26 & 2.09 & 0.17 \\
1.52 & 2.23 & 2.09 & 0.14 \\
2.51 & 2.23 & 2.09 & 0.14 \\
4.38 & 2.20 & 2.09 & 0.11 \\
3.61 & 2.23 & 2.09 & 0.14 \\
\hline
\end{tabular}

\begin{tabular}{c|c|c|c|c}
\hline \multicolumn{2}{c|}{$\begin{array}{c}\text { Measured } n \\
(0.95)\end{array}$} & \multicolumn{2}{c|}{$\mathbf{1 2 5 5}^{\circ} \mathbf{C}$} & $\boldsymbol{\varphi}=0.17$ \\
NN Power Law (PP) & \\
\hline $\begin{array}{c}\text { Temp } \\
{ }^{\circ} \mathbf{C}\end{array}$ & $\boldsymbol{\gamma}^{\mathbf{- 1}}$ & $\begin{array}{c}\log \boldsymbol{\eta} \text { (meas) } \\
\text { Pa s }\end{array}$ & $\begin{array}{c}\log \boldsymbol{\eta} \text { (calc) } \\
\text { Pa s }\end{array}$ & $\begin{array}{c}\text { Diff } \\
(+/-)\end{array}$ \\
\hline 781.19 & $5.8 \times 10^{-5}$ & 9.72 & 8.80 & 0.92 \\
760.52 & $7.0 \times 10^{-6}$ & 10.63 & 9.45 & 1.18 \\
770.44 & $1.3 \times 10^{-5}$ & 10.38 & 9.14 & 1.24 \\
750.29 & $2.4 \times 10^{-6}$ & 11.10 & 9.80 & 1.30 \\
\hline
\end{tabular}


Tables A-9. Measured and calculated magma viscosities using Herschel Bulkley equation, results in Figure 3.44.

\begin{tabular}{|c|c|c|c|c|}
\hline \multicolumn{2}{|c|}{$\begin{array}{l}\text { Measured } n \\
\quad(0.74)\end{array}$} & \multicolumn{2}{|c|}{$\begin{array}{c}1226^{\circ} \mathrm{C} \\
\text { Herschel Bulklev }(\mathrm{CC})\end{array}$} & \multirow{2}{*}{\begin{tabular}{|c|}
$\varphi=0.42$ \\
$\begin{array}{r}\text { Diff } \\
(+/-)\end{array}$
\end{tabular}} \\
\hline $\begin{array}{r}\dot{\gamma} \\
\mathrm{s}^{-1}\end{array}$ & $\begin{array}{c}\tau \\
\mathbf{P a}\end{array}$ & $\begin{array}{c}\log \eta \text { (meas) } \\
\text { Pa s }\end{array}$ & $\begin{array}{c}\log \eta(\text { calc }) \\
\text { Pa } s\end{array}$ & \\
\hline 1.48 & 1255 & 2.93 & 2.93 & 0.00 \\
\hline 1.74 & 1399 & 2.92 & 2.91 & 0.01 \\
\hline 2.83 & 1945 & 2.91 & 2.84 & 0.07 \\
\hline 0.69 & 775 & 2.93 & 3.05 & 0.12 \\
\hline 1.82 & 1442 & 2.91 & 2.90 & 0.01 \\
\hline 3.79 & 2386 & 2.87 & 2.80 & 0.08 \\
\hline 1.63 & 1339 & 2.91 & 2.92 & 0.00 \\
\hline 1.63 & 1339 & 2.91 & 2.92 & 0.01 \\
\hline 2.58 & 1828 & 2.88 & 2.85 & 0.03 \\
\hline 2.66 & 1865 & 2.87 & 2.85 & 0.02 \\
\hline 3.05 & 2049 & 2.86 & 2.83 & 0.03 \\
\hline 0.61 & 721 & 2.92 & 3.07 & 0.15 \\
\hline 1.68 & 1366 & 2.90 & 2.91 & 0.01 \\
\hline
\end{tabular}

\begin{tabular}{|c|c|c|c|c|c|}
\hline \multicolumn{3}{|c|}{$\begin{array}{c}\text { Measured } n \\
\quad(0.74)\end{array}$} & \multicolumn{2}{|c|}{$\begin{array}{c}1226^{\circ} \mathrm{C} \\
\text { Herschel Bulkley (PP) }\end{array}$} & \multirow{2}{*}{$\begin{array}{c}\varphi=0.42 \\
\text { Diff } \\
(+/-)\end{array}$} \\
\hline $\begin{array}{c}\text { Temp } \\
{ }^{\circ} \mathrm{C} \\
\end{array}$ & $\begin{array}{c}\dot{\gamma} \\
\mathrm{s}^{-1}\end{array}$ & $\begin{array}{c}\tau \\
\mathbf{P a} \\
\end{array}$ & $\begin{array}{c}\log \eta(\text { meas }) \\
\text { Pa s }\end{array}$ & $\begin{array}{c}\log \eta(\text { calc }) \\
\text { Pa s } \\
\end{array}$ & \\
\hline 1008 & $9 \times 10^{-7}$ & 141 & 11.16 & 8.18 & 2.97 \\
\hline 993 & $3 \times 10^{-7}$ & 141 & 11.71 & 8.73 & 2.97 \\
\hline 998 & $2 \times 10^{-7}$ & 141 & 11.88 & 8.91 & 2.97 \\
\hline 984 & $7 \times 10^{-8}$ & 141 & 12.30 & 9.33 & 2.97 \\
\hline 974 & $5 \times 10^{-8}$ & 141 & 12.45 & 9.47 & 2.97 \\
\hline
\end{tabular}


A-9 Continued.

\begin{tabular}{c|c|c|c|c}
\hline \multicolumn{2}{c|}{$\begin{array}{c}\text { Measured } \boldsymbol{n} \\
(\boldsymbol{0 . 8 1})\end{array}$} & \multicolumn{2}{|c|}{$\mathbf{1 2 3 4}^{\circ} \mathbf{C}$} & $\boldsymbol{\varphi}=\mathbf{0 . 3 0}$ \\
\hline $\boldsymbol{\gamma}$ & $\boldsymbol{\tau}$ & Herschel Bulkley (CC) & \\
$\mathbf{S}^{-\mathbf{1}}$ & $\mathbf{P a} \boldsymbol{\eta}$ (meas) & $\begin{array}{c}\log \boldsymbol{\eta} \text { (calc) } \\
\text { Pa s }\end{array}$ & $\begin{array}{c}\text { Diff } \\
\text { Pa } \mathbf{+}\end{array}$ \\
\hline 2.37 & 878 & 2.50 & 2.57 & 0.07 \\
1.25 & 568 & 2.56 & 2.66 & 0.10 \\
0.54 & 343 & 2.61 & 2.80 & 0.19 \\
0.31 & 261 & 2.67 & 2.92 & 0.26 \\
1.39 & 609 & 2.59 & 2.64 & 0.05 \\
2.77 & 981 & 2.54 & 2.55 & 0.01 \\
4.30 & 1357 & 2.46 & 2.50 & 0.04 \\
3.53 & 1171 & 2.42 & 2.52 & 0.10 \\
\hline
\end{tabular}

\begin{tabular}{c|c|c|c|c|c}
\hline \multicolumn{3}{c|}{$\begin{array}{c}\text { Measured } n \\
(\mathbf{0 . 8 1})\end{array}$} & \multicolumn{2}{c|}{$\mathbf{1 2 3 4}^{\circ} \mathbf{C}$} & $\boldsymbol{\varphi}=\mathbf{0 . 3 0}$ \\
\hline $\begin{array}{c}\text { Temp } \\
{ }^{\circ} \mathbf{C}\end{array}$ & $\boldsymbol{\gamma}^{\mathbf{- 1}}$ & $\begin{array}{c}\boldsymbol{\tau} \\
\text { Pa }\end{array}$ & $\begin{array}{c}\text { log } \boldsymbol{\eta} \text { (meas) } \\
\text { Pa s }\end{array}$ & $\begin{array}{c}\log \boldsymbol{\eta} \text { (calc) } \\
\text { Pa s }\end{array}$ & $\begin{array}{c}\text { Diff } \\
(+/-)\end{array}$ \\
\hline 820.73 & $2 \times 10^{-5}$ & 114 & 10.16 & 6.74 & 3.42 \\
800.34 & $2.7 \times 10^{-6}$ & 114 & 11.05 & 7.63 & 3.42 \\
810.21 & $5.7 \times 10^{-6}$ & 114 & 10.72 & 7.30 & 3.42 \\
790.11 & $1.7 \times 10^{-6}$ & 114 & 11.24 & 7.82 & 3.42 \\
770.15 & $4.6 \times 10^{-6}$ & 114 & 11.81 & 8.39 & 3.42 \\
779.66 & $5.7 \times 10^{-6}$ & 114 & 11.72 & 8.30 & 3.42 \\
\hline
\end{tabular}


A-9 Continued.

\begin{tabular}{|c|c|c|c|c|}
\hline \multicolumn{2}{|c|}{$\begin{array}{l}\text { Measured } n \\
\qquad(0.89)\end{array}$} & \multicolumn{2}{|c|}{$\begin{array}{c}1236^{\circ} \mathrm{C} \\
\text { Herschel Bulkley (CC) }\end{array}$} & \multirow{2}{*}{$\begin{array}{c}\varphi=0.25 \\
\text { Diff } \\
(+/-)\end{array}$} \\
\hline $\begin{array}{r}\dot{\gamma} \\
\mathbf{s}^{-1}\end{array}$ & $\begin{array}{c}\tau \\
\mathbf{P a}\end{array}$ & $\begin{array}{c}\log \eta(\text { meas) } \\
\text { Pa s } \\
\end{array}$ & $\begin{array}{c}\log \eta \text { (calc) } \\
\text { Pa s }\end{array}$ & \\
\hline 3.40 & 1298 & 2.52 & 2.58 & 0.06 \\
\hline 2.17 & 889 & 2.59 & 2.61 & 0.02 \\
\hline 1.87 & 787 & 2.58 & 2.62 & 0.04 \\
\hline 1.32 & 593 & 2.58 & 2.65 & 0.07 \\
\hline 1.06 & 500 & 2.63 & 2.67 & 0.05 \\
\hline 0.59 & 323 & 2.64 & 2.73 & 0.09 \\
\hline 0.59 & 323 & 2.64 & 2.73 & 0.09 \\
\hline 0.16 & 142 & 2.71 & 2.95 & 0.24 \\
\hline 1.94 & 813 & 2.59 & 2.62 & 0.03 \\
\hline 3.96 & 1479 & 2.56 & 2.57 & 0.01 \\
\hline 5.10 & 1837 & 2.55 & 2.56 & 0.00 \\
\hline 3.24 & 1246 & 2.58 & 2.59 & 0.01 \\
\hline 2.28 & 929 & 2.59 & 2.61 & 0.02 \\
\hline
\end{tabular}

\begin{tabular}{c|c|c|c|c|c}
\hline \multicolumn{3}{c|}{$\begin{array}{c}\text { Measured } n \\
(\mathbf{0 . 8 9})\end{array}$} & \multicolumn{2}{c|}{$\mathbf{1 2 3 6}^{\circ} \mathbf{C}$} & $\boldsymbol{\varphi}=\mathbf{0 . 2 5}$ \\
\hline $\begin{array}{c}\text { Temp } \\
{ }^{\circ} \mathbf{C}\end{array}$ & $\boldsymbol{s}^{-1}$ & $\begin{array}{c}\boldsymbol{\tau} \\
\text { Pa }\end{array}$ & $\begin{array}{c}\log \boldsymbol{\eta} \text { (meas) } \\
\text { Pa s }\end{array}$ & $\begin{array}{c}\log \boldsymbol{\eta} \text { (calc) } \\
\text { Pa s }\end{array}$ & $\begin{array}{c}\text { Diff } \\
(+/-)\end{array}$ \\
\hline 798.92 & $7.8 \times 10^{-5}$ & 62 & 9.59 & 5.90 & 3.70 \\
778.17 & $9.9 \times 10^{-6}$ & 61 & 10.48 & 6.79 & 3.69 \\
788.24 & $1.7 \times 10^{-5}$ & 61 & 10.24 & 6.55 & 3.69 \\
758.42 & $1.8 \times 10^{-6}$ & 61 & 11.23 & 7.54 & 3.69 \\
768.07 & $3.3 \times 10^{-6}$ & 61 & 10.96 & 7.27 & 3.69 \\
748.26 & $6.2 \times 10^{-7}$ & 61 & 11.68 & 8.00 & 3.69 \\
\hline
\end{tabular}


A-9 Continued.

\begin{tabular}{|c|c|c|c|c|}
\hline \multicolumn{2}{|c|}{$\begin{array}{l}\text { Measured } n \\
(0.91)\end{array}$} & \multicolumn{2}{|c|}{$\begin{array}{c}1241^{\circ} \mathrm{C} \\
\text { Herschel Bulkley (CC) }\end{array}$} & \multirow{2}{*}{$\begin{array}{c}\varphi=0.23 \\
\text { Diff } \\
(+/-)\end{array}$} \\
\hline $\begin{array}{r}\gamma \\
s^{-1}\end{array}$ & $\begin{array}{c}\tau \\
\mathbf{P a}\end{array}$ & $\begin{array}{c}\log \eta(\text { meas }) \\
\text { Pa s }\end{array}$ & $\begin{array}{c}\log \eta(\text { calc }) \\
\text { Pa s }\end{array}$ & \\
\hline 1.52 & 367 & 2.34 & 2.38 & 0.04 \\
\hline 2.94 & 646 & 2.32 & 2.34 & 0.02 \\
\hline 3.43 & 739 & 2.32 & 2.33 & 0.02 \\
\hline 1.51 & 364 & 2.35 & 2.38 & 0.03 \\
\hline 0.74 & 203 & 2.38 & 2.44 & 0.05 \\
\hline 0.27 & 97 & 2.42 & 2.56 & 0.14 \\
\hline 0.27 & 97 & 2.43 & 2.56 & 0.13 \\
\hline 1.34 & 330 & 2.36 & 2.39 & 0.03 \\
\hline
\end{tabular}

\begin{tabular}{c|c|c|c|c|c}
\hline \multicolumn{3}{c|}{$\begin{array}{c}\text { Measured } n \\
(\text { 0.91) }\end{array}$} & \multicolumn{2}{c|}{ 1241 $^{\circ} \mathbf{C}$} & $\boldsymbol{\varphi}=\mathbf{0 . 2 3}$ \\
\hline $\begin{array}{c}\text { Temp } \\
{ }^{\circ} \mathbf{C}\end{array}$ & $\boldsymbol{\gamma}$ & $\begin{array}{c}\boldsymbol{\tau} \\
\mathbf{s}^{-1}\end{array}$ & $\begin{array}{c}\text { Pa } \\
\text { Pa (meas) }\end{array}$ & $\begin{array}{c}\text { log } \boldsymbol{\eta} \text { (calc) } \\
\text { Pa s }\end{array}$ & $\begin{array}{c}\text { Diff } \\
\text { Pa s }\end{array}$ \\
\hline 790.33 & $5.8 \times 10^{-5}$ & 26 & 9.72 & 5.64 & 4.07 \\
769.16 & $7.7 \times 10^{-6}$ & 26 & 10.60 & 6.52 & 4.07 \\
779.17 & $1.4 \times 10^{-5}$ & 26 & 10.35 & 6.28 & 4.07 \\
749.35 & $1.5 \times 10^{-5}$ & 26 & 11.32 & 7.25 & 4.07 \\
759.19 & $2.4 \times 10^{-6}$ & 26 & 11.10 & 7.03 & 4.07 \\
739.55 & $4.5 \times 10^{-7}$ & 26 & 11.82 & 7.75 & 4.07 \\
\hline
\end{tabular}


A-9 Continued.

\begin{tabular}{|c|c|c|c|c|}
\hline \multicolumn{2}{|c|}{$\begin{array}{c}\text { Measured } n \\
(0.95)\end{array}$} & \multicolumn{2}{|c|}{$\begin{array}{c}1255^{\circ} \mathrm{C} \\
\text { Herschel Bulkley (CC) }\end{array}$} & \multirow{2}{*}{$\begin{array}{c}\varphi=0.17 \\
\text { Diff } \\
(+/-)\end{array}$} \\
\hline $\begin{array}{r}\gamma \\
s^{-1}\end{array}$ & $\begin{array}{c}\tau \\
\mathbf{P a}\end{array}$ & $\begin{array}{c}\log \eta(\text { meas }) \\
\text { Pa s }\end{array}$ & $\begin{array}{c}\log \eta(\text { calc }) \\
\text { Pa s }\end{array}$ & \\
\hline 3.46 & 581 & 2.21 & 2.22 & 0.02 \\
\hline 2.48 & 428 & 2.21 & 2.24 & 0.03 \\
\hline 1.38 & 253 & 2.23 & 2.26 & 0.03 \\
\hline 0.86 & 167 & 2.24 & 2.29 & 0.05 \\
\hline 0.41 & 92 & 2.26 & 2.35 & 0.09 \\
\hline 1.52 & 275 & 2.23 & 2.26 & 0.02 \\
\hline 2.51 & 432 & 2.23 & 2.24 & 0.01 \\
\hline 4.38 & 722 & 2.20 & 2.22 & 0.02 \\
\hline 3.61 & 604 & 2.23 & 2.22 & 0.00 \\
\hline
\end{tabular}

\begin{tabular}{|c|c|c|c|c|c|}
\hline \multicolumn{3}{|c|}{$\begin{array}{c}\text { Measured } n \\
(0.95)\end{array}$} & \multicolumn{2}{|c|}{$\begin{array}{c}1255^{\circ} \mathrm{C} \\
\text { Herschel Bulkley (PP) }\end{array}$} & \multirow{2}{*}{$\begin{array}{c}\varphi=0.17 \\
\text { Diff } \\
(+/-)\end{array}$} \\
\hline $\begin{array}{c}\text { Temp } \\
{ }^{\circ} \mathrm{C} \\
\end{array}$ & $\begin{array}{c}\dot{\gamma} \\
\mathrm{s}^{-1}\end{array}$ & $\begin{array}{c}\tau \\
\mathbf{P a}\end{array}$ & $\begin{array}{c}\log \eta(\text { meas }) \\
\text { Pa s }\end{array}$ & $\begin{array}{c}\log \eta(\text { calc }) \\
\text { Pa s }\end{array}$ & \\
\hline 781.19 & $5.8 \times 10^{-5}$ & 17 & 9.72 & 5.47 & 4.25 \\
\hline 760.52 & $7.0 \times 10^{-6}$ & 17 & 10.63 & 6.38 & 4.25 \\
\hline 770.44 & $1.3 \times 10^{-5}$ & 17 & 10.38 & 6.13 & 4.25 \\
\hline 750.29 & $2.4 \times 10^{-6}$ & 17 & 11.10 & 6.86 & 4.25 \\
\hline
\end{tabular}


Tables A-10. Measured and calculated magma viscosity using the Non-Newtonian power law equation, and empirical $n$ for sample $1226^{\circ} \mathrm{C}$. Values provided in Figure 3.45 , along with previously given values in Tables A-8.

\begin{tabular}{c|c|c|c}
\hline $\begin{array}{c}\text { Measured } n \\
(\mathbf{0 . 7 4})\end{array}$ & \multicolumn{2}{|c|}{$\mathbf{1 2 2 6}^{\circ} \mathbf{C}$} & $\boldsymbol{\varphi}=\mathbf{0 . 4 2}$ \\
\hline $\boldsymbol{\gamma}$ & Non-Newtonian (CC) & \\
\hline $\mathbf{s}^{-\mathbf{1}}$ & $\mathbf{l o g} \boldsymbol{\eta}$ (meas) & $\log \boldsymbol{\eta}$ (calc) & Diff \\
Pa s & Pa s & $(+/-)$ \\
\hline 1.48 & 2.93 & 4.65 & 1.71 \\
1.74 & 2.92 & 4.63 & 1.71 \\
2.83 & 2.91 & 4.57 & 1.67 \\
0.69 & 2.93 & 4.73 & 1.80 \\
1.82 & 2.91 & 4.62 & 1.72 \\
3.79 & 2.87 & 4.54 & 1.67 \\
1.63 & 2.91 & 4.64 & 1.72 \\
1.63 & 2.91 & 4.64 & 1.73 \\
2.58 & 2.88 & 4.58 & 1.71 \\
2.66 & 2.87 & 4.58 & 1.71 \\
3.05 & 2.86 & 4.57 & 1.71 \\
0.61 & 2.92 & 4.75 & 1.82 \\
1.68 & 2.90 & 4.63 & 1.73 \\
\hline
\end{tabular}

\begin{tabular}{c|c|c|c|c}
\hline \multicolumn{2}{c|}{$\begin{array}{c}\text { Measured } \boldsymbol{n} \\
(\mathbf{0 . 7 4})\end{array}$} & \multicolumn{2}{c|}{$\mathbf{1 2 2 6}^{\circ} \mathbf{C}$} & $\boldsymbol{\varphi}=\mathbf{0 . 4 2}$ \\
Non-Newtonian (PP) & \\
\hline $\begin{array}{c}\text { Temp } \\
{ }^{\circ} \mathbf{C}\end{array}$ & $\boldsymbol{\gamma}^{\mathbf{1}}$ & $\begin{array}{c}\log \boldsymbol{\eta} \text { (meas) } \\
\text { Pa s }\end{array}$ & $\begin{array}{c}\log \boldsymbol{\eta} \text { (calc) } \\
\text { Pa s }\end{array}$ & $\begin{array}{c}\text { Diff } \\
(+/-)\end{array}$ \\
\hline 1008 & $9 \times 10^{-7}$ & 11.16 & 8.31 & 2.85 \\
993 & $3 \times 10^{-7}$ & 11.71 & 8.57 & 3.13 \\
998 & $2 \times 10^{-7}$ & 11.88 & 8.68 & 3.20 \\
984 & $7 \times 10^{-8}$ & 12.30 & 8.90 & 3.40 \\
974 & $5 \times 10^{-8}$ & 12.45 & 9.09 & 3.36 \\
\hline
\end{tabular}

